RELIABILITY OF STOPPING AND DECISION SIGHT DISTANCE AT ROUNDABOUTS

\author{
By
}

Jafar Faizi

B.Sc. Civil Engineering, Kabul University, 2013

\author{
A thesis \\ presented to Ryerson University \\ in partial fulfillment of the \\ requirements for the degree of \\ Master of Applied Science \\ in the program of \\ Civil Engineering
}

Toronto, Ontario, Canada, 2018

(C) Jafar Faizi 2018 


\section{AUTHOR'S DECLARATION}

I hereby declare that I am the sole author of this thesis. This is a true copy of the thesis, including any required final revisions, as accepted by my examiners.

I authorize Ryerson University to lend this thesis to other institutions or individuals for scholarly research.

I further authorize Ryerson University to reproduce this thesis by photocopying or by other means, in total or in part, at the request of other institutions or individuals for the purpose of scholarly research.

I understand that my thesis may be electronically available to the public. 


\title{
Reliability of Stopping and Decision Sight Distance at Roundabouts
}

\author{
Jafar Faizi
}

Master of Applied Science, 2018

Department of Civil Engineering

Ryerson University

\begin{abstract}
The existing Stopping Sight Distance (SSD) and Decision Sight Distance (DSD) design methods for roundabouts are deterministic. This means that all of the design variables are predetermined, fixed values. This study presents a probabilistic method for the determination of SSD and DSD at roundabouts based on the equation recommended by the American Association of State Highway and Transportation Officials (AASHTO 2011). The reliability-based method considers all design parameters as random variables. Three types of SSD (SSD for approaches, SSD along the circulatory lane, and SSD for exiting vehicles to the pedestrian crosswalk) were considered in this study. DSD was considered for roundabout approaches. The First-Order Second-Moment and Advanced First-Order Second-Moment methods were used to model SSD and DSD. Once the required SSD and DSD were determined, the lateral clearance requirements at every point of the roundabout were calculated.
\end{abstract}




\section{ACKOWLEDGEMENTS}

I would like to thank my academic supervisor, Dr. Said M. Easa, for the outstanding research idea and for his help and precious advice throughout my research. I would also like to thank Dr. Kaamran Rahimifar and Dr. Essam Dabbour for their helpful suggestions. 


\section{CONTENTS}

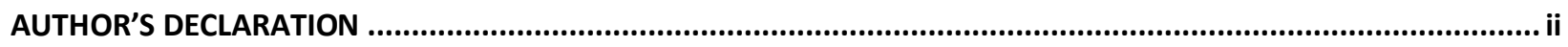

ABSTRACT

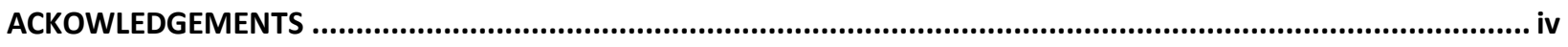

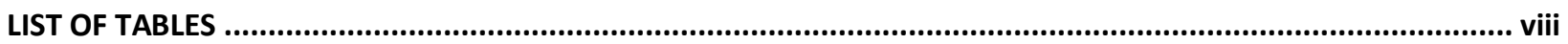

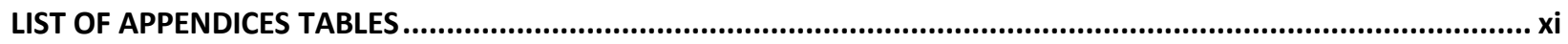

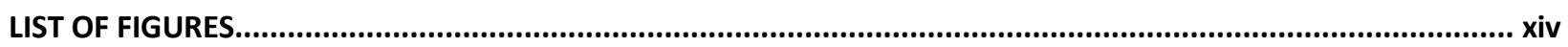

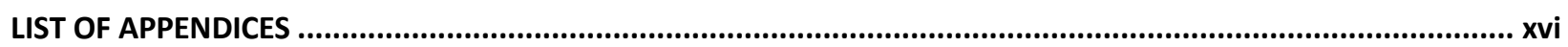

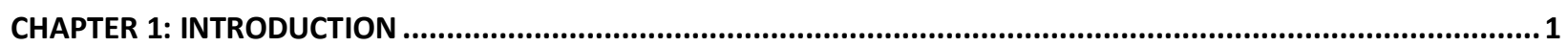

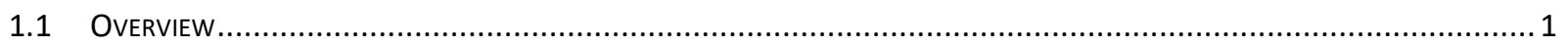

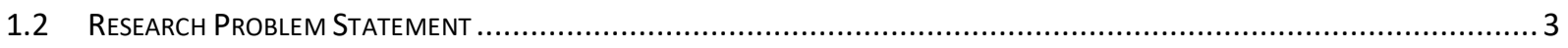

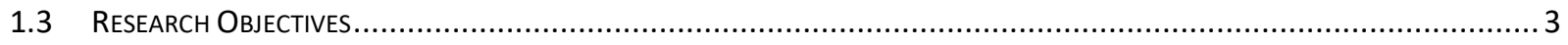

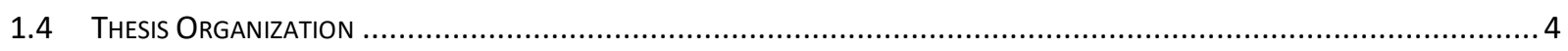

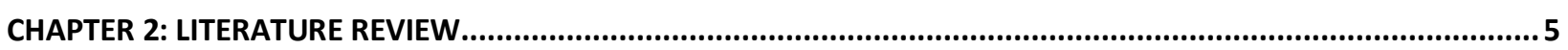

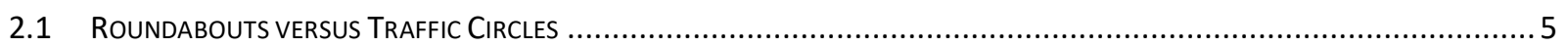

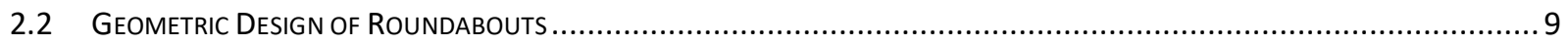

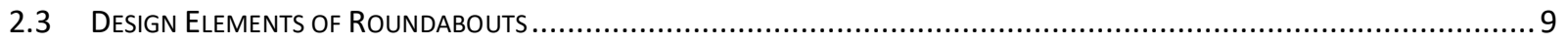

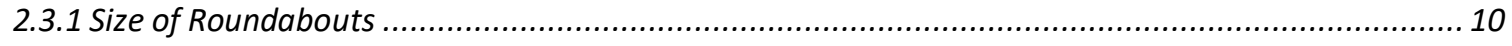

2.3.2 Alignment of Approaching Legs and Angle between Approaching Legs ...................................... 13

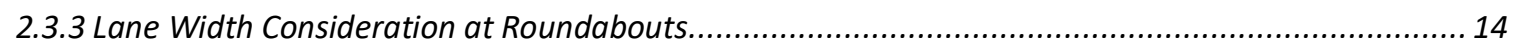

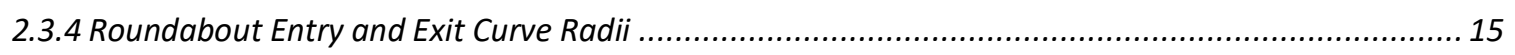

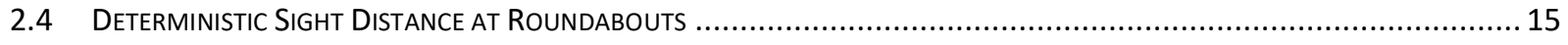

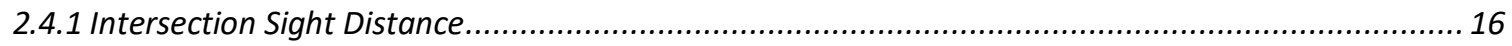

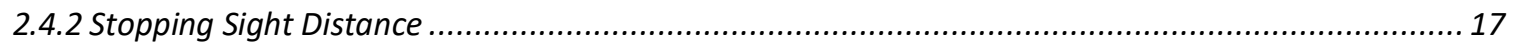

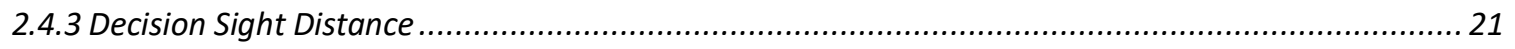

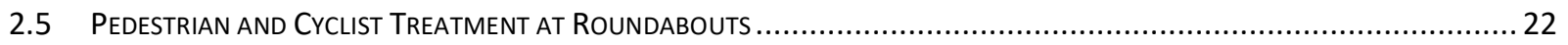

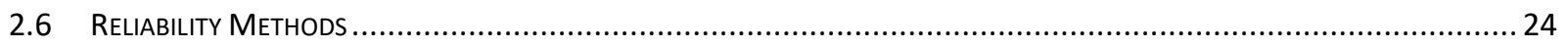

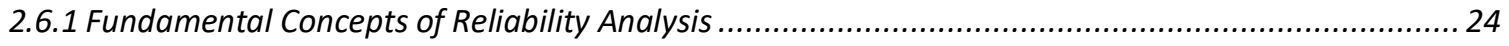

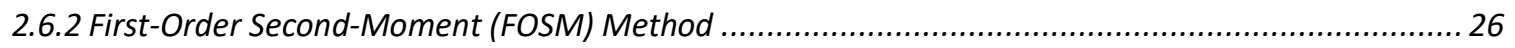

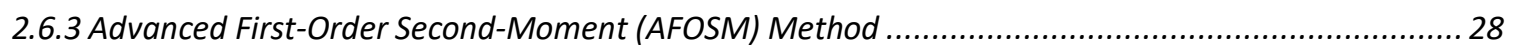

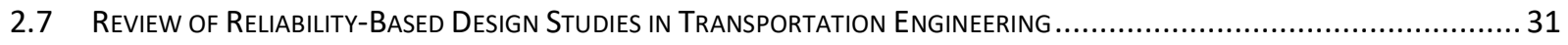

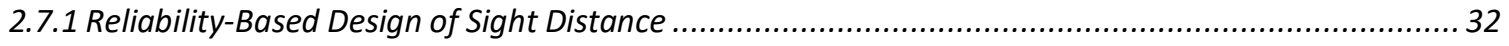

2.7.2 Reliability Analysis of Horizontal and Vertical Elements of Highways .........................................3 34 
CHAPTER 3: DEVELOPMENT OF THE RELIABILITY-BASED DESIGN FOR ROUNDABOUTS BASED ON SSD AND DSD 37

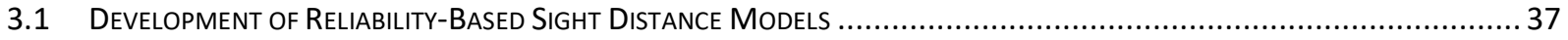

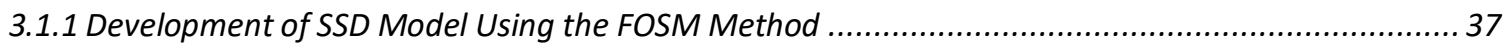

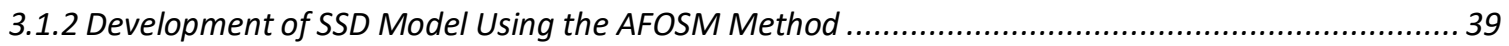

3.1.3 Reliability-Based Design of Decision Sight Distance...................................................................... 40

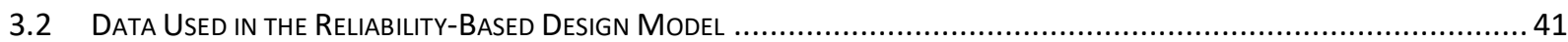

3.2.1 Evaluation of the Correlation between Design Variables in SSD and DSD......................................... 41

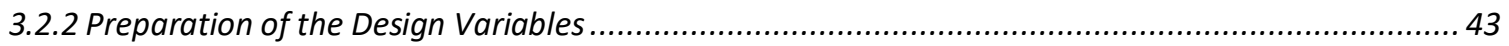

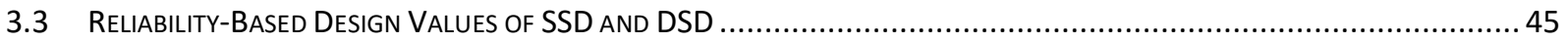

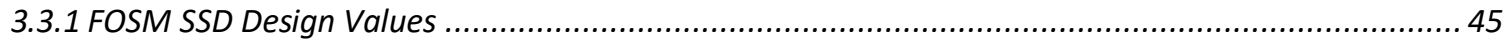

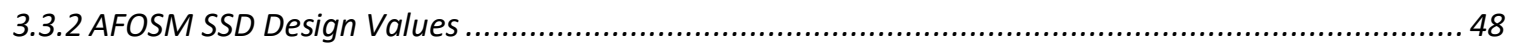

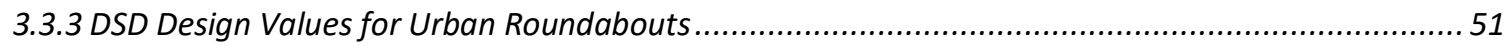

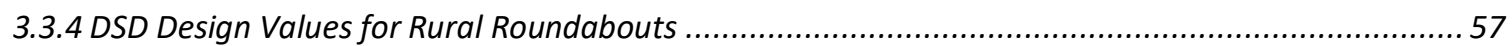

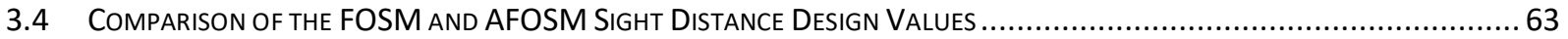

3.5 Design Aids for Lateral Clearance Requirements to Satisfy Probabilistic SSD ............................................ 65

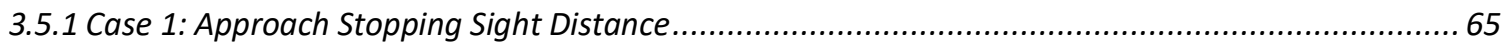

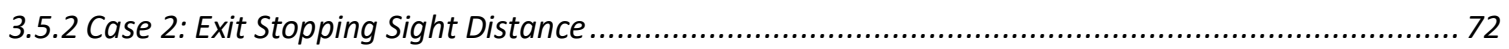

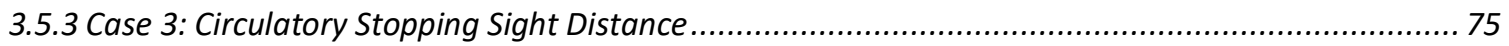

3.6 Design Aids for Lateral Clearance Requirements Based on Probabilistic DSD ........................................... 77

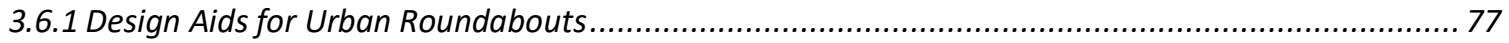

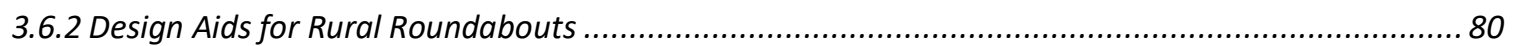

3.7 Comparison of the Lateral Clearance Values Obtained Using the Deterministic and Probabilistic SSD and DSD

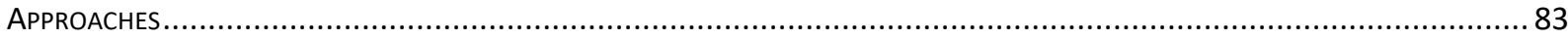

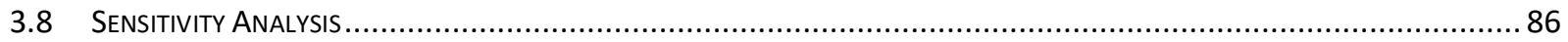

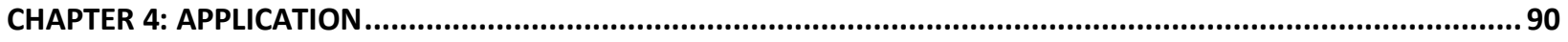

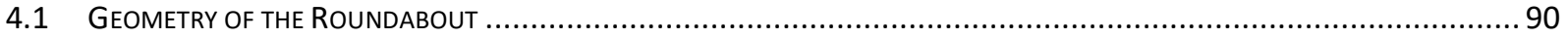

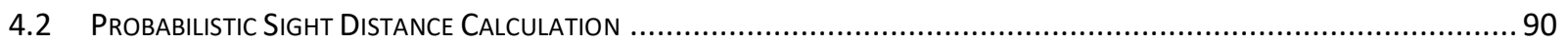

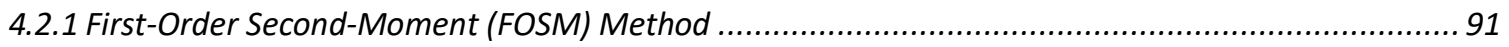

4.2.2 Advanced First-Order Second-Moment (AFOSM) Method ........................................................ 92

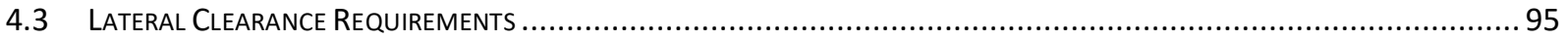

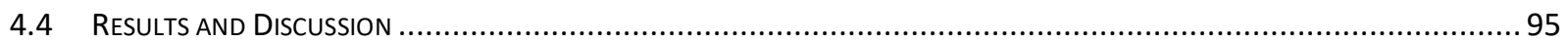

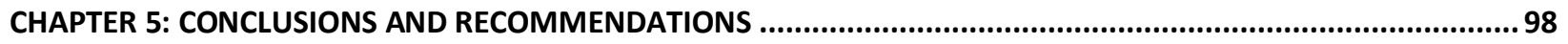

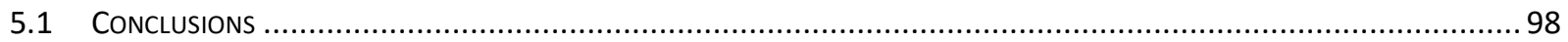

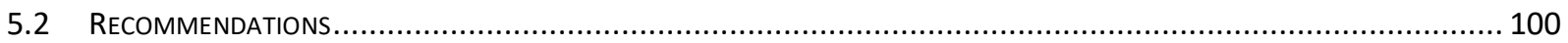

APPENDIX A 


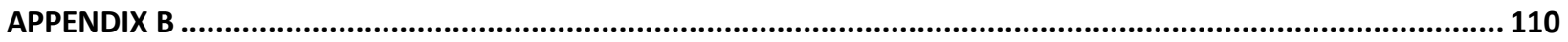

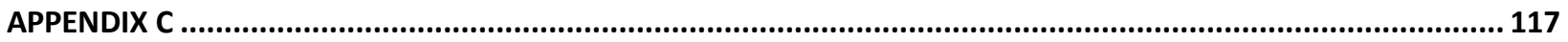

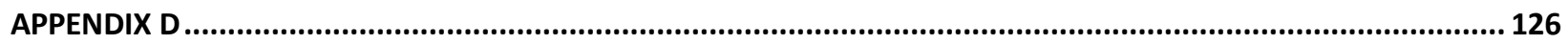

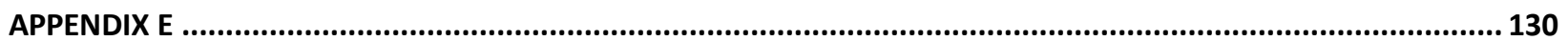

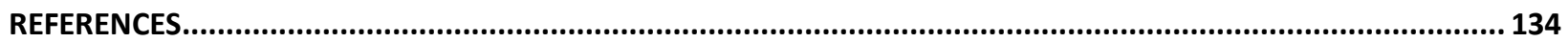




\section{LIST OF TABLES}

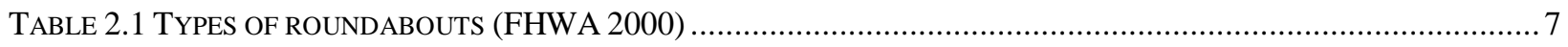

TABLE 2.2 DESIGN VEHICLE AND INSCRIBED CIRCLE DIAMETER (FHWA 2000) .................................................. 11

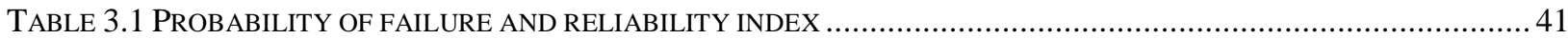

TABLE 3.2 DECELERATION RATE OF PASSENGER CARS FOR DIFFERENT VEHICLE SPEEDS ....................................... 43

TABLE 3.3 DECELERATION RATE OF TRUCKS FOR DIFFERENT VEHICLE SPEEDS ....................................................... 43

TABLE 3.4 DATA USED FOR THE DESIGN OF SSD USING THE PROBABILISTIC APPROACH........................................ 44

TABLE 3.5 DATA USED FOR THE DESIGN OF DSD USING THE PROBABILISTIC APPROACH ......................................... 44

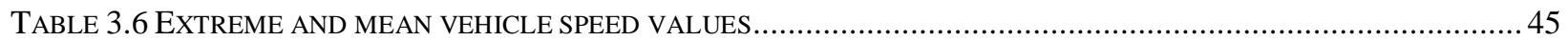

TABLE 3.7 SSD DESIGN VALUES CALCULATED USING THE FOSM METHOD, CV = 5\% …........................................ 46

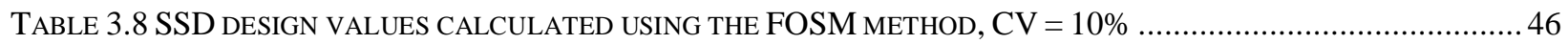

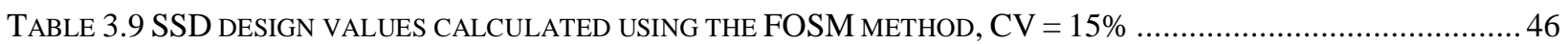

TABLE 3.10 SSD DESIGN VALUES CALCULATED USING THE AFOSM METHOD, CV = 5\% ...................................... 49

TABLE 3.11 SSD DESIGN VALUES CALCULATED USING THE AFOSM METHOD, CV = 10\% ....................................49

TABLE 3.12 SSD DESIGN VALUES CALCULATED USING THE AFOSM METHOD, CV = 15\% .....................................49

TABLE 3.13 DSD DESIGN OF URBAN ROUNDABOUTS, FOSM METHOD, CV = 5\% ……...................................... 52

TABLE 3.14 DSD DESIGN OF URBAN ROUNDABOUTS, FOSM METHOD, CV = 10\% .......................................... 52

TABLE 3.15 DSD DESIGN OF URBAN ROUNDABOUTS, FOSM METHOD, CV = 15\% ...........................................52

TABLE 3.16 DSD DESIGN OF URBAN ROUNDABOUTS, AFOSM METHOD, CV = 5\% ............................................ 53

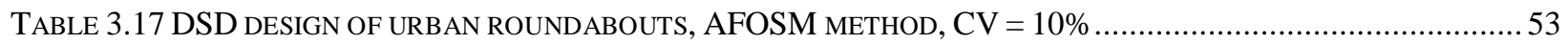

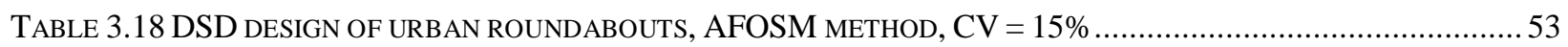

TABLE 3.19 DSD DESIGN OF RURAL ROUNDABOUTS, FOSM METHOD, CV = 5\% ............................................... 57

TABLE 3.20 DSD DESIGN OF RURAL ROUNDABOUTS, FOSM METHOD, CV = 10\% …........................................... 57

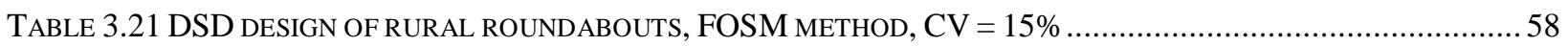

TABLE 3.22 DSD DESIGN OF RURAL ROUNDABOUTS, AFOSM METHOD, CV = 5\% ….........................................5

TABLE 3.23 DSD DESIGN OF RURAL ROUNDABOUTS, AFOSM METHOD, CV = 10\% …........................................58

TABLE 3.24 DSD DESIGN OF RURAL ROUNDABOUTS, AFOSM METHOD, CV = 15\% ….........................................59

TABLE 3.25 SIGHT DISTANCE REQUIRED AT THE APPROACHES OF URBAN ROUNDABOUTS ......................................62

TABLE 3.26 SIGHT DISTANCE REQUIRED AT THE APPROACHES OF RURAL ROUNDABOUTS........................................ 63

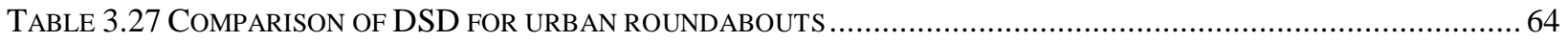

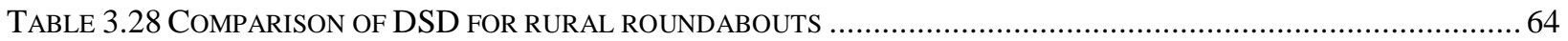

TABLE 3.29 LATERAL CLEARANCE DESIGN VALUES FOR THE APPROACHES (SSD to THE CROSSWALK), PF $=0.01 \%$,

$\mathrm{CV}=10 \%$ 69 
TABLE 3.30 LATERAL CLEARANCE DESIGN VALUES FOR THE APPROACHES (SSD TO THE YIELD LINE), PF $=0.01 \%, \mathrm{CV}$ $=10 \%$ .70

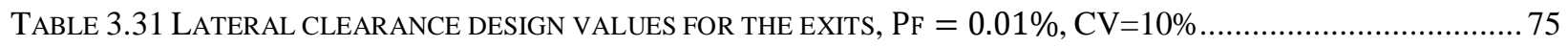

TABLE 3.32 LATERAL CLEARANCE DESIGN VALUES FOR THE CIRCULATORY LANE, PF $=0.01 \%, C V=10 \% \ldots \ldots \ldots \ldots . . .77$

TABLE 3.33 LATERAL CLEARANCE DESIGN VALUES FOR URBAN ROUNDABOUTS (DSD TO THE CROSSWALK), PF $=$ $0.01 \%, \mathrm{CV}=10 \%$. .78

TABLE 3.34 LATERAL CLEARANCE DESIGN VALUES FOR URBAN ROUNDABOUTS (DSD TO THE YIELD LINE), PF $=$ $0.01 \%, \mathrm{CV}=10 \%$. .79

TABLE 3.35 LATERAL CLEARANCE DESIGN VALUES FOR RURAL ROUNDABOUTS (DSD TO THE CROSSWALK), PF $=$ $0.01 \%, \mathrm{CV}=10 \%$ 81

TABLE 3.36 LATERAL CLEARANCE DESIGN VALUES FOR RURAL ROUNDABOUTS (DSD TO THE YIELD LINE), PF = $0.01 \%, \mathrm{CV}=10 \%$. 82

TABLE 3.37 SENSITIVITY OF THE RELIABILITY INDEX TO DIFFERENT RANDOM VARIABLES, V = 40 KM/H A. . .87

TABLE 3.38 SENSITIVITY OF THE RELIABILITY INDEX TO DIFFERENT RANDOM VARIABLES, V = $60 \mathrm{KM} / \mathrm{H}$ A. .87

TABLE 3.39 SENSITIVITY OF THE RELIABILITY INDEX TO THE CORRELATION COEFFICIENT OF VARIABLES, V = 40 KM/H A. . .88

TABLE 3.40 SENSITIVITY OF THE RELIABILITY INDEX TO THE CORRELATION COEFFICIENT OF VARIABLES, V = 60 KM/H A. 88

TABLE 3.41 SENSITIVITY OF B TO THE COEFFICIENT OF VARIATION OF VARIABLES, V = $40 \mathrm{KM} / \mathrm{H}$ A ........................ 88

TABLE 3.42 SENSITIVITY OF B TO THE COEFFICIENT OF VARIATION OF VARIABLES, V = 60 KM/H A ......................... 89

TABLE 4.1 DATA USED FOR THE PROBABILISTIC SSD AND DSD DESIGN A …........................................................ 91

TABLE 4.2 ITERATIONS FOR THE RELIABILITY INDEX, BZ, OF THE SSD COMPONENTS FOR SSDREQ $=50 \mathrm{M}$................ 92

TABLE 4.3 DESIGN PARAMETERS RELATED TO THE FINAL ITERATION OF THE APPROACH SSD, SSDREQ = 50 M ...........92

TABLE 4.4 ITERATIONS FOR THE RELIABILITY INDEX, BZ, OF THE SSD COMPONENTS FOR SSDREQ $=19.6 \mathrm{M} \ldots \ldots \ldots \ldots \ldots . . . . .93$

TABLE 4.5 DESIGN PARAMETERS RELATED TO THE FINAL ITERATION FOR THE CIRCULATORY AND EXIT SSD, SSDREQ = $19.6 \mathrm{M}$. .93

TABLE 4.6 ITERATIONS FOR THE RELIABILITY INDEX, BZ, OF THE DSD OF URBAN ROUNDABOUT COMPONENTS FOR DSDREQ $=119 \mathrm{M}$ .93

TABLE 4.7 DESIGN PARAMETERS RELATED TO THE FINAL ITERATION FOR DSD AT URBAN ROUNDABOUTS, DSDREQ = $119 \mathrm{M}$.

TABLE 4.8 ITERATIONS FOR THE RELIABILITY INDEX, BZ, OF THE DSD OF RURAL ROUNDABOUT COMPONENTS FOR DSDREQ $=55 \mathrm{M}$.

TABLE 4.9 DESIGN PARAMETERS RELATED TO THE FINAL ITERATION FOR DSD AT URBAN ROUNDABOUTS DSDREQ $=$ $55 \mathrm{M}$.

TABLE 4.10 COMPARISON OF THE RESULTS OF THE DESIGN ELEMENTS OF APPROACHES BASED ON SSD .96

TABLE 4.11 COMPARISON OF THE RESULTS OF THE DESIGN ELEMENTS OF THE EXITS AND CIRCULATORY LANE BASED ON SSD 
TABLE 4.12 COMPARISON OF THE RESULTS OF THE DESIGN ELEMENTS OF URBAN ROUNDABOUTS BASED ON DSD ..... 97

TABLE 4.13 COMPARISON OF THE RESULTS OF THE DESIGN ELEMENTS OF RURAL ROUNDABOUTS BASED ON DSD ..... 97 


\section{LIST OF APPENDICES TABLES}

TABLE A3.1 Design VAlues of LATERAL ClEARANCE ON THE APPROACHES (SSD to THE CROSSWALK), PF $=0.01 \%$, $\mathrm{CV}=5 \%$ 102

TABle A3.2 Design VALUeS OF LATERAL ClEARANCE ON THE APPROACHES (SSD to the YIELD LiNE), PF $=0.01 \%$, $\mathrm{CV}=5 \%$. 102

TABLE A3.3 Design VAlues of LATERAL ClEARANCE ON THE APPROACHES (SSD tO THE CROSSWALK), PF $=0.1 \%$, $\mathrm{CV}=5 \%$. 103

TABle A3.4 Design VALUES OF LATERAL CLEARANCE ON THE APPROACHES (SSD TO THE YIELD LiNE), PF = 0.1\%, $\mathrm{CV}=5 \%$ 103

TABle A3.5 Design VAlues of LATERAL CleARANCE ON THE APPROACHES (SSD to THE CROSSWALK), PF $=1.00$, $\mathrm{CV}=5 \%$

TABle A3.6 Design VAlues of lateral Clearance On the APPROACHeS (SSD to YIELD LINE), PF $=1.00 \%$, $\mathrm{CV}=5 \%$.

TABle A3.7 Design Values of lateral Clearance ON THE APPROACHES (SSD TO THE CROSSWALK), PF = 5.00\%, $\mathrm{CV}=5 \%$. 105

TAble A3.8 Design Values of lateral Clearance on the APPROAChes (SSD to Yield Line), PF $=5.00 \%$, $\mathrm{CV}=5 \%$. 105

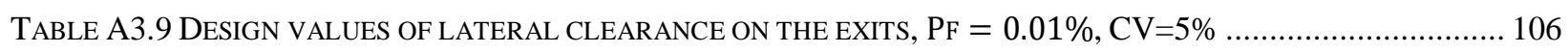

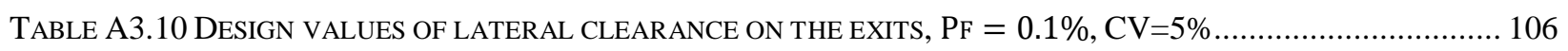

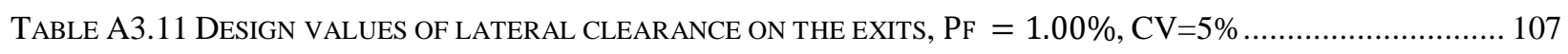

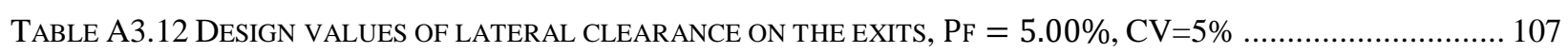

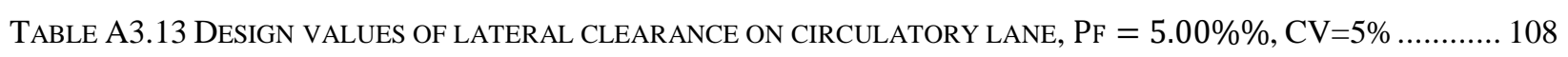

TABLE A3.14 DESIGN VALUES Of LATERAL ClEARANCE ON CIRCULATORY LANE, PF = 0.1\%, CV=5\% ............... 108

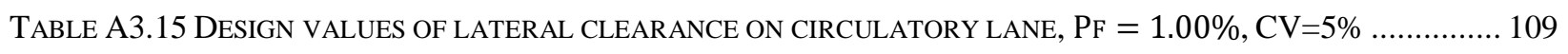

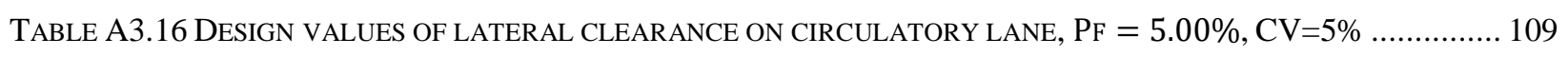

TABLE B3.1 Design Values of LATERAL ClearanCE ON THE APPROACHES (SSD TO THE CROSSWALK), PF $=0.1 \%$, $\mathrm{CV}=10 \%$. 111

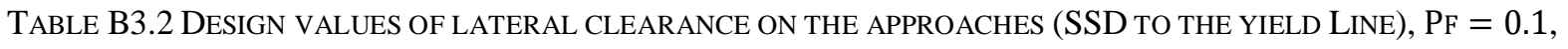
$\mathrm{CV}=10 \%$.

TABle B3.3 Design Values of lateral ClearanCE ON THE APPROACHES (SSD to THE CROSSWALK), PF = 1.00\%, $\mathrm{CV}=10 \%$.

TABLE B3.4 Design VAlues of LATERAL ClEARANCE ON THE APPROACHeS (SSD to YIELD LINE), PF = 1.00\%, $\mathrm{CV}=10 \%$.

TABLE B3.5 Design VAlues OF LATERAL ClEARANCE ON THE APPROACHES (SSD TO THE CROSSWALK), PF $=5.00 \%$, $\mathrm{CV}=10 \%$. 


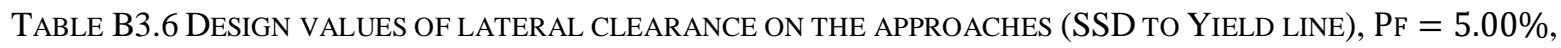
$\mathrm{CV}=10 \%$.

TABle B3.7 Design Values of lateral CLEarance ON THE EXITS, PF $=0.10 \%, C V=10 \%$ 114

TABle B3.8 Design Values of lateral Clearance on the EXITS, PF $=1.00 \%, C V=10 \%$ 114

TABLE B3.9 Design Values of Lateral ClearanCE ON THE EXITS, $\mathrm{PF}=5.00 \%, \mathrm{CV}=10 \%$ 115

TABLE B3.10 DESIGN VALUES OF LATERAL CLEARANCE ON CIRCULATORY LANE, PF $=0.1 \%, C V=10 \%$ 115

TABle B3.11 Design VAlues of LATERAl CleARANCE ON CirCULATORY LANe, PF $=1.00 \%, \mathrm{CV}=10 \%$ 116

TABle B3.12 Design Values of Lateral Clearance on CiRCUlatory lane, PF $=5.00 \%, C V=10 \%$ 116

TABle C3.1 Design Values of lateral ClearanCE ON the APPROAChes (SSD tO THE CROSSWALK), PF $=0.01 \%$, $\mathrm{CV}=15 \%$ 118

TABLE C3.2 Design Values of lateral Clearance ON THE APPROACHES (SSD to the YIELD LiNE), PF $=0.01 \%$, $\mathrm{CV}=15 \%$. 118

TABle C3.3 Design Values of lateral Clearance on the APPROACHES (SSD to the CROSSWALK), PF $=0.1 \%$, $\mathrm{CV}=15 \%$. 119

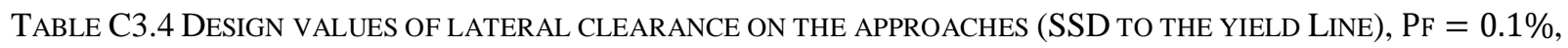
$\mathrm{CV}=15 \%$

TABle C3.5 Design Values of lateral ClearanCE ON THE APPROACheS (SSD to the CROSSWALK), PF = $1.00 \%, C V=15 \%$

TABLE C3.6 Design VAlueS OF LATERAL ClEARANCE ON THE APPROACHES (SSD TO YIELD LINE), PF $=1.00 \%$, $\mathrm{CV}=15 \%$.

TABLE C3.7 Design Values of Lateral Clearance ON THE APPROACHES (SSD to THE CROSSWALK), PF = $5.00 \%, \mathrm{CV}=15 \%$.

TABLE C3.8 Design VALUES OF LATERAL ClEARANCE ON THE APPROACHES (SSD TO YIELD LINE), PF $=5.00 \%$, $\mathrm{CV}=15 \%$

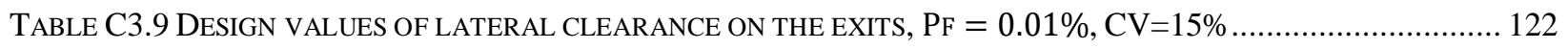

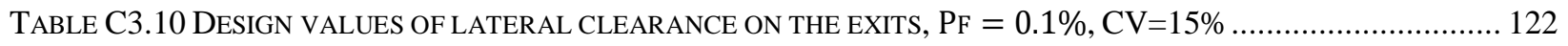

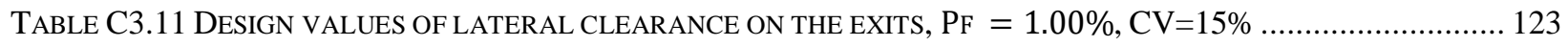

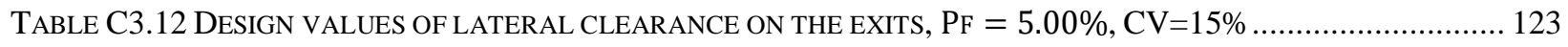

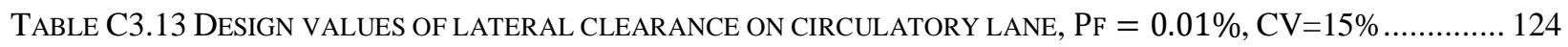

TABLE C3.14DESIGN VALUES OF LATERAL CLEARANCE ON CIRCULATORY LANE, PF $=0.1 \%, \mathrm{CV}=15 \% \ldots \ldots \ldots \ldots \ldots . . . . .124$

TABLE C3.15 Design VALUES Of LATERAL ClEARANCE ON CIRCULATORY LANE, PF $=1.00 \%, C V=15 \% \ldots \ldots \ldots \ldots . . . .125$

TABLE C3.16 Design VALUES OF LATERAL CLEARANCE ON CiRCULATORY LANE, PF $=5.00 \%$, CV $=15 \% \ldots \ldots \ldots \ldots . . . .125$

TABLE D3. 1 LATERAL CLEARANCE DESIGN VALUES FOR URBAN ROUNDABOUTS (DSD TO THE CROSSWALK), PF $=$

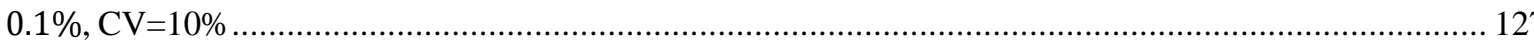

TABLE D3. 2 LATERAL ClEARANCE DESIGN VALUES FOR URBAN ROUNDABOUTS (DSD TO THE CROSSWALK) PF $=$ $1.0 \%, \mathrm{CV}=10 \%$ 127 
TABLE D3. 3 LATERAL CLEARANCE DESIGN VALUES FOR URBAN ROUNDABOUTS (DSD TO THE CROSSWALK), PF $=$

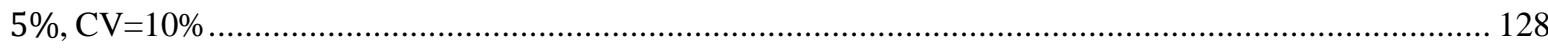

TABLE D3. 4 LATERAL CLEARANCE DESIGN VALUES FOR URBAN ROUNDABOUTS (DSD TO THE YIELD LINE), PF =

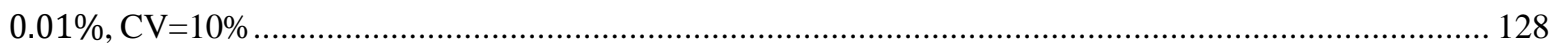

TABLE D3. 5 LATERAL CLEARANCE DESIGN VALUES FOR URBAN ROUNDABOUTS (DSD TO THE YIELD LINE), PF =

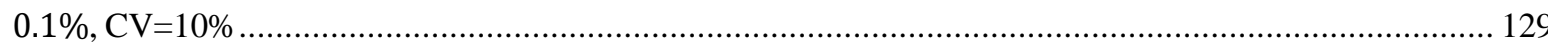

TABLE D3. 6 LATERAL CLEARANCE DESIGN VALUES FOR URBAN ROUNDABOUTS (DSD TO THE YIELD LINE), PF $=$

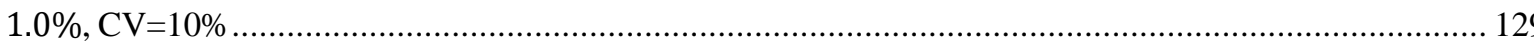

TABLE E3.1 LATERAL CLEARANCE DESIGN VALUES FOR RURAL ROUNDABOUTS (DSD TO THE CROSSWALK), PF $=$

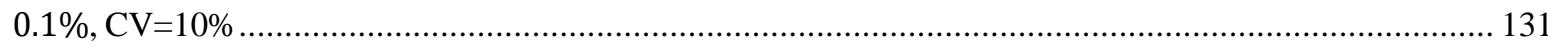

TABLE E3.2 LATERAL CLEARANCE DESIGN VALUES FOR RURAL ROUNDABOUTS (DSD TO THE CROSSWALK), PF =

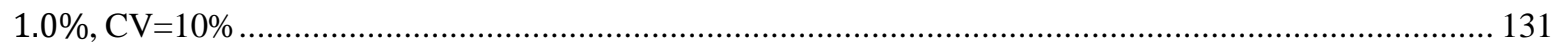

TABLE E3.3 LATERAL ClEARANCE DESign VALUES FOR RURAL ROUNDABOUTS (DSD TO THE CROSSWALK), PF $=5 \%$,

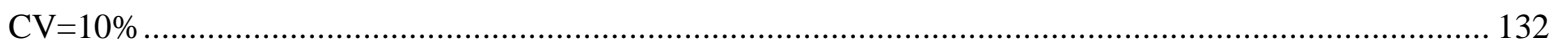

TABLE E3.4 LATERAL CLEARANCE DESIGN VALUES FOR RURAL ROUNDABOUTS (DSD TO THE YIELD LINE), PF =

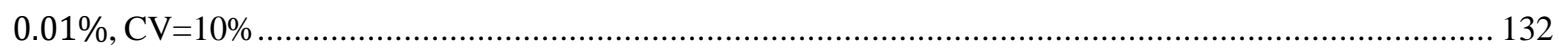

TABLE E3.5 LATERAL CLEARANCE DESIGN VALUES FOR RURAL ROUNDABOUTS (DSD TO THE YIELD LINE), PF $=$

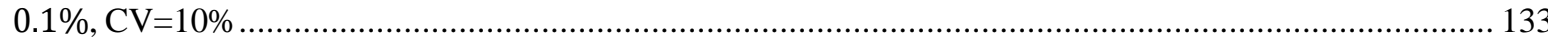

TABLE E3.6 LATERAL CLEARANCE DESIGN VALUES FOR RURAL ROUNDABOUTS (DSD TO THE YIELD LINE), PF $=$ $1.0 \%, \mathrm{CV}=10 \%$. 


\section{LIST OF FIGURES}

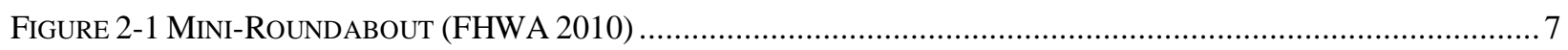

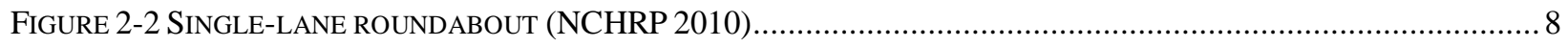

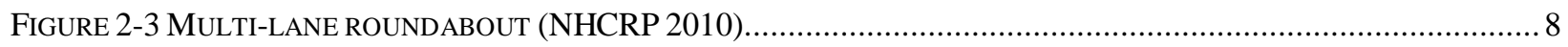

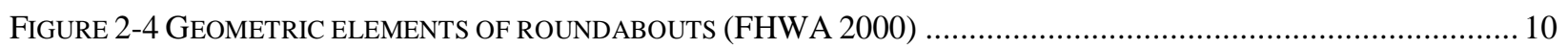

FIGURE 2-5 MiNIMUM SPLITTER ISLAND DIMENSIONS (FHWA 2000)............................................................... 13

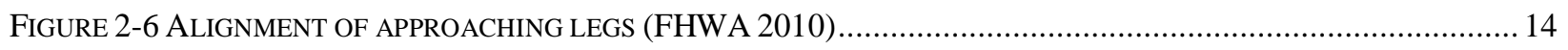

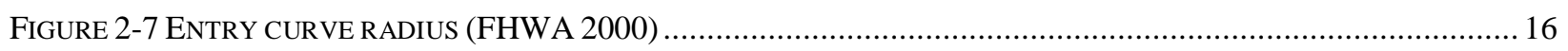

FIGURE 2-8 GEOMETRY OF ROUNDABOUT EXITS (FHWA 2000) ........................................................................ 16

FIGURE 2-9 SIGHT TRIANGLE OF INTERSECTION SIGHT DIST ANCE AT A ROUNDABOUT (FHWA 2000) ........................ 17

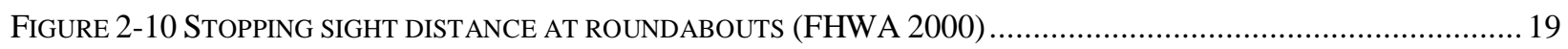

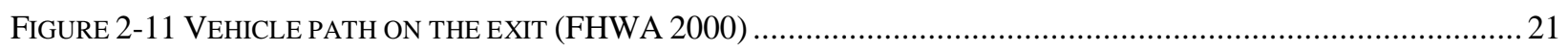

FiguRE 2-12 ProbabILITY DiSTRIBUtION OF THE OBJECTIVE FUNCTION (HUSSAIN 2004) .................................... 26

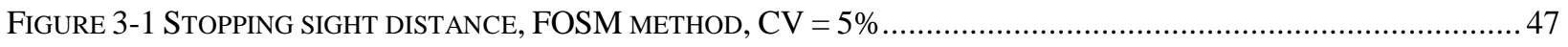

FIGURE 3-2 STOPPING SIGHT DISTANCE, FOSM METHOD, CV = 10\% .............................................................. 47

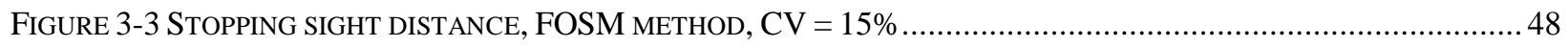

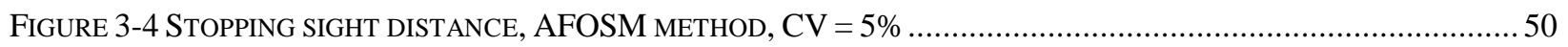

FigURE 3-5 StoPPING SIGHT DISTANCE, AFOSM MeTHOD, CV = 10\% ....................................................... 50

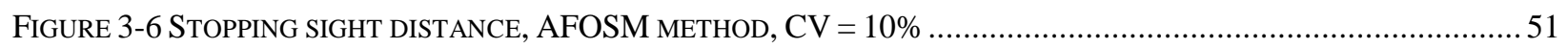

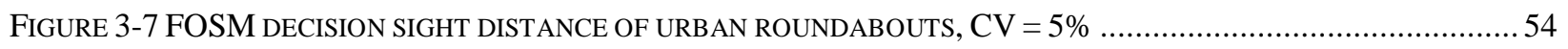

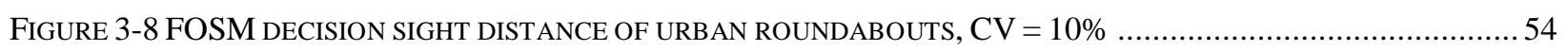

FIGURE 3-9 FOSM DECISION Sight DiSTANCE OF URBAN RouNDABOUTS, CV = 15\% …........................................5

Figure 3-10 AFOSM Decision Sight Distance of Urban Roundabouts, CV = 5\% …................................. 55

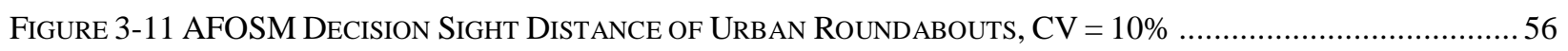

Figure 3-12 AFOSM Decision Sight Distance of Urban Roundabouts, CV = 15\% …................................56

FIGURE 3-13 FOSM DECISION SIGHT DISTANCE OF RURAL ROUNDABOUTS, CV = 5\% ..........................................59

FIGURE 3-14 FOSM DECISION SIGHT DISTANCE OF RURAL ROUNDABOUTS, CV = 10\% ......................................... 60

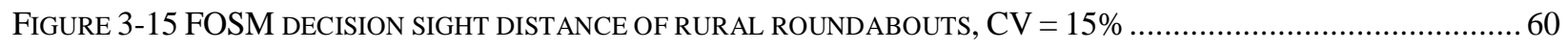

FIGURE 3-16 AFOSM DECISION SIGHT DISTANCE OF RURAL ROUNDABOUTS, CV = 5\% ….................................. 61

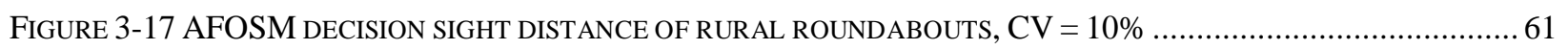

FIGURE 3-18 AFOSM DECISION SIGHT DISTANCE OF RURAL ROUNDABOUTS, CV = 15\% …................................... 62

FIGURE 3-19 COMPARISON OF DETERMINISTIC, FOSM, AND AFOSM SSD RESULTS ............................................... 64 
FiguRE 3-20 LATERAL CLEARANCE REQUIREMENTS ON THE APPROACHES OF ROUNDABOUTS (EASA 2017)...... 66

FIGURE 3-21 LATERAL CLEARANCE VALUES REQUIRED TO SATISFY SSD FOR THE APPROACHES, R1 = 300 , R2 = 40 .71

FIGURE 3-22 LATERAL CLEARANCE VALUES REQUIRED TO SATISFY SSD FOR THE APPROACHES R1 = 1000, R2 = 40

FIGURE 3-23 LATERAL CLEARANCE VALUES REQUIRED TO SATISFY SSD FOR THE APPROACHES R1 = 1000 , R2 = 20

FIGURE 3-24 EXIT SSD AND THE LATERAL CLEARANCE REQUIREMENTS FOR CROSSWALKS (EASA 2017) ................ 73

FigURE 3-25 GEOMETRY OF ROUNDABOUT CIRCULATORY LANE (EASA, 2017) ............................................ 76

FIGURE 3-26 LATERAL CLEARANCE DESIGN VALUES USED TO SATISFY DSD FOR THE APPROACHES OF URBAN

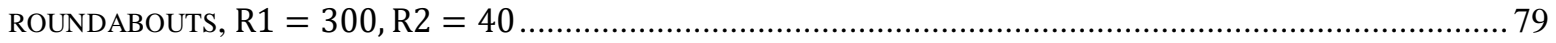

FIGURE 3-27 LATERAL CLEARANCE DESIGN VALUES USED TO SATISFY DSD FOR THE APPROACHES OF URBAN ROUNDABOUTS

FIGURE 3-28 LATERAL CLEARANCE DESIGN VALUES USED TO SATISFY DSD FOR THE APPROACHES OF URBAN ROUNDABOUTS, R1 $=1000, \mathrm{R} 2=20$.

FIGURE 3-29 LATERAL CLEARANCE DESIGN VALUES USED TO SATISFY DSD FOR THE APPROACHES OF RURAL ROUNDABOUTS, R1 $=300, \mathrm{R} 2=40$

FIGURE 3-30 LATERAL CLEARANCE DESIGN VALUES USED TO SATISFY DSD FOR THE APPROACHES OF RURAL

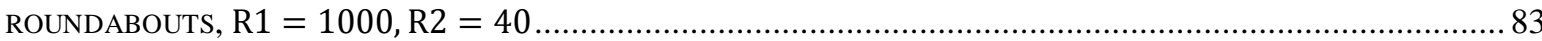

FIGURE 3-31 LATERAL CLEARANCE DESIGN VALUES USED TO SATISFY DSD FOR THE APPROACHES OF RURAL ROUNDABOUTS, R1 $=1000, \mathrm{R} 2=20$

FIGURE 3-32 COMPARISON OF THE LATERAL CLEARANCE VALUES REQUIRED TO SATISFY THE DETERMINISTIC AND PROBABILISTIC SSD FOR THE APPROACHES OF ROUNDABOUTS . 84

FIGURE 3-33 COMPARISON OF THE LATERAL CLEARANCE VALUES REQUIRED TO SATISFY THE DETERMINISTIC AND PROBABILISTIC DSD FOR THE APPROACHES OF URBAN ROUNDABOUTS

FIGURE 3-34 COMPARISON OF THE LATERAL CLEARANCES VALUES REQUIRED TO SATISFY THE DETERMINISTIC AND PROBABILISTIC DSD OF THE APPROACHES OF RURAL ROUNDABOUTS 


\section{LIST OF APPENDICES}

APPENDIX-A DESIGN AIDS FOR LATERAL CLEARANCE REQUIREMENTS, CV = 5\% ..........................101

APPENDIX-B DESIGN AIDS FOR LATERAL CLEARANCE REQUIREMENTS, CV = $10 \% \ldots \ldots \ldots \ldots \ldots \ldots \ldots \ldots . . . . . . . . . . . .110$

APPENDIX-C DESIGN AIDS FOR LATERAL CLEARANCE REQUIREMENTS, CV = $15 \% \ldots \ldots \ldots \ldots \ldots \ldots \ldots \ldots . . . . . . . . . . . .117$

APPENDIX-D DESIGN AIDS FOR DECISION SIGHT DISTANCE AT URBAN ROUNDABOUTS..................126

APPENDIX-E DESIGN AIDS FOR DECISION SIGHT DISTANCE AT RURAL ROUNDABOUTS.................130 


\section{CHAPTER 1: INTRODUCTION}

\subsection{Overview}

While roundabouts and traffic circles may look alike, there are significant differences between them in terms of traffic operation and geometric design. In fact, modern roundabouts are an improved form of traditional circular intersections. A modern roundabout is a controlled intersection in which vehicles from all approaches can enter the circulatory roadway when there is a sufficient gap, traverse the circulatory roadway in one direction around the central island, and exit in the desired leg.

Some researchers claim that circular intersections have been in use since the invention of the first vehicle (Persaud et al. 2001). The Columbus circle, built in 1905 and located in Manhattan, New York, was the first circular intersection in North America. The Arc de Triomphe, built in 1907, was the first circular intersection in France (Chanchai and Wayne 2016). In the past, circular intersections were less favorable due to traffic delays and major safety concerns. While traffic circles have been used in Germany since 1930, their implementation was slowed down in 1960 due to safety and traffic operation problems (Brilon and Vandehey, 2008). In the United States, traffic circles were prohibited until 1940 due to significant delays for motorists; Improvements were made at that time (Chanchai and Wayne 2016). According to Myers (1994), New Jersey installed other types of intersections instead of circular intersections for safety and mobility reasons. Safety and traffic delays are two major problems associated with traffic circles.

A modern roundabout is a modified version of a traditional circular intersection which overcomes the flaws associated with traffic circles. According to Sisiupiku and Oh (2001), the first roundabout was developed and implemented in the United Kingdom in 1963. According to Chanchai and Wayne (2016), the British Ministry of Transport published the first roundabout design guideline in 1971. Sisiupiku and Oh (2001) claim that the concept that entry vehicles must yield to vehicles in the circulatory lane was the first step in the development of modern roundabouts. Later, approaching legs were deflected and the flare was added to improve the safety and capacity of the junctions. According to Brilon and Vandehey (2008), German transportation engineers began the

implementation of roundabouts for experimental purposes around the year 1980. Van and 
Balmefrezol (2007) state that the first roundabout was implemented in France around the year 1970 for the evaluation of effectiveness. The yield rule was added to the highway code in France in 1983, after roundabouts proved to be beneficial (Van and Balmefrezol 2007). Roundabouts have been implemented in the United Kingdom, Australia, New Zeeland, and other countries for years, but this did not become common practice in North America until 1990. Rodegerdts (2005) states that the first modern roundabout was built in Nevada, US, in 1990. Because of the safety improvements, the implementation of roundabouts has been increasing in many countries around the world.

Safety is one of the dominant parameters in the design of roundabouts. Achieving the desired operating speed is one of the major goals in the design of roundabouts. In roundabouts, speed is controlled by the provision of curvature. In order for roundabouts to be safe, the SSD requirements must be met at every single point. DSD is considered at intersections where drivers require a longer time to perceive a hazard and react to it. Currently, SSD and DSD are calculated using the formula recommended by AASHTO (2011), in which the design variables are predetermined, fixed values. Once SSD and DSD are calculated, their adequacy is verified at the approaches, exits and circulatory lane of roundabouts (driver sight obstructions). Sight distance requirements are checked graphically for the adequacy of SSD. Some authors have developed analytical models to check sight distance requirements. Easa (2017) developed an analytical model for lateral clearance requirements for SSD at single-lane, symmetrical roundabouts. Easa (2018) also proposed an analytical model for lateral clearance requirements for SSD at single-lane, unsymmetrical roundabouts.

In reality, design variables are not fixed values, but random variables which are sometimes correlated with one another. The reliability-based design method is applied in different branches of civil engineering. Some authors have applied the probabilistic method to the design of sight distance, traffic signals, and the horizontal and vertical elements of highways. The results of studies of the application of probability in transportation engineering indicate that reliability-based design values provide a more accurate representation of the requirements of design values based on the randomness of the design variables. The reliability-based approach provides designers with the option to choose the level of reliability of their design. The SSD and DSD design values increase as the probability of failure decreases, and vice versa. In the deterministic design method, 
the same extreme values of the design variables are applied in different regions. In the probabilistic method, the roundabout design makes use of data collected for that particular intersection.

\subsection{Research Problem Statement}

The design of stopping sight distance at roundabouts is an important task since it highly impacts the safety of road users. Because of the complexity of roundabouts and possible unfamiliarity, drivers may require more time to notice and react to hazards. Decision sight distance is considered in situations where drivers have difficulty receiving information about hazards. Vehicle operating speed is controlled by the provision of deflection at the entries and exits of roundabouts. The existing SSD and DSD design methods for roundabouts (deterministic method) are based on predetermined, fixed values for the design variables. Although the current design methods may not impose any safety risks, they do not provide any insight into the reliability of the design. The intent of this research study was to develop a probabilistic method for the design of SSD and DSD in roundabouts. With the probabilistic design method, designers will be able to obtain SSD and DSD based on their desired (acceptable) probability of noncompliance.

\subsection{Research Objectives}

The intent of this thesis was to develop a probabilistic (reliability-based) method for the design of SSD and DSD in roundabouts based on the equation recommended by the AASHTO (2011) for the calculation of SSD and DSD. The aim of this study is to develop models for the calculation of SSD and DSD using the First-Order Second-Moment (FOSM) and Advanced First-Order SecondMoment (AFOSM) reliability methods.

The research objective is to apply probabilistic SSD design values for calculations of lateral clearance at the approaches, exits, and circulatory lane of roundabouts. The goal of this study is to prepare lateral clearance design aids based on the design speed and geometry of roundabouts. Design aids for lateral clearance based on DSD at the approaches of roundabouts were also developed. The reliability model developed in this study was applied to an existing roundabout. 


\subsection{Thesis Organization}

This thesis consists of five chapters. A description of each chapter is provided below:

Chapter 1 provides a brief overview of roundabout operation and geometric parameters. In this section, the historic development of modern roundabouts and the implementation of these intersections in different regions are described. The thesis problem and research objectives are also described.

Chapter 2 provides a comprehensive review of the geometric design of roundabouts. This chapter also provides a brief description of the differentiating factors between roundabouts and other types of circular intersections. An overview of the existing sight distance design methods for roundabouts is provided. The First-Order Second-Moment (FOSM) and Advanced First-Order Second-Moment (AFOSM) reliability methods are described. This chapter also presents a review of research studies on the probabilistic design method in transportation engineering.

Chapter 3 covers the development of reliability-based SSD and DSD design models. Sight distances were modeled using the FOSM and AFOSM methods. The DSD design values were calculated for the approaches of urban and rural roundabouts. A comparison between the results of the FOSM and AFOSM reliability methods is also provided. Design aids for the stopping sight distance requirements of roundabouts are provided for three cases: 1) SSD for the approaches, 2) SSD for the circulatory lane, and 3) SSD for the exits. Design aids for lateral clearance to satisfy DSD were also developed. A comparison of the lateral clearance design values obtained using the deterministic and probabilistic design methods is provided. A sensitivity analysis was performed to determine the elements of random variables which have a major impact on the reliability index.

Chapter 4 shows the application of the probabilistic method for the design of SSD and DSD at roundabouts. The sight distances were first calculated using the FOSM and AFOSM reliability methods. A comparison of the sight distance design values obtained using the FOSM, AFOSM and deterministic methods was then conducted. Lastly, the lateral clearance and the adequacy of the geometric dimensions needed to satisfy the required sight distance were checked.

Chapter 5 presents the conclusions, recommendations, and limitations of this study. 


\section{CHAPTER 2: LITERATURE REVIEW}

\subsection{Roundabouts versus Traffic Circles}

Although modern roundabouts and traffic circles may resemble one another, there are some important differences between them in terms of traffic control and geometry. These differences include the speed of vehicles through the intersection, the size of the intersection, the use of traffic control devices, pedestrian treatment, and the alignment of the approaching legs. Myers (1994) believes that the traffic control devices, flare, and curvature of the entry and exits are the three major elements which differentiate modern roundabouts and traditional circular intersections.

The operating speed of vehicles is higher in traditional circular intersections compared to modern roundabouts. According to Persaud et al. (2001), vehicle speed is a major differentiating element between traditional circular intersections and roundabouts. In roundabouts, vehicle speed is controlled by the diameter of the central island and the deflection imposed on the entries and exits.

Roundabouts are always controlled by the yield sign, while traditional circular and rotary intersections can be controlled by stop signs, traffic signals, a mixture of traffic signals and stop signs, or they can be uncontrolled. In modern roundabouts, vehicles in the circulatory lane always have the right of way and vehicles entering the roundabout must yield to them. In circular intersections, circulating vehicles also yield to entry vehicles. Traditional circular and rotary intersections may contain stop signs, traffic signals or yield signs for the vehicles in the circulatory lane. Flannery and Datta (n.d.) state that two of the most dominant characteristics of modern roundabouts include the deflected entry leg and the fact that vehicles entering the roundabout must yield to traffic in the circulatory lane.

Traditional circular and rotary intersections can accommodate parking spots along the circulatory roadway; this is not the case for modern roundabouts.

Pedestrian treatment is another difference between circular intersections and modern roundabouts. In roundabouts, pedestrian crosswalks are provided on the entry legs from all approaches just in front of the yield line. In traffic circles, pedestrians can cross through the intersection. Unlike 
traditional circular and rotary intersections, pedestrian crossing is prohibited on the circular roadway of roundabouts.

In modern roundabouts, the entry legs are skewed to control the speed of vehicles. In traditional circular and rotary intersections, the approaching legs intersect with the circular roadway at nearly a right angle. The deflection imposed on the approaches forces entry vehicles to reduce their speed. According to Myers (1994), the deflection imposed on approaches reduces vehicle speed, leading to a reduction in collisions.

Although transportation professionals use different classification systems, roundabouts are generally categorized into three types based on their size: mini-roundabouts, single-lane roundabouts and multilane-roundabouts.

Robenson et al. (2000) classified roundabouts into six categories based on their size and environmental conditions: mini-roundabouts, urban compact roundabouts, urban single-lane roundabouts, urban two-lane roundabouts, rural single-lane roundabouts, and rural two-lane roundabouts. Each type of roundabout has different speed requirements and is sufficient up to a certain traffic volume. The approach speed of the same type of roundabout can also differ in urban and rural areas. The different types of roundabouts are shown in Table 2.1.

The mini-roundabout is generally used on low speed urban roadways. The radius and height of the inscribed circle in mini-roundabouts are smaller compared to single-lane and multi-lane roundabouts. According to Werner and Mark (1998), the radius of mini-roundabouts ranges from 6 to 12 meters $(m)$. The small entry curve and central island radius force vehicles to reduce their speed. When the entry curve radius and central island diameter are small, accommodating large trucks can be challenging. Werner and Mark (1998) state that passenger cars can travel and circulate around the central island while large trucks can traverse over the central island. Because of the low vehicle speed and short crossing distance, mini-roundabouts are very convenient for pedestrians (Robinson et al. 2000). Lochrane et al. (2012) claim that although mini-roundabouts have been used in other countries for several years, they have only recently gained popularity in the USA. Lochrane et al. (2012) state that mini-roundabouts are a desirable junction which improves mobility and safety. Figure 2-1 illustrates a typical mini-roundabout. 
Table 2.1 Types of roundabouts (FHWA 2000)

\begin{tabular}{cccc}
\hline Design Elements & Mini-Roundabout & $\begin{array}{c}\text { Single-Lane } \\
\text { Roundabout }\end{array}$ & $\begin{array}{c}\text { Multi-Lane } \\
\text { Roundabout }\end{array}$ \\
\hline $\begin{array}{c}\text { Entry Speed }(\mathrm{Km} / \mathrm{h}) \\
\text { Number of Entry } \\
\text { Lanes }\end{array}$ & 25 to 30 & 30 to 40 & 40 to 50 \\
$\begin{array}{c}\text { Central Island } \\
\text { Treatment } \\
\begin{array}{c}\text { Typical Daily Traffic } \\
\text { Volume }\end{array}\end{array}$ & Fully traversable & $\begin{array}{c}\text { Raised (may have a } \\
\text { traversable apron) }\end{array}$ & $\begin{array}{c}\text { Raised (may have a } \\
\text { traversable apron) }\end{array}$ \\
\hline
\end{tabular}

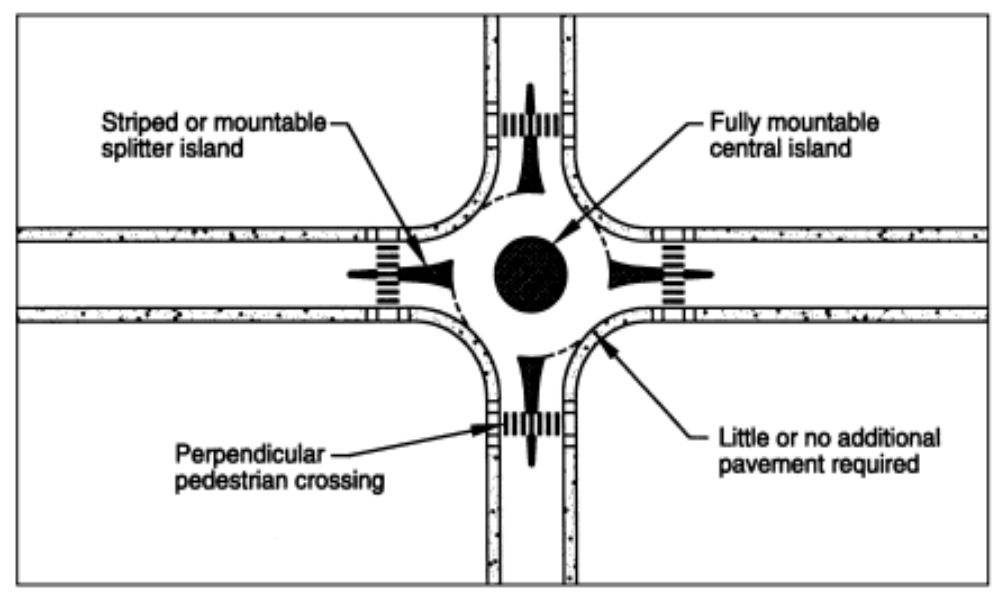

Figure 2-1 Mini-Roundabout (FHWA 2010)

A single-lane roundabout has one entry lane for all approaches and one circulatory lane around the central island. According to Robinson et al. (2000), single-lane roundabouts are characterized by a larger inscribed circle radius compared to mini-roundabouts, a truck apron, and a raised and untraversable central island. Because there are fewer conflict points between different flows in single-lane roundabouts compared to other types of intersections, the vehicle collision rate is much lower. Jensen (2017) states that single-lane roundabouts provide the highest safety level compared to other types of intersections when the height of the central islands is sufficient or an independent path is provided for bicycles. Figure 2-2 illustrates a typical single-lane roundabout. 


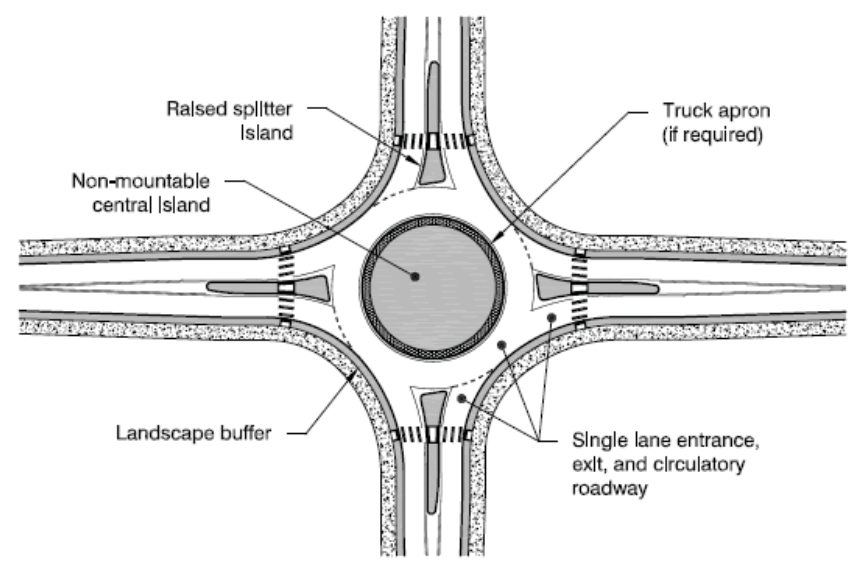

Figure 2-2 Single-lane roundabout (NCHRP 2010)

Multi-lane roundabouts have two or more circulatory roadways around the central island and more than one entry lane at one or more of the approaches. Two-lane roundabouts can serve a higher traffic volume compared to mini and single-lane-roundabouts. The entry legs of roundabouts are skewed in order to control vehicle operating speed. The basic characteristics of multi-lane roundabouts include a raised central island, raised splitter islands, a truck apron, skewed entry legs, and multiple entry and circulating lanes. Figure 2-3 illustrates the geometry of multi-lane roundabouts.

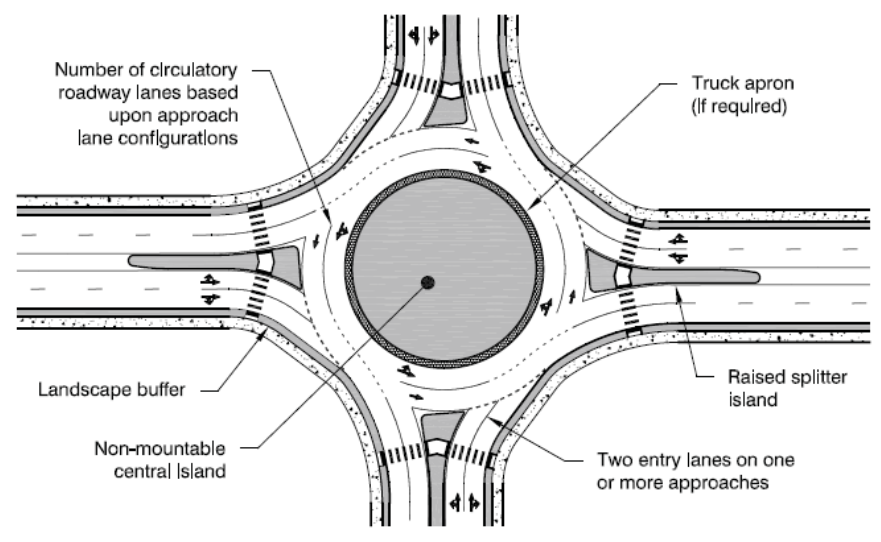

Figure 2-3 Multi-lane roundabout (NHCRP 2010) 


\subsection{Geometric Design of Roundabouts}

Once the initial geometry of a roundabout is designed, the roundabout is checked to see whether or not it meets the design objectives. The design of each element of the roundabout is repeated until all of the design objectives are met. According to Robinson et al. (2000), the primary objectives of the design of roundabouts include the optimization of traffic performance, safety, and the accommodation of the design vehicle. Easa and Mehmood (2004) state that the major objectives of roundabout design include safety and traffic operation performance. A well-designed roundabout will improve road user safety and reduce traffic delays.

Easa and Mehmood (2004) developed an analytical model for the design of single-lane roundabouts. The authors claim that the geometric features provided by their model will reduce vehicle delays and minimize the speed differences between different vehicle paths. The same theory was used by Mujahid (2012) to develop a model for the design of double- lane roundabouts. Both models consider vehicle speed consistency as a measure of safety and traffic delay as a measure of traffic operation performance. One of the major shortcomings of these models is that they are not applicable to roundabouts with more or less than four legs and to roundabouts in which the entry legs do not intersect with each other at a right angle.

Speed consistency is a major parameter for the evaluation of safety in roundabouts. Rubio-Martín et al. (2015) proposed a method for the design of single-lane roundabouts in which vehicle speeds are consistent for different flows and vehicle paths. Unlike the method developed by Easa and Mehmood (2004), this method is applicable to roundabouts with any number of approaching legs in which all legs intersect with each other at different angles. This method makes use of a random search technique called the heuristic technique. The authors believe that this method is applicable to urban and rural environments.

\subsection{Design Elements of Roundabouts}

Each geometric element of a roundabout has a significant impact on the capacity and safety of the intersection. Robinson et al. (2000) describe the geometric design of roundabouts as a trade-off between capacity and safety. A focus on high user safety will lead to a reduction in capacity. Lower vehicle speeds improve the safety performance of roundabouts. In order to reduce vehicle 
operating speeds, the dimensions of the geometric elements need to be reduced which will negatively affect capacity. On the other hand, increasing the capacity of roundabouts will reduce safety. The geometric features that affect the safety and capacity of roundabouts include the entry lane width, the number of entry lanes, the rate of deflection for the entry and exit legs, the circulating lane width, the radius of the central island, the flare length, and the radius of the inscribed circle. Mahdalova et al. (2013) claim that drivers will traverse the entry curves of roundabouts at a lower speed if all of the geometric features are well designed. The geometric elements of roundabouts are illustrated in Figure 2-4.

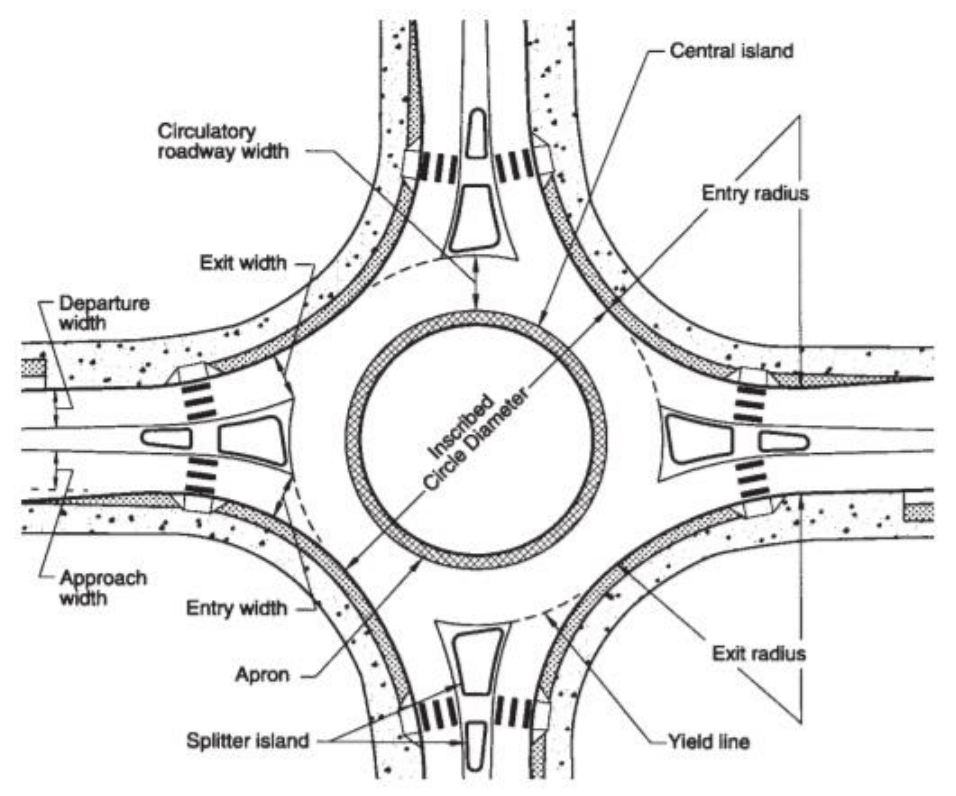

Figure 2-4 Geometric elements of roundabouts (FHWA 2000)

\subsubsection{Size of Roundabouts}

The size of a roundabout is chosen based on the path alignment, design speed, and design vehicle. The location, size, and alignment of the approaching legs are selected so that the design speed is controlled, the largest vehicle is accommodated, the design fits the site constraints, and all of the other design criteria are met (Robinson et al. 2000). The design process begins with the selection of an initial size of the inscribed circle. The final size of the inscribed circle is determined based on the design parameters (Robinson et al. 2000). According to Godavarthy et al. (2016), the radius of the inscribed circle is mostly affected by the turning path required for the design vehicle for 
single-lane roundabouts. Table 2.2 shows common design vehicles considered for roundabouts and their corresponding required inscribed circle diameter.

Mahdalova et al. (2013) evaluated the effect of the inscribed circle radius on the safety of roundabouts. The results of their analysis revealed that increases in the radius of the inscribed circle reduce the rate of collisions. After reaching a certain inscribed circle radius, the crash rate increases as the inscribed circle radius increases. According to Mahdalova et al. (2013), a large inscribed circle radius increases the vehicle speed which in turn increases the frequency of collisions. On the other hand, if the radius of the inscribed circle is very small, it is necessary to increase the width of the circulatory roadway in order to accommodate the design vehicle. Since a small inscribed circle diameter with a wide roadway does not force the vehicles to reduce their speed, vehicles would traverse the circulatory roadway in almost a straight line, increasing the crash rate. Mahdalova et al. (2013) claim that $20 \mathrm{~m}$ is the desired inscribed circle radius for the safety of single-lane roundabouts.

Table 2.2 Design vehicle and inscribed circle diameter (FHWA 2000)

\begin{tabular}{ccc}
\hline Roundabout & Design vehicle & Inscribed circle diameter $(\mathrm{m})$ \\
\hline \multirow{3}{*}{ Single-lane roundabout } & B-12 & 27 to 46 \\
& WB-15 & 32 to 46 \\
& WB-20 & 40 to 55 \\
\hline \multirow{2}{*}{ Double-lane roundabout } & WB-15 & 46 to 67 \\
& WB-20 & 50 to 67 \\
\hline \multirow{2}{*}{ Three-lane roundabout } & WB-15 & 61 to 76 \\
& WB-20 & 67 to 91 \\
\hline
\end{tabular}

The raised, circular, and non-traversable area of roundabouts is called the central island. Truck aprons may also be considered as part of the central island. The central island is generally designed in a circular shape to control vehicle operating speed. Jensen (2017) claims that the radius and elevation of the central island has an impact on the safety of cyclists. Montella et al. (2013) state that the central island should be seen from the required stopping sight distance, because the central island act as a barrier to the vehicles in the junction. Jensen (2017) states that a central island radius of 10 to $20 \mathrm{~m}$ and height of $2 \mathrm{~m}$ will improve the safety of roundabouts for cyclists. Robinson et al. (2000) claim that oval and other geometric shapes may cause differential speeds in the 
circulatory roadway, leading to safety problems. In order to provide consistent speed in the circulatory lane of roundabouts, a circular central island is recommended.

Sculptures and other urban features can be added to the central island for aesthetic reasons. The entry and exit curvatures at the approaches and exits of the roundabouts depend on the size of the inscribed circle. The radius of the central island is directly linked with the radius of the inscribed circle and the width of the circulatory roadway. Robinson et al. (2000) state that in order to accommodate larger design vehicles and improve sight distance, a larger central island diameter should be used in rural areas compared to urban areas.

Truck aprons are provided at roundabouts to allow larger vehicles to make a turn while controlling vehicle speed on the circulatory roadway by restricting the dimensions. Once the design vehicle is defined for the proposed roundabout, the width of the truck apron can be calculated based on the required turning path of the design vehicle. Godavarthy (2012) states that truck aprons should be designed to discourage passenger cars from using them while allowing large trucks to traverse them. Robinson et al. (2000) recommend a truck apron height of 5 to 7.5 centimeters above the road surface level. According to Robinson et al. (2000), CAD-based software or a vehicle design template are used to determine the swept path of the design vehicle. Robinson et al. (2000) suggest a truck apron width of 1 to $4.6 \mathrm{~m}$ and a cross slope of 1 to 2 percent. The truck apron should be constructed from a different material than the circulatory roadway so that it will not be perceived as a driveway. Figure 2-4 illustrates the accommodation of a truck apron in a roundabout.

The main objectives of splitter islands are the provision of a refuge space for pedestrians, the separation of the entry and exit lanes, speed management, and the placement of traffic control signs (Robinson et al. 2000). Robinson et al. (2000) claim that in order to provide enough of a refuge area for pedestrians and to alert approaching vehicles, the total length of the splitter island needs to be at least $15 \mathrm{~m}$ and the width needs to be at least $1.8 \mathrm{~m}$. A splitter island length above $200 \mathrm{~m}$ is preferred in rural areas where the design speed is high. Figure 2-5 illustrates the geometry of a splitter island at a roundabout. The American Association of State and Highway Transportation Official (AASHTO 2011) guideline is recommended for the design of splitter islands in roundabouts. 


\subsubsection{Alignment of Approaching Legs and Angle between Approaching Legs}

The degree of curvature at the entry and exit points of roundabouts, the accommodation of the design vehicle, and the sight distance are all affected by the choice of alignment of the approaching legs (Robinson et al. 2000). The location and size of roundabouts alters the optimal alignment of the approaches. It is a common design practice for the centerline of all approaching legs to pass through the center of the inscribed circle. The centerline of the legs can be offset to the right or left of the center of the inscribed circle. The overall purpose of the provision of deflection at the entry and exit points is to control vehicle speed. When the centerline of the leg is shifted to the right of the center of the inscribed circle, the curvature of the entry legs is decreased. On the other hand, the speed of the vehicles will be reduced if the centerline of the approaching legs is shifted to the left of the center of the inscribed circle. Robinson et al. (2000) state that shifting the centerline of the approaching leg to the right is not an ideal option to achieve the design speed and other design criteria. Although shifting the centerline of the approach legs to the left reduces the speed of the entering vehicles, it reduces the control of the speed at the exits. Figure 2-6 illustrates the alignment of the approaching legs of roundabouts.

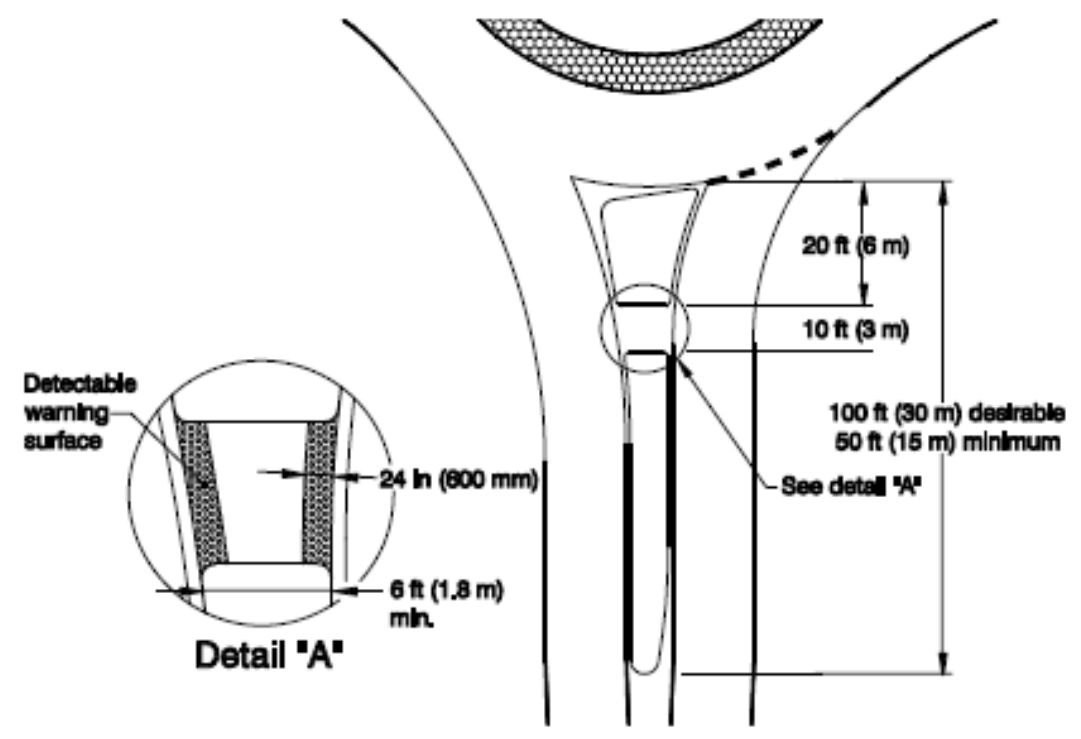

Figure 2-5 Minimum splitter island dimensions (FHWA 2000)

The angle between the approaching legs plays a significant role in the design of roundabouts. A change in the angle between different approaches will bring changes to other design parameters. Robinson et al. (2000) state that in a modern roundabout, it is desirable for the approaching legs 
to intersect with each other at a 90 degree angle or a nearly right angle. Robinson et al. (2000) state that if the angle between two approaching legs of a roundabout is less than 90 degrees, it will be difficult for larger vehicles to make a turn. On the other hand, when the angle between two approaching legs is significantly greater than 90 degrees, the operational speed of the vehicles inside the circulatory roadway will be greatly increased.

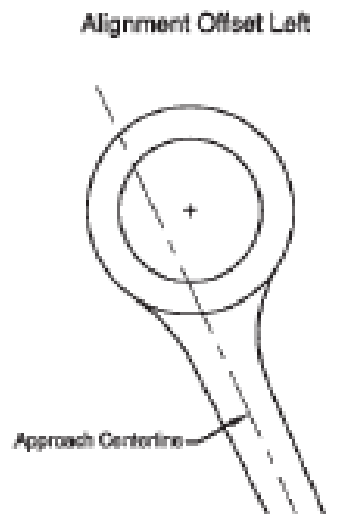

PREFERRED

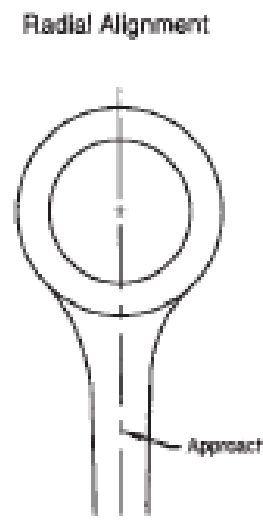

ACCEPTABLE
Alignment Offset Right

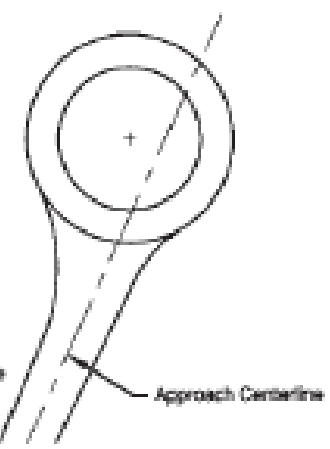

UNACCEPTABLE

Figure 2-6 Alignment of approaching legs (FHWA 2010)

\subsubsection{Lane Width Consideration at Roundabouts}

The entry lane width is defined as the distance between the left edge and right edge of the roadway, along a line that intersects with the right curb at a 90 degree angle (Robinson et al. 2000). Increasing or decreasing the entry lane width will affect the entry speed and capacity of the roundabout. The desired operating speed, capacity, and design vehicle are factors that affect the width of the entry lanes. It is good practice for the left edge of the approach lane to be tangent to the truck apron or the central island. The entry lane should not be wide enough for two vehicles to be placed side by side. Robinson et al. (2000) argue that if the entry lane width is larger than 5.5 $m$ or greater than the width of the circulatory roadway, drivers may perceive it as a two-lane entry. According to Robinson et al. (2000), the common entry lane width for a single-lane roundabout varies between 4.2 and $5.5 \mathrm{~m}$.

The width of the circulatory roadway is determined by the number of lanes entering the circulatory roadway and the turning path required to accommodate the design vehicle (Robinson et al. 2000). The width of the circulatory roadway is kept constant for the whole length around the central island for single-lane roundabouts. A turning template or CAD-based software is used to determine the 
swept path of the vehicles for each turning movement. According to Robinson et al. (2000), the width of the circulatory roadway should always exceed the width of the maximum entry lane and increase up to 20 percent beyond the maximum entry width. The circulatory roadway should not be wide enough for two vehicles to move side-by-side. Common circulatory roadway width for single-lane roundabouts ranges from 4.5 to $6 \mathrm{~m}$. In order to accommodate large trucks, a truck apron may be considered for single-lane roundabouts. The width of the exiting lane is also chosen based on the design vehicle and capacity requirements.

\subsubsection{Roundabout Entry and Exit Curve Radii}

The entry curve radius has a significant effect on the capacity and safety of roundabouts. Nikou et al. (2015) recommend sequential curves with different curve radii to control the approaching speed at roundabouts. Figure 2-7 illustrates the entry geometry of roundabouts. According to Robinson et al. (2000), the proper design of the entry path radius should have two major characteristics. First, it should be less than or equal to the circulating path radius. Second, it must achieve the desired entry speed. The design of the entry curve radius for single-lane roundabouts is based on the design speed of vehicles on the fastest path.

The exit curve radius is designed to improve the traffic flow and reduce the collision rate at the exits. The exit radius is provided in order to control vehicle speed since pedestrian safety is affected by the speed of exiting vehicles. According to Robinson et al. (2000), the exit curve radius should not be less than the radius of the circulating path. Robinson et al. (2000) state that if the circulating path radius is larger than the exit curve radius, vehicles will move around the central island at higher speeds, increasing the risk of collisions. On the other hand, if the radius of the exit curve is too large compared to the circulating path radius, the speed of the exiting vehicles will increase, putting pedestrians at risk. Figure 2-8 shows the exit geometry of roundabouts.

\subsection{Deterministic Sight Distance at Roundabouts}

The stopping and intersection sight distance need to be provided at roundabouts. Stopping sight distance is defined as the distance travelled by a vehicle from the time the driver sees an object until the vehicle comes to a complete stop. Intersection sight distance (ISD) is defined as the minimum distance needed for a driver to perceive and safely react to a hazard when the driver does not have the right of way. In complex situations, situations in which drivers require more time to 
perceive and react to a hazard, decision sight distance must be provided. Currently, the determination of sight distance at roundabouts is based on predetermined, fixed design variables. This method is called the deterministic design method.

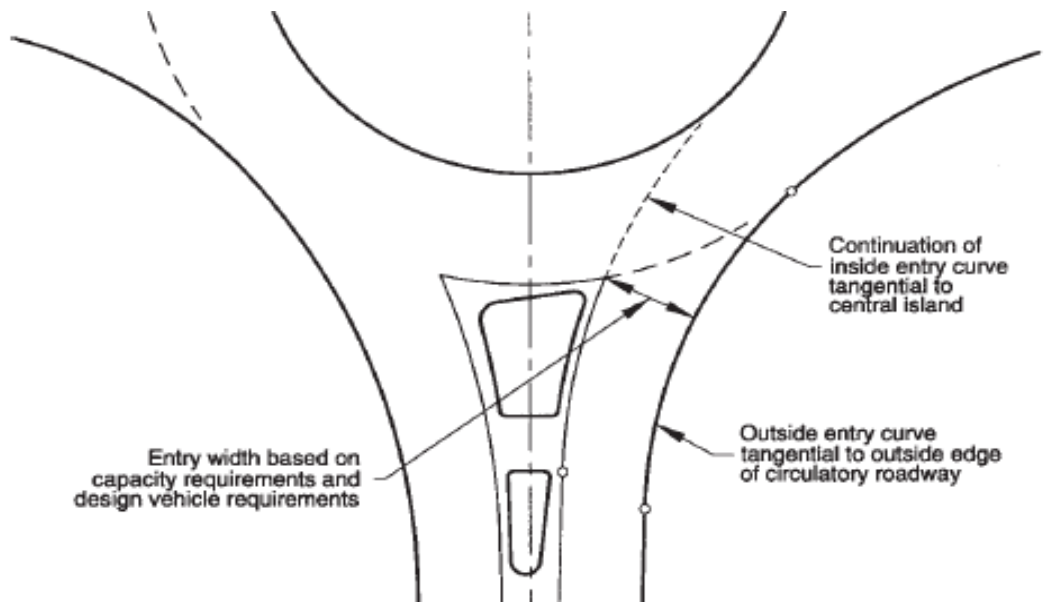

Figure 2-7 Entry curve radius (FHWA 2000)

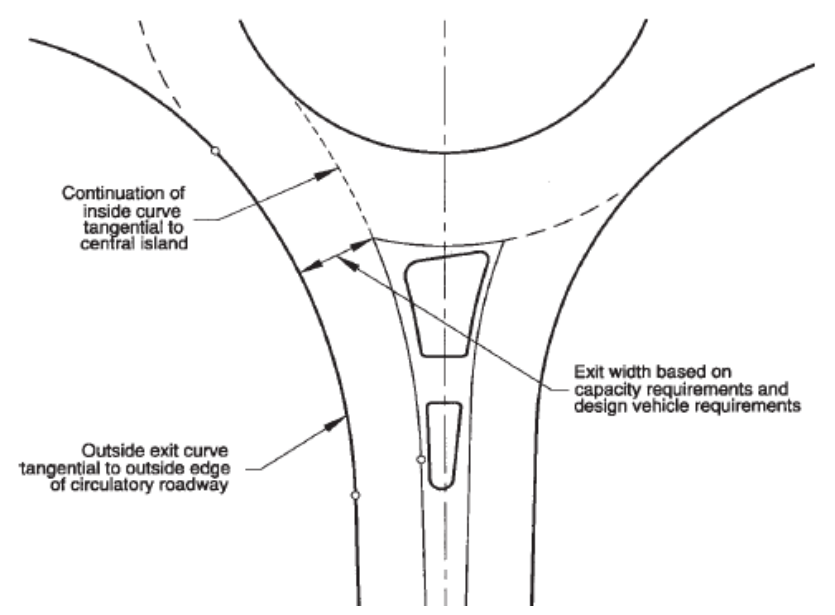

Figure 2-8 Geometry of roundabout exits (FHWA 2000)

\subsubsection{Intersection Sight Distance}

At roundabouts, entry vehicles do not have the right of way and need to yield to vehicles already in the circulatory lane. ISD is required at the entries of roundabouts. The sight triangle is used for the determination of ISD. Figure 2-9 illustrates the sight triangle of intersection sight distance for roundabouts. The length of each leg of the sight triangle is calculated based on the sight distance for circulating and entering vehicles just outside of the entry. The sight triangle is comprised of the length of the approach leg and two conflicting legs, one to the circulating vehicle and another to the vehicle from the closest upstream approach. Robinson et al. (2000) claim that the approach 
leg of the sight triangle must not exceed $15 \mathrm{~m}$. They argue that if the approach leg of the sight triangle is increased, the safety of the roundabout will be reduced.

The length of the conflicting legs of a sight triangle are expressed in Equation (2.1).

$$
b=0.278 V_{\text {Major }} t_{c}
$$

where:

$\mathrm{b}=$ length of the conflicting leg of the sight triangle, $\mathrm{m}$

$t_{c}=$ critical gap for entering the circulatory road, $\mathrm{Km} / \mathrm{h}, 6.5 \mathrm{~s}$

$V_{\text {Major }}=$ design speed of the conflicting movement, $\mathrm{Km} / \mathrm{h}$

Robinson et al. (2000) state that an ISD which is higher than required will reduce the safety of the roundabout.

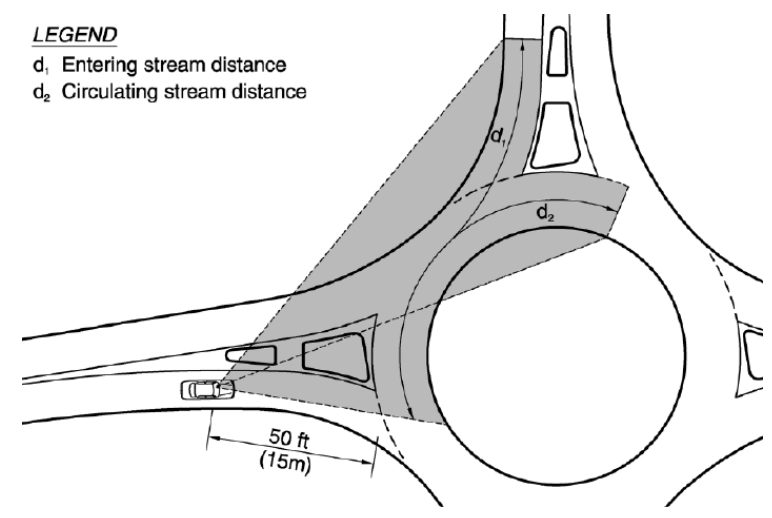

Figure 2-9 Sight triangle of intersection sight distance at a roundabout (FHWA 2000)

\subsubsection{Stopping Sight Distance}

Stopping sight distance is defined as the minimum distance a driver requires to perceive and react to a hazard in order to bring the vehicle to a complete stop before colliding with the object. SSD must be provided at every single point of roundabouts. AASHTO (2011) defines SSD as the distance a vehicle travels from the time the driver sees an object to the time the brakes are applied, plus the distance travelled by the vehicle from the time the brakes are applied to the time the vehicle comes to a complete stop. SSD is measured along the centerline of the drive lane which can be on a straight portion of streets or along horizontal and vertical curves. The distance travelled by a vehicle from the moment the brakes are applied to the moment the vehicle comes to a complete 
stop depends on the initial speed and deceleration rate of the vehicle. Fambro et al. (2000) state that SSD impacts the dimensions of the roundabout, safety, and the overall cost of the project. de Santos-Berbel et al. (2017) believe that sight distance is the most important safety factor. Sight distance has a huge influence on safety and traffic flow in roundabouts.

SSD is checked at the approaches, circulatory roadway, and exits of roundabouts. For the approaches of roundabouts, SSD is checked at the pedestrian crosswalk and at the yield line. Figure 2-10 illustrates SSD at roundabouts. Easa (2017) states that the drivers eye height and an object height of $1.08 \mathrm{~m}$ is considered for the calculation of SSD when the drivers sightline is obstructed. The design variables include the driver's perception-reaction time, vehicle speed, and vehicle deceleration rate.

AASHTO (2011) recommends Equation (2.2) for the calculation of stopping sight distance.

$$
S S D=0.278 V t+0.039 \frac{V^{2}}{a}
$$

where:

$$
\begin{aligned}
& \mathrm{SSD}=\text { stopping sight distance, } \mathrm{m} \\
& \mathrm{V}=\text { design speed }, \mathrm{Km} / \mathrm{h} \\
& \mathrm{t} \quad=\text { perception-reaction time, } 2.5 \mathrm{~s} \\
& \mathrm{a} \quad=\text { deceleration rate, } 3.4 \mathrm{~m} / \mathrm{s}^{2}
\end{aligned}
$$

The time from the moment the driver sees an object to the moment the brakes are applied is called the perception-reaction time. The perception-reaction time varies from driver to driver and depends on many factors. According to AASHTO (2011), the perception-reaction time depends on the distance of the object from the vehicle, the weather conditions, the level of complexity of the road geometry, driver visual acuity, the color, and level of severity of the hazard, road conditions, and many other factors. In 1940, the average perception-reaction time was assumed to be 2 seconds for a design speed of $50 \mathrm{Km} / \mathrm{h}$ and 3 seconds for a design speed of $110 \mathrm{Km} / \mathrm{h}$. 

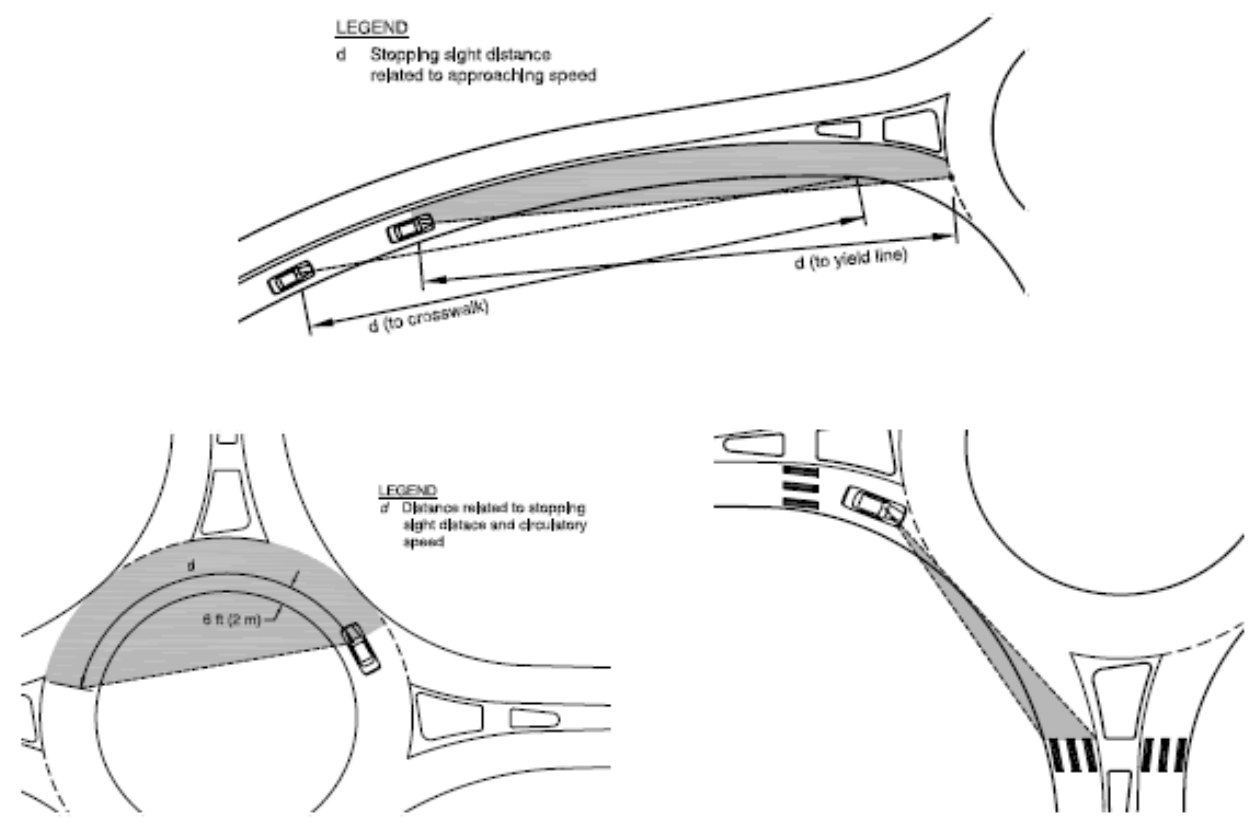

Figure 2-10 Stopping sight distance at roundabouts (FHWA 2000)

Fambro et al. (n.d.) evaluated the perception-reaction time for a stopping sight distance situation. Four field studies were conducted to evaluate driver perception-reaction time. The time recording and measurement of vehicle acceleration/deceleration was done using an in-vehicle instrument. In studies 1,2, and 3, drivers were asked to bring the vehicle to a stop by observing an expected object. In study 4, drivers were exposed to an unexpected object and asked to bring the vehicle to a stop. This study concluded that a perception-reaction time of 2 seconds is sufficient for the majority of drivers in different situations.

Johansson and Rumar (1971) studied the perception-reaction time of drivers exposed to an unexpected traffic condition and required to immediately push the brakes. The perception-reaction time of the same drivers was measured under two different road conditions. First, drivers reacted to an object while driving under normal roadway conditions. Next, driver perception-reaction time was measured when the driver was exposed to an unexpected object on the road. Drivers perceived and reacted to an expected object in 2 seconds and an unexpected object in 3 seconds.

Roundabout vehicle paths consist of different curves which can affect the amount of time required by a driver to perceive and react to the presence of an object. Fambro et al. (n.d.) claim that drivers require less time to perceive and react to an expected object on a straight portion of a highway 
(such as traffic signals) and more time to perceive and react in a complex situation. Although perception-reaction time varies between different groups of drivers, a perception-reaction time of 2.5 seconds is believed to exceed the necessary perception-reaction time of almost all drivers and this value is recommended for the design of SSD (AASHTO 2011).

The deceleration rate varies from vehicle to vehicle (passenger cars, trucks, trailers, and other types of vehicles). Maurya and Bokare (2012) claim that for all types of vehicles, a high vehicle speed causes the maximum deceleration rate. The results of the study conducted by Maurya and Bokare (2012) revealed that passenger cars decelerate at a higher rate compared to other vehicle types. According to Fambro et al (1997), the majority of drivers decelerate at a rate of 6.5 to $9.0 \mathrm{~m} / \mathrm{s}^{2}$. The majority of vehicles with anti-lock braking systems decelerate at a rate of $4.0 \mathrm{~m} / \mathrm{s}^{2}$ on dry pavement and $2.8 \mathrm{~m} / \mathrm{s}^{2}$ on wet pavement. Fambro et al. (1997) believe that about 90 percent of drivers decelerate at a rate of $3.4 \mathrm{~m} /$ or higher and recommend this value for the design of SSD. AASHTO (2011) also recommends a vehicle deceleration rate of $3.4 \mathrm{~m} / \mathrm{s}^{2}$ for the design of SSD.

Vehicle operating speed varies depending on the location of the roundabout and SSD is calculated based on different vehicle speeds. Fambro et al. (1997) claim that the vehicle speed used to calculate SSD should be the speed desired by the majority of drivers, with the exception of careless drivers. Many factors affect the operating speed of vehicles including road conditions and time of day. Driving beyond the posted speed limit of the road does not indicate an unsafe highway segment. Fambro et al. (1997) state that due to changes in driver behavior and improvements in the design of vehicles and highways, the collision rate has not increased even though the driver speeds exceed the design speed of the road. The vehicle speed at which $85 \%$ of drivers traverse a segment of a road is called the 85th percentile speed (vehicle operating speed). Fambro et al. (1997) suggest using the 85th percentile speed for the calculation of SSD.

The design speed of the road segment before the beginning of the entry curve is used for the calculation of SSD at roundabout approaches (Easa 2017). The vehicle speed (initial speed) considered for the design of SSD at roundabout exits is based on the fastest vehicle path speed. Vehicle path is defined as the flattest and smoothest path a vehicle can take, without the presence of other vehicles and ignoring all street markings, to travel across the entry and out the exit (Robinson et al. 2010). Figure 2-11 illustrates the vehicle path at the exits of roundabouts. The 
fastest vehicle path can be drawn by free-hand or using computer software. Robinson et al. (2010) recommend that the vehicle path be sketched by free-hand and that CAD software be used to determine the minimum radius for the fastest vehicle path. The design speed on the exit is calculated based on the smallest radius of the fastest vehicle path. The design speed used to calculate SSD for the circulatory lane is based on the operating speed of the vehicles in the circulatory lane (Easa 2017).

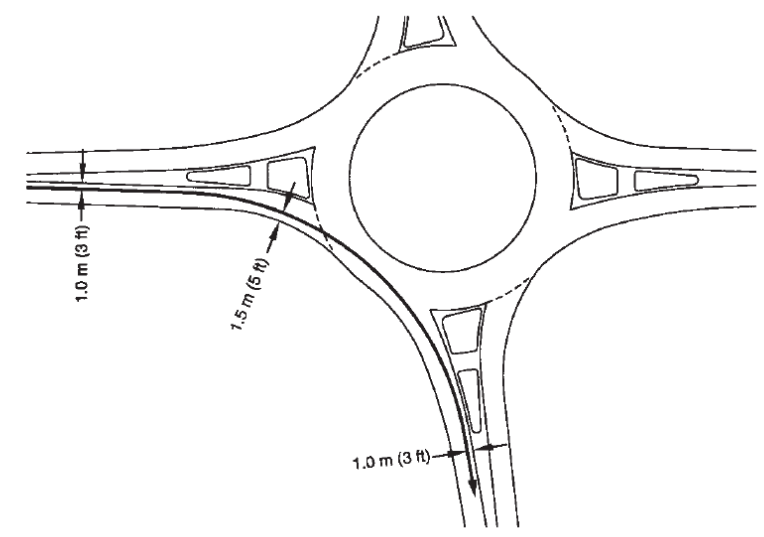

Figure 2-11 Vehicle path on the exit (FHWA 2000)

\subsubsection{Decision Sight Distance}

Generally, SSD enables an alert driver to perceive a hazard in normal and familiar road conditions and safely bring the vehicle to a stop. In order for a driver to maneuver in complex road conditions or momentarily react to a hazard, the decision sight distance must be provided. The decision sight distance value is larger than the SSD value. AASHTO (2011) and the Transportation Association of Canada (TAC 2007) name five preventative actions for decision sight distance.

$>$ Avoidance maneuver A: Stop on rural roads

$>$ Avoidance maneuver B: Stop on urban roads

$>$ Avoidance maneuver C: Speed/path/direction change on rural roads

$>$ Avoidance maneuver D: Speed/path/direction change on suburban roads

$>$ Avoidance maneuver E: Speed/path/direction change on urban roads

Equation (2.2) is used for the calculation of DSD for avoidance maneuvers A \& B and the premaneuver time is used instead of the perception-reaction time. The pre-maneuver time is relatively 
larger than the perception-reaction time and its values are determined mechanically. AASHTO (2011) recommends the following Equation for the calculation of DSD for avoidance maneuvers C, D, and E:

$$
\mathrm{DSD}=0.278 \mathrm{Vt}
$$

where:

$$
\begin{aligned}
& \text { DSD = decision sight distance, } \mathrm{m} \\
& \mathrm{V}=\text { design speed, } \mathrm{Km} / \mathrm{h} \\
& \mathrm{t}=\text { total pre-maneuver and maneuver time, } \mathrm{s}
\end{aligned}
$$

\subsection{Pedestrian and Cyclist Treatment at Roundabouts}

The accommodation of cyclists and pedestrians at roundabouts is an important task since they are the most vulnerable road users in this situation. The location of the pedestrian crossing is selected in order to improve traffic operations and the safety of pedestrians. Cyclists can travel through the roundabout like a vehicle, have a separate road crossing, or cross the road like pedestrians. Robinson et al. (2000) argue that if the pedestrian crossing is positioned too far from the yield line, pedestrians will cross the street somewhere other than the crosswalk. In order to minimize the crossing distance, the location of the pedestrian crossing should be chosen appropriately. Furthermore, it must be not be close to the yield line so that drivers can focus on pedestrians. This improves traffic safety and prevents traffic build up on the circulatory roadway. Robinson et al. (2000) recommend a pedestrian crossing width larger than $1.8 \mathrm{~m}$ and $7.5 \mathrm{~m}$ away from the yield line for the single-lane roundabouts and 7.5, 15, and $22.5 \mathrm{~m}$ away from the yield line for multilane roundabouts. Van and Balmefrezol (2007) recommend one vehicle length space between the circulatory roadway and pedestrian crosswalk.

Accommodating pedestrians at roundabouts, specifically visually impaired individuals, is a very important task for design engineers. Unlike signalized intersections, roundabouts are not equipped with audible devices to facilitate crossing for those who are visually impaired. The basic concept of roundabouts is that they are controlled by the yield sign. In order to make roundabouts more accessible, some transportation professionals propose pedestrian signals. 
Schroeder et al. (2008) evaluated the effect of pedestrian signals on the operational performance of roundabouts. The microscopic simulation technique was used to perform the analysis. The results of their analysis indicate that the operational performance of roundabouts is affected by pedestrian crossing signals. The results of their study suggest that roundabouts have optimal performance when the traffic volume is near capacity in the presence of pedestrian crossing signals.

Candappa et al. (2014) proposed the implementation of raised pedestrian crosswalks in front of the yield line and evaluated their effectiveness. This pedestrian design concept was applied to a roundabout in South Melbourne. The safety of the intersection was evaluated before and after the implementation of the design concept. The results revealed that the implementation of these raised crosswalks reduced crossing time by up to 4 seconds for pedestrians. Furthermore, vehicle speed was also slightly reduced. Pedestrians were also surveyed on the effectiveness of the new pedestrian crosswalks and the responses were positive.

The accommodation of cyclists in roundabouts is more complicated. Depending on the geometric and traffic operation characteristics of the particular roundabout, a separate bicycle facility can be provided or cyclists can traverse the roundabout in the same manner as vehicles or pedestrians. Van and Balmefrezol (2007) claim that the volume of cyclists and the dimensions of roundabouts will determine whether a bicycle lane should be added on the circulatory roadway or if a separate bicycle lane should be considered around the circulatory lane.

Sakshaug et al. (2010) studied the effectiveness of separate bicycle crossings at roundabouts and the integration of cyclists with motorists in terms of cyclist safety. For their study, the authors chose two roundabouts with two different cyclist accommodation methods. The analysis methods included accident analysis, video recording, and a field study. The results of their study revealed that roundabouts which accommodate cyclists with a separate road crossing are safer than roundabouts which integrate cyclists with motorists. Although this study concluded that the provision of a separate cyclist crossing is effective, this method can increase traffic delay for motorists. The objective of roundabout design is the improvement of safety for all road users. 


\subsection{Reliability Methods}

The probabilistic design approach is mostly applied to structural and geotechnical engineering, but this method is gaining popularity among transportation professionals. The result of the application of the reliability approach in transportation engineering indicates that deterministic design methods sometimes underestimate or overestimate design values. For example, the results of a study on left turn lane offset distance indicated that the deterministic design method overestimated the left-turn lane offset distance, increasing the overall cost of the project (Hussain and Easa 2016). Previous studies on the probabilistic design method indicate that the reliability-based design method yields a more precise estimate of the performance of the facility based on the randomness of the design variables.

Unlike the deterministic method, the reliability-based (probabilistic) design method considers all of the design variables as random variables. Easa (1994) states that, practically, the design variables used for the design of a highway segment are not deterministic, but, random variables which sometimes can be correlated with one another.

There are many reliability analysis methods including the First-Order Second-Moment Method, the Point-Estimate Method, and the Exact Method. Because of its ease of application, the FirstOrder Second-Moment (FOSM) method is widely used in different areas of science and engineering. The First-Order Second-Moment method expands the safety margin about the mean values of random variables. On the other hand, the Advanced First-Order Second-Moment (AFOSM) method expands the safety margin at a point on the failure boundary.

The following sections provide a brief overview of the fundamental concepts of reliability and the First-Order Reliability Methods (FOSM \& AFOSM).

\subsubsection{Fundamental Concepts of Reliability Analysis}

\subsubsection{Safety Margin}

Reliability predicts the probability of failure of a designed facility. In the probabilistic (reliabilitybased) approach, the safety margin (objective function) is defined as the provided design element dimensions minus the required design element dimensions. In structural engineering, demand is the value of the applied load and supply is the strength of a structure (Smith 1986). In regards to 
sight distance, the supplied design element dimensions are provided by the geometry of the highway segment and the required sight distance is based on driver and vehicle characteristics. Achieving a negative value for the safety margin function means that the system failed (demand exceeded supply). In transportation engineering, a negative value for the safety margin does not indicate that an accident would happen; it simply means that some restrictions would be imposed and that the likelihood of a collision is increased (Easa \& Hussain 2016). The design variables in the safety margin are random and the range of values selected for these variables depends on the acceptable degree of probability of failure for the specific design (Smith 1986). The safety margin is defined as the supplied sight distance minus the required sight distance. The safety margin is given by Equation (2.4).

$$
F=S-D
$$

where:

$$
\begin{aligned}
& \mathrm{F}=\text { safety margin } \\
& \mathrm{S}=\text { supply } \\
& \mathrm{D}=\text { demand }
\end{aligned}
$$

When the supply value is larger than the demand value, the safety margin is positive, indicating a safe zone. When the demand value is larger than the supply value, the safety margin is negative, indicating that the probability of failure exists.

\subsubsection{Reliability Index}

The safety or level of reliability of a facility can be expressed in terms of the reliability index, $\beta$. Figure 2-12 illustrates the probability distribution of the safety margin. The distance from the mean of the safety margin, $\mathrm{E}[\mathrm{F}]$, to the failure boundary $(\mathrm{F}=0)$ can be expressed in terms of the standard deviation of the safety margin, $\sigma_{\mathrm{F}}$, and equal to $\sigma_{\mathrm{F}} \beta$. The mean value of the safety margin, $\mathrm{E}[\mathrm{F}]$, over the standard deviation of the safety margin, $\sigma_{\mathrm{F}}$, is referred to as the reliability index. The reliability index is given by Equation (2.5).

$$
\beta=\frac{E[F]}{\sigma_{F}}
$$

where: 


$$
\begin{aligned}
& E[F]=\text { the expected value of the safety margin } \\
& \sigma_{\mathrm{F}}=\text { the standard deviation of the safety margin }
\end{aligned}
$$

Smith (1986) states that the reliability index considers the mean values of the demand and supply as well as the standard deviation of the objective function, which are measures of the level of uncertainty of the demand and supply.

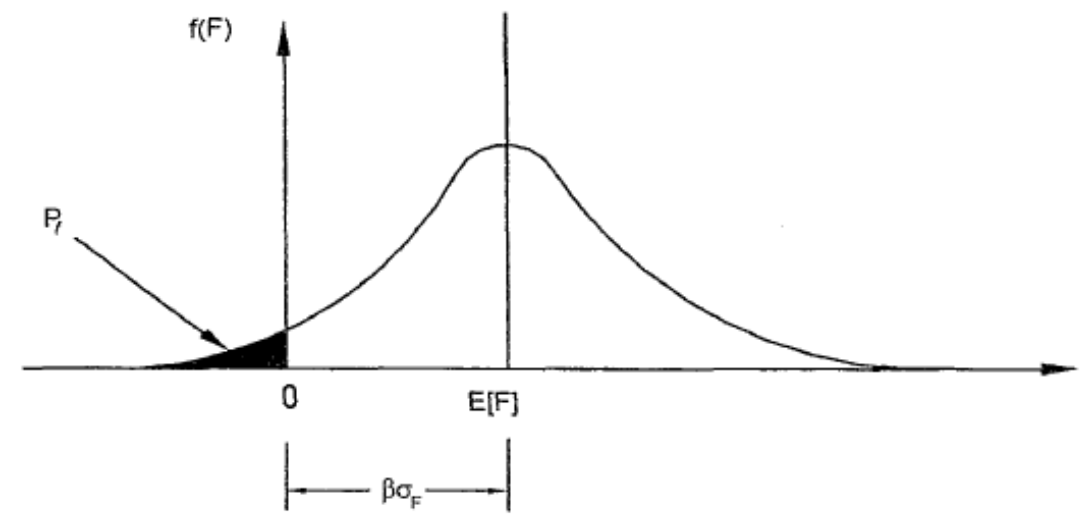

Figure 2-12 Probability distribution of the objective function (Hussain 2004)

\subsubsection{Probability of Failure}

When the demand exceeds the supply, there is a probability of failure. In Figure 2-12, the shaded area represents a negative value for the safety margin, which means that the probability of failure exists. The probability of failure is expressed by Equation (2.6).

$$
P_{f}=\Phi(-\beta)=1-\Phi(\beta)
$$

In Equation (2.6), $\Phi(-\beta)$ is the sum of the area under the density curve of the safety margin from $-\infty$ to $-\beta$. A table of the standard normal variate or a computer software program is used to obtain the value of $\Phi(-\beta)$. Based on the assigned probability of failure, the corresponding value of reliability index is used for the calculation of sight distance.

\subsubsection{First-Order Second-Moment (FOSM) Method}

The First-Order Second-Moment Method, also known as the Mean-Value First-Order SecondMoment Method (MVFOSM), is widely used in civil engineering as it requires simple 
mathematics. As the name implies, two moments (mean and variance) are required in the FOSM reliability method.

Suppose that the safety margin, consisting of multiple variables, is expressed as:

$$
F=f\left(X_{1}, X_{2}, X_{3}, \ldots \ldots, X_{n}\right)
$$

The Taylor series is used to expand and linearize the safety margin about the mean values of the variables and is expressed as:

$$
F=f\left(\mu_{x 1}, \mu_{x 2}, \mu_{x 3}, \ldots \ldots, \mu_{x n}\right)+\sum_{i=1}^{n} \frac{d f\left(x_{i}\right)}{d X_{i}}\left(X_{i}-\mu_{x i}\right)+\varepsilon
$$

where:

$$
\varepsilon=\text { higher order terms of the Taylor series expansion }
$$

In Equation (2.8), the partial derivatives are calculated about the mean values of the variables. The truncated form of the Taylor series expansion is used to measure the approximate values of the mean and the variance of the safety margin. The mean and variance of the safety margin are expressed by Equations (2.9) and (2.10), respectively.

$$
\begin{gathered}
E[F] \approx f\left(\mu_{x 1}, \mu_{x 2}, \mu_{x 3}, \ldots \ldots, \mu_{x n}\right) \\
\operatorname{Var}[F]=\sigma_{F}^{2}=\Sigma \Sigma \frac{d f\left(X_{i}\right)^{2}}{\partial X_{i} \partial X_{j}} \operatorname{Cov}\left[x_{i}, x_{j}\right]+\sum_{i=1}^{n}\left(\frac{d f\left(X_{i}\right)}{d X_{i}} \sigma_{x i}\right)^{2}
\end{gathered}
$$

The partial derivative in Equation (2.10) is calculated using mean values and $\operatorname{Cov}\left[x_{i}, x_{j}\right]$ is the covariance of $x_{i}$ and $x_{j}$. Covariance describes how two variables vary together. The covariance of two random variables is expressed as:

$$
\operatorname{Cov}\left[x_{i}, x_{j}\right]=\rho_{\mathrm{x}_{\mathrm{i}} \mathrm{x}_{\mathrm{j}}} \sigma_{\mathrm{xi}} \sigma_{\mathrm{xj}}
$$

where:

$$
\begin{aligned}
& \rho_{x_{i} x_{j}}=\text { coefficient of correlation between } \\
& \sigma_{x i}=\text { standard deviation of random variable }
\end{aligned}
$$




$$
\sigma_{x j}=\text { standard deviation of random variable }
$$

The coefficient of variation, $C V$, helps to illustrate how one random variable is dispersed compared to the mean of all other variables. The coefficient of variation is expressed as:

$$
C V=\frac{\sigma_{x i}}{\mu_{x i}}
$$

Where:

$$
\begin{aligned}
& \sigma_{\mathrm{xi}}=\text { standard deviation of random variable } \\
& \mu_{\mathrm{xi}}=\text { mean value of random variable }
\end{aligned}
$$

Although the FOSM reliability method is easy to use, it has some shortcomings. These shortcomings include the lack of availability of information about the distribution of variables, errors because of the shortening of the Taylor series, and that the reliability index depends on the way the objective function is defined, meaning, when the safety margin is written in two different ways, two different reliability indexes are obtained. To overcome this error, the Advanced FirstOrder Second-Moment (AFOSM) method uses the invariant reliability index. AFOSM is an iterative method which resolves the errors associated with the FOSM method.

\subsubsection{Advanced First-Order Second-Moment (AFOSM) Method}

The Advanced First-Order Second-Moment reliability method was developed by (Hasofer and Lind 1974). According to the authors, the point chosen from the failure boundary for linear approximation will provide the invariant reliability index. The safety margin $f(X)$ was already defined in Equation (2.7). Generally, it is more favorable to work in terms of normalized or standardized variables because they are dimensionless. The normalized variable is given by:

$$
y_{i}=\frac{x_{i}-\mu_{x i}}{\sigma_{x i}}
$$

where:

$$
\begin{aligned}
& \sigma_{\mathrm{xi}}=\text { standard deviation } \\
& \mu_{x i}=\text { mean value } \\
& x_{i}=\text { obtained value of a variable }
\end{aligned}
$$


The mean value of distribution function of a normalized variables is zero and the standard deviation is one. The performance function is evolved with normalized variables and expressed as:

$$
Z=h(y)=h\left(y_{1}, y_{2}, y_{3}, \ldots \ldots, y_{n}\right)
$$

The Taylor series, first-order approximation of $Z$, at the standard design values at which the approximation is taken, $y_{i}^{*}=h\left(y_{1}^{*}, y_{2}^{*}, y_{3}^{*}, \ldots \ldots, y_{n}^{*}\right)$ is expressed as:

$$
Z=\frac{\sum_{i=1}^{n}\left(y_{i}-y_{i}^{*}\right) d h\left(y^{*}\right)}{d\left(y_{i}^{*}\right)}
$$

where:

$d h\left(y^{*}\right) / d\left(y_{i}^{*}\right)=$ the first derivatives of the performance function with respect to, calculated at design points, $y_{i}^{*}$

The mean and standard deviation of safety margin (Z) are given by Equations (2.16) and (2.17), respectively.

$$
\begin{gathered}
\mu_{z}=-\frac{\sum_{i=1}^{n}\left(y_{i}^{*}\right) d h\left(y^{*}\right)}{d\left(y_{i}^{*}\right)} \\
\sigma_{z}=\sqrt{\sum_{i=1}^{n} \frac{d h\left(y^{*}\right)^{2}}{d\left(y_{i}^{*}\right)}}
\end{gathered}
$$

The solution in terms of normalized variables is given by:

$$
y_{i}^{*}=-\frac{\frac{d h\left(y^{*}\right)}{d\left(y_{i}^{*}\right)}}{\sigma_{z}}\left(\beta+\frac{h(y)}{\sigma_{z}}\right)
$$

where:

$$
\begin{aligned}
& \sigma_{\mathrm{z}}=\text { standard deviation } \\
& \beta=\text { reliability index } \\
& h(y)=\text { performance function }
\end{aligned}
$$


The reliability index $(\beta)$ is expressed as:

$$
\beta=\sqrt{\sum_{i=1}^{n} y_{i}^{2}}
$$

Smith (1986) recommends the following iterative algorithm for the determination of the invariant reliability index, $\beta$.

1. Obtain an expression for the objective function, $f(X)$

2. Evolve the objective function using a normalized variable, $\mathrm{h}(\mathrm{y})$

3. Obtain an expression for first derivatives of $\mathrm{h}(\mathrm{y})$ with respect to each variable

4. Set values of $\mathrm{y}$ and $\beta$ to equal zero, $\mathrm{y}=0$

5. Calculate all $d h\left(y^{*}\right) / d\left(y_{i}^{*}\right)$

6. Calculate $\mathrm{h}(\mathrm{y})$

7. Calculate the standard deviation of $\mathrm{Z}$ using Equation (2.17)

8. Calculate the new values for, $y_{i}^{*}$ using Equation (2.18)

9. Calculate the new reliability index, $\beta$, using Equation (2.19)

10. Repeat steps 5 to 9 until the values converge

When random variables are correlated with each other, a procedure is used to transform the correlated variables into uncorrelated variables while allowing for correlation effects. After the safety margin function is evolved with transformed, uncorrelated, and reduced variables, the AFOSM iterative procedure is applied. The covariance matrix, denoted as $C V_{X}$ for correlated variables, $X_{1}, X_{2}, X_{3}, \ldots \ldots, X_{n}$, is expressed as:

$$
C V_{X}=\left[\begin{array}{ccc}
\sigma_{x 1}^{2} & \cdots & \operatorname{COV}\left[X_{1}, X_{n}\right] \\
\vdots & \ddots & \vdots \\
\operatorname{COV}\left[X_{n}, X_{1}\right] & \cdots & \sigma_{x n}^{2}
\end{array}\right]
$$

The leading diagonal values of the covariance matrix are variances of the correlated variables and the off-diagonal values are the related covariances. The covariance matrix is used to find uncorrelated variables. The procedure for the determination of uncorrelated variables is basically the determination of the eigenvalues and eigenvector of the covariance matrix. 
The eigenvalues of the covariance matrix can be obtained by the diagonalization of the covariance matrix using the Jacobi method. This is an iterative process. The off-diagonal elements of the covariance matrix are gradually eliminated until the covariance matrix is transformed into a diagonal matrix, $A$. If it takes $n$ iterations to transform $C V_{X}$ to $A$, then there are $R_{1}, R_{2}, R_{3}, R_{4}, \ldots, R_{n}$ rotational matrices. The diagonal elements of diagonal matrix, $A$, are variances of transformed variables. The standard deviation of transformed variables can be calculated by taking the square root of the eigenvalues.

The normalized model matrix (normalized eigenvectors) denoted as $B$, can be obtained by multiplying all of the rotation matrices. The normalized modal matrix is expressed as:

$$
\mathrm{B}=R_{1} \cdot R_{2} \cdot R_{3} \cdot R_{4} \ldots \ldots R_{n}
$$

The original variables, $X_{1}, X_{2}, X_{3}, \ldots \ldots, X_{n}$, multiplied by transposing the modal matrix, $B^{T}$, will result in a set of uncorrelated, transformed variables. The uncorrelated variables, $Y$, and their expected values, $E[Y]$, are given by Equations (2.22) and (2.23), respectively.

$$
\begin{gathered}
Y=B^{T} X \\
\mathrm{E}[\mathrm{Y}]=\mathrm{B}^{\mathrm{T}} \mathrm{E}[\mathrm{X}]
\end{gathered}
$$

The transformed and uncorrelated variables are standardized in order to obtain normalized, uncorrelated variables, $y_{1}, y_{2}, y_{3}, \ldots \ldots, y_{n}$. The multiplication of the inverse of the transpose of the modal matrix, $\left(B^{T}\right)^{-1}$ with transformed, reduced, and uncorrelated variables, $y$, will result in a set of $X$ variables expressed in terms of $Y$ variables. Then:

$$
X=\left(B^{T}\right)^{-1} y
$$

The safety margin is expressed with transformed, reduced, and uncorrelated variables, y, by substituting for $X$ from Equation (2.24).

\subsection{Review of Reliability-Based Design Studies in Transportation Engineering}

The following sections provide a comprehensive review of previous studies regarding the application of reliability analysis in transportation engineering. 


\subsubsection{Reliability-Based Design of Sight Distance}

The following sections describe the application of reliability-based analysis for the design of sight distance at intersections. Both intersection sight distance and stopping sight distance studies are reviewed.

\subsubsection{Intersection Sight Distance Design}

Easa (2000) used the reliability method to design the intersection sight distance. The existing intersection sight distance is based on constant design variables rather than random variables. The author used the First-Order Second-Moment reliability method to design the intersection sight distance for yield, non-controlled, and stop-controlled intersections. The relationship between design variables from the AASHTO and probabilistic elements was used to obtain probabilistic random variable values due to the lack of availability of sufficient random variable data for the design of intersection sight distance. The objective function was defined as the difference between the supplied intersection sight distance and the required intersection sight distance. A closed form mathematical expression was developed for the calculation of intersection sight distance. The results of the study revealed that the intersection sight distance is increased when a smaller probability of failure is assigned and vice versa. The author also performed a sensitivity analysis of different elements for intersection sight distance and concluded that the mean and variance of the design speed, maximum speed in a chosen gear, and friction coefficient are very sensitive intersection sight distance variables. The author expressed the need for a database containing design variables and their variability.

\subsubsection{Left-Turn Sight Distance at Signalized Intersections}

Hussain and Easa (2016) analyzed the reliability of left-turn sight distance at signalized intersections. The authors used random variables as design parameters for the analysis of sight distance, rather than the extreme values currently in use. The objective function was defined as the available sight distance minus the required sight distance. The First-Order Second Moment method was used to calculate the probability of failure of left-turn sight distance at signalized intersections. Hussain and Easa (2016) validated their reliability model using the Monte Carlo simulation technique. The authors also developed design graphs for the determination of the left-turn lane offset distance based on different probabilities of failure. A sensitivity analysis indicated that the 
vehicle width and lateral distance between two left turn vehicles were very sensitive sight distance parameters (Hussain and Easa 2016). The authors state that although the design manuals would work well most of the time, design guidelines can overestimate or underestimate some design values. The authors believe that the deterministic design method results in a larger left-turn lane offset distance which increases the overall cost of the project. According to Hussain and Easa (2016), the left-turn lane offset distances increase as the probability of noncompliance is lowered, and vice versa. The authors state that in areas where left-turn offset distances cannot be changed, their proposed reliability method will enable cities and municipalities to be aware of the probability of noncompliance of those intersections.

\subsubsection{Sight Distance Design at Railroad Crossings}

Easa (1994) proposed a probabilistic method for the design of sight distance at railroad crossings. The author considered two cases: 1) sight distance requirements along the railroad and highway for an oncoming vehicle, and 2) sight distance along the railroad for a stopped vehicle. The randomness of the design variables and the correlation between the design variables were considered in this design method. The Advanced First-Order Second Moment (AFOSM) reliability method was used for the development of the reliability-based design method. A graph relating the probability of failure with the reliability index and the correlation coefficient was developed. The Monte Carlo simulation was used to validate the proposed AFOSM probabilistic design method. The sight distance calculated using the deterministic method provided values 15 to 30 percent lower than those calculated using the reliability-based method with a probability of failure of $0.01 \%$. A sensitivity analysis indicated that vehicle and train speed, perception-reaction time, and friction factors are sensitive sight distance variables at railroad crossings (Easa 1994). The author states that the reliability-based design method will improve the safety of roads and highways.

\subsubsection{Sight Distance at Stop Sign-Controlled Intersections}

Easa and Hussain (2016) developed a reliability-based model for the design of the intersection sight distance required for vehicles crossing or turning left onto a major road from a minor road. The objective function was defined as the available sight distance minus the required sight distance. Available sight distance is achieved based on the geometry of the intersection. Required sight distance is based on gap acceptance and vehicle speed. All of the design variables were 
random and the correlation between variables was considered. The First-Order Second-Moment FOSM method was used to develop the relationship between the mean value and the variance of the objective function. The proposed probabilistic model was validated using the Monte Carlo simulation method. Design aids were prepared for the determination of intersection sight distance at two-way stop-controlled intersections based on a 5\% and $10 \%$ coefficient of variation and a $1 \%$, $5 \%$, and $10 \%$ probability of failure, respectively. Easa and Hussain (2016) state that their reliability model can be applied to the design of sight distance at a new intersection or the determination of the level of non-compliance of existing intersections.

\subsubsection{Reliability Analysis of Horizontal and Vertical Elements of Highways}

The following sections describe the application of probability for the design and analysis of the horizontal and vertical elements of highways.

\subsubsection{Horizontal Curve Design}

The probabilistic method of horizontal curve design was proposed by (Himes and Donnell 2014). The authors believe that the variability of random variables which occurs in the field should be considered rather than using constant critical values. The objective function was defined as the difference between the supplied side friction and the required side friction. Side frictions are expressed in terms of the vehicle speed, superelevation, and the radius of the curve. Since the authors did not have access to real curve radius data, the deterministic curve radius was considered. Himes and Donnell (2014) used field data for the probabilistic design method. Vehicle speed was measured using a Hi-Star NC-97 traffic sensor and LIDAR devices. Pavement friction was measured using a dynamic friction tester. A non-contact laser measurement device was used for the calculation of the pavement macro texture. Tire-pavement friction values were calculated from the measured micro and macro texture values. The First-Order (FORM) and Second-Order (SORM) reliability methods were used for the formulation of the horizontal curve. The results of their study illustrated that equivalent design values for the horizontal curve were obtained with the first-order and second-order reliability methods. Himes and Donnell (2014) state that vehicle speed and superelevation rates are important variables in the design of the horizontal curve. The authors state that when field data are used in the design, the probabilistic design method is beneficial. 


\subsubsection{Three-Dimensional Design of Horizontal Lateral Clearance}

Sarhan and Hassan (2011) developed a probabilistic method to calculate the horizontal lateral clearance (horizontal sight offset) for 3D alignments. This study went one step further from the previous deterministic design method for the calculation of horizontal sight offset (HSO) distance by considering both the horizontal and vertical alignment in the design. The authors believe that when a horizontal curve overlaps with a vertical curve and an object restricts the available sight distance, the proposed probabilistic method for the three-dimensional design of horizontal lateral clearance yields more precise design values compared to the existing deterministic method. Sarhan and Hassan (2011) prepared design aids for the calculation of 2D and 3D lateral clearances based on different vehicle speeds and probabilities of failure.

\subsubsection{Safety Risks of Narrow Medians}

Richl and Sayed (2006) state that in British Columbia, Canada, narrow medians are used in highway curves as wider medians are very costly and impose some restrictions on sight distance. The authors developed a probabilistic method for the measurement of the safety of these highways in terms of the associated risks. The probability of non-compliance was defined as the inability of driver to stop within the available sight distance in a horizontal curve (Richl and Sayed 2006). The probability of non-compliance was calculated for horizontal curves with different sight obstructions. The authors state that the probability of failure does not mean that an accident would happen. It simply means that the frequency of a collision is increased if the driver is not able to bring the vehicle to a complete stop within the available sight distance due to high speed. The probability of non-compliance decreases as the horizontal curve radius is increased and vice versa (Richl and Sayed 2006).

\subsubsection{Application of the Probabilistic Design Method for Traffic Signals}

The following sections describe the application of the reliability-based design method for the design of intergreen intervals and the minimum pedestrian green interval at traffic signals.

\subsubsection{Intergreen Interval Design for Traffic Signals}

Easa (1993) proposed a probabilistic method to calculate the intergreen interval timing at traffic signals. The intergreen interval represents all of the yellow and red intervals at traffic signals. The 
safety margin was defined as the clearing distance (the distance that a vehicle can cross the intersection before the end of the yellow light plus all-red intervals), minus the stopping distance, (the distance required for a vehicle to come to a complete stop before entering the intersection). The First-Order reliability method was used to calculate the mean and variance of the safety margin function. A closed-form mathematical Equation was developed for the calculation of the intergreen interval. The Monte Carlo simulation technique was used to validate the proposed reliability method. A sensitivity analysis indicated that the deceleration rate is a sensitive element in the design of the intergreen interval (Easa 1993). Design graphs were prepared for the determination of the intergreen interval based on varying intersection dimension elements, vehicle speeds, and the coefficient of variation for a system probability of non-compliance of 5\%. Easa (1993) states that because the probabilistic method of the design of the intergreen interval is very sensitive to the perception-reaction time and vehicle deceleration rate, accurate data regarding the distribution of these two variables must be obtained.

\subsubsection{Minimum Pedestrian Green Interval for Traffic Signals}

A probabilistic method for the design of the pedestrian green interval at signalized intersections was developed by (Easa and Cheng 2013). In the proposed reliability method, the pedestrian startup time and speed are considered random variables. The design variables were collected from 14 intersections in Toronto, Canada, and Nanjing, China. The safety margin function was defined as the difference between the provided pedestrian green interval and the required pedestrian green interval. The First-Order Second-Moment method was used to establish the relationship between the mean and variance of the safety margin function. The Monte Carlo simulation technique was used to verify the validity of the proposed model. Design graphs were prepared for the determination of the pedestrian green interval at signalized intersections based on a system probability of failure of $1 \%$ and $5 \%$. Pedestrian walking speed has a major impact on the timing

of the pedestrian green interval (Easa and Cheng 2013). Based on analysis of data obtained from two different countries (Canada and China) and different land uses (urban, sub-urban, and rural areas), the authors concluded that the design variables obtained from different regions provide different design values. 


\section{CHAPTER 3: DEVELOPMENT OF THE RELIABILITY-BASED DESIGN FOR ROUNDABOUTS BASED ON SSD AND DSD}

\subsection{Development of Reliability-Based Sight Distance Models}

The First-Order Second-Moment (FOSM) and Advance First-Order Second-Moment (AFOSM) methods are used to develop reliability-based models for the determination of SSD and DSD at roundabouts. SSD and DSD are formulated with the FOSM and AFOSM reliability methods based on an expression recommended by (AASHTO 2011). The random variables included in the probabilistic SSD design methods include the driver perception-reaction time, vehicle speed, and vehicle deceleration rate. The pre-maneuver time, vehicle speed and vehicle deceleration rate are the design variables used for DSD.

\subsubsection{Development of SSD Model Using the FOSM Method}

SSD for roundabouts is formulated using the FOSM method based on a formula recommended by (AASHTO 2011) (see Equation 2.2). The design variables are denoted as $(X)$ variables for the ease of performance of mathematical operations and the required $\operatorname{SSD}\left(S S D_{R e q}\right)$ is obtained as follows:

$$
S S D_{\text {Req }}=0.278 X_{1} X_{2}+0.039 \frac{X_{1}^{2}}{X_{3}}
$$

where:

$$
\begin{aligned}
& \mathrm{SSD}_{\text {Req }}=\text { required stopping sight distance, } \mathrm{m} \\
& \mathrm{X}_{1}=\text { vehicle speed, } \mathrm{Km} / \mathrm{h} \\
& \mathrm{X}_{2}=\text { perception-reaction time, } \mathrm{s} \\
& \mathrm{X}_{3}=\text { deceleration rate, } \mathrm{m} / \mathrm{s}^{2}
\end{aligned}
$$

The safety margin for SSD at roundabouts is defined as the SSD provided by the geometry of the roundabout minus the SSD required based on vehicle and driver performance characteristics. Since the design elements in the probability method are random variables, the safety margin is also a random variable. The safety margin $(H)$ for SSD is expressed as:

$$
H=S S D_{\text {sup }}-S S D_{\text {Req }}
$$


where:

$$
\begin{aligned}
& S S D_{\text {sup }}=\text { supplied stopping sight distance, } \mathrm{m} \\
& S S D_{\text {Req }}=\text { required stopping sight distance, } \mathrm{m}
\end{aligned}
$$

The expected value of the required $S S D\left(E\left[S S D_{R e q}\right]\right)$ is given by:

$$
E\left[S S D_{R e q}\right]=0.278 \mu_{x 1} \mu_{x 2}+0.039 \frac{\mu_{x 1}^{2}}{\mu_{x 3}}
$$

where:

$$
\begin{aligned}
& \mu_{x 1}=\text { mean value of the vehicle speed, } \mathrm{Km} / \mathrm{h} \\
& \mu_{x 2}=\text { mean value of the perception-reaction time, } \mathrm{s} \\
& \mu_{x 3}=\text { mean value of the vehicle deceleration rate, } \mathrm{m} / \mathrm{s}^{2}
\end{aligned}
$$

The vehicle speed is correlated with the perception-reaction time and vehicle deceleration rate. There is no correlation between the perception-reaction time and the vehicle deceleration rate. The covariance of the perception-reaction time and vehicle speed $\left(\operatorname{Cov}\left[x_{1}, x_{2}\right]\right)$ and vehicle deceleration rate and vehicle speed $\left(\operatorname{Cov}\left[x_{1}, x_{3}\right]\right)$ are given by Equations (3.4) and (3.5), respectively.

$$
\begin{aligned}
& \operatorname{Cov}\left[x_{1}, x_{2}\right]=\rho_{x_{1} x_{2}} \sigma_{x 1} \sigma_{x 2} \\
& \operatorname{Cov}\left[x_{1}, x_{3}\right]=\rho_{x_{1} x_{3}} \sigma_{x 1} \sigma_{x 3}
\end{aligned}
$$

where:

$$
\begin{aligned}
& \rho_{\mathrm{x}_{1} \mathrm{x}_{2}}=\text { coefficient of correlation between } \mathrm{x}_{1} \text { and } \mathrm{x}_{2} \\
& \rho_{\mathrm{x}_{1} \mathrm{x}_{3}}=\text { coefficient of correlation between } \mathrm{x}_{1} \text { and } \mathrm{x}_{3} \\
& \sigma_{\mathrm{x} 1}=\text { standard deviation of random variable } x_{1} \\
& \sigma_{\mathrm{x} 2}=\text { standard deviation of random variable } x_{2} \\
& \sigma_{\mathrm{x} 3}=\text { standard deviation of random variable } x_{3}
\end{aligned}
$$

The mean and variance of the safety margin are given by Equations (3.6) and (3.7), respectively.

$$
E[H] \approx S S D_{\text {sup }}-E\left[S S D_{\text {Req }}\right]
$$




$$
\begin{gathered}
\operatorname{Var}[H]=\sigma_{H}^{2}=2 \frac{d h(X)}{d x_{1}} \frac{d h(X)}{d x_{2}} \operatorname{Cov}\left[x_{1}, x_{2}\right]+2 \frac{d h(X)}{d x_{1}} \frac{d h(X)}{d X_{3}} \operatorname{Cov}\left[x_{1}, x_{3}\right]+ \\
\left(\frac{d h(X)}{d x_{1}} \sigma_{x 1}\right)^{2}+\left(\frac{d h(X)}{d X_{2}} \sigma_{x 2}\right)^{2}+\left(\frac{d h(X)}{d x_{3}} \sigma_{x 3}\right)^{2}
\end{gathered}
$$

$\operatorname{Cov}\left[X_{1}, X_{2}\right]$ and $\operatorname{Cov}\left[X_{1}, X_{3}\right]$ are given by Equations (3.4) and (3.5), respectively. The first derivatives of the safety margin with respect to design speed, perception-reaction time, and vehicle deceleration rate are given by Equations (3.8), (3.9), and (3.10), respectively.

$$
\begin{gathered}
\frac{d H(X)}{d X_{1}}=0.278 X_{2}+0.078 \frac{X_{1}}{X_{3}} \\
\frac{d H(X)}{d X_{2}}=0.278 X_{1} \\
\frac{d H(X)}{d X_{3}}=-\frac{0.039 X_{1}^{2}}{X_{3}{ }^{2}}
\end{gathered}
$$

The reliability index $(\beta)$ for the calculation of SSD at roundabouts is the ratio of the mean values of the safety margin $(\mathrm{E}[\mathrm{H}])$ and the standard deviation of the safety margin $\left(\sigma_{\mathrm{H}}\right)$. The reliability index is given by:

$$
\beta_{H}=\frac{E[H]}{\sigma_{H}}
$$

Substituting $E[H]$ from Equation (3.11) to Equation (3.6) and calculating the provided SSD $\left(S S D_{\text {Sup }}\right)$ will yields the following Equation:

$$
S S D_{\text {sup }}=\beta \sigma_{H}+E\left[S S D_{\text {req }}\right]
$$

Equation (3.12) provides a direct solution for the required SSD based on the assigned probability of failure and the randomness of the design variables.

\subsubsection{Development of SSD Model Using the AFOSM Method}

The safety margin was already defined by Equation (3.2). Before applying the AFOSM method to Equation (3.2), the correlated variables need to be transformed into uncorrelated variables while allowing for correlation effects. The covariance matrix $\left(C V_{X}\right)$ for correlated variables is given by Equation (3.13). The leading diagonal values of the covariance matrix are variances of the correlated variables and the off-diagonal values are the related covariance. 


$$
C V_{X}=\left[\begin{array}{ccc}
\sigma_{x 1}^{2} & \operatorname{Cov}\left[x_{1}, x_{2}\right] & \operatorname{Cov}\left[x_{1}, x_{3}\right] \\
\operatorname{Cov}\left[x_{1}, x_{2}\right] & \sigma_{x 2}^{2} & 0 \\
\operatorname{Cov}\left[x_{1}, x_{3}\right] & 0 & \sigma_{x 3}^{2}
\end{array}\right]
$$

where:

$$
\begin{aligned}
& \sigma_{x 1}^{2}=\text { variance of } X_{1} \text { (vehicle speed) } \\
& \sigma_{x 2}^{2}=\text { variance of } X_{2} \text { (perception-reaction time) } \\
& \sigma_{x 3}^{2}=\text { variance of } X_{3} \text { (vehicle deceleration rate) } \\
& \operatorname{COV}\left(X_{1}, X_{2}\right)=\text { covariance of } X_{1} \text { and } X_{2} \\
& \operatorname{COV}\left(X_{1}, X_{3}\right)=\text { covariance of } X_{1} \text { and } X_{3}
\end{aligned}
$$

In Equation (3.13), $\sigma_{x 1}^{2}, \sigma_{x 2}^{2}$, and $\sigma_{x 3}^{2}$ values are obtained from Equation (2.12) (note that the $\sigma_{\mathrm{F}}=$ $\sqrt{\operatorname{Var}[\mathrm{F}]}) . \operatorname{COV}\left[X_{1}, X_{2}\right]$ and $\operatorname{COV}\left[X_{1}, X_{3}\right]$ values are obtained from Equations (3.4) and (3.5), respectively.

The procedure for the determination of uncorrelated variables was described in section 2.6.3. After the safety margin function is evolved with transformed, uncorrelated, and reduced variables, the AFOSM method is applied. The iterative algorithm is applied for the determination of the invariant reliability index (Smith 1986).

\subsubsection{Reliability-Based Design of Decision Sight Distance}

Because of the geometry of roundabouts and the difference between the operation of roundabouts and other types of intersections, drivers may require more time to perceive and react to a hazard. Decision sight distance is therefore considered at roundabout approaches. For the design of DSD at roundabouts, drivers should be able to bring the vehicle to a complete stop. DSD design values were developed for urban and rural roundabouts. For the design of DSD in a situation where the vehicle needs to stop, AASHTO (2011) recommends Equation (2.2). The formulation of DSD with the FOSM and AFOSM methods, for both urban and rural roundabouts, is the same as SSD. The only difference is that the pre-maneuver time is applied instead of the perception-reaction time. Pre-maneuver time is different for urban and rural roundabouts. 


\subsection{Data Used in the Reliability-Based Design Model}

The stopping and decision sight distances were developed for variable coefficient of variations of $5 \%, 10 \%$, and $15 \%$. The SSD and DSD design values were developed for a probability of noncompliance of $0.01 \%$ to $15 \%$. Equations (3.14) and (3.15) were used to calculate the reliability index for a given probability of failure (Easa 1992). Table 3.1 shows the values for the probability of failure and the corresponding reliability index.

$$
\begin{gathered}
\beta=-0.615+\left[0.378-2.199\left(0.841+\ln P_{f}\right)\right]^{0.5} \quad P_{f} \leq 0.1 \\
\mathrm{P}_{\mathrm{f}}=\exp \left(-0.841-0.558 \beta-0.455 \beta^{2}\right) \quad \beta \leq 0.1
\end{gathered}
$$

Table 3.1 Probability of failure and reliability index

\begin{tabular}{cl}
\hline $\mathrm{P}_{\mathrm{f}}(\%)$ & $\beta$ \\
\hline 0.01 & 3.72 \\
0.05 & 3.29 \\
0.10 & 3.09 \\
0.50 & 2.57 \\
1.00 & 2.33 \\
5.00 & 1.65 \\
10.00 & 1.28 \\
15.00 & 1.03 \\
\hline
\end{tabular}

\subsubsection{Evaluation of the Correlation between Design Variables in SSD and DSD}

The correlation effect of design variables is considered when evaluating SSD and DSD with the reliability method. There was not enough data to obtain a correlation coefficient between design speed and perception-reaction time, however, the literature suggests a correlation coefficient of +0.5 . This value was used in this study.

The deceleration coefficient data recommended by the State of Queensland, Department of Transport and Main Roads, for the design of SSD was used to calculate the correlation coefficient between the design speed and vehicle deceleration rate. Deceleration coefficients are multiplied 
by gravity to obtain the vehicle deceleration rate in $\mathrm{m} / \mathrm{s}^{2}$. Table 3.2 shows the vehicle deceleration rates corresponding to various design speeds for passenger cars. The Pearson correlation coefficient formula was used to calculate the correlation coefficient between the design speed and vehicle deceleration rate. The Pearson correlation coefficient formula is given by:

$$
\rho_{x_{i} x_{j}}=\frac{1}{n-1} \sum\left[\frac{x_{i}-u_{x i}}{\sigma_{x i}}\right]\left[\frac{x_{j}-u_{x j}}{\sigma_{x j}}\right]
$$

where:

$$
\begin{aligned}
& n=\text { number of observations } \\
& x_{i}=\text { measured value of variable } x_{i} \\
& u_{x i}=\text { mean value of variable } x_{i} \\
& \sigma_{x i}=\text { standard deviation of variable } x_{i} \\
& x_{j}=\text { measured value of variable } x_{j} \\
& u_{x j}=\text { mean value of variable } x_{j} \\
& \sigma_{x j}=\text { standard deviation of variable } x_{j}
\end{aligned}
$$

Using Equation (3.16), the correlation coefficient between the vehicle speed and deceleration rate is -0.98 for passenger cars. Table 3.3 shows the design speed and deceleration rate values for trucks. Using Equation (3.16), the correlation coefficient between the vehicle speed and deceleration rate is -0.67 for trucks. When considering the deceleration rate of both trucks and passenger cars, the correlation coefficient between the vehicle speed and deceleration rate is -0.43 .

For the development of the SSD and DSD design values, a correlation coefficient of -0.5 between the design speed and vehicle deceleration rate was used. 
Table 3.2 Deceleration rate of passenger cars for different vehicle speeds

\begin{tabular}{ccc}
\hline $\begin{array}{c}\text { Design Speed } \\
(\mathrm{Km} / \mathrm{h})\end{array}$ & $\begin{array}{c}\text { Coefficient of Longitudinal } \\
\text { Deceleration }\end{array}$ & $\begin{array}{c}\text { Deceleration rate Range } \\
\left(\mathrm{m} / \mathrm{s}^{2}\right)\end{array}$ \\
\hline 50 & 0.52 & 5.1 \\
60 & 0.48 & 4.7 \\
70 & 0.45 & 4.4 \\
80 & 0.43 & 4.2 \\
90 & 0.41 & 4.1 \\
100 & 0.39 & 3.8 \\
110 & 0.37 & 3.6 \\
120 & 0.35 & 3.4 \\
130 & 0.33 & 3.3 \\
\hline
\end{tabular}

Table 3.3 Deceleration rate of trucks for different vehicle speeds

\begin{tabular}{ccc}
\hline $\begin{array}{c}\text { Design Speed } \\
(\mathrm{Km} / \mathrm{h})\end{array}$ & $\begin{array}{c}\text { Coefficient of Longitudinal } \\
\text { Deceleration }\end{array}$ & $\begin{array}{c}\text { Deceleration Rate Range } \\
\left(\mathrm{m} / \mathrm{s}^{2}\right)\end{array}$ \\
\hline 50 & 0.29 & 2.9 \\
60 & 0.48 & 2.9 \\
70 & 0.45 & 2.9 \\
80 & 0.43 & 2.9 \\
90 & 0.41 & 2.9 \\
100 & 0.39 & 2.9 \\
110 & 0.37 & 2.9 \\
120 & 0.35 & 2.8 \\
130 & 0.33 & 2.6 \\
\hline
\end{tabular}

\subsubsection{Preparation of the Design Variables}

The mean and variance of the design variables are required for reliability analysis. The mean and variance of the vehicle operating speed, perception-reaction time, total pre-maneuver time, and vehicle deceleration rate can be collected at roundabouts. For the purpose of this study, the mean values were calculated from the extreme values with the assumption that random variables are normally distributed. The expression relating the mean and extreme value is given by: 


$$
\mu_{X}=\frac{X}{1+Z C V}
$$

where:

$$
\begin{aligned}
& X=\text { extreme value } \\
& \mu_{X}=\text { mean value } \\
& C V=\text { coefficient of variation } \\
& \mathrm{Z}=\text { number of standard deviations of the normal distribution corresponding to a certain } \\
& \text { percentile }
\end{aligned}
$$

In this study, the perception-reaction time for the design of SSD and the pre-maneuver time for the design of DSD is assumed to represent the 95th percentile $(Z=1.65)$, the vehicle deceleration rate was assumed to represent the 5 th percentile $(Z=-1.65)$, and the design speed was assumed to represent the 99th percentile $(\mathrm{Z}=2.32)$. A coefficient of variation of $10 \%$ was used for the calculation of the mean values of all variables. The mean values of the vehicle deceleration rate and perception-reaction time for the design of SSD are presented in Table 3.4. Table 3.5 shows the pre-maneuver time considered for the design of DSD for urban and rural roundabouts.

Table 3.4 Data used for the design of SSD using the probabilistic approach

\begin{tabular}{ccc}
\hline Variable & $\begin{array}{c}\text { Extreme Values } \\
\text { (AASHTO) }\end{array}$ & $\begin{array}{c}\text { Mean Values } \\
\text { (Estimated) }\end{array}$ \\
\hline $\mathrm{t}(\mathrm{s})$ & 2.50 & 2.15 \\
$\mathrm{a}(\mathrm{m})$ & 3.40 & 4.07 \\
\hline
\end{tabular}

Table 3.5 Data used for the design of DSD using the probabilistic approach

\begin{tabular}{ccc}
\hline Variable & $\begin{array}{c}\text { Extreme Values } \\
\text { (AASHTO) }\end{array}$ & $\begin{array}{c}\text { Mean Values } \\
\text { (Estimated) }\end{array}$ \\
\hline Pre-maneuver time at urban roundabouts (s) & 9.1 & 7.81 \\
Pre-maneuver time at rural roundabouts (s) & 3.0 & 2.57 \\
\hline
\end{tabular}

Design speeds ranging from 40 to $70 \mathrm{Km} / \mathrm{h}$ were considered for the approaches of roundabouts. Design speeds ranging from $20 \mathrm{Km} / \mathrm{h}$ to $40 \mathrm{Km} / \mathrm{h}$ were considered for the circulatory lane and exits of roundabouts. The mean design speed values are presented in Table 3.6. 
Table 3.6 Extreme and mean vehicle speed values

\begin{tabular}{cc}
\hline $\begin{array}{c}\text { Extreme Value } \\
(\mathrm{Km} / \mathrm{h})\end{array}$ & $\begin{array}{c}\text { Mean Value } \\
(\mathrm{Km} / \mathrm{h})\end{array}$ \\
\hline 20 & 16 \\
30 & 24 \\
40 & 32 \\
50 & 40 \\
60 & 48 \\
70 & 57 \\
\hline
\end{tabular}

\subsection{Reliability-Based Design Values of SSD and DSD}

In this section, SSD design values were developed for different probabilities of failure for design speeds of 20 to $70 \mathrm{Km} / \mathrm{h}$ using the FOSM and AFOSM reliability methods. DSD design values were developed for design speed of 40 to $70 \mathrm{Km} / \mathrm{h}$ for urban and rural roundabouts. A comparison of the results obtained using the FOSM and AFOSM reliability methods is provided.

\subsubsection{FOSM SSD Design Values}

Tables 3.7, 3.8, and 3.9 present the SSD design values calculated using the FOSM reliability method using a coefficient of variation of $5 \%, 10 \%$, and $15 \%$, respectively.

Figures 3-1, 3-2, and 3-3 illustrate the stopping sight distance versus probability of failure calculated using the FOSM reliability method using a coefficient of variation of $5 \%$, $10 \%$, and $15 \%$, respectively.

The Tables and Figures reveal that high reliability level requires large stopping sight distance design value. On the other hand, for high probability of failure, small stopping sight distance design values is required. 
Table 3.7 SSD design values calculated using the FOSM method, CV $=5 \%$

\begin{tabular}{ccccccccc}
\hline \multirow{2}{*}{$\begin{array}{c}\text { Design Speed } \\
(\mathrm{Km} / \mathrm{h})\end{array}$} & \multicolumn{7}{c}{ Stopping sight distance, SSD (m) } \\
\cline { 2 - 9 } & 0.01 & 0.05 & 0.10 & 0.50 & 1.00 & 5.00 & 10.00 & 15.00 \\
\hline 20 & 15.9 & 15.5 & 15.3 & 14.7 & 14.5 & 13.8 & 13.4 & 13.1 \\
\hline 30 & 26.4 & 25.6 & 25.3 & 24.4 & 24.0 & 22.8 & 22.1 & 21.7 \\
\hline 40 & 38.5 & 37.4 & 36.9 & 35.5 & 34.9 & 33.2 & 32.2 & 31.6 \\
\hline 50 & 52.2 & 50.7 & 50.0 & 48.2 & 47.4 & 45.0 & 43.7 & 42.9 \\
\hline 60 & 67.7 & 65.7 & 64.8 & 62.5 & 61.4 & 58.3 & 56.6 & 55.5 \\
\hline 70 & 87.1 & 84.5 & 83.4 & 80.3 & 78.9 & 74.9 & 72.7 & 71.3 \\
\hline
\end{tabular}

Table 3.8 SSD design values calculated using the FOSM method, CV $=10 \%$

\begin{tabular}{ccccccccc}
\hline & \multicolumn{7}{c}{ Stopping sight distance, SSD (m) } \\
\cline { 2 - 9 } $\begin{array}{c}\text { Design Speed } \\
(\mathrm{Km} / \mathrm{h})\end{array}$ & 0.01 & 0.05 & 0.10 & 0.50 & 1.00 & 5.00 & 10.00 & 15.00 \\
\cline { 2 - 9 } & 19.8 & 18.9 & 18.5 & 17.4 & 16.9 & 15.5 & 14.7 & 14.2 \\
\hline 20 & 32.9 & 31.4 & 30.7 & 28.9 & 28.0 & 25.6 & 24.4 & 23.5 \\
\hline 30 & 48.0 & 45.8 & 44.8 & 42.1 & 40.9 & 37.4 & 35.5 & 34.2 \\
\hline 40 & 65.2 & 62.2 & 60.8 & 57.2 & 55.5 & 50.8 & 48.2 & 46.4 \\
\hline 50 & 84.6 & 80.7 & 78.9 & 74.1 & 72.0 & 65.8 & 62.4 & 60.1 \\
\hline 60 & 108.9 & 103.8 & 101.5 & 95.4 & 92.6 & 84.6 & 80.3 & 77.3 \\
\hline 70 & & & & & & & 70.3 \\
\hline
\end{tabular}

Table 3.9 SSD design values calculated using the FOSM method, $\mathrm{CV}=15 \%$

\begin{tabular}{ccccccccc}
\hline & \multicolumn{7}{c}{ Stopping sight distance, SSD (m) } \\
\cline { 2 - 9 } \begin{tabular}{c} 
Design Speed $\begin{array}{c}7 \\
(\mathrm{Km} / \mathrm{h})\end{array}$ \\
\cline { 2 - 9 }
\end{tabular} & 0.01 & 0.05 & 0.10 & 0.50 & 1.00 & 5.00 & 10.00 & 15.00 \\
\hline 20 & 23.8 & 22.4 & 21.8 & 20.1 & 19.4 & 17.2 & 16.1 & 15.3 \\
\hline 30 & 39.4 & 37.1 & 36.1 & 33.3 & 32.1 & 28.5 & 26.6 & 25.3 \\
\hline 40 & 57.5 & 54.2 & 52.7 & 48.7 & 46.9 & 41.6 & 38.8 & 36.9 \\
\hline 50 & 78.2 & 73.7 & 71.6 & 66.2 & 63.7 & 56.6 & 52.7 & 50.1 \\
\hline 60 & 101.5 & 95.6 & 92.9 & 85.8 & 82.5 & 73.3 & 68.2 & 64.8 \\
\hline 70 & 130.7 & 123.1 & 119.6 & 110.5 & 106.2 & 94.3 & 87.8 & 83.4 \\
\hline
\end{tabular}




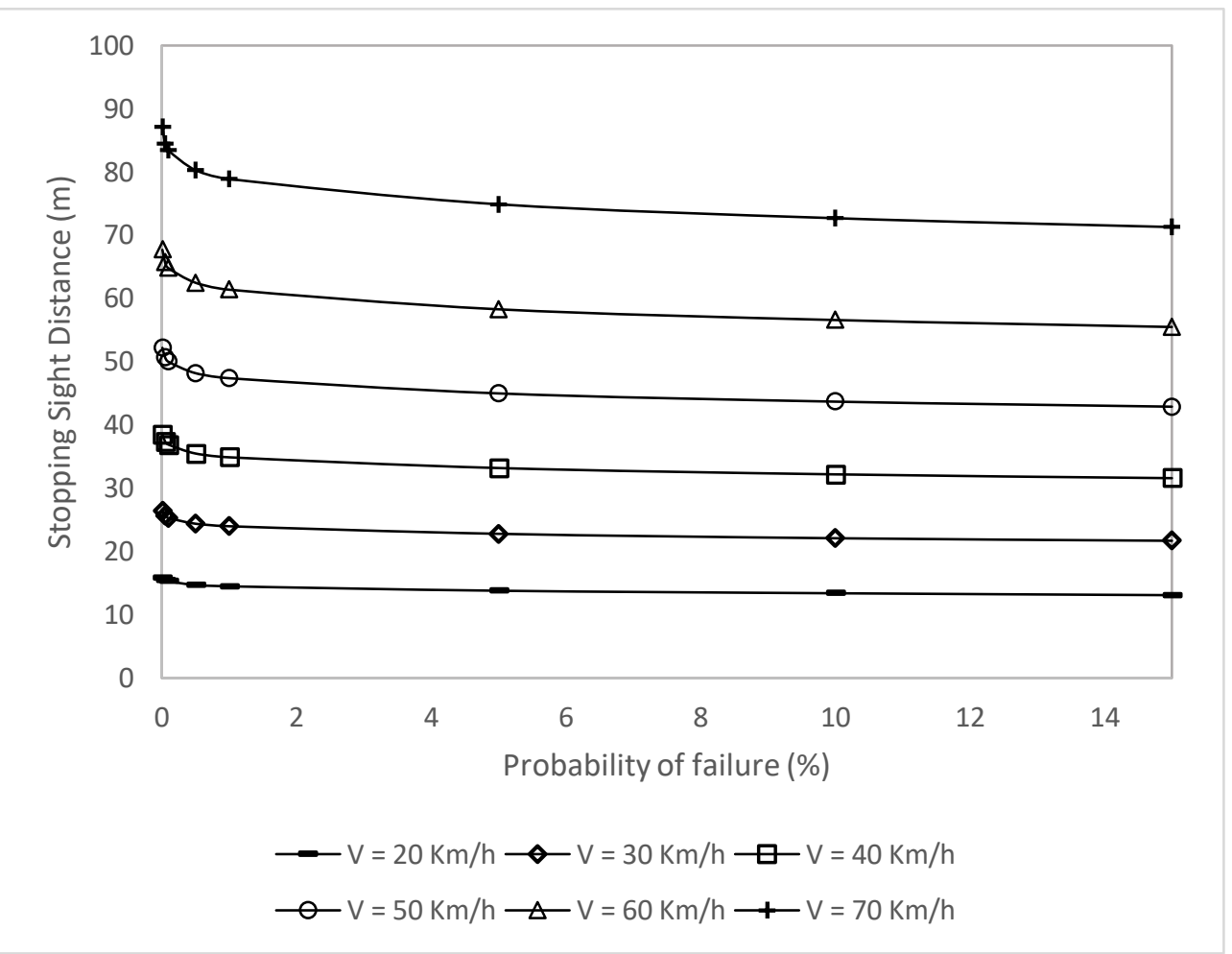

Figure 3-1 Stopping sight distance, FOSM method, $\mathrm{CV}=5 \%$

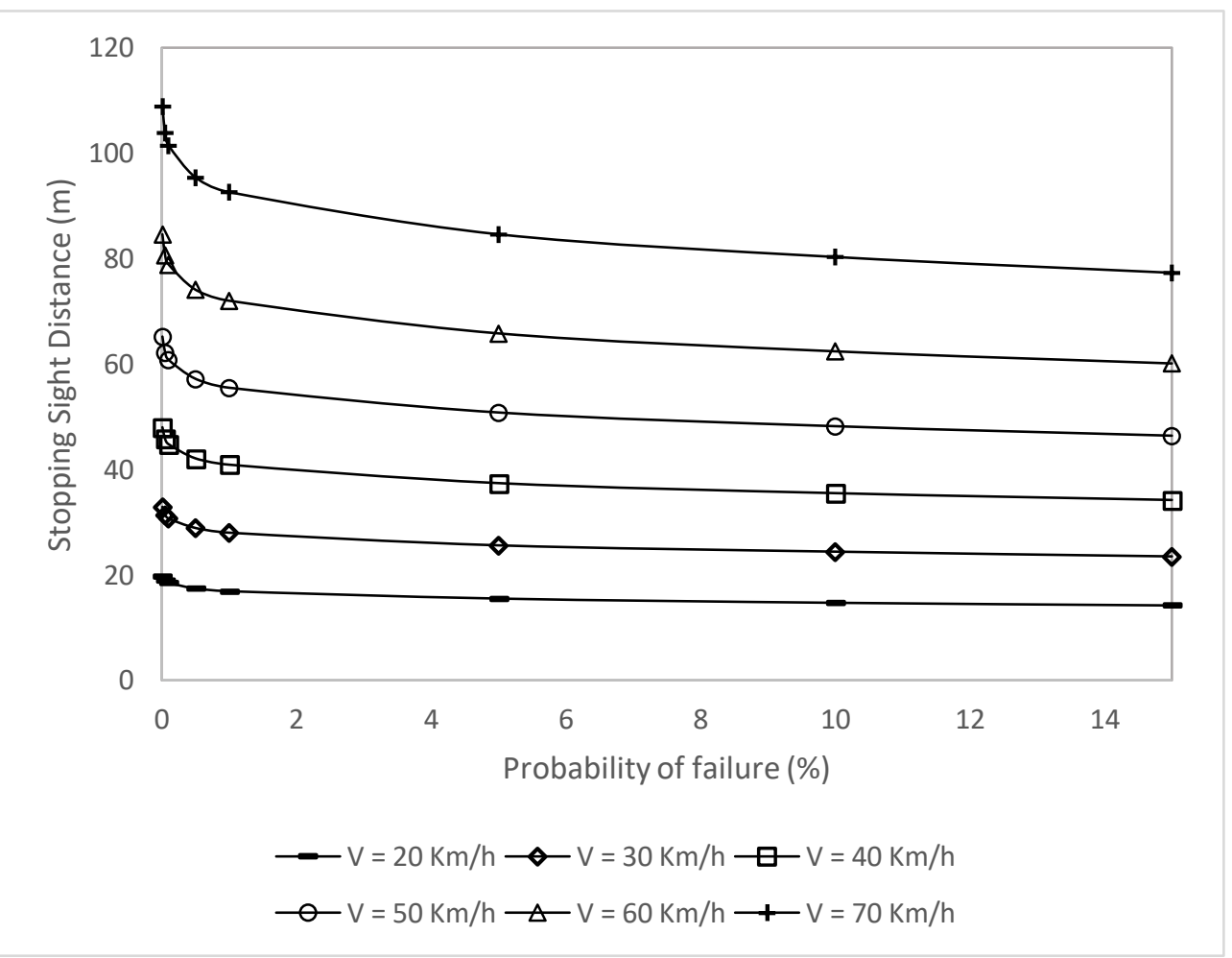

Figure 3-2 Stopping sight distance, FOSM method, $\mathrm{CV}=10 \%$ 


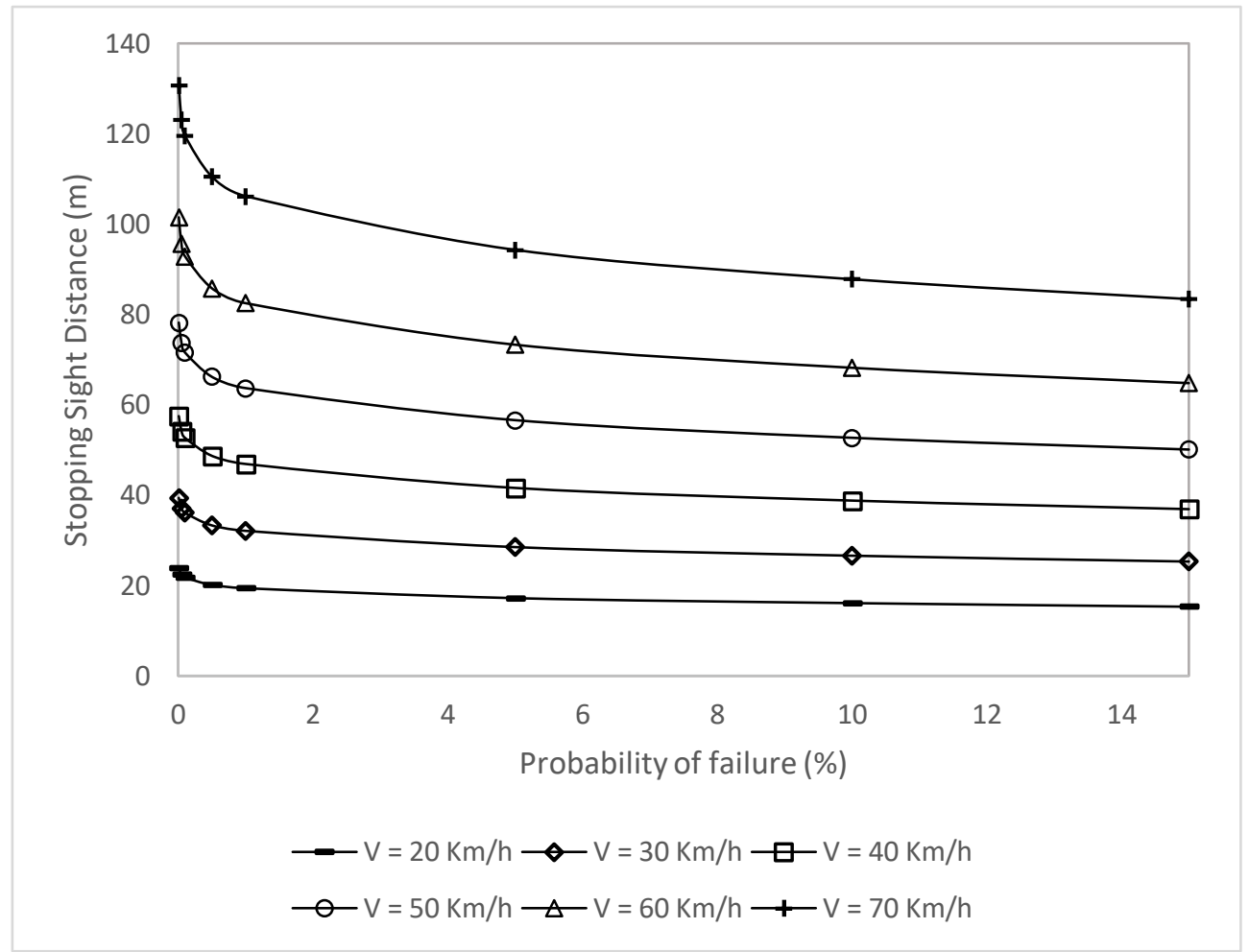

Figure 3-3 Stopping sight distance, FOSM method, CV $=15 \%$

\subsubsection{AFOSM SSD Design Values}

Tables 3.10, 3.11, and 3.12 present the SSD design values calculated using the AFOSM reliability method using a coefficient of variation of $5 \%, 10 \%$, and $15 \%$, respectively.

Figures 3-4, 3-5, and 3-6 illustrate the SSD versus probability of failure calculated using the AFOSM reliability method using a coefficient of variation of 5\%,10\%, and 15\%, respectively.

The Tables and Figures reveal that, with AFOSM reliability method, high reliability levels require large stopping sight distance design values and vice versa. 
Table 3.10 SSD design values calculated using the AFOSM method, $\mathrm{CV}=5 \%$

\begin{tabular}{ccccccccc}
\hline & \multicolumn{7}{c}{ Stopping sight distance, SSD (m) } \\
\cline { 2 - 8 } $\begin{array}{c}\text { Design Speed } \\
(\mathrm{Km} / \mathrm{h})\end{array}$ & 0.01 & 0.05 & 0.10 & 0.50 & 1.00 & 5.00 & 10.00 & 15.00 \\
\cline { 2 - 8 } & 15.6 & 15.1 & 14.9 & 14.4 & 14.2 & 13.5 & 13.2 & 13.0 \\
\hline 20 & 25.6 & 24.9 & 24.6 & 23.7 & 23.3 & 22.3 & 21.7 & 21.4 \\
\hline 30 & 37.7 & 36.6 & 36.1 & 34.7 & 34.2 & 32.6 & 31.7 & 31.2 \\
\hline 40 & 52.3 & 50.6 & 49.9 & 47.9 & 47.1 & 44.1 & 43.4 & 42.6 \\
\hline 50 & 70.5 & 68.0 & 66.9 & 64.2 & 63.0 & 59.6 & 58.0 & 56.7 \\
\hline 60 & 94.0 & 90.2 & 88.5 & 84.1 & 82.2 & 76.9 & 74.2 & 72.3 \\
\hline 70 & & &
\end{tabular}

Table 3.11 SSD design values calculated using the AFOSM method, CV $=10 \%$

Design Speed

$(\mathrm{Km} / \mathrm{h})$
Stopping sight distance, SSD (m)

Probability of failure $(\%)$

\begin{tabular}{cccccccc}
0.01 & 0.05 & 0.10 & 0.50 & 1.00 & 5.00 & 10.00 & 15.00 \\
\hline 19.6 & 18.2 & 17.8 & 16.6 & 16.2 & 14.8 & 14.2 & 13.7 \\
\hline 32.9 & 31.0 & 30.2 & 28.1 & 27.2 & 24.9 & 23.7 & 22.9 \\
\hline 50.0 & 46.4 & 45.0 & 41.7 & 40.3 & 36.6 & 34.7 & 33.5 \\
\hline 69.7 & 65.1 & 63.1 & 58.2 & 56.1 & 50.6 & 47.8 & 46.1 \\
\hline 94.6 & 88.1 & 85.2 & 78.2 & 75.3 & 67.5 & 63.6 & 61.1 \\
\hline 130.0 & 119.2 & 114.6 & 103.7 & 99.1 & 87.4 & 81.8 & 78.2
\end{tabular}

Table 3.12 SSD design values calculated using the AFOSM method, $\mathrm{CV}=15 \%$

\begin{tabular}{ccccccccc}
\hline \multirow{2}{*}{$\begin{array}{c}\text { Design Speed } \\
(\mathrm{Km} / \mathrm{h})\end{array}$} & \multicolumn{7}{c}{ Stopping sight distance, SSD (m) } \\
\cline { 2 - 9 } & 0.01 & 0.05 & 0.10 & 0.50 & 1.00 & 5.00 & 10.00 & 15.00 \\
\hline & 24.2 & 22.3 & 21.5 & 19.5 & 18.7 & 16.5 & 15.4 & 14.7 \\
\hline 20 & 42.3 & 38.3 & 36.7 & 32.9 & 31.3 & 27.4 & 25.5 & 24.3 \\
\hline 30 & 66.6 & 59.9 & 57.1 & 50.6 & 48.0 & 41.3 & 38.2 & 36.2 \\
\hline 40 & 95.1 & 84.9 & 80.6 & 70.9 & 67.0 & 57.1 & 52.5 & 49.6 \\
\hline 50 & 132.8 & 117.2 & 110.8 & 96.4 & 90.6 & 76.5 & 70.0 & 66.0 \\
\hline 60 & 172.3 & 152.0 & 143.7 & 124.7 & 117.0 & 98.2 & 89.5 & 84.1 \\
\hline 70 & & & & & & & &
\end{tabular}




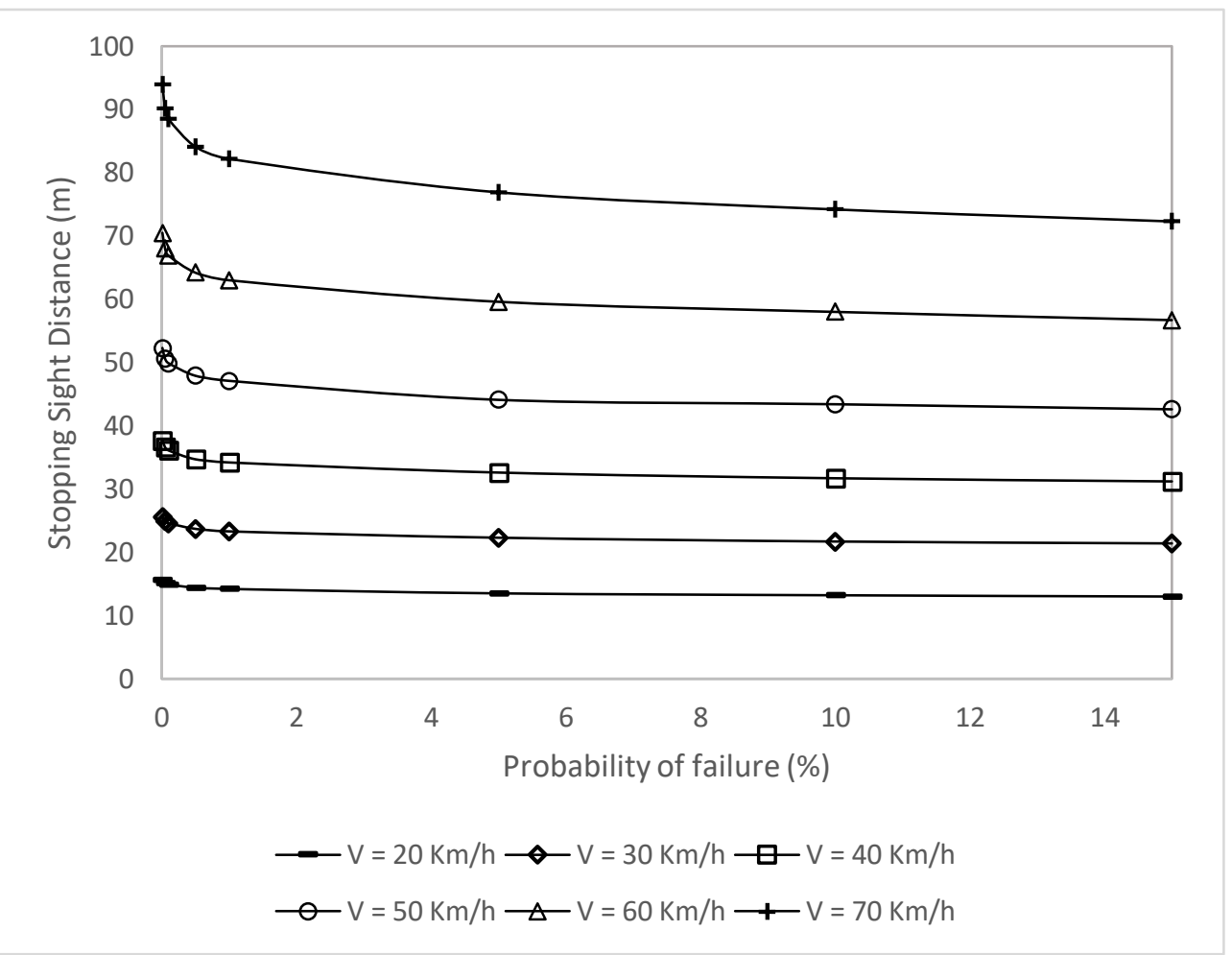

Figure 3-4 Stopping sight distance, AFOSM method, $\mathrm{CV}=5 \%$

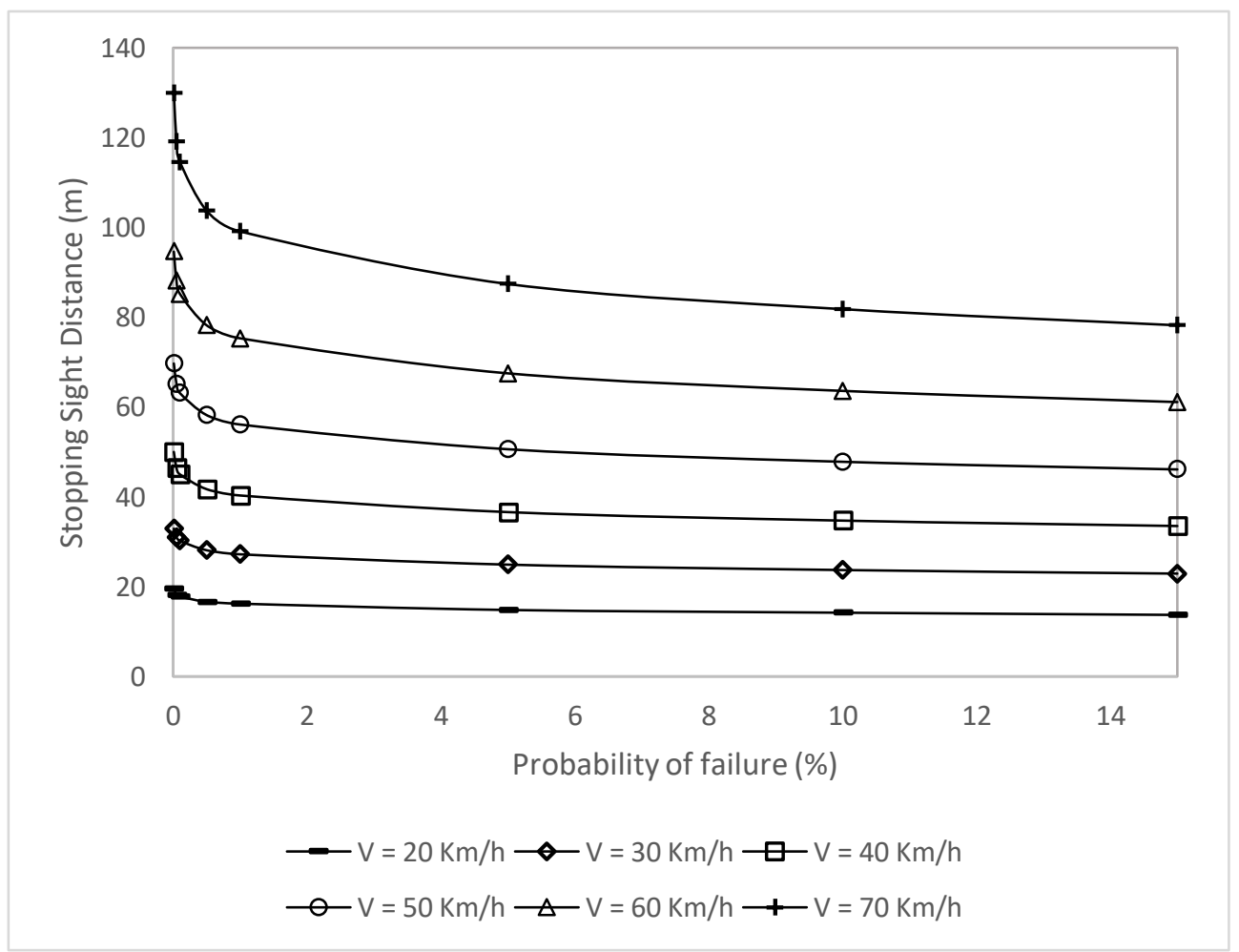

Figure 3-5 Stopping sight distance, AFOSM Method, CV $=10 \%$ 


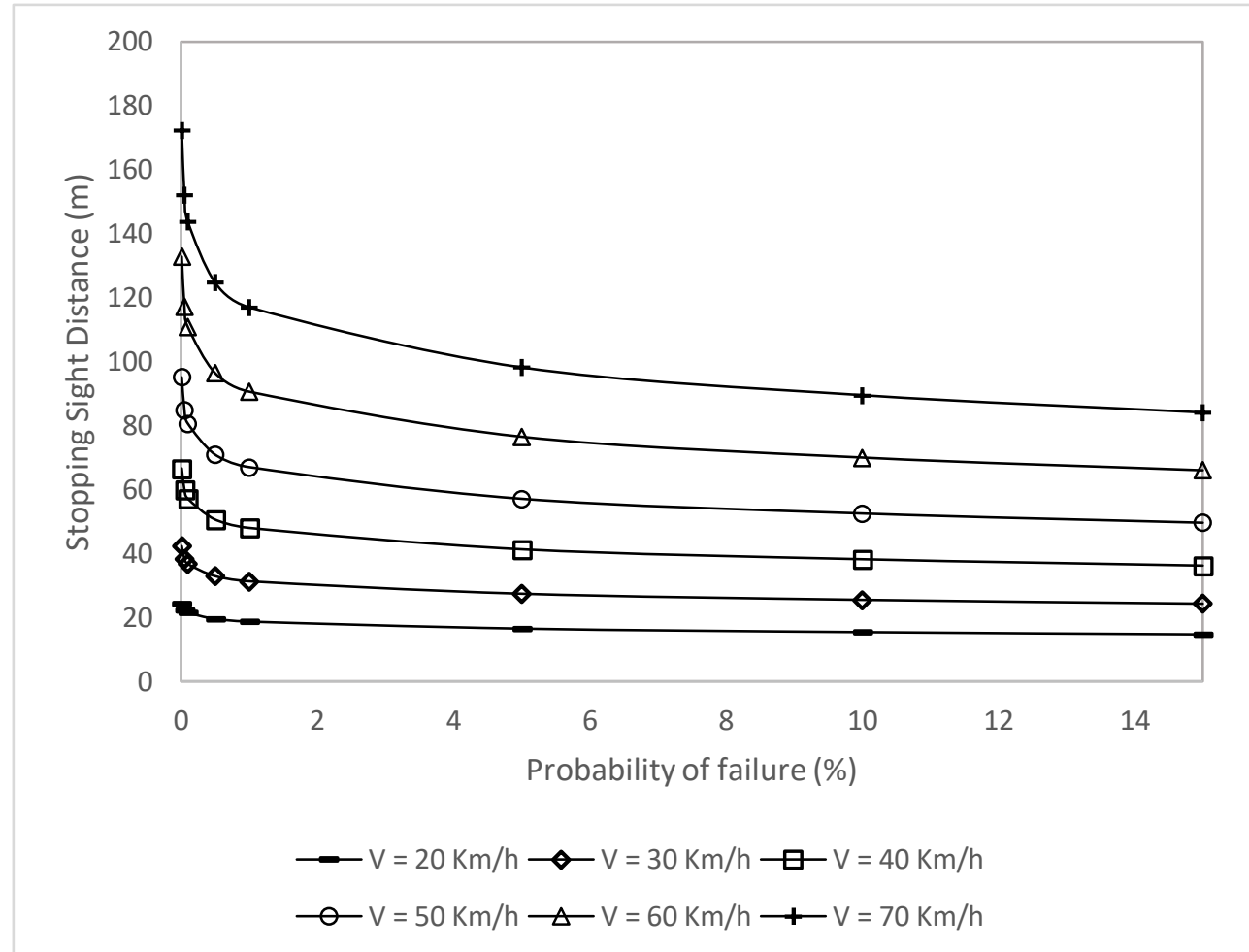

Figure 3-6 Stopping sight distance, AFOSM method, CV $=10 \%$

\subsubsection{DSD Design Values for Urban Roundabouts}

Tables 3.13, 3.14, and 3.15 present the DSD design values calculated using the FOSM reliability method for urban roundabouts using a coefficient of variation of 5\%,10\%, and 15\%, respectively. Tables 3.16, 3.17, and 3.18 present the DSD design values calculated using the AFOSM reliability method for urban roundabouts using a coefficient of variation of 5\%,10\%, and 15\%, respectively.

Figures 3-7, 3-8, and 3-9 illustrate the decision sight distance calculated using the FOSM reliability method at urban roundabout approaches using a coefficient of variation of $5 \%, 10 \%$, and $15 \%$, respectively. Figures 3-10, 3-11, and 3-12 illustrate the decision sight distance calculated using the AFOSM reliability method at urban roundabout approaches using a coefficient of variation of 5\%, $10 \%$, and $15 \%$, respectively. 
Table 3.13 DSD design of urban roundabouts, FOSM method, $\mathrm{CV}=5 \%$

\begin{tabular}{ccccccccc}
\hline & \multicolumn{7}{c}{ Decision sight distance, DSD (m) } \\
\cline { 2 - 8 } $\begin{array}{c}\text { Design Speed } \\
(\mathrm{Km} / \mathrm{h})\end{array}$ & 0.01 & 0.05 & 0.10 & 0.50 & 1.00 & 5.00 & 10.00 & 15.00 \\
\cline { 2 - 8 } & 105 & 102 & 100 & 97 & 95 & 91 & 88 & 86 \\
\hline 40 & 135 & 131 & 129 & 125 & 123 & 117 & 113 & 111 \\
\hline 50 & 167 & 162 & 160 & 155 & 152 & 144 & 140 & 137 \\
\hline 60 & 205 & 199 & 196 & 189 & 186 & 177 & 172 & 169 \\
\hline 70 & & & & & & & & \\
\hline
\end{tabular}

Table 3.14 DSD design of urban roundabouts, FOSM method, CV =10\%

\begin{tabular}{ccccccccc}
\hline & \multicolumn{7}{c}{ Decision sight distance, DSD (m) } \\
\cline { 2 - 8 } $\begin{array}{c}\text { Design Speed } \\
(\mathrm{Km} / \mathrm{h})\end{array}$ & 0.01 & 0.05 & 0.10 & 0.50 & 1.00 & 5.00 & 10.00 & 15.00 \\
\cline { 2 - 8 } & 130 & 124 & 122 & 115 & 111 & 102 & 97 & 95 \\
\hline 40 & 168 & 160 & 157 & 148 & 143 & 131 & 125 & 121 \\
\hline 50 & 208 & 198 & 194 & 183 & 177 & 162 & 154 & 149 \\
\hline 60 & 255 & 243 & 238 & 225 & 218 & 199 & 189 & 183 \\
\hline 70 & & & & & & & \\
\hline
\end{tabular}

Table 3.15 DSD design of urban roundabouts, FOSM method, CV = 15\%

\begin{tabular}{ccccccccc}
\hline & \multicolumn{7}{c}{ Decision sight distance, DSD (m) } \\
\cline { 2 - 8 } $\begin{array}{c}\text { Design Speed } \\
(\mathrm{Km} / \mathrm{h})\end{array}$ & 0.05 & 0.10 & 0.50 & 1.00 & 5.00 & 10.00 & 15.00 \\
\cline { 2 - 8 } & 0.01 & 0.00 & 142 & 127 & 113 & 105 & 100 \\
\hline 40 & 156 & 147 & 143 & 132 & 130 \\
\hline 50 & 201 & 190 & 185 & 171 & 164 & 146 & 136 & 129 \\
\hline 60 & 249 & 235 & 228 & 211 & 203 & 181 & 168 & 160 \\
\hline 70 & 305 & 288 & 280 & 259 & 249 & 222 & 206 & 196 \\
\hline
\end{tabular}


Table 3.16 DSD design of urban roundabouts, AFOSM method, $\mathrm{CV}=5 \%$

\begin{tabular}{ccccccccc}
\hline \multirow{2}{*}{$\begin{array}{c}\text { Design Speed } \\
(\mathrm{Km} / \mathrm{h})\end{array}$} & \multicolumn{7}{c}{ Decision sight distance, DSD (m) } \\
\cline { 2 - 9 } & 0.01 & 0.05 & 0.10 & 0.50 & 1.00 & 5.00 & 10.00 & 15.00 \\
\hline 40 & 98 & 96 & 94 & 92 & 91 & 87 & 86 & 85 \\
\hline 50 & 127 & 124 & 122 & 119 & 118 & 113 & 110 & 109 \\
\hline 60 & 158 & 155 & 152 & 148 & 146 & 140 & 137 & 135 \\
\hline 70 & 195 & 191 & 189 & 183 & 180 & 172 & 168 & 166 \\
\hline
\end{tabular}

Table 3.17 DSD design of urban roundabouts, AFOSM method, CV $=10 \%$

\begin{tabular}{ccccccccc}
\hline & \multicolumn{7}{c}{ Decision sight distance, DSD (m) } \\
\cline { 2 - 8 } $\begin{array}{c}\text { Design Speed } \\
(\mathrm{Km} / \mathrm{h})\end{array}$ & 0.01 & 0.05 & 0.10 & 0.50 & 1.00 & 5.00 & 10.00 & 15.00 \\
\cline { 2 - 8 } & 119 & 114 & 111 & 106 & 103 & 96 & 92 & 90 \\
\hline 40 & 155 & 148 & 146 & 138 & 134 & 124 & 119 & 116 \\
\hline 50 & 198 & 190 & 185 & 174 & 170 & 157 & 150 & 146 \\
\hline 60 & 245 & 233 & 227 & 214 & 208 & 191 & 183 & 177 \\
\hline 70 & & & & & & & & \\
\hline
\end{tabular}

Table 3.18 DSD design of urban roundabouts, AFOSM method, CV $=15 \%$

\begin{tabular}{ccccccccc}
\hline & \multicolumn{7}{c}{ Decision sight distance, DSD (m) } \\
\cline { 2 - 8 } $\begin{array}{c}\text { Design Speed } \\
(\mathrm{Km} / \mathrm{h})\end{array}$ & 0.01 & 0.05 & 0.10 & 0.50 & 1.00 & 5.00 & 10.00 & 15.00 \\
\cline { 2 - 8 } & 143 & 134 & 130 & 121 & 116 & 105 & 99 & 95 \\
\hline 40 & 190 & 178 & 172 & 159 & 152 & 136 & 128 & 123 \\
\hline 50 & 242 & 225 & 218 & 200 & 192 & 171 & 160 & 153 \\
\hline 60 & 307 & 285 & 275 & 250 & 240 & 212 & 198 & 189 \\
\hline 70 & & & & & & & & \\
\hline
\end{tabular}




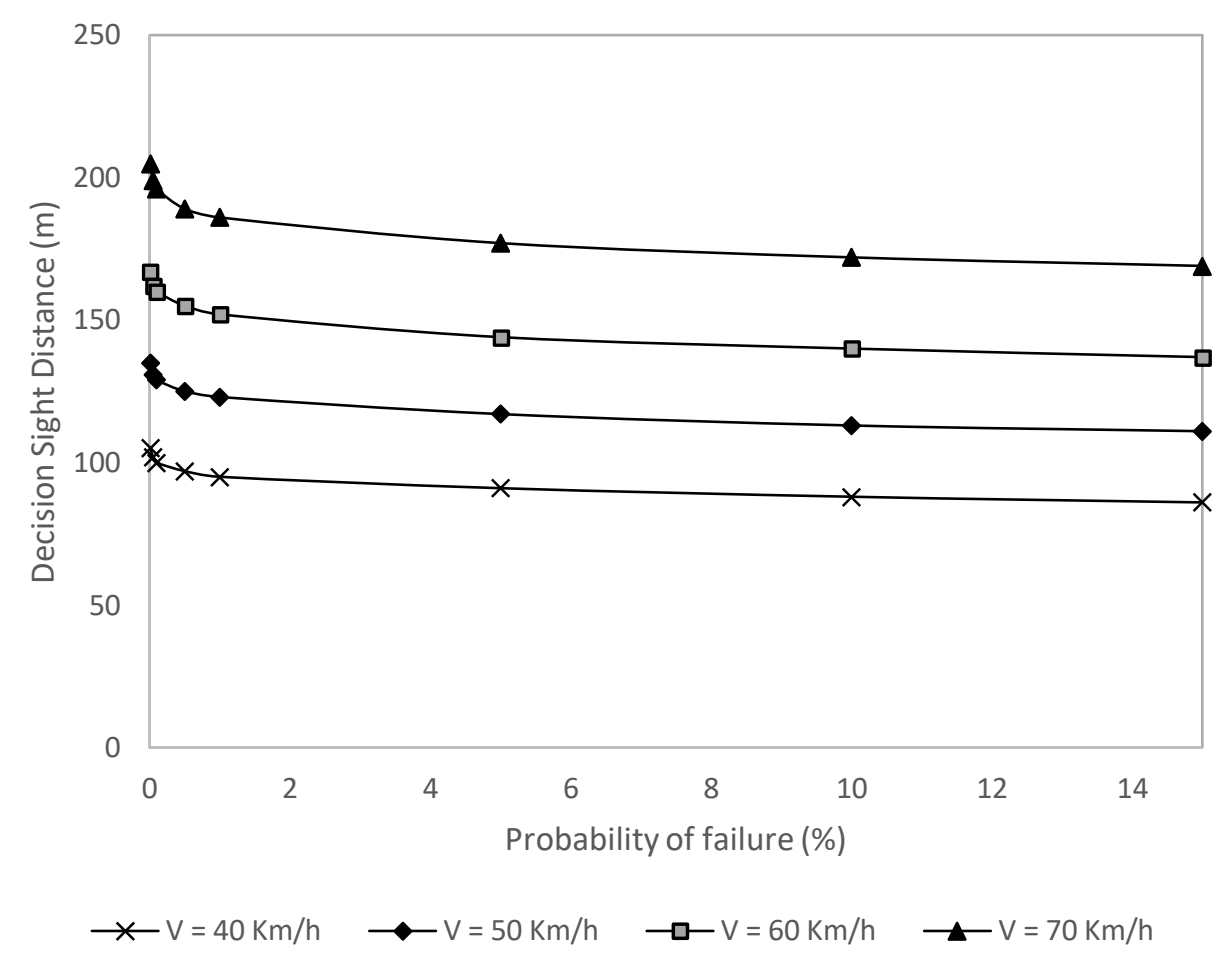

Figure 3-7 FOSM decision sight distance of urban roundabouts, $\mathrm{CV}=5 \%$

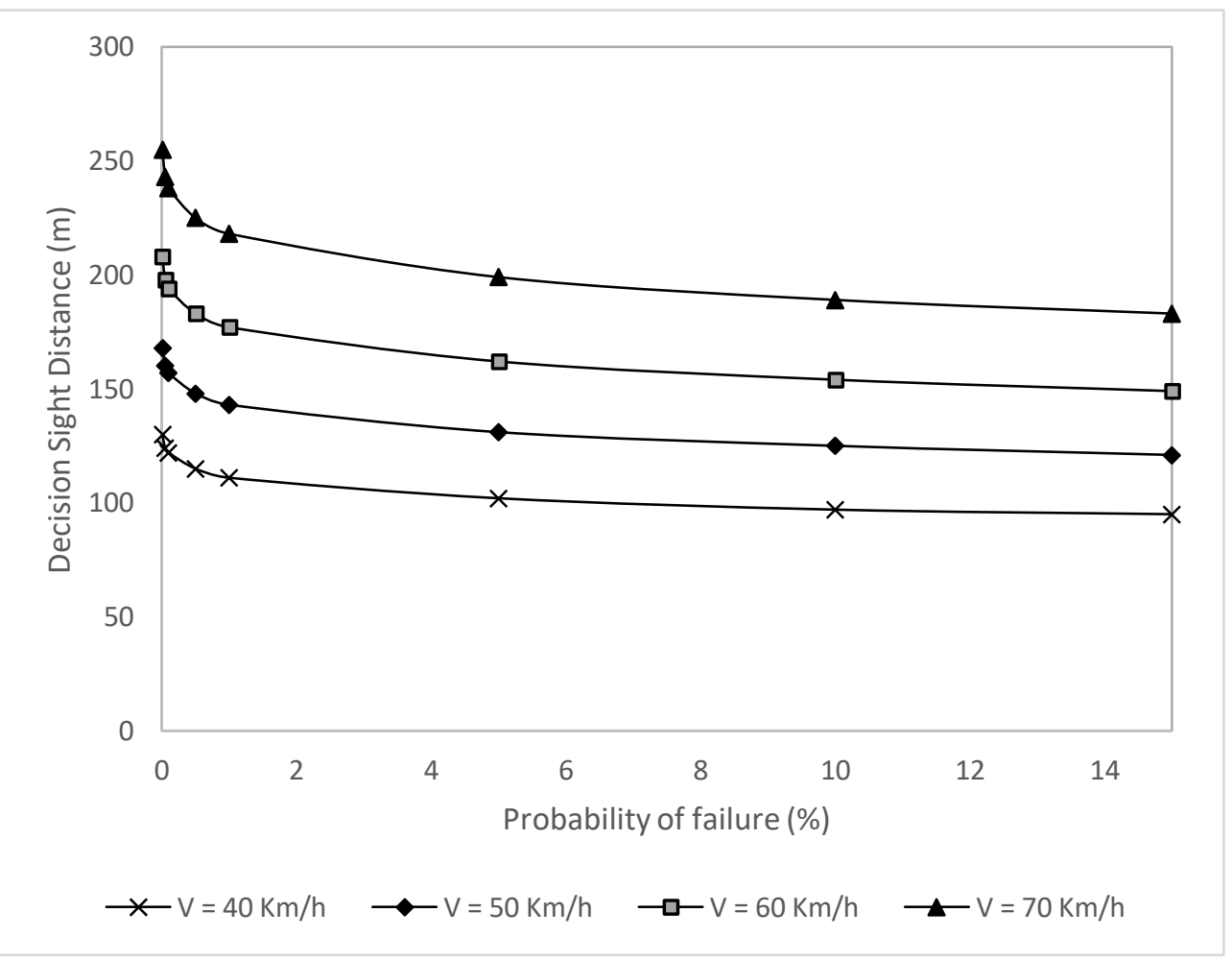

Figure 3-8 FOSM decision sight distance of urban roundabouts, $\mathrm{CV}=10 \%$ 


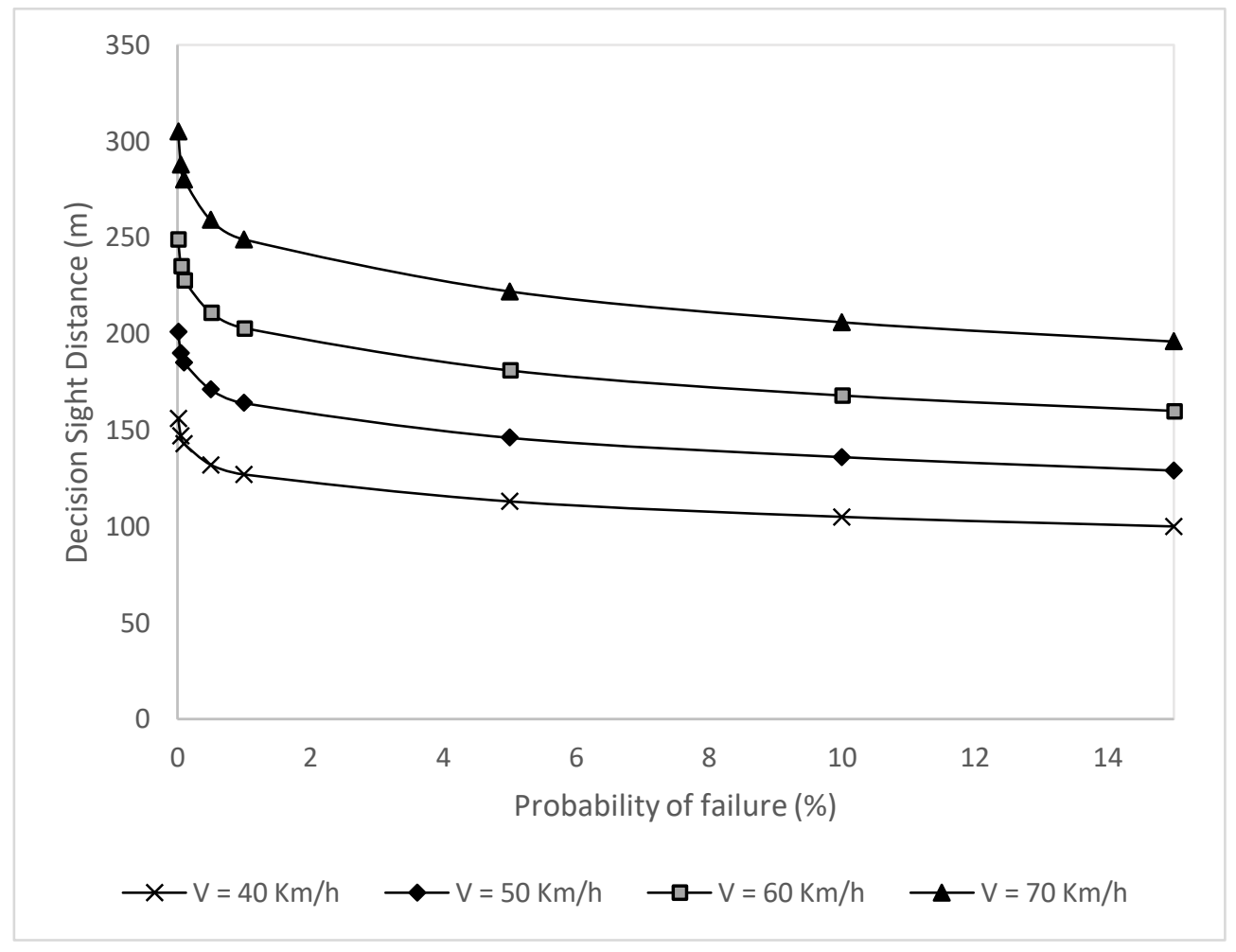

Figure 3-9 FOSM Decision Sight Distance of Urban Roundabouts, CV $=15 \%$

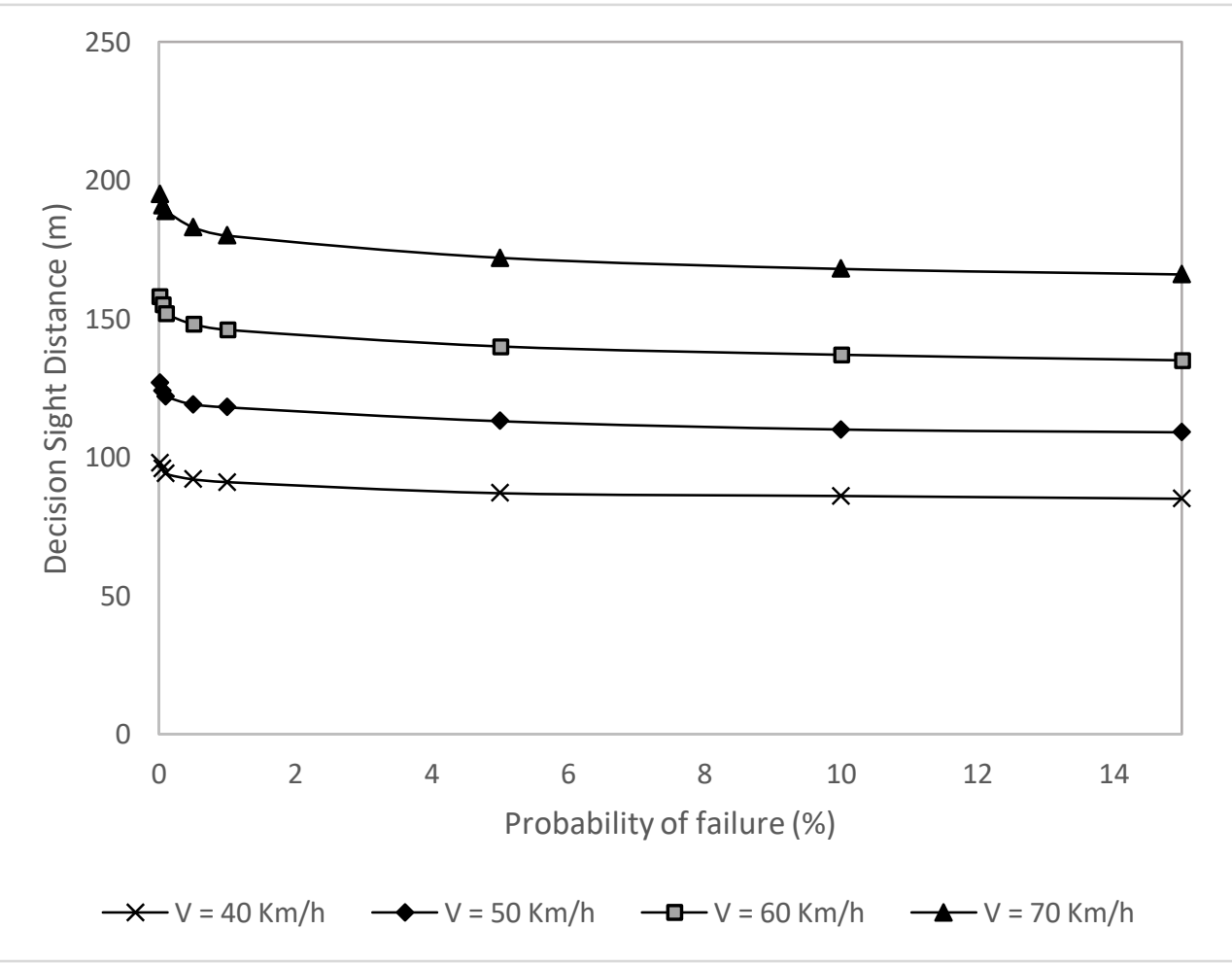

Figure 3-10 AFOSM Decision Sight Distance of Urban Roundabouts, CV $=5 \%$ 


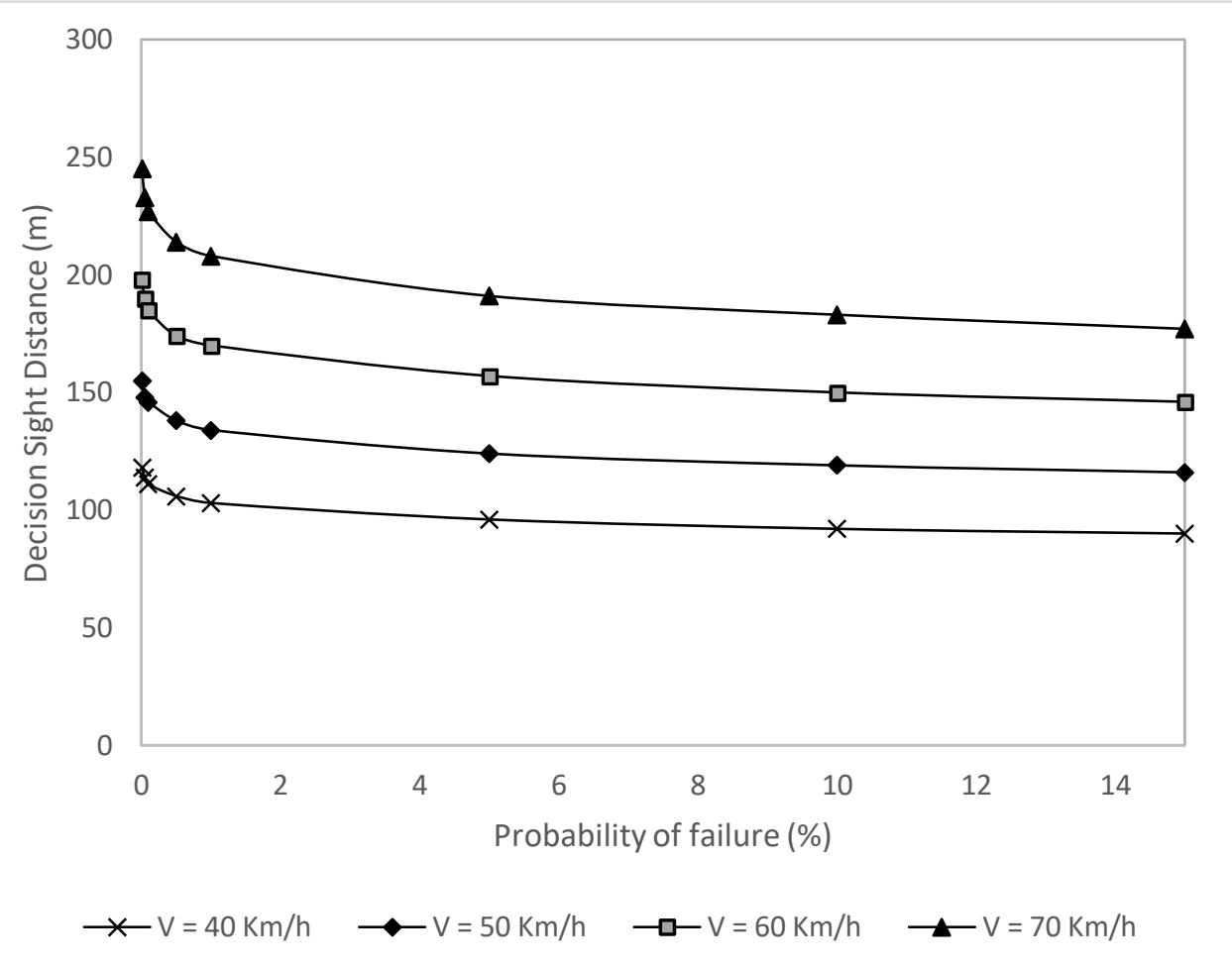

Figure 3-11 AFOSM Decision Sight Distance of Urban Roundabouts, CV = 10\%

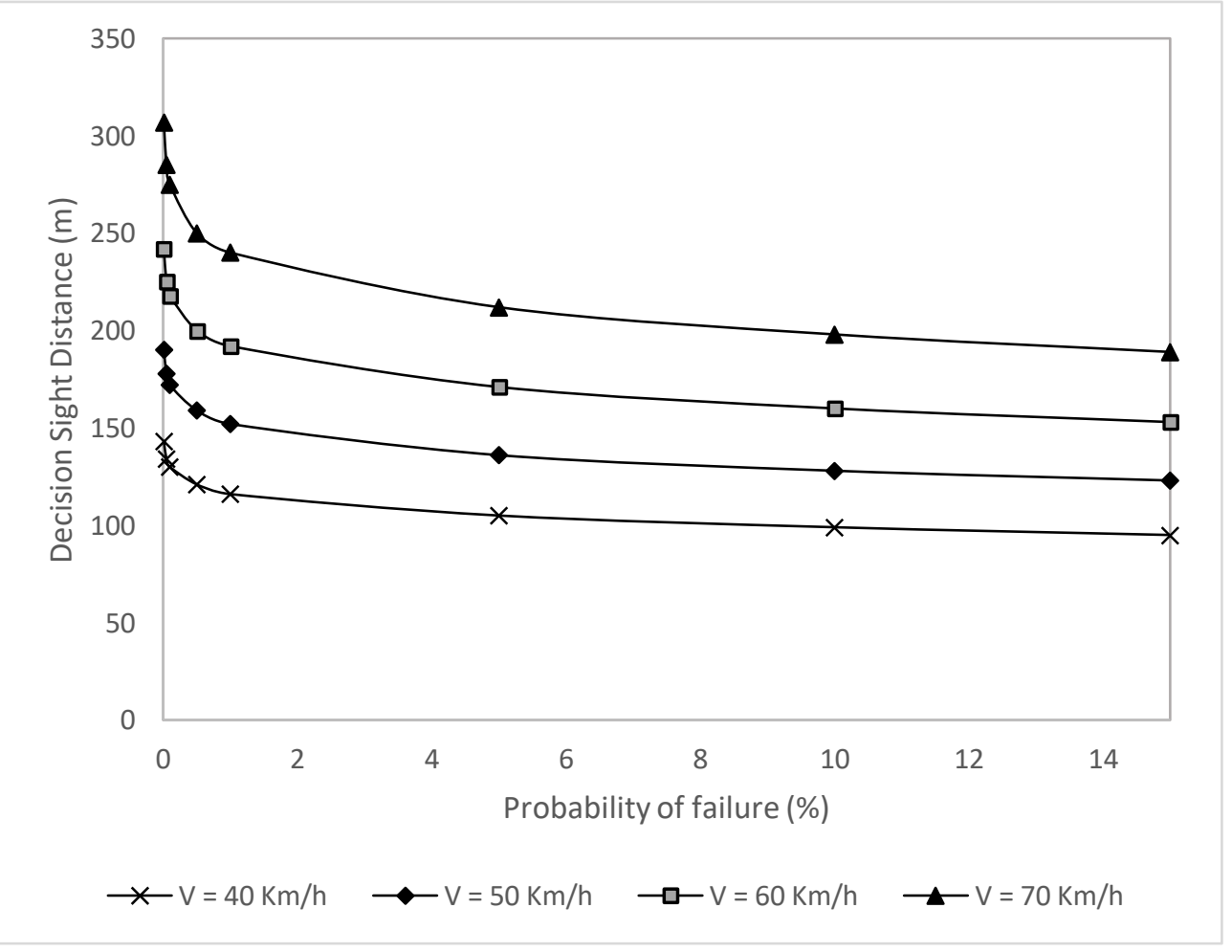

Figure 3-12 AFOSM Decision Sight Distance of Urban Roundabouts, CV = 15\% 


\subsubsection{DSD Design Values for Rural Roundabouts}

Tables 3.19, 3.20, and 3.21 present the DSD design values calculated using the FOSM reliability method for rural roundabouts using a coefficient of variation of 5\%,10\%, and 15\%, respectively. Tables 3.22, 3.23, and 3.24 present the DSD design values calculated using the AFOSM reliability method for rural roundabouts using a coefficient of variation of 5\%, 10\%, and 15\%, respectively.

Figures 3-13, 3-14, and 3-15 illustrate the decision sight distance calculated using the FOSM reliability method at rural roundabouts approaches using a coefficient of variation of 5\%, 10\%, and 15\%, respectively. Figures 3-16, 3-17, and 3-18 illustrate the decision sight distance calculated using the AFOSM reliability method at rural roundabouts approaches using a coefficient of variation of $5 \%, 10 \%$, and $15 \%$, respectively.

Table 3.19 DSD design of rural roundabouts, FOSM method, CV = 5\%

\begin{tabular}{ccccccccc}
\hline & \multicolumn{7}{c}{ Decision sight distance, DSD (m) } \\
\cline { 2 - 9 } $\begin{array}{c}\text { Design Speed } \\
(\mathrm{Km} / \mathrm{h})\end{array}$ & 0.01 & 0.05 & 0.10 & 0.50 & 1.00 & 5.00 & 10.00 & 15.00 \\
\cline { 2 - 9 } & 43 & 42 & 41 & 40 & 39 & 37 & 36 & 35 \\
\hline 40 & 58 & 56 & 56 & 54 & 53 & 50 & 49 & 48 \\
\hline 50 & 75 & 73 & 72 & 69 & 68 & 64 & 62 & 61 \\
\hline 60 & 96 & 93 & 91 & 88 & 87 & 82 & 80 & 78 \\
\hline 70 & & & & & 78
\end{tabular}

Table 3.20 DSD design of rural roundabouts, FOSM method, CV $=10 \%$

\begin{tabular}{ccccccccc}
\hline & \multicolumn{7}{c}{ Decision sight distance, DSD (m) } \\
\cline { 2 - 9 } $\begin{array}{c}\text { Design Speed } \\
(\mathrm{Km} / \mathrm{h})\end{array}$ & 0.01 & 0.05 & 0.10 & 0.50 & 1.00 & 5.00 & 10.00 & 15.00 \\
\cline { 2 - 8 } & 54 & 52 & 50 & 47 & 46 & 42 & 40 & 39 \\
\hline 40 & 73 & 70 & 68 & 64 & 62 & 57 & 54 & 52 \\
\hline 50 & 94 & 89 & 87 & 82 & 80 & 73 & 69 & 67 \\
\hline 60 & 120 & 114 & 112 & 105 & 102 & 93 & 88 & 85 \\
\hline 70 & & & & & & & \\
\hline
\end{tabular}


Table 3.21 DSD design of rural roundabouts, FOSM method, CV $=15 \%$

\begin{tabular}{ccccccccc}
\hline & \multicolumn{7}{c}{ Decision sight distance, DSD (m) } \\
\cline { 2 - 9 } $\begin{array}{c}\text { Design Speed } \\
(\mathrm{Km} / \mathrm{h})\end{array}$ & 0.01 & 0.05 & 0.10 & 0.50 & 1.00 & 5.00 & 10.00 & 15.00 \\
\cline { 2 - 9 } & 65 & 61 & 59 & 55 & 53 & 47 & 44 & 41 \\
\hline 40 & 87 & 82 & 80 & 74 & 71 & 63 & 59 & 56 \\
\hline 50 & 112 & 106 & 103 & 95 & 91 & 81 & 76 & 72 \\
\hline 60 & 144 & 135 & 131 & 121 & 117 & 104 & 96 & 92 \\
\hline 70 & & & & & & & & \\
\hline
\end{tabular}

Table 3.22 DSD design of rural roundabouts, AFOSM method, $\mathrm{CV}=5 \%$

\begin{tabular}{ccccccccc}
\hline & \multicolumn{7}{c}{ Decision sight distance, DSD (m) } \\
\cline { 2 - 9 } $\begin{array}{c}\text { Design Speed } \\
(\mathrm{Km} / \mathrm{h})\end{array}$ & 0.01 & 0.05 & 0.10 & 0.50 & 1.00 & 5.00 & 10.00 & 15.00 \\
\cline { 2 - 9 } & 55 & 53 & 51 & 47 & 46 & 42 & 40 & 38 \\
\hline 40 & 77 & 72 & 70 & 65 & 62 & 57 & 55 & 52 \\
\hline 50 & 101 & 94 & 91 & 84 & 81 & 73 & 69 & 66 \\
\hline 60 & 131 & 122 & 118 & 109 & 105 & 94 & 88 & 85 \\
\hline 70 & & & & & & & \\
\hline
\end{tabular}

Table 3.23 DSD design of rural roundabouts, AFOSM method, CV =10\%

\begin{tabular}{ccccccccc}
\hline & \multicolumn{7}{c}{ Decision sight distance, DSD (m) } \\
\cline { 2 - 8 } $\begin{array}{c}\text { Design Speed } \\
(\mathrm{Km} / \mathrm{h})\end{array}$ & 0.05 & 0.10 & 0.50 & 1.00 & 5.00 & 10.00 & 15.00 \\
\cline { 2 - 8 } & 0.01 & 53 & 51 & 47 & 46 & 42 & 40 & 38 \\
\hline 40 & 55 & 72 & 70 & 65 & 62 & 57 & 55 & 52 \\
\hline 50 & 101 & 94 & 91 & 84 & 81 & 73 & 69 & 66 \\
\hline 60 & 131 & 122 & 118 & 109 & 105 & 94 & 88 & 85 \\
\hline 70 & & & & 710
\end{tabular}


Table 3.24 DSD design of rural roundabouts, AFOSM method, CV = 15\%

\begin{tabular}{ccccccccc}
\hline \multirow{2}{*}{$\begin{array}{c}\text { Design Speed } \\
(\mathrm{Km} / \mathrm{h})\end{array}$} & \multicolumn{7}{c}{ Decision sight distance, DSD (m) } \\
\cline { 2 - 9 } & 0.01 & 0.05 & 0.10 & 0.50 & 1.00 & 5.00 & 10.00 & 15.00 \\
\hline 40 & 72 & 65 & 63 & 56 & 53 & 47 & 43 & 40 \\
\hline 50 & 102 & 91 & 88 & 77 & 73 & 63 & 59 & 55 \\
\hline 60 & 136 & 122 & 116 & 102 & 96 & 82 & 77 & 72 \\
\hline 70 & 182 & 161 & 153 & 133 & 126 & 106 & 97 & 92 \\
\hline
\end{tabular}

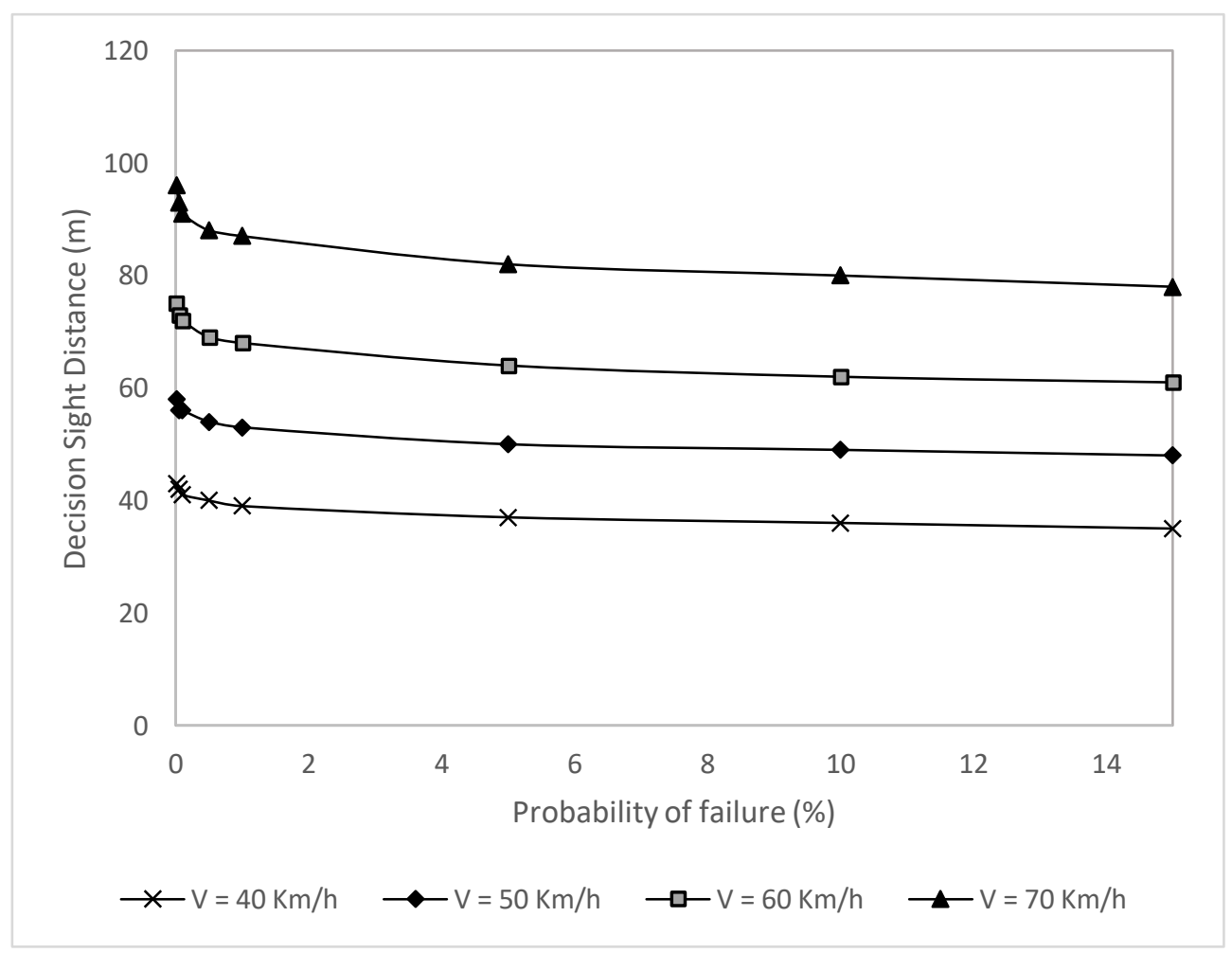

Figure 3-13 FOSM decision sight distance of rural roundabouts, $\mathrm{CV}=5 \%$ 


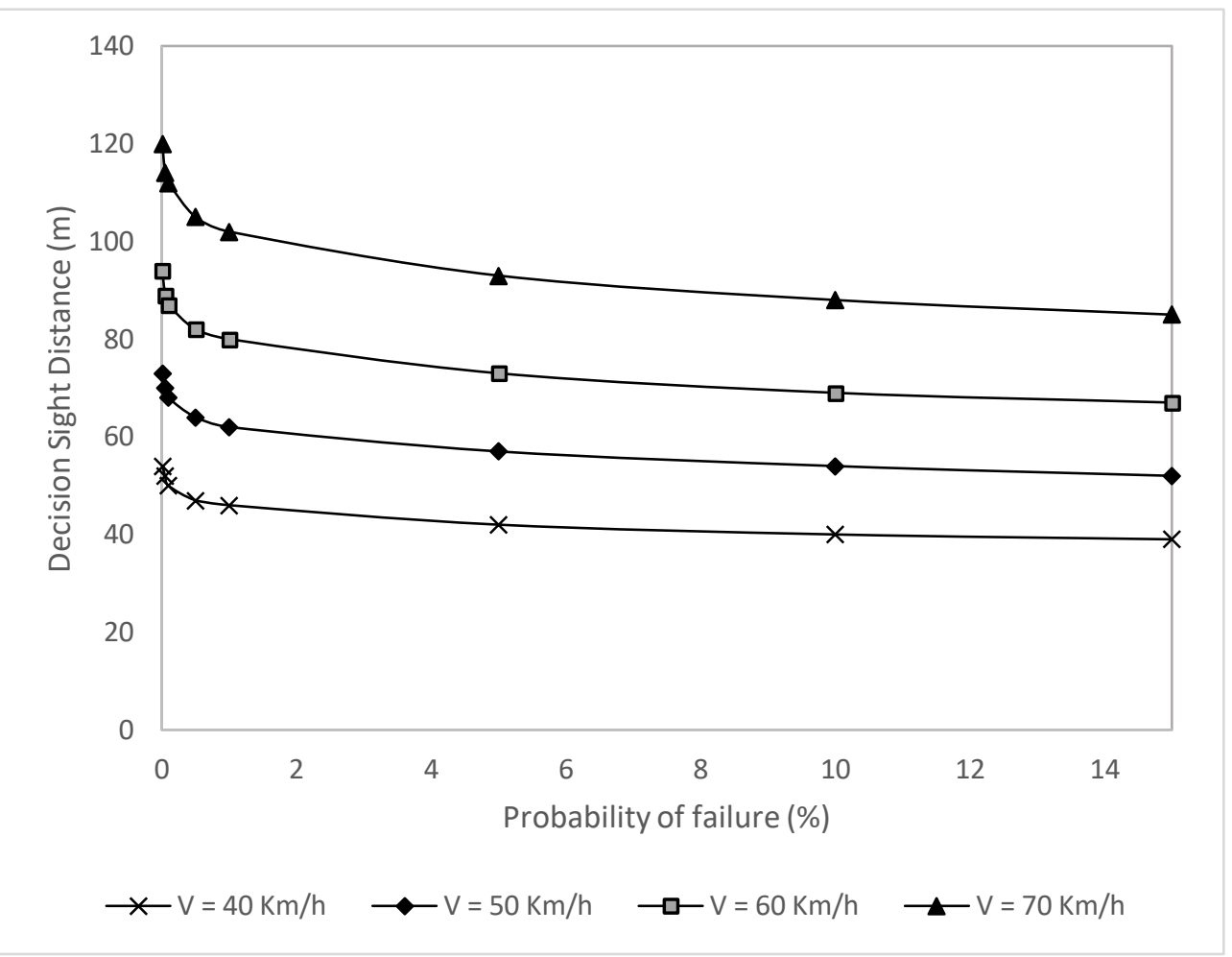

Figure 3-14 FOSM decision sight distance of rural roundabouts, $\mathrm{CV}=10 \%$

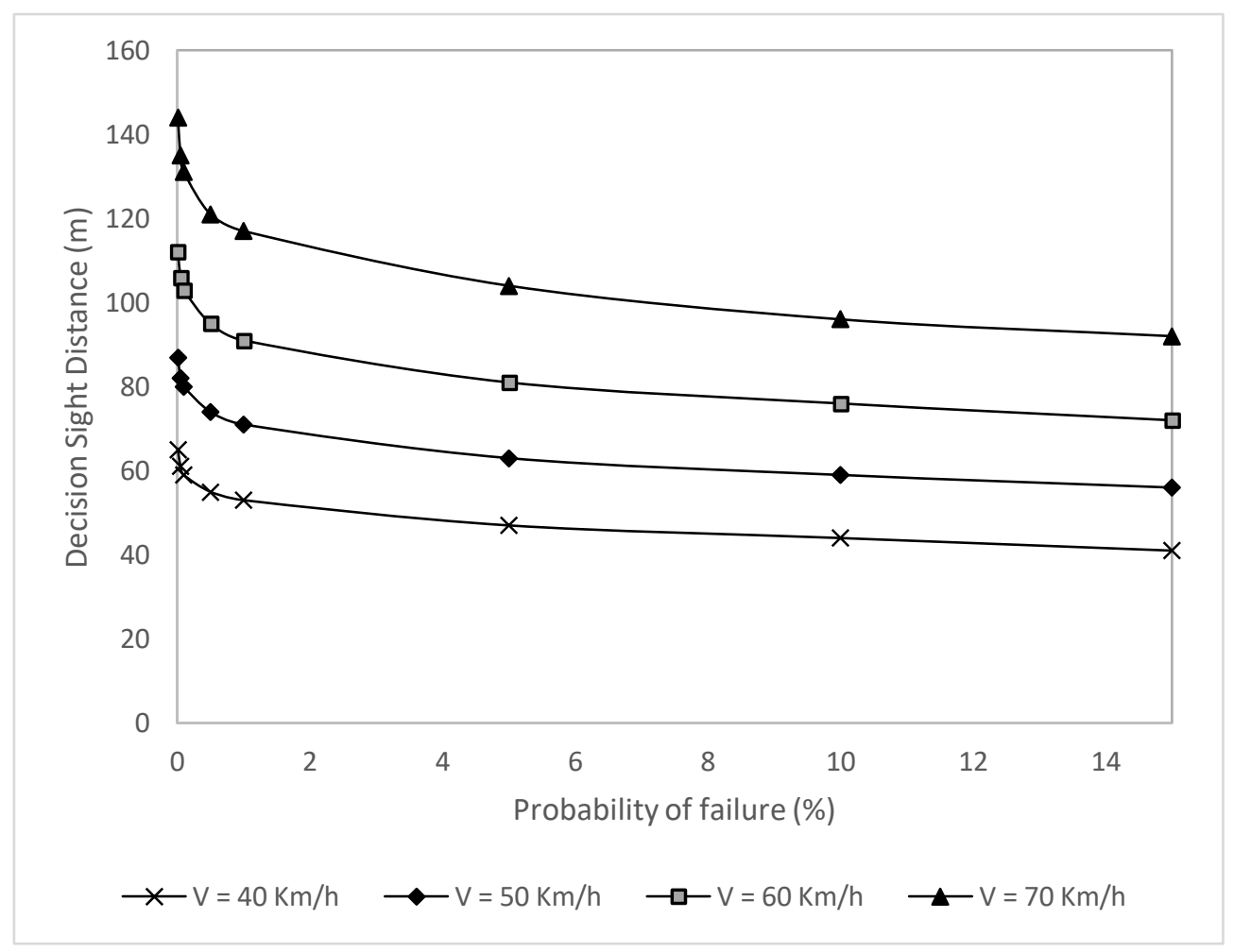

Figure 3-15 FOSM decision sight distance of rural roundabouts, CV $=15 \%$ 


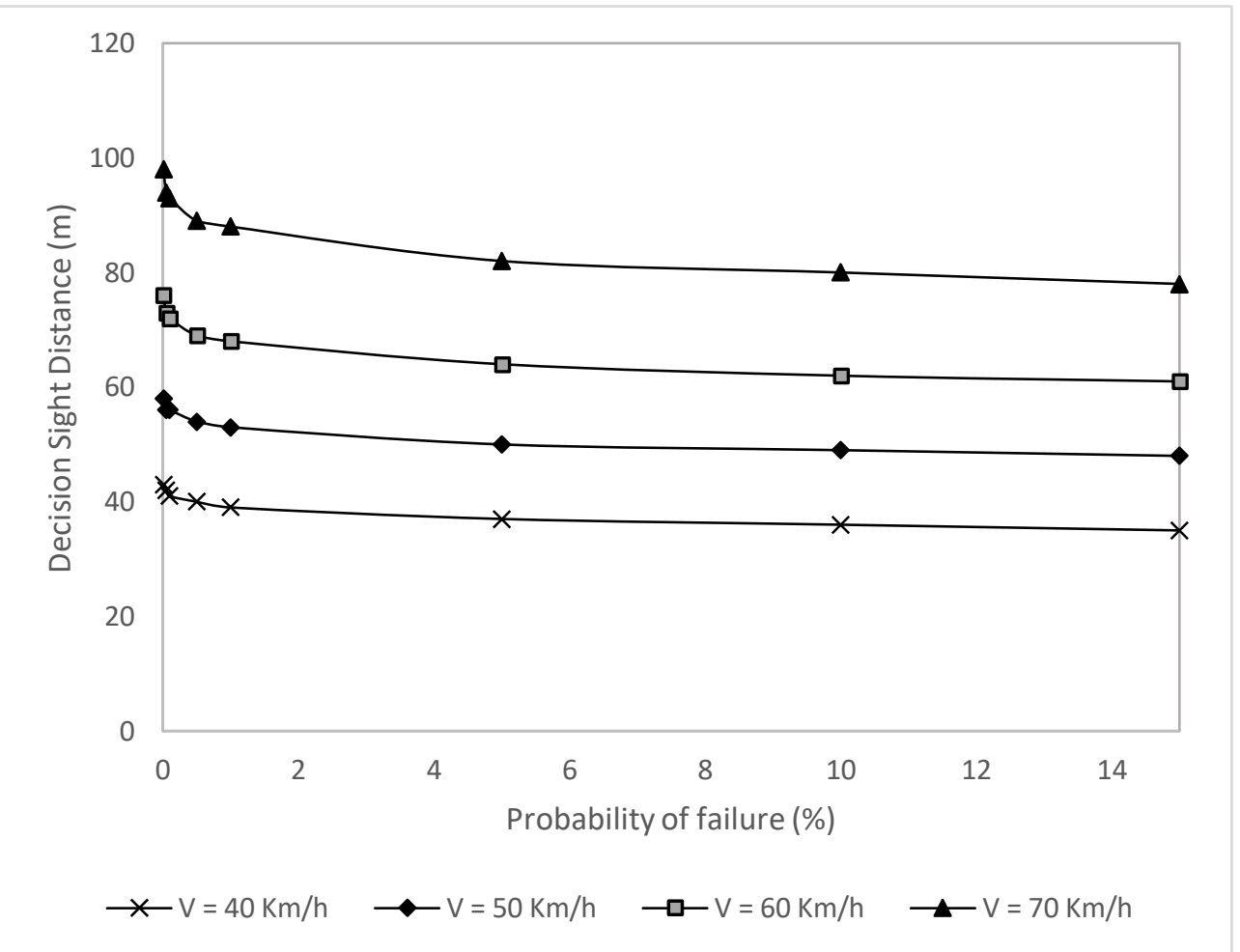

Figure 3-16 AFOSM decision sight distance of rural roundabouts, $\mathrm{CV}=5 \%$

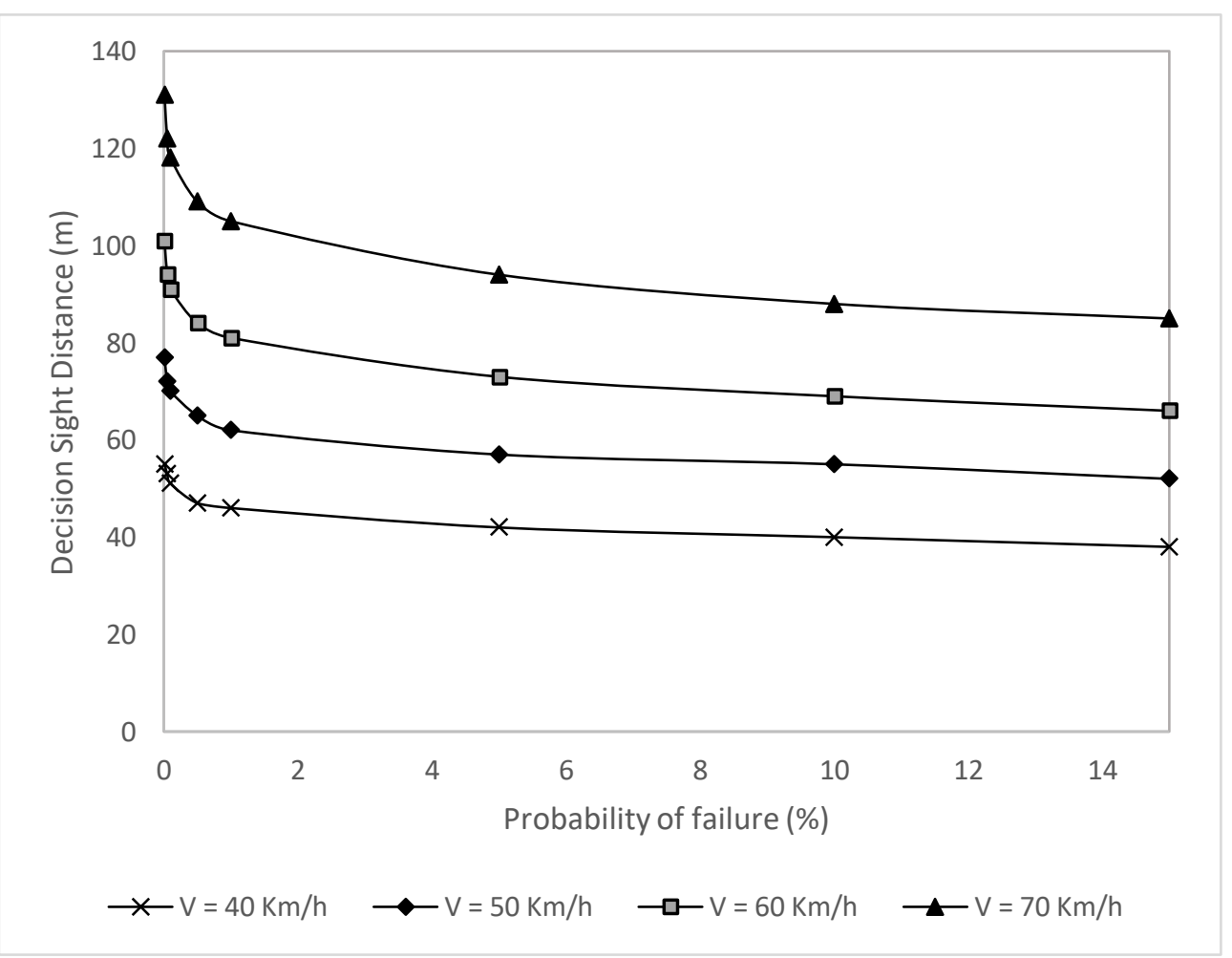

Figure 3-17 AFOSM decision sight distance of rural roundabouts, CV $=10 \%$ 


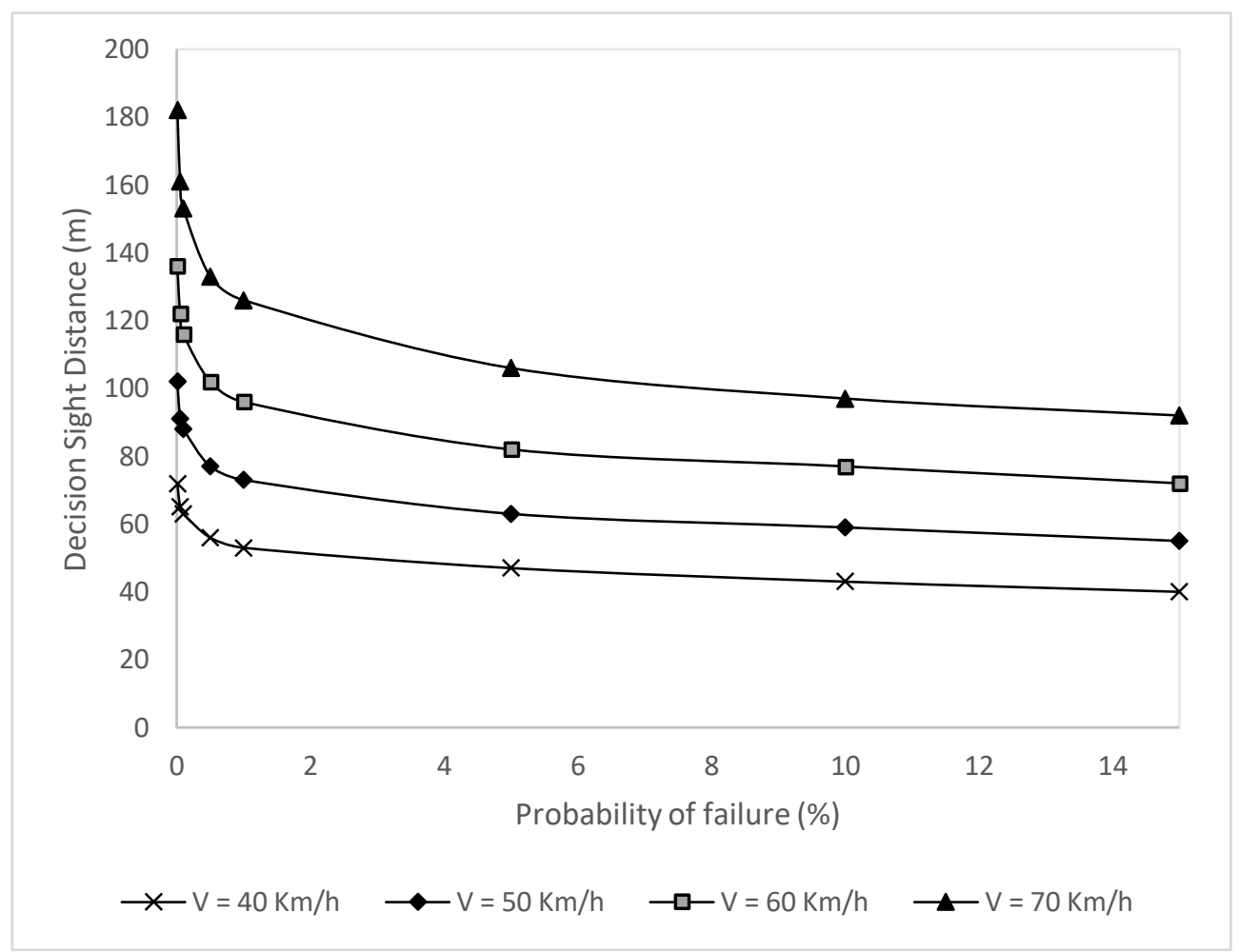

Figure 3-18 AFOSM decision sight distance of rural roundabouts, $\mathrm{CV}=15 \%$

Both SSD and DSD are considered for roundabout approaches. The DSD values differ for urban and rural roundabouts. For design purposes, a 95\% reliability level is acceptable in most situations. Table 3.25 shows the sight distances (SSD and DSD) required at the approaches of urban roundabouts. Table 3.26 shows the sight distances (SSD and DSD) required at the approaches of rural roundabouts.

Table 3.25 Sight distance required at the approaches of urban roundabouts

\begin{tabular}{ccccc}
\hline \multirow{2}{*}{$\begin{array}{c}\text { Design Speed } \\
(\mathrm{Km} / \mathrm{h})\end{array}$} & \multicolumn{2}{c}{$\begin{array}{c}\text { Deterministic } \\
\text { Method }\end{array}$} & \multicolumn{2}{c}{$\begin{array}{c}\text { AFOSM Method } \\
\mathrm{P}_{\mathrm{f}}=5.00 \%\end{array}$} \\
\cline { 2 - 5 } & SSD (m) & DSD (m) & SSD (m) & DSD (m) \\
\hline 40 & 48 & 121 & 37 & 96 \\
50 & 66 & 158 & 51 & 124 \\
60 & 87 & 197 & 68 & 157 \\
70 & 110 & 238 & 88 & 191 \\
\hline
\end{tabular}


Table 3.26 Sight distance required at the approaches of rural roundabouts

\begin{tabular}{ccccc}
\hline \multirow{2}{*}{$\begin{array}{c}\text { Design Speed } \\
(\mathrm{Km} / \mathrm{h})\end{array}$} & \multicolumn{2}{c}{$\begin{array}{c}\text { Deterministic } \\
\text { Method }\end{array}$} & \multicolumn{2}{c}{$\begin{array}{c}\text { AFOSM Method } \\
\mathrm{P}_{\mathrm{f}}=5.00 \%\end{array}$} \\
\cline { 2 - 5 } & $\mathrm{SSD}(\mathrm{m})$ & $\mathrm{DSD}(\mathrm{m})$ & $\mathrm{SSD}(\mathrm{m})$ & $\mathrm{DSD}(\mathrm{m})$ \\
\hline 40 & 48 & 121 & 37 & 96 \\
50 & 66 & 158 & 51 & 124 \\
60 & 87 & 197 & 68 & 157 \\
70 & 110 & 238 & 88 & 191 \\
\hline
\end{tabular}

\subsection{Comparison of the FOSM and AFOSM Sight Distance Design Values}

A comparison of the SSD design values obtained using the FOSM and AFOSM reliability methods indicates that the AFOSM method provides more conservative design values. shows the deterministic, FOSM, and FOSM stopping sight distances versus the design speed. The probabilistic SSD values were based on a probability of noncompliance of $0.01 \%$ and a coefficient of variation of $10 \%$. The FOSM and AFOSM methods yield almost the same design values for lower vehicle speeds, but the AFOSM method yields larger design values for high design speeds. The reason that the results of FOSM and AFOSM methods are different is that FOSM method produces error while AFOSM method is more accurate as it finds the solution at the design point.

Table 3.27 shows the DSD design values for urban roundabouts calculated using the FOSM, AFOSM, and deterministic methods. The probabilistic DSD values were based on a system probability of failure of $0.01 \%$ and a coefficient of variation of $10 \%$. For urban roundabouts, the DSD values obtained using the FOSM reliability method were slightly larger than the values obtained using the AFOSM method. Table 3.28 illustrates the DSD design values for rural roundabouts calculated using the FOSM, AFOSM, and deterministic methods. For rural roundabouts, the DSD design values obtained using the AFOSM method were larger than the values obtained using the FOSM and deterministic methods.

Since the AFOSM method provides higher and more accurate sight distance design values (SSD \& DSD) compared to the FOSM method, the AFOSM sight distance design values were used for the development of design aids for lateral clearance requirements at roundabouts. 


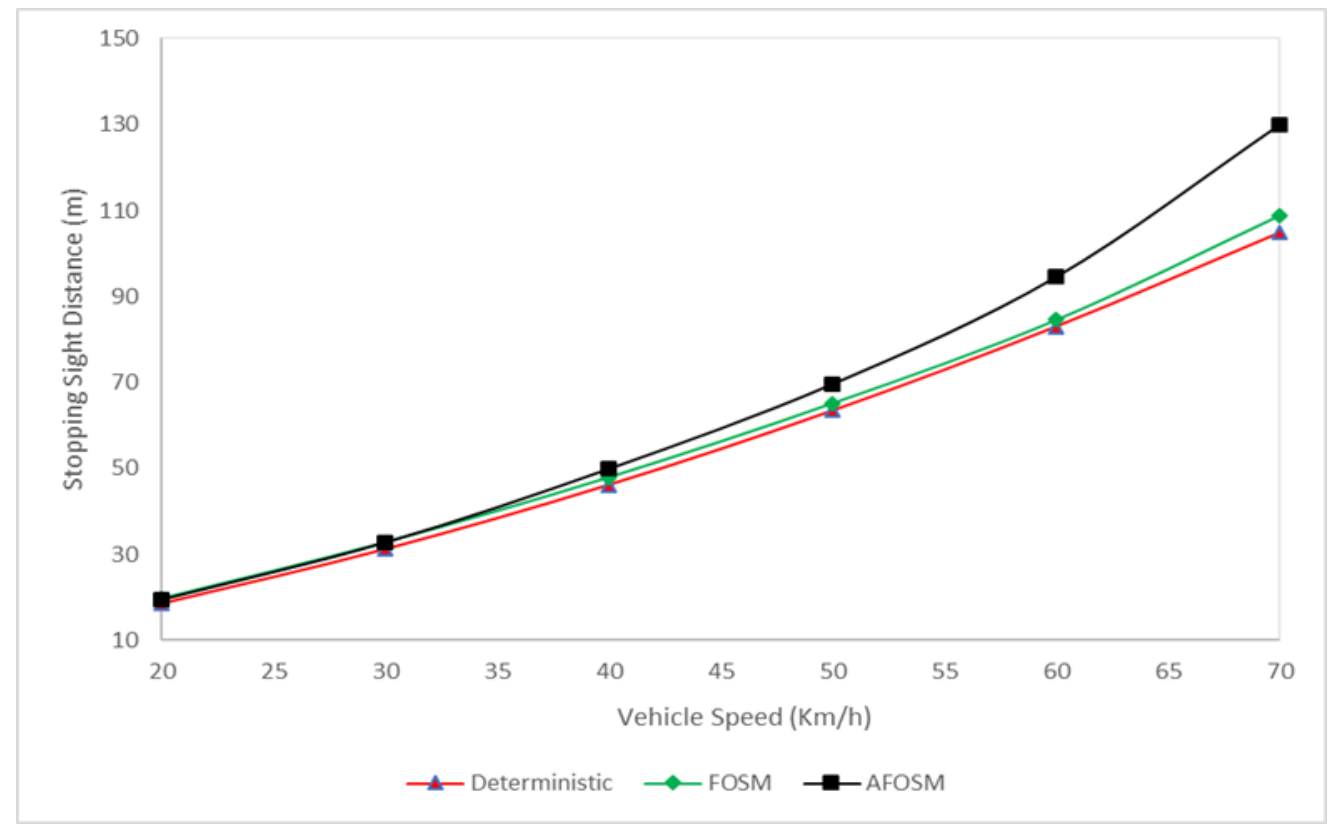

Figure 3-19 Comparison of deterministic, FOSM, and AFOSM SSD results

Table 3.27 Comparison of DSD for urban roundabouts

\begin{tabular}{cccc}
\hline \multirow{2}{*}{$\begin{array}{c}\text { Design Speed } \\
(\mathrm{Km} / \mathrm{h})\end{array}$} & \multicolumn{2}{c}{ Decision sight distance, DSD $(\mathrm{m})$} \\
\cline { 2 - 4 } & AASHTO & FOSM & AFOSM \\
\hline 40 & 119 & 130 & 119 \\
50 & 155 & 168 & 155 \\
60 & 193 & 208 & 198 \\
70 & 233 & 255 & 245 \\
\hline
\end{tabular}

Table 3.28 Comparison of DSD for rural roundabouts

\begin{tabular}{cccc}
\hline \multirow{2}{*}{$\begin{array}{c}\text { Design Speed } \\
(\mathrm{Km} / \mathrm{h})\end{array}$} & \multicolumn{3}{c}{ Decision sight distance, DSD (m) } \\
\cline { 2 - 4 } & AASHTO & FOSM & AFOSM \\
\hline 40 & 52 & 54 & 55 \\
50 & 70 & 73 & 77 \\
60 & 91 & 94 & 101 \\
70 & 115 & 120 & 131 \\
\hline
\end{tabular}




\subsection{Design Aids for Lateral Clearance Requirements to Satisfy Probabilistic SSD}

According to AASHTO (2011), physical elements outside of the vehicle path, such as trees, vegetation, walls, buildings, cut slopes or any other longitudinal barriers are obstructions to the drivers sightlines. The city of Calgary (2010) states that monuments or other objects placed on the central island can restrict the driver sightline in the circulatory lane. SSD requirements are checked graphically at roundabouts. In order to eliminate the iterative procedure for determining the adequacy of SSD at roundabouts, Easa (2017) developed an analytical model for the calculation of lateral clearance requirements for the approach, exit and circulatory SSD of single-lane symmetrical roundabouts.

The lateral clearance requirements necessary to satisfy SSD are developed for the approach SSD, exit SSD, and circulatory lane SSD. These lateral clearance design values were calculated using the SSD design values obtained using the AFOSM method.

Design aids were based on the following geometric design parameters of roundabouts.

$>$ Entry, exit, and circulatory lane widths $w_{1}=6 \mathrm{~m}$

$>$ Crosswalk width $w_{c}=3 \mathrm{~m}$

$>$ Distance from the driver's eye to the right curb $\mathrm{A}=1.77 \mathrm{~m}$

$>$ Distance from the driver's eye to the front of the vehicle, $d_{e}=2.4 \mathrm{~m}$

$>$ Distance from the near edge of the crosswalk to the inscribed circle $L_{\min }=6 \mathrm{~m}$

Distance from the near edge of the crosswalk to the yield line $\mathrm{D}=7 \mathrm{~m}$

$>$ Offset distance of pedestrian from the curb, $f_{p}=2 \mathrm{~m}$

$>$ Length of the curve from start of entry curve to the far edge of crosswalk, $L_{p}=9 \mathrm{~m}$

\subsubsection{Case 1: Approach Stopping Sight Distance}

At the roundabout approaches, lateral clearance design values are calculated to satisfy SSD values obtained using the AFOSM method to the pedestrian crosswalk and to the yield line. Two consecutive entry curves (curved in the same direction) with varying radii, are considered.

Easa (2017) developed an analytical model for the calculation of the lateral clearance at roundabout approaches. 
In order to calculate the lateral clearance to satisfy SSD to the crosswalk, the location of pedestrians and vehicles is first determined. The lateral clearance is then formulated. The Cartesian coordinate illustrated in Figure 3-20 defines the location of the driver's eye and pedestrians.

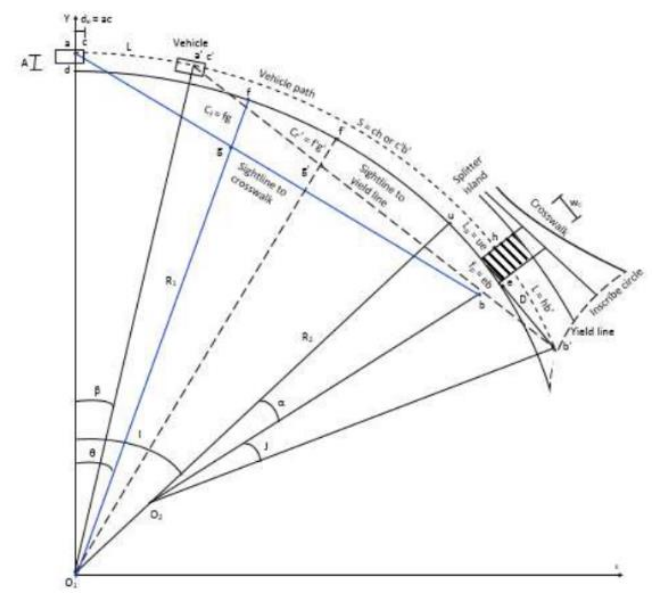

Figure 3-20 Lateral clearance requirements on the approaches of roundabouts (Easa 2017)

The angles $\alpha, \mathrm{I}, \mathrm{J}$, and $\beta$ illustrated in Figure 3-20 are given by:

$$
\begin{gathered}
I=\frac{R_{2}\left(S+d_{e}\right)-\left(R_{2}+A\right)\left(L_{p}-w_{c}\right)}{R_{2}\left(R_{1}+A\right)} \\
J=\cos ^{-1}\left(\frac{R_{2}^{2}+\left(R_{2}+A\right)^{2}-D^{2}}{2 R_{2}\left(R_{2}+A\right)}\right) \\
\beta=\frac{\left(R_{2}+A\right) J+w_{c}}{R_{1}+A}
\end{gathered}
$$

where:

$$
\begin{aligned}
& L_{p}=\text { length of the curve from the start of entry to far the edge of the crosswalk, } \mathrm{m} \\
& R_{1}=\text { radius of the first entry curve, } \mathrm{m} \\
& R_{2}=\text { radius of the second entry curve }, \mathrm{m} \\
& d_{e}=\text { distance from the drivers eye to the front of the vehicle, } \mathrm{m} \\
& A=\text { distance from the right edge of the curb to the vehicle path, } \mathrm{m} \\
& w_{c}=\text { crosswalk width, } \mathrm{m}
\end{aligned}
$$


$\mathrm{D}=$ distance from the curb at the far edge of the crosswalk to the intersection of the yield line and vehicle path, $\mathrm{m}$

The vehicle $\left(x_{a}, y_{a}\right)$ and pedestrian $\left(x_{b}, y_{b}\right)$ coordinates are expressed as (Easa, 2017):

$$
\begin{gathered}
x_{a}=0 \\
y_{a}=R_{1}+A \\
x_{b}=\left(R_{1}-R_{2}\right) \sin (I)+\left(R_{2}+f_{p}\right) \sin (I+\alpha) \\
y_{b}=\left(R_{1}-R_{2}\right) \cos (I)+\left(R_{2}-f_{p}\right) \cos (I+\alpha)
\end{gathered}
$$

where:

$$
f_{p}=\text { Offset distance of the pedestrian from the curb, } \mathrm{m}
$$

The slope of the sightline from the eye of the driver to the pedestrian crosswalk is given by:

$$
P=\frac{y_{b}-y_{a}}{x_{b}-x_{a}}
$$

An arbitrary point $f\left(x_{f}, y_{f}\right)$ is selected to formulate the lateral clearance. The slopes of point $f\left(x_{f}, y_{f}\right)$ with respect to curve centers $\mathrm{O}_{1}$ and $\mathrm{O}_{2}$ are given by:

$$
\begin{gathered}
\frac{p_{f}=x_{f}}{y_{f}}, \quad x_{f} \leq x_{u} \\
p_{f}=\frac{y_{f}-y_{02}}{x_{f}-x_{02}}, \quad x_{f} \geq x_{u}
\end{gathered}
$$

where:

$$
x_{u}=\mathrm{x} \text {-coordinate of the common tangent point } u
$$

Solving the Equations of lines $a b$ and line $O_{1} f$ or line $a b$ and line $O_{2} f$, coordinate of intersection point $\left(x_{g}, y_{g}\right)$ can be determined. Coordinate of intersecting point is given:

$$
\begin{gathered}
x_{g}=\frac{y_{a}-y_{f}-x_{a} p+x_{f} p_{f}}{p_{f}-p} \\
y_{g}=y_{f}+\left(x_{g}-x_{f}\right) p_{f}
\end{gathered}
$$


The lateral clearance at point $f\left(C_{f}\right)$ is defined as $R_{1}$ minus the length of $O_{1} g$ or $R_{2}$ minus $O_{2} g$. Equations (3.30) and (3.31) are used to calculate the lateral clearance at any point along the entry curves from the driver's eye to the pedestrian crosswalk.

$$
\begin{gathered}
C_{f}=R_{1}+\sqrt{x_{g}^{2}+y_{g}^{2}}, \quad x_{f} \leq x_{u} \\
C_{f}=R_{2}-\sqrt{\left(x_{g}-x_{O 2}\right)^{2}+\left(y_{g}-y_{O 2}\right)^{2}}, \quad x_{f} \geq x_{u}
\end{gathered}
$$

The Excel solver is used to determine the maximum lateral clearance required. In the Excel solver, $C_{f}$ is defined as the objective function which needs to be maximized.

$$
Z=C_{f}
$$

Subjected to:

$$
\mathrm{x}_{\mathrm{a}} \leq \mathrm{x}_{\mathrm{f}} \leq \mathrm{x}_{\mathrm{b}}
$$

The lateral clearance design values to satisfy SSD to the crosswalk were developed by applying the geometric parameters of roundabouts and the AFOSM SSD design values.

Table 3.29 shows the lateral clearance design values for a system probability of noncompliance of $0.01 \%$ and a coefficient of variation of $10 \%$. The lateral clearance design values for the approaches to satisfy SSD to the crosswalk based on a coefficient of variation of 5\% and a probability of noncompliance of $0.01 \%, 0.1 \%, 1.0 \%$, and $5.0 \%$ are shown in APPENDIX-A. The lateral clearance design values for the approaches to satisfy SSD to the crosswalk based on a coefficient of variation of $10 \%$ and a probability of noncompliance of $0.1 \%, 1.0 \%$, and $5.0 \%$ are shown in APPENDIX-B. The lateral clearance design values for the approaches to satisfy SSD to the crosswalk based on a coefficient of variation of $15 \%$ and a probability of noncompliance of $0.01 \%$, $0.1 \%, 1.0 \%$, and $5.0 \%$ are shown in APPENDIX-C. 
Table 3.29 Lateral clearance design values for the approaches (SSD to the crosswalk), $P_{f}=0.01 \%, \mathrm{CV}=10 \%$

\begin{tabular}{|c|c|c|c|c|c|}
\hline \multirow{5}{*}{$\begin{array}{c}\text { First Entry } \\
\text { Curve Radius } \\
R_{1}(\mathrm{~m})\end{array}$} & \multirow{5}{*}{$\begin{array}{c}\text { Second Entry } \\
\text { Curve Radius } \\
\qquad R_{2}(\mathrm{~m})\end{array}$} & \multicolumn{4}{|c|}{ Maximum Lateral Clearance (m) } \\
\hline & & \multicolumn{4}{|c|}{ Speed $(K m / h)^{a}$} \\
\hline & & 40 & 50 & 60 & 70 \\
\hline & & \multicolumn{4}{|c|}{ Stopping Sight Distance (m) } \\
\hline & & 50 & 70 & 95 & 130 \\
\hline \multirow[t]{3}{*}{100} & 20 & 4.9 & 7.6 & & \\
\hline & 30 & 4.5 & 7.4 & & \\
\hline & 40 & 4.4 & 7.3 & & \\
\hline \multirow[t]{3}{*}{300} & 20 & 3.5 & 4.1 & 5.5 & 8.5 \\
\hline & 30 & 3.0 & 3.6 & 5.1 & 8.3 \\
\hline & 40 & 2.8 & 3.4 & 5.0 & 8.2 \\
\hline \multirow[t]{3}{*}{500} & 20 & 3.3 & 3.6 & 4.2 & 5.9 \\
\hline & 30 & 2.9 & 3.2 & 3.8 & 5.5 \\
\hline & 40 & 2.6 & 2.9 & 3.6 & 5.4 \\
\hline \multirow[t]{3}{*}{1000} & 20 & 3.2 & 3.5 & 3.7 & 4.1 \\
\hline & 30 & 2.7 & 3.0 & 3.2 & 3.7 \\
\hline & 40 & 2.5 & 2.7 & 3.0 & 3.5 \\
\hline
\end{tabular}

${ }^{a}$ For shaded cells, $R_{1}$ is less than $R_{\min }$ for the respective vehicle speed on the approaches and a superelevation of up to 0.06 .

For the calculation of the lateral clearance required to satisfy SSD to the yield line, the same procedure used to calculate the lateral clearance to the crosswalk was applied. The sight line extends from the new location of the vehicle $a$ ' to the intersection of the vehicle path and the yield line, as shown in Figure 3-20.

The coordinates of the driver's eye $\left(x_{a}^{\prime}, y_{a}^{\prime}\right)$ and the intersection of yield line and vehicle path $\left(x_{b}^{\prime}, y_{b}^{\prime}\right)$ are obtained using the following Equations:

$$
\begin{gathered}
X_{a^{\prime}}=\left(R_{1}+A\right) \sin (\beta) \\
y_{a^{\prime}}=\left(R_{1}+A\right) \cos (\beta) \\
x_{b^{\prime}}=\left(R_{1}-R_{2}\right) \sin (I)+\left(R_{2}-f_{p}\right) \sin (I+\alpha+J) \\
y_{b^{\prime}}=\left(R_{1}-R_{2}\right) \cos (I)+\left(R_{2}-f_{p}\right) \cos (I+\alpha+J)
\end{gathered}
$$


The same method for calculation of lateral clearance to satisfy SSD to the yield line is used as the SSD to the pedestrian crosswalk. The lateral clearance design values are obtained by applying the AFOSM SSD values and the dimensions of the geometric elements of the roundabout.

Table 3.30 shows the lateral clearance design values to satisfy SSD to the yield line for a system probability of noncompliance of $0.01 \%$ and a coefficient of variation of $10 \%$. The lateral clearance design values for the approaches to satisfy SSD to the yield line based on a coefficient of variation of $5 \%$ and a probability of noncompliance of $0.01 \%, 0.1 \%, 1.0 \%$, and $5.0 \%$ are shown in APPENDIX-A. The lateral clearance design values for the approaches to satisfy SSD to the yield line based on a coefficient of variation of $10 \%$ and a probability of noncompliance of $0.1 \%, 1.0 \%$, and $5.0 \%$ are shown in APPENDIX-B. The lateral clearance design values for the approaches to satisfy SSD to the yield line based on a coefficient of variation of $15 \%$ and a probability of noncompliance of $0.1 \%, 1.0 \%$, and $5.0 \%$ are shown in APPENDIX-C.

Table 3.30 Lateral clearance design values for the approaches (SSD to the yield line),

$$
P_{f}=0.01 \%, \mathrm{CV}=10 \%
$$

\begin{tabular}{|c|c|c|c|c|c|}
\hline \multirow{5}{*}{$\begin{array}{c}\text { First Entry } \\
\text { Curve Radius } \\
R_{1}(\mathrm{~m})\end{array}$} & \multirow{5}{*}{$\begin{array}{l}\text { Second Entry } \\
\text { Curve Radius } \\
\qquad R_{2}(\mathrm{~m})\end{array}$} & \multicolumn{4}{|c|}{ Maximum Lateral Clearance (m) } \\
\hline & & \multicolumn{4}{|c|}{ Speed $(K m / h)^{a}$} \\
\hline & & 40 & 50 & 60 & 70 \\
\hline & & \multicolumn{4}{|c|}{ Stopping Sight Distance (m) } \\
\hline & & 50 & 70 & 95 & 130 \\
\hline \multirow[t]{3}{*}{100} & 20 & 4.6 & 7.3 & & \\
\hline & 30 & 3.3 & 6.2 & & \\
\hline & 40 & 2.7 & 5.6 & & \\
\hline \multirow[t]{3}{*}{300} & 20 & 3.4 & 4.3 & 5.6 & 8.6 \\
\hline & 30 & 1.9 & 2.8 & 4.3 & 7.5 \\
\hline & 40 & 1.2 & 2.1 & 3.7 & 6.9 \\
\hline \multirow[t]{3}{*}{500} & 20 & 3.2 & 3.9 & 4.6 & 6.1 \\
\hline & 30 & 1.7 & 2.3 & 3.0 & 4.8 \\
\hline & 40 & 0.9 & 1.4 & 2.3 & 4.2 \\
\hline \multirow[t]{3}{*}{1000} & 20 & 3.0 & 3.6 & 4.0 & 4.6 \\
\hline & 30 & 1.5 & 1.9 & 2.3 & 2.9 \\
\hline & 40 & 0.8 & 1.1 & 1.4 & 2.2 \\
\hline
\end{tabular}

${ }^{\text {a }}$ For shaded cells, $R_{1}$ is less than $R_{\min }$ for the respective vehicle speed on the approaches and a superelevation of up to 0.06 . 
Figure 3-21 shows the lateral clearance design values for the approaches of roundabouts with a first entry curve radius of $300 \mathrm{~m}$ and a second entry curve radius of $40 \mathrm{~m}$. Figure 3-22 shows the lateral clearance design values for the approaches of roundabouts with a first entry curve radius of $1000 \mathrm{~m}$ and a second entry curve radius of $40 \mathrm{~m}$. Figure 3-23 shows the lateral clearance design values for the approaches of roundabouts with a first entry curve radius of $1000 \mathrm{~m}$ and a second entry curve radius of $20 \mathrm{~m}$.

The results indicate that, in most cases, the lateral clearance values to satisfy SSD to the crosswalk are larger than the lateral clearance values to satisfy SSD to the yield line. When the first entry curve radius is very large and the second entry curve radius is small, the lateral clearance values to satisfy SSD to the yield line are larger than the lateral clearance values to satisfy SSD to the crosswalk. Figure 3-23 reveals that the SSD to the crosswalk results in higher lateral clearance values for design speeds of 40 to $47 \mathrm{Km} / \mathrm{h}$. However, when the design speed is greater than 47 $\mathrm{Km} / \mathrm{h}$, the SSD to the yield line results in larger lateral clearance design values. The trend of lateral clearance to crosswalk and yield line depends of the values of the radii of the approach and entry curves.

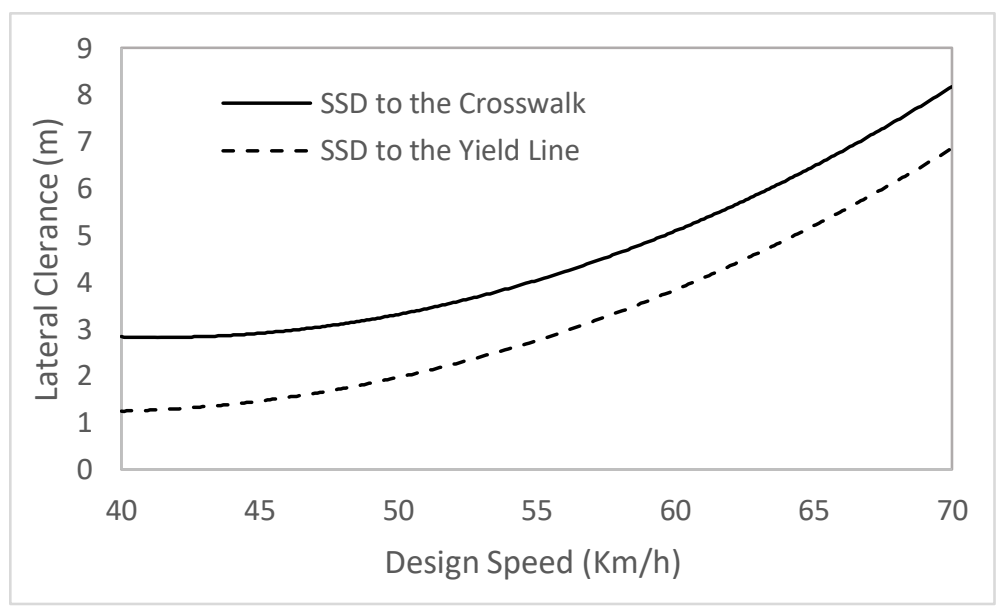

Figure 3-21 Lateral clearance values required to satisfy SSD for the approaches,

$$
R_{1}=300, R_{2}=40
$$




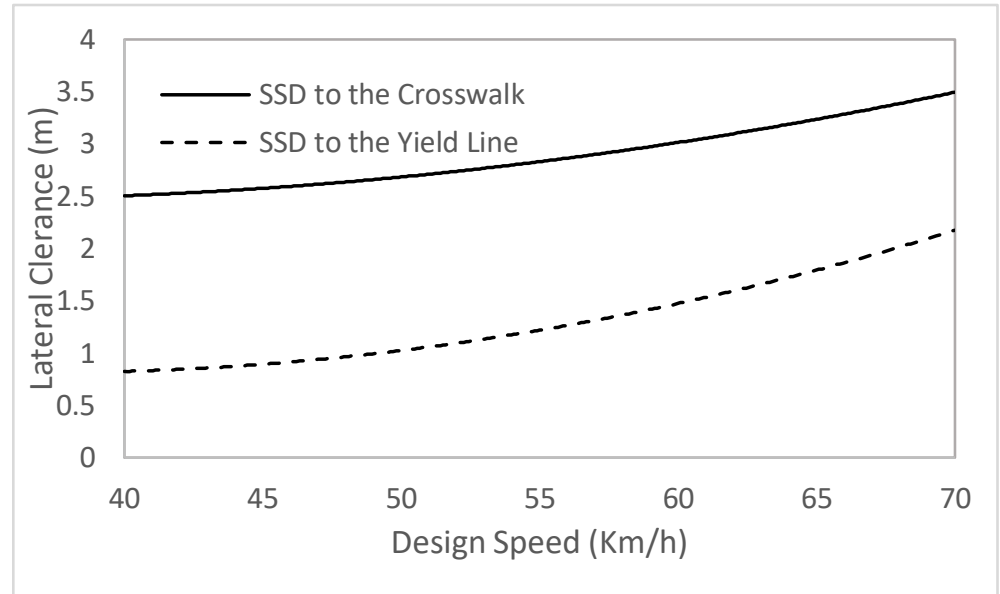

Figure 3-22 Lateral clearance values required to satisfy SSD for the approaches

$$
R_{1}=1000, R_{2}=40
$$

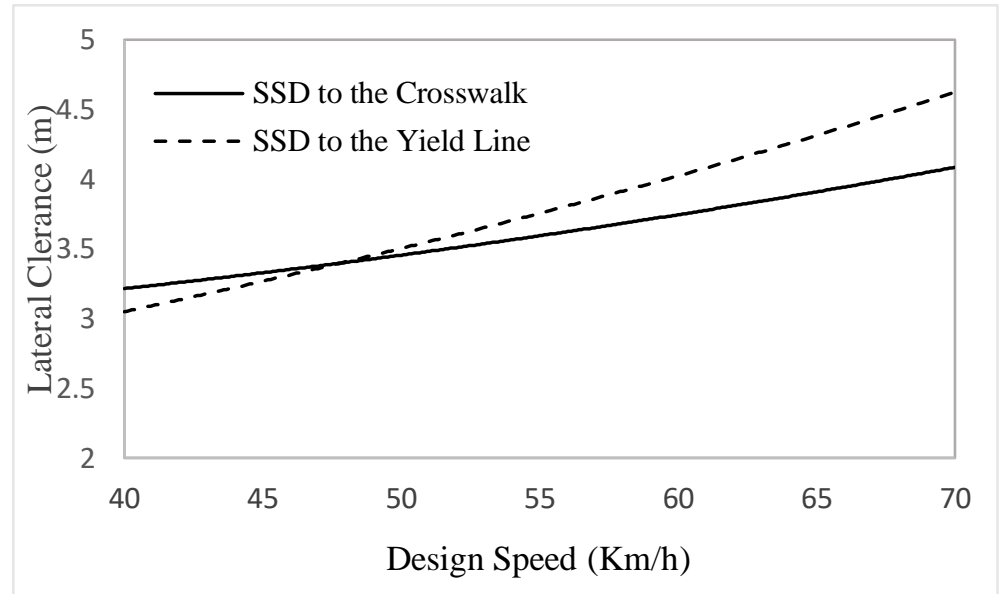

Figure 3-23 Lateral clearance values required to satisfy SSD for the approaches

$$
R_{1}=1000, R_{2}=20
$$

\subsubsection{Case 2: Exit Stopping Sight Distance}

At the roundabout exits, lateral clearance design values are calculated to satisfy SSD using the AFOSM method. Figure 3-24 illustrates the SSD requirements at roundabout exits. The typical location of the pedestrian crosswalks, $6 \mathrm{~m}$ away from the yield line, is checked for the adequacy of the SSD. For negative values of $D$ (the difference between the location of the near edge of a typical crosswalk and the location of the near edge of the crosswalk based on the required SSD), the crosswalk should be moved away from the inscribed circle. Another option would be to reduce the vehicle speed. 
Easa (2017) developed an analytical method for the calculation of the lateral clearance required to satisfy SSD on the exit of roundabouts. This method only applies to a vehicle entering on one leg of the roundabout and exiting on the next closest leg.

For the calculation of the lateral clearance on the exits, SSD is measured from the intersection of the vehicle path and yield line to the near edge of the crosswalk. The available sight distance is measured from the intersection of the vehicle path and yield line to the near edge of a typical crosswalk. The Cartesian coordinate for the determination of the location of pedestrians and the driver's eye is illustrated in Figure 3-24.

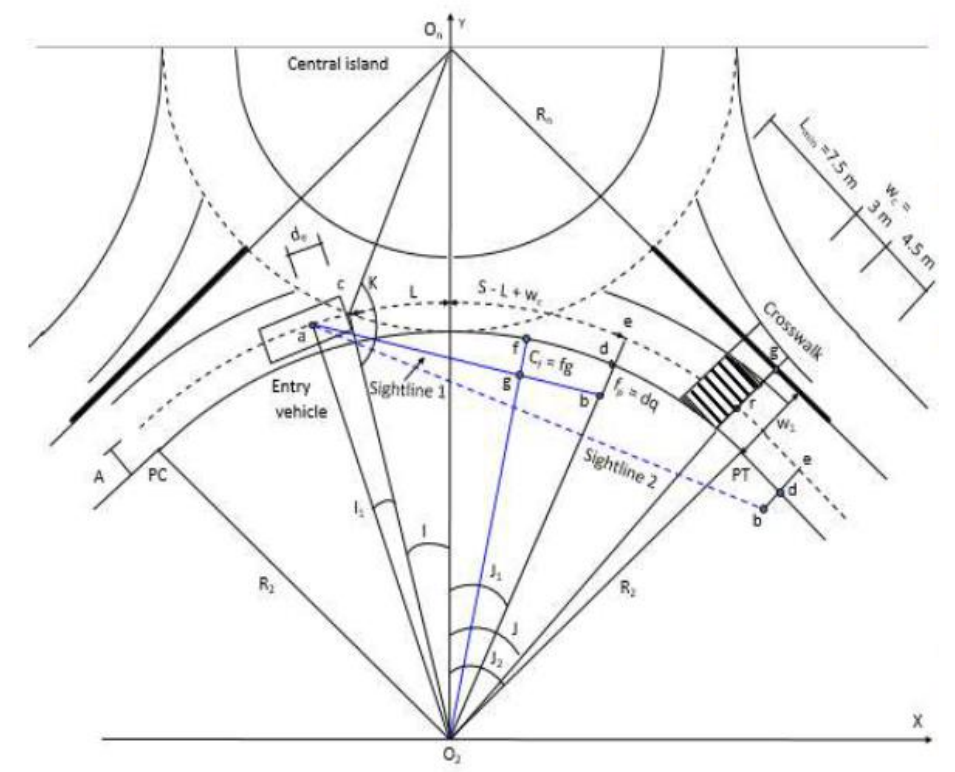

Figure 3-24 Exit SSD and the lateral clearance requirements for crosswalks (Easa 2017)

The angles $I, I_{1}$, and $J_{1}$ are given by Equations (3.38), (3.39), and (3.40), respectively.

$$
\begin{gathered}
I=\sin ^{-1}\left\{\frac{R_{n}}{R_{n}+R_{2}} \sin \left[\cos ^{-1}\left(\frac{R_{n}^{2}+\left(R_{2}+A\right)^{2}-\left(R_{n}+R_{2}\right)^{2}}{2 R_{n}\left(R_{2}+A\right)}\right)\right]\right\} \\
I_{1}=\frac{d_{e}}{R_{2}+A} \\
J_{1}=\frac{S-L+w_{c}}{R_{2}+A}
\end{gathered}
$$


where:

$$
\begin{aligned}
& R_{n}=\text { radius of the inscribed circle, } \mathrm{m} \\
& R_{2}=\text { radius of the entry-exit curve, } \mathrm{m} \\
& d_{e}=\text { distance from the drivers eye to the front of the vehicle, } \mathrm{m} \\
& A=\text { distance from the right edge of the curb to the vehicle path, } \mathrm{m} \\
& w_{c}=\text { crosswalk width, } \mathrm{m} \\
& \mathrm{L}=\text { distance travelled before the } \mathrm{y} \text {-axis }\left(\mathrm{L}=\left(R_{2}+A\right) I\right), \mathrm{m}
\end{aligned}
$$

The relationship between the radius of the inscribed circle and the exit curve radius is given by (Easa, 2018):

$$
R_{2}=\frac{w_{1}-R_{n} \sin (45)}{\sin (45)-1}
$$

where:

$$
\begin{aligned}
& R_{n}=\text { radius of the inscribed circle, } \mathrm{m} \\
& R_{2}=\text { radius of the entry-exit curve, } \mathrm{m} \\
& \Phi_{1}=\text { half of the angle between the intersecting legs of the roundabout }
\end{aligned}
$$

Connecting points $a$ and $b$ will give the driver's sightline. The coordinates of the drivers eye $\left(x_{a}, y_{a}\right)$ and pedestrian $\left(x_{b}, y_{b}\right)$ are given by:

$$
\begin{gathered}
x_{a}=-\left(R_{2}+A\right) \sin \left(I_{1}+I\right) \\
y_{a}=\left(R_{2}+A\right) \cos \left(I_{1}+I\right) \\
x_{b}=\left(R_{2}-f_{p}\right) \sin \left(J_{1}\right) \\
y_{b}=\left(R_{2}-f_{p}\right) \cos \left(J_{1}\right)
\end{gathered}
$$

The same procedure used to calculate the lateral clearance of the approaches is applied to calculate the lateral clearance of the exits.

The lateral clearance design values for the roundabout exits were developed using the AFOSM SSD and the dimensions of the geometric elements of roundabouts. Table 3.31 illustrates the lateral clearance design values required to satisfy SSD on the exits for a system probability of 
noncompliance of $0.01 \%$ and a coefficient of variation of $10 \%$. The lateral clearance design values used to satisfy SSD at the exits based on a coefficient of variation of $5 \%$ and a probability of noncompliance of $0.01 \%, 0.1 \%, 1.0 \%$, and $5.0 \%$ are shown in APPENDIX-A. The lateral clearance design values used to satisfy SSD at the exits based on a coefficient of variation of $10 \%$ and a probability of noncompliance of $0.1 \%, 1.0 \%$, and $5.0 \%$ are shown in APPENDIX-B. The lateral clearance design values used to satisfy SSD at the exits based on a coefficient of variation of $15 \%$ and a probability of noncompliance of $0.01 \%, 0.1 \%, 1.0 \%$, and $5.0 \%$ are shown in APPENDIX-C.

Table 3.31 Lateral clearance design values for the exits, $P_{f}=0.01 \%, \mathrm{CV}=10 \%$

\begin{tabular}{|c|c|c|c|c|c|c|}
\hline \multirow{5}{*}{$\begin{array}{c}\text { Entry-Exit } \\
\text { Curve Radius } \\
\text { `R (m) }\end{array}$} & \multicolumn{6}{|c|}{${ }^{\mathrm{a}}$ Speed $(\mathrm{km} / \mathrm{h})$} \\
\hline & \multicolumn{2}{|c|}{20} & \multicolumn{2}{|c|}{30} & \multicolumn{2}{|c|}{40} \\
\hline & \multicolumn{6}{|c|}{ Stopping Sight Distance (m) } \\
\hline & \multicolumn{2}{|c|}{20} & \multicolumn{2}{|c|}{33} & \multicolumn{2}{|c|}{50} \\
\hline & ${ }^{\mathrm{b}} \mathrm{C}$ & ${ }^{\mathrm{c}} \mathrm{D}$ & ${ }^{\mathrm{b}} \mathrm{C}$ & ${ }^{\mathrm{c}} \mathrm{D}$ & ${ }^{\mathrm{b}} \mathrm{C}$ & ${ }^{\mathrm{c}} \mathrm{D}$ \\
\hline 20 & 3.7 & -0.64 & & & & \\
\hline 30 & 2.9 & 2.21 & 5.6 & -10.80 & & \\
\hline 40 & 2.5 & 5.21 & 4.5 & -7.79 & & \\
\hline 50 & 2.2 & 8.27 & 3.8 & -4.74 & 7.3 & -21.74 \\
\hline 60 & 2.1 & 11.33 & 3.3 & -1.68 & 6.2 & -18.68 \\
\hline
\end{tabular}

${ }^{\text {a }}$ For shaded areas, radius of exit curve is less than minimum radius for the entry speed and cross slopes.

${ }^{\mathrm{b}}$ Maximum Lateral Clearance on the exits

${ }^{\mathrm{c}}$ Difference between available sight distance (length of curve on vehicle path from vehicle entry on yield line to near edge of the typical crosswalk, $6 \mathrm{~m}$ away from yield line) and location of near edge of the crosswalk to satisfy SSD.

\subsubsection{Case 3: Circulatory Stopping Sight Distance}

The lateral clearance design values for the circulatory lane of roundabouts were developed using the AFOSM SSD design values and the geometry of roundabouts. The adequacy of the drivers peripheral angle $(\psi)$ was verified. For peripheral angle values larger than 2.44 Radians (140 degrees), $\psi>2.44$, the design speed should be reduced or the radius of the central island should be increased. 
For the calculation of the lateral clearance of a circular horizontal curve, AASHTO (2011) recommends the use of Equation (3.46). The geometry of the circulatory lane of a roundabout is illustrated in Figure 3-25.

$$
M=R\left(1-\cos \left(\frac{90\left(S S D+d_{e}\right)}{\pi R}\right)\right)
$$

where:

$\mathrm{M}=$ required lateral clearance on the circulatory lane, $\mathrm{m}$

$\mathrm{R}=$ radius of the vehicle path, $\mathrm{m}$

$d_{e}=$ distance from the drivers eye to the front of the vehicle, $\mathrm{m}$

$\mathrm{SSD}=$ stopping sight distance

A driver eye height and object height of $1.08 \mathrm{~m}$ was used for the calculation of the lateral clearance and SSD of the circulatory lane.

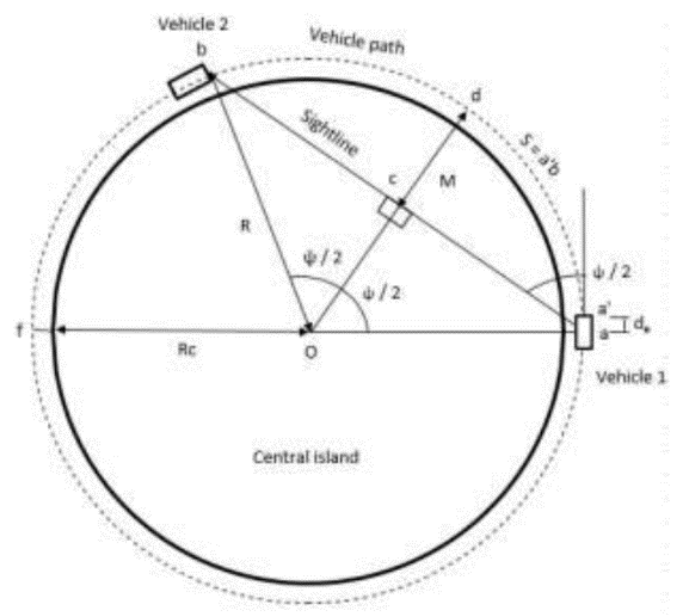

Figure 3-25 Geometry of roundabout circulatory lane (Easa, 2017)

Table 3.32 presents the lateral clearance design values used to satisfy SSD for a system probability of noncompliance of $0.01 \%$ and a coefficient of variation of $10 \%$. The lateral clearance design values for the circulatory lane required to satisfy SSD based on a coefficient of variation of 5\% and a probability of noncompliance of $0.01 \%, 0.1 \%, 1.0 \%$, and $5.0 \%$ are shown in APPENDIXA. The lateral clearance design values for the circulatory lane required to satisfy SSD based on a coefficient of variation of $10 \%$ and a probability of noncompliance of $0.1 \%, 1.0 \%$, and $5.0 \%$ are 
shown in APPENDIX-B. The lateral clearance design values for the circulatory lane required to satisfy SSD based on a coefficient of variation of $15 \%$ and a probability of noncompliance of $0.01 \%, 0.1 \%, 1.0 \%$, and $5.0 \%$ are shown in APPENDIX-C.

Table 3.32 Lateral clearance design values for the circulatory lane, $\mathrm{P}_{\mathrm{f}}=0.01 \%, \mathrm{CV}=10 \%$

\begin{tabular}{|c|c|c|c|c|c|c|}
\hline \multirow{5}{*}{$\begin{array}{c}\text { Central Island } \\
\text { Radius } \\
\text { R (m) }\end{array}$} & \multicolumn{6}{|c|}{ Speed $(\mathrm{Km} / \mathrm{h})$} \\
\hline & \multicolumn{2}{|c|}{20} & \multicolumn{2}{|c|}{30} & \multicolumn{2}{|c|}{40} \\
\hline & \multicolumn{6}{|c|}{ Stopping Sight Distance (m) } \\
\hline & \multicolumn{2}{|c|}{20} & \multicolumn{2}{|c|}{33} & \multicolumn{2}{|c|}{50} \\
\hline & ${ }^{\mathrm{a}} \mathrm{M}$ & ${ }^{\mathrm{b}} \psi$ & ${ }^{\mathrm{a}} \mathrm{M}$ & ${ }^{\mathrm{b}} \psi$ & ${ }^{\mathrm{a}} \mathrm{M}$ & ${ }^{\mathrm{b}} \psi$ \\
\hline 20 & 3.0 & 1.12 & 7.4 & 1.77 & 14.9 & 2.62 \\
\hline 30 & 2.1 & 0.75 & 5.1 & 1.18 & 10.8 & 1.75 \\
\hline 40 & 1.6 & 0.56 & 3.9 & 0.89 & 8.3 & 1.31 \\
\hline 50 & 1.3 & 0.45 & 3.1 & 0.71 & 6.7 & 1.1 \\
\hline
\end{tabular}

${ }^{a}$ Maximum lateral clearance for the circulatory lane

${ }^{\mathrm{b}}$ Driver peripheral vision (Central angle) in radians; a central island radius with a design speed which results in a peripheral vision above 2.44 is inadequate and should not be used in design.

\subsection{Design Aids for Lateral Clearance Requirements Based on Probabilistic DSD}

\subsubsection{Design Aids for Urban Roundabouts}

Tables 3.33 and 3.34 present the lateral clearance design values required to satisfy DSD for the approaches of urban roundabouts to the pedestrian crosswalk and the yield line, respectively, for a system probability of noncompliance of $0.01 \%$ and a coefficient of variation of $10 \%$. The lateral clearance design values for the approaches of urban roundabouts required to satisfy DSD to the pedestrian crosswalk and yield line based on a system probability of failure of $0.1 \%, 1.0 \%$, and 5\% are shown in APPENDIX-D.

Figure 3-26 shows the lateral clearance values required to satisfy DSD for the approaches of urban roundabouts with a first entry curve radius of $300 \mathrm{~m}$ and a second entry curve radius of $40 \mathrm{~m}$. Figure 3-27 shows the lateral clearance values required to satisfy DSD for the approaches of urban roundabouts with a first entry curve radius of $1000 \mathrm{~m}$ and a second entry curve radius of $40 \mathrm{~m}$. Figure 3-28 shows the lateral clearance values required to satisfy DSD for the approaches of urban 
roundabouts with a first entry curve radius of $1000 \mathrm{~m}$ and a second entry curve radius of $20 \mathrm{~m}$. The DSDs used for the development of these graphs were based on a coefficient of variation of $10 \%$ and a probability of failure of $0.01 \%$.

In most cases, the lateral clearance design values used to satisfy DSD to the crosswalk are larger than the lateral clearance values used to satisfy DSD to the yield line. When the first entry curve is very large and the second entry curve is small, the lateral clearance design values used to satisfy DSD to the yield line were larger than the lateral clearance values used to satisfy DSD to the crosswalk.

Table 3.33 Lateral clearance design values for urban roundabouts (DSD to the crosswalk),

$$
P_{f}=0.01 \%, \mathrm{CV}=10 \%
$$

\begin{tabular}{|c|c|c|c|c|c|}
\hline \multirow{5}{*}{$\begin{array}{c}\text { First Entry } \\
\text { Curve Radius } \\
R_{1}(\mathrm{~m})\end{array}$} & \multirow{5}{*}{$\begin{array}{l}\text { Second Entry } \\
\text { Curve Radius } \\
\qquad R_{2}(\mathrm{~m})\end{array}$} & \multicolumn{4}{|c|}{ Maximum Lateral Clearance (m) } \\
\hline & & \multicolumn{4}{|c|}{ Speed $(\mathrm{Km} / \mathrm{h})^{\mathrm{a}}$} \\
\hline & & 40 & 50 & 60 & 70 \\
\hline & & \multicolumn{4}{|c|}{ Decision Sight Distance (m) } \\
\hline & & 119 & 155 & 198 & 245 \\
\hline \multirow[t]{3}{*}{100} & 20 & 18.6 & 29.8 & & \\
\hline & 30 & 18.5 & 29.7 & & \\
\hline & 40 & 18.4 & 29.6 & & \\
\hline \multirow[t]{3}{*}{300} & 20 & 7.5 & 11.5 & 17.7 & 26.1 \\
\hline & 30 & 7.2 & 11.2 & 17.6 & 26.0 \\
\hline & 40 & 7.0 & 11.1 & 17.4 & 25.9 \\
\hline \multirow[t]{3}{*}{500} & 20 & 5.2 & 7.6 & 11.3 & 16.4 \\
\hline & 30 & 4.9 & 7.3 & 11.0 & 16.2 \\
\hline & 40 & 4.7 & 7.1 & 10.9 & 16.0 \\
\hline \multirow[t]{3}{*}{1000} & 20 & 3.9 & 4.8 & 6.5 & 9.0 \\
\hline & 30 & 3.5 & 4.4 & 6.2 & 8.7 \\
\hline & 40 & 3.2 & 4.2 & 6.0 & 8.5 \\
\hline
\end{tabular}

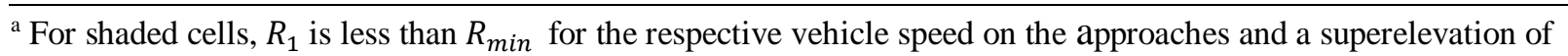
up to 0.06 . 
Table 3.34 Lateral clearance design values for urban roundabouts (DSD to the yield line), $P_{f}=0.01 \%, \mathrm{CV}=10 \%$

\begin{tabular}{|c|c|c|c|c|c|}
\hline \multirow{5}{*}{$\begin{array}{c}\text { First Entry } \\
\text { Curve Radius } \\
R_{1}(\mathrm{~m})\end{array}$} & \multirow{5}{*}{$\begin{array}{l}\text { Second Entry } \\
\text { Curve Radius } \\
\qquad R_{2}(\mathrm{~m})\end{array}$} & \multicolumn{4}{|c|}{ Maximum Lateral Clearance (m) } \\
\hline & & \multicolumn{4}{|c|}{ Speed $(\mathrm{Km} / \mathrm{h})^{\mathrm{a}}$} \\
\hline & & 40 & 50 & 60 & 70 \\
\hline & & \multicolumn{4}{|c|}{ Decision Sight Distance (m) } \\
\hline & & 119 & 155 & 198 & 245 \\
\hline \multirow[t]{3}{*}{100} & 20 & 18.0 & 29.0 & & \\
\hline & 30 & 17.2 & 28.4 & & \\
\hline & 40 & 16.8 & 28.0 & & \\
\hline \multirow[t]{3}{*}{300} & 20 & 7.5 & 11.5 & 17.6 & 26.0 \\
\hline & 30 & 6.4 & 10.4 & 16.6 & 25.0 \\
\hline & 40 & 5.8 & 9.9 & 16.1 & 24.6 \\
\hline \multirow[t]{3}{*}{500} & 20 & 5.5 & 7.7 & 11.3 & 16.4 \\
\hline & 30 & 4.2 & 6.6 & 10.3 & 15.4 \\
\hline & 40 & 3.6 & 6.0 & 9.8 & 14.9 \\
\hline \multirow[t]{3}{*}{1000} & 20 & 4.4 & 5.2 & 6.8 & 9.2 \\
\hline & 30 & 2.7 & 3.8 & 5.5 & 8.1 \\
\hline & 40 & 1.9 & 3.1 & 4.9 & 7.5 \\
\hline
\end{tabular}

${ }^{\text {a }}$ For shaded cells, $R_{1}$ is less than $R_{\min }$ for the respective vehicle speed on the approaches and a superelevation of up to 0.06 .

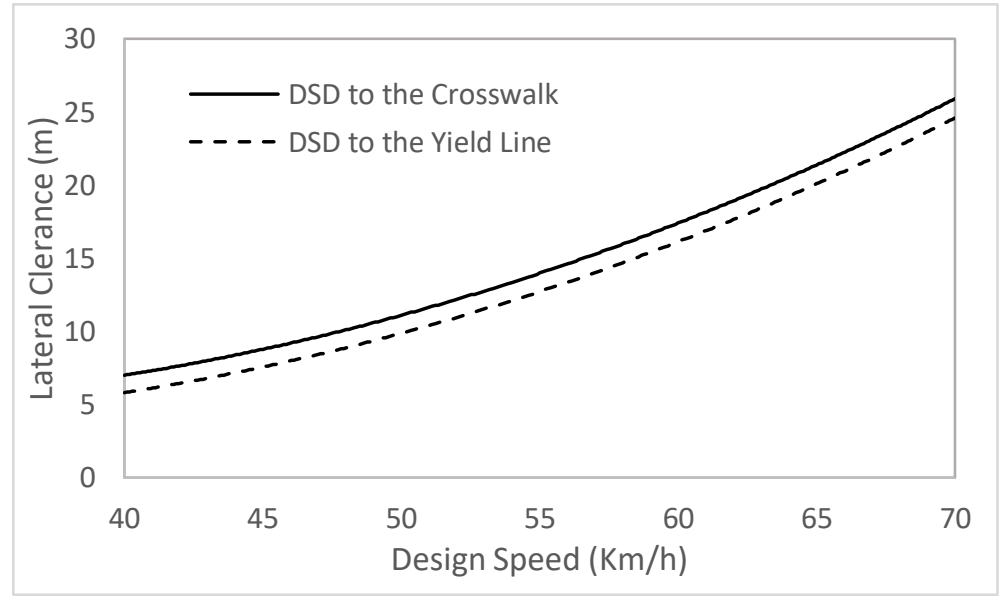

Figure 3-26 Lateral clearance design values used to satisfy DSD for the approaches of urban roundabouts, $R_{1}=300, R_{2}=40$ 


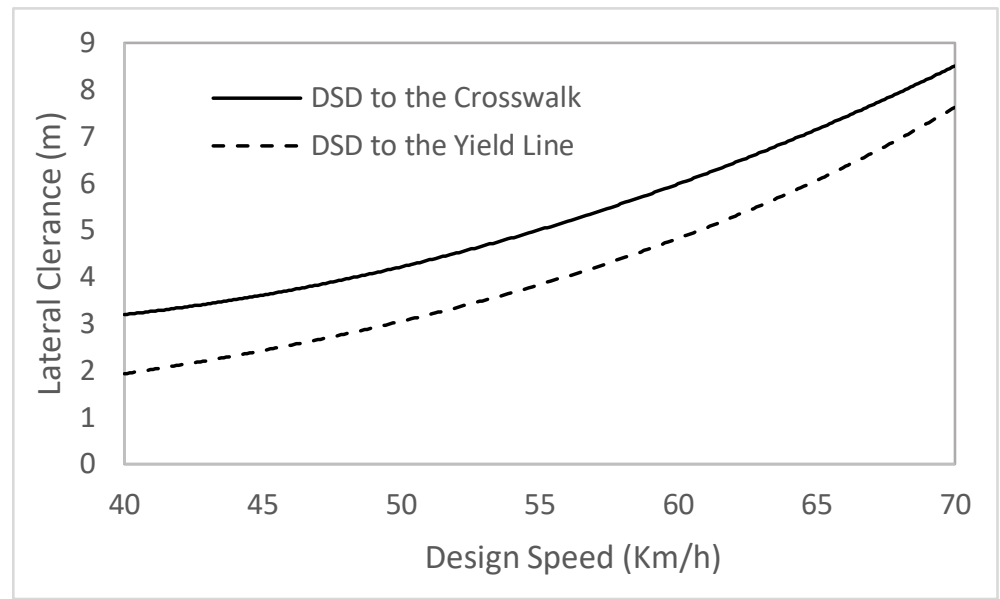

Figure 3-27 Lateral clearance design values used to satisfy DSD for the approaches of urban roundabouts, $R_{1}=1000, R_{2}=40$

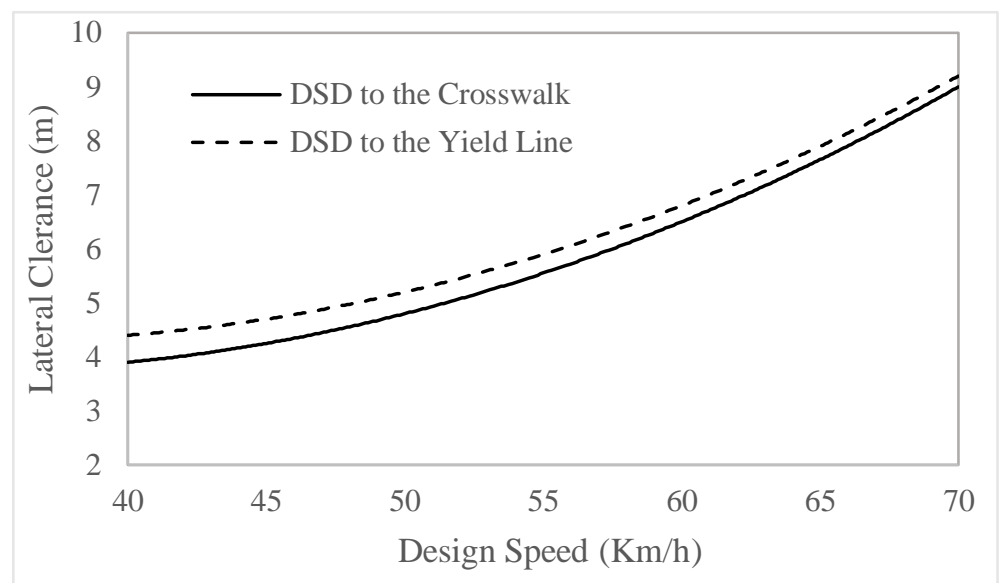

Figure 3-28 Lateral clearance design values used to satisfy DSD for the approaches of urban roundabouts, $R_{1}=1000, R_{2}=20$

\subsubsection{Design Aids for Rural Roundabouts}

Tables 3.35 and 3.36 present the lateral clearance design values required to satisfy DSD for the approaches of rural roundabouts to the pedestrian crosswalk and to the yield line, respectively, for a system probability of noncompliance of $0.01 \%$ and a coefficient of variation of $10 \%$. The lateral clearance design values used to satisfy DSD for the approaches of rural roundabouts for a system probability of noncompliance of $0.1 \%, 1.0 \%$, and $5 \%$ are shown in APPENDIX-E.

Figure 3-29 shows the lateral clearance design values used to satisfy DSD for the approaches of rural roundabouts with a first entry curve radius of $300 \mathrm{~m}$ and a second entry curve radius of $40 \mathrm{~m}$. Figure 3-30 shows the lateral clearance design values used to satisfy DSD for the approaches of 
rural roundabouts with a first entry curve radius of $1000 \mathrm{~m}$ and a second entry curve radius of 40 $m s$. Figure 3-31 shows the lateral clearance design values used to satisfy DSD for the approaches of rural roundabouts with a first entry curve radius of $1000 \mathrm{~m}$ and a second entry curve radius of $20 \mathrm{~m}$. The DSDs used for the development of these graphs were based on a coefficient of variation of $10 \%$ and a probability of failure of $0.01 \%$.

The results presented in the graphs and tables illustrate that, in most cases, the lateral clearance design values required to satisfy DSD to the crosswalk are larger than the lateral clearance values required to satisfy DSD to the yield line. When the first entry curve radius is very large and the second entry curve radius is small, the lateral clearance design values required to satisfy DSD to the yield line are larger than the lateral clearance design values required to satisfy DSD to the crosswalk.

Table 3.35 Lateral clearance design values for rural roundabouts (DSD to the crosswalk),

$$
P_{f}=0.01 \%, \mathrm{CV}=10 \%
$$

\begin{tabular}{|c|c|c|c|c|c|}
\hline \multirow{5}{*}{$\begin{array}{c}\text { First Entry } \\
\text { Curve Radius } \\
R_{1}(\mathrm{~m})\end{array}$} & \multirow{5}{*}{$\begin{array}{c}\text { Second Entry } \\
\text { Curve Radius } \\
\qquad R_{2}(\mathrm{~m})\end{array}$} & \multicolumn{4}{|c|}{ Maximum Lateral Clearance (m) } \\
\hline & & \multicolumn{4}{|c|}{ Speed $(\mathrm{Km} / \mathrm{h})^{\mathrm{a}}$} \\
\hline & & 40 & 50 & 60 & 40 \\
\hline & & \multicolumn{4}{|c|}{ Decision Sight Distance (m) } \\
\hline & & 55 & 77 & 101 & 131 \\
\hline \multirow[t]{3}{*}{100} & 20 & 5.4 & 8.8 & & \\
\hline & 30 & 5.1 & 8.6 & & \\
\hline & 40 & 5.0 & 8.5 & & \\
\hline \multirow[t]{3}{*}{300} & 20 & 3.7 & 4.4 & 5.9 & 8.6 \\
\hline & 30 & 3.1 & 4.0 & 5.6 & 8.4 \\
\hline & 40 & 2.9 & 3.8 & 5.4 & 8.2 \\
\hline \multirow[t]{3}{*}{500} & 20 & 3.4 & 3.8 & 4.4 & 5.9 \\
\hline & 30 & 2.9 & 3.3 & 4.0 & 5.6 \\
\hline & 40 & 2.6 & 3.1 & 3.8 & 5.4 \\
\hline \multirow[t]{3}{*}{1000} & 20 & 3.2 & 3.5 & 3.7 & 4.1 \\
\hline & 30 & 2.7 & 3.0 & 3.2 & 3.7 \\
\hline & 40 & 2.5 & 2.8 & 2.9 & 3.5 \\
\hline
\end{tabular}

${ }^{a}$ For shaded cells, $R_{1}$ is less than $R_{\min }$ for the respective vehicle speed on the approaches and a superelevation of up to 0.06 . 
Table 3.36 Lateral clearance design values for rural roundabouts (DSD to the yield line),

$$
P_{f}=0.01 \%, \mathrm{CV}=10 \%
$$

\begin{tabular}{|c|c|c|c|c|c|}
\hline \multirow{5}{*}{$\begin{array}{c}\text { First Entry } \\
\text { Curve Radius } \\
R_{1}(\mathrm{~m})\end{array}$} & \multirow{5}{*}{$\begin{array}{l}\text { Second Entry } \\
\text { Curve Radius } \\
\qquad R_{2}(\mathrm{~m})\end{array}$} & \multicolumn{4}{|c|}{ Maximum Lateral Clearance (m) } \\
\hline & & \multicolumn{4}{|c|}{ Speed $(K m / h)^{a}$} \\
\hline & & 40 & 50 & 60 & 40 \\
\hline & & \multicolumn{4}{|c|}{ Decision Sight Distance (m) } \\
\hline & & 55 & 77 & 101 & 131 \\
\hline \multirow[t]{3}{*}{100} & 20 & 5.1 & 8.4 & & \\
\hline & 30 & 3.9 & 7.4 & & \\
\hline & 40 & 3.3 & 6.9 & & \\
\hline \multirow[t]{3}{*}{300} & 20 & 3.6 & 4.6 & 6.0 & 8.8 \\
\hline & 30 & 2.1 & 3.1 & 4.8 & 7.6 \\
\hline & 40 & 1.3 & 2.5 & 4.2 & 7.0 \\
\hline \multirow[t]{3}{*}{500} & 20 & 3.3 & 4.1 & 4.8 & 6.1 \\
\hline & 30 & 1.8 & 2.4 & 3.4 & 4.9 \\
\hline & 40 & 1.0 & 1.6 & 2.7 & 4.3 \\
\hline \multirow[t]{3}{*}{1000} & 20 & 3.2 & 3.7 & 4.2 & 4.6 \\
\hline & 30 & 1.6 & 2.0 & 2.4 & 3.0 \\
\hline & 40 & 0.8 & 1.2 & 1.6 & 2.3 \\
\hline
\end{tabular}

${ }^{a}$ For shaded cells, $R_{1}$ is less than $R_{\min }$ for the respective vehicle speed on the approaches and a superelevation of up to 0.06 .

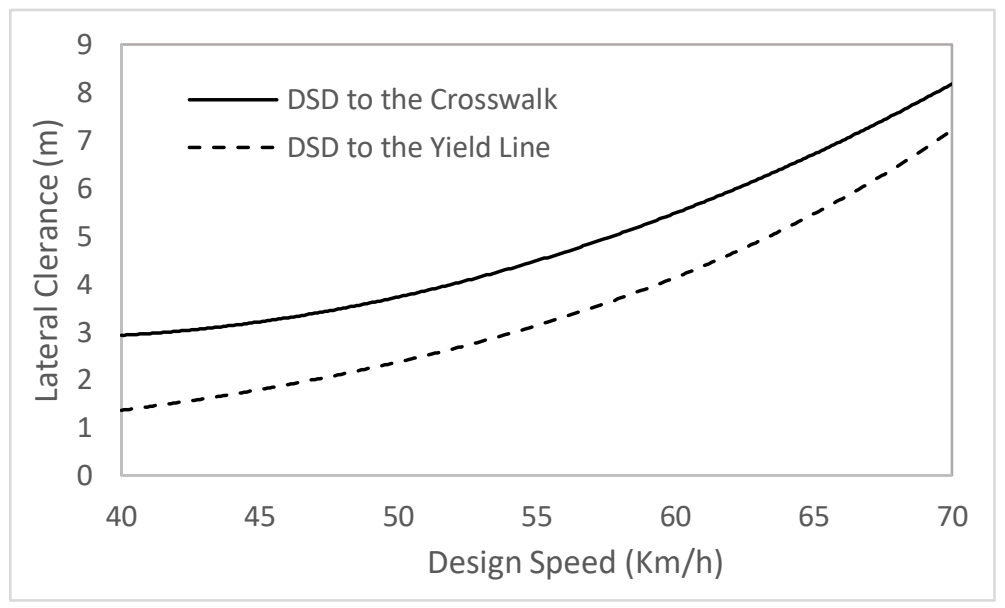

Figure 3-29 Lateral clearance design values used to satisfy DSD for the approaches of rural roundabouts, $R_{1}=300, R_{2}=40$ 


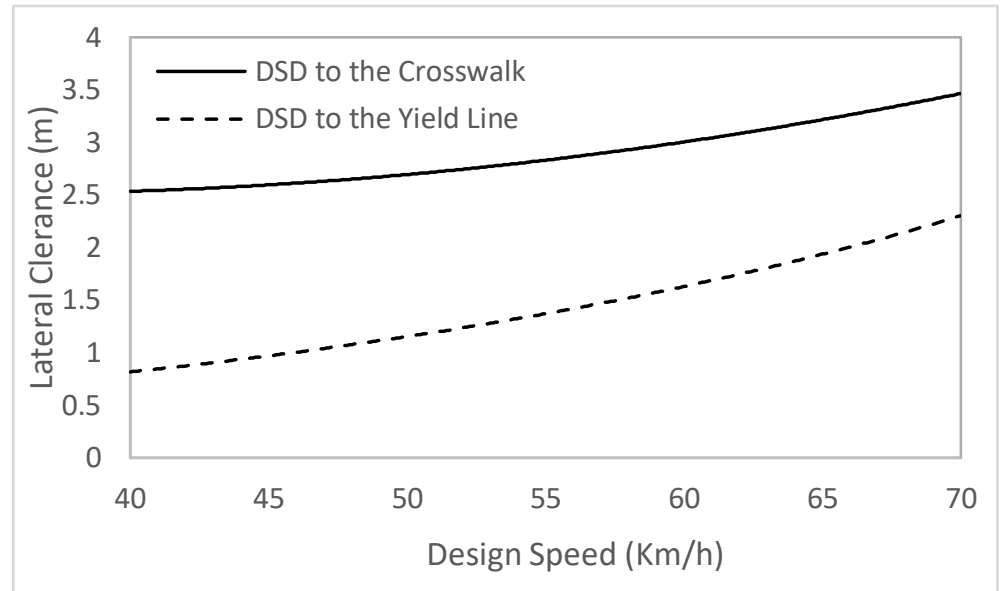

Figure 3-30 Lateral clearance design values used to satisfy DSD for the approaches of rural roundabouts, $R_{1}=1000, R_{2}=40$

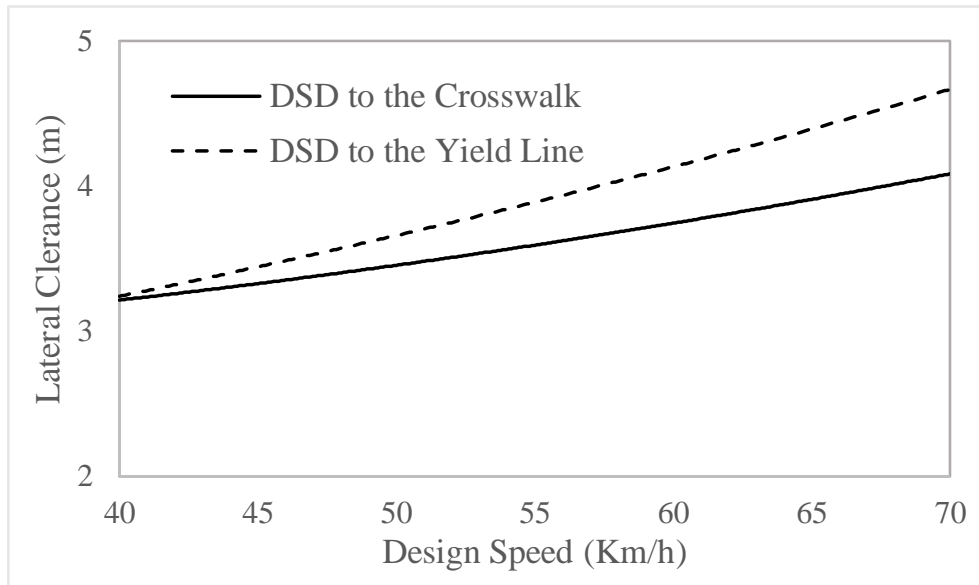

Figure 3-31 Lateral clearance design values used to satisfy DSD for the approaches of rural roundabouts, $R_{1}=1000, R_{2}=20$

\subsection{Comparison of the Lateral Clearance Values Obtained Using the Deterministic and Probabilistic SSD and DSD Approaches}

Figures 3-32 shows the lateral clearance design values for the approaches of roundabouts based on the deterministic and probabilistic (AFOSM) SSD to the pedestrian crosswalk for the system probabilities of noncompliance of 0.01 to $5.0 \%$. Figures 3-33 shows the lateral clearance design values for the approaches of urban roundabouts required to satisfy the deterministic and probabilistic (AFOSM) DSD for the system probabilities of noncompliance of 0.01 to $5.0 \%$. Figures 3-34 shows the lateral clearance design values for the approaches of rural roundabouts 
required to satisfy the deterministic and probabilistic (AFOSM) DSD to the crosswalk for the system probabilities of noncompliance of $0.01 \%$ to $5.0 \%$.

The lateral clearance design values for the approaches of roundabouts used for comparison were based on a first entry curve radius of $300 \mathrm{~m}$ and a second entry curve radius of $40 \mathrm{~m}$.

The results illustrated in the graphs reveal that the probabilistic SSD and DSD values with a probability of noncompliance of $0.01 \%$ provide higher lateral clearance design values compared to the deterministic SSD and DSD design values. The results illustrated in the graphs also reveal that the probabilistic SSD and DSD values with a probability of noncompliance of $1.00 \%$ provide smaller lateral clearance design values compared to the deterministic SSD and DSD design values. It can be concluded that the deterministic SSD and DSD provide very conservative lateral clearance design values.

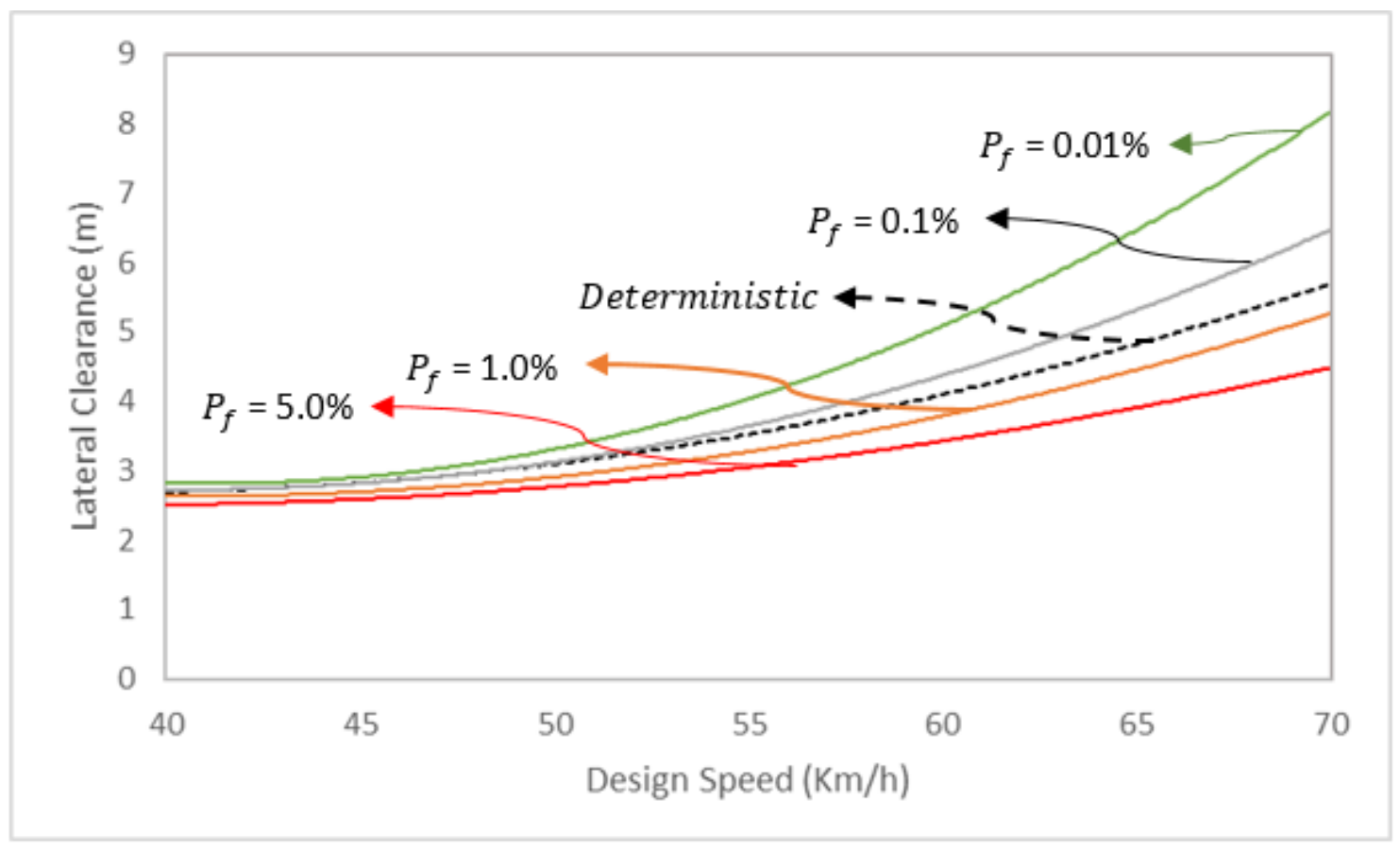

Figure 3-32 Comparison of the lateral clearance values required to satisfy the deterministic and probabilistic SSD for the approaches of roundabouts 


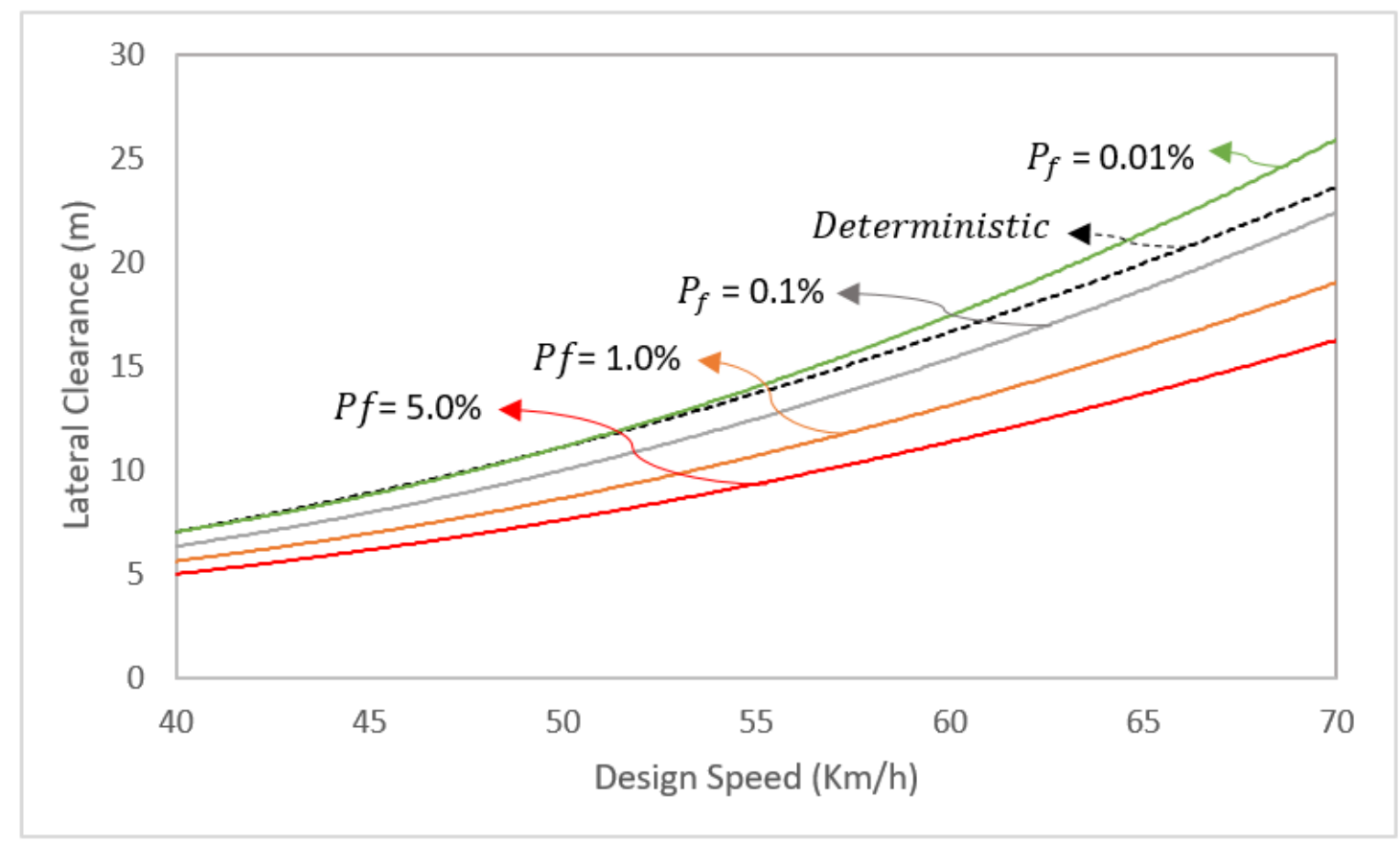

Figure 3-33 Comparison of the lateral clearance values required to satisfy the deterministic and probabilistic DSD for the approaches of urban roundabouts

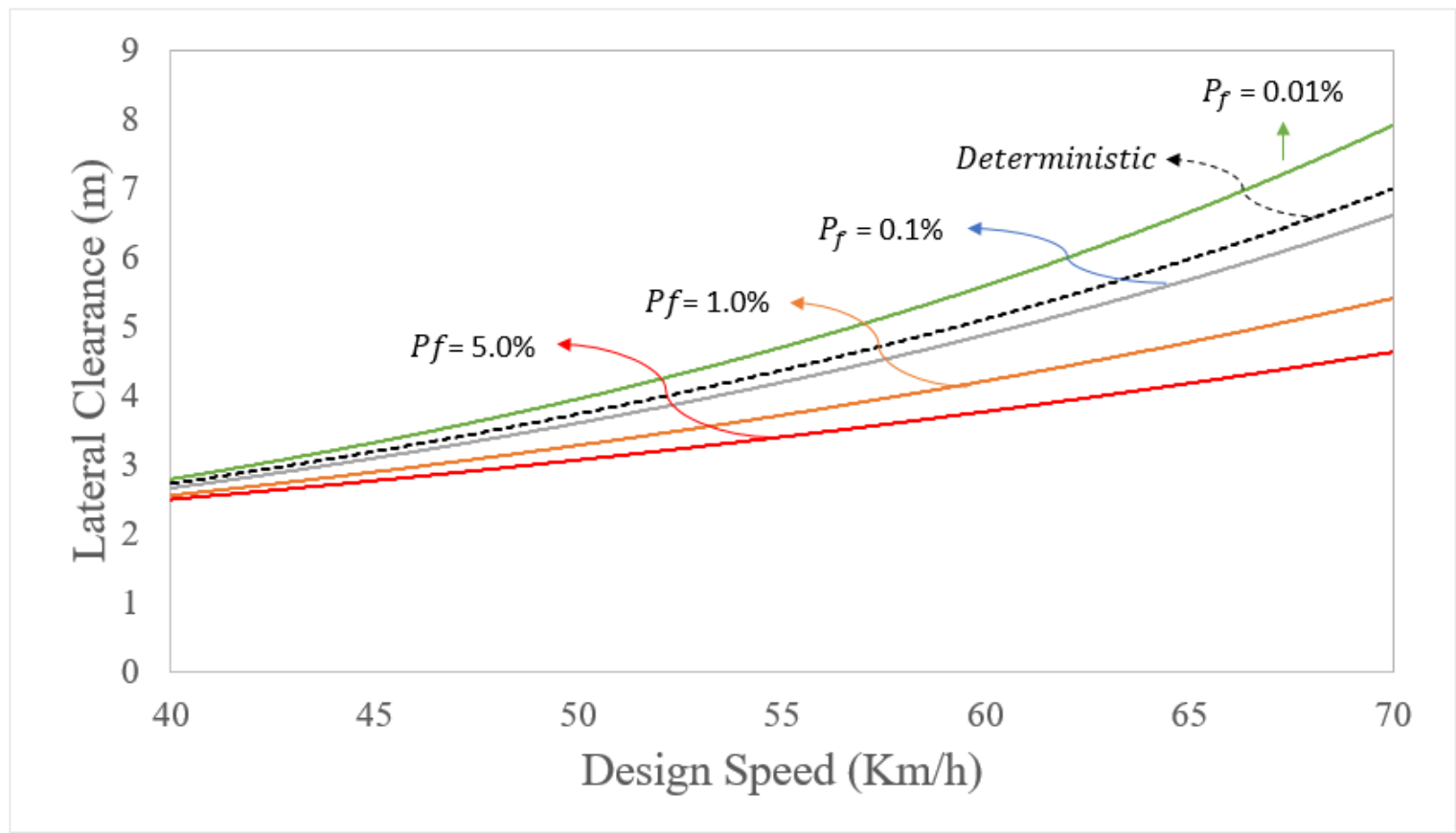

Figure 3-34 Comparison of the lateral clearances values required to satisfy the deterministic and probabilistic DSD of the approaches of rural roundabouts 


\subsection{Sensitivity Analysis}

The sensitivity analysis was carried out in order to measure the sensitivity of the reliability index, $\beta$, to the design variables. The mean values of the variables, from Table 3.4, were used as base values for the perception-reaction time and deceleration rate. Vehicle speeds of $40 \mathrm{Km} / \mathrm{h}$ and 60 $\mathrm{Km} / \mathrm{h}$, with mean values of $32 \mathrm{Km} / \mathrm{h}$ and $48 \mathrm{Km} / \mathrm{h}$, respectively, were obtained from Table 3.6. A coefficient of variation of $10 \%$, correlation coefficient of +0.5 between the vehicle speed and perception-reaction time, and correlation coefficient of -0.5 between the vehicle speed and deceleration rate were used as base values. The significance of each random variable can be seen in the sensitivity analysis.

Each design element of the random variable was increased by 15 percent, while the other random variables were kept at the base values. The changes made to the reliability index due to the $15 \%$ increase in the values of the random variables were noted. The sensitivity of the reliability index to variables for vehicle speeds of $40 \mathrm{Km} / \mathrm{h}$ and $60 \mathrm{Km} / \mathrm{h}$ are provided in Tables 3.37 and 3.38, respectively. Vehicle speed was the most sensitive variable, followed by the perception-reaction time and vehicle deceleration rate. The least sensitive element was the correlation coefficient.

Tables 3.39 and 3.40 illustrate the percentage changes in the reliability index due to the different arrangement of correlation coefficients for vehicle speeds of $40 \mathrm{Km} / \mathrm{h}$ and $60 \mathrm{Km} / \mathrm{h}$, respectively. The results indicate that the correlation coefficients of the vehicle speed and perception-reaction time have a larger effect on the reliability index compared to the correlation coefficients of the vehicle speed and vehicle deceleration rate. Since correlation coefficients impact the reliability index, correlation coefficients based on field data are recommended.

The sensitivity of the reliability index to the coefficient of variation is illustrated in Tables 3.41 and 3.42 for vehicle speeds of $40 \mathrm{Km} / \mathrm{h}$ and $60 \mathrm{Km} / \mathrm{h}$, respectively. The reliability index is most sensitive to vehicle speed and least sensitive to the vehicle deceleration rate. 
Table 3.37 Sensitivity of the reliability index to different random variables, $V=40 \mathrm{Km} / \mathrm{h}^{\text {a }}$

\begin{tabular}{cccc}
\hline $\begin{array}{c}\text { Elements of Random } \\
\text { Variables }\end{array}$ & $\begin{array}{c}\text { Base Values of } \\
\text { Random variables }\end{array}$ & $\begin{array}{c}\text { Reliability Index, } \\
\beta\end{array}$ & $\begin{array}{c}\text { Percent Change in } \beta, \\
\text { due to a 15\% Increase } \\
\text { in the Elements }\end{array}$ \\
\hline$\mu_{V}$ & 32 & 2.10 & -43.6 \\
$\mu_{t}$ & 2.15 & 2.89 & -22.5 \\
$\mu_{a}$ & 4.07 & 4.17 & +12.1 \\
$\rho_{\mathrm{x}_{1} \mathrm{x}_{2}}$ & +0.5 & 3.64 & -2.1 \\
$\rho_{\mathrm{x}_{1} \mathrm{x}_{3}}$ & -0.5 & 3.71 & -0.1 \\
$\sigma_{\mathrm{V}}$ & 3.2 & 3.36 & -9.7 \\
$\sigma_{\mathrm{t}}$ & 0.215 & 3.57 & -4.1 \\
$\sigma_{\mathrm{a}}$ & 0.407 & 3.71 & -0.1 \\
\hline
\end{tabular}

${ }^{\text {a }}$ For the base data, $S S D_{\text {sup }}=48 \mathrm{~m}, \beta=3.72, \mathrm{CV}=10 \%$

Table 3.38 Sensitivity of the reliability index to different random variables, $\mathrm{V}=60 \mathrm{Km} / \mathrm{h}^{\text {a }}$

\begin{tabular}{cccc}
\hline $\begin{array}{c}\text { Elements of Random } \\
\text { Variables }\end{array}$ & $\begin{array}{c}\text { Base Values of } \\
\text { Random variables }\end{array}$ & $\begin{array}{c}\text { Reliability Index, } \\
\beta\end{array}$ & $\begin{array}{c}\text { Percent Change in } \beta, \\
\text { due to a 15\% Increase } \\
\text { in the Elements }\end{array}$ \\
\hline$\mu_{V}$ & 32 & 2.10 & -43.6 \\
$\mu_{t}$ & 2.15 & 2.89 & -22.5 \\
$\mu_{a}$ & 4.07 & 4.17 & +12.1 \\
$\rho_{\mathrm{x}_{1} \mathrm{x}_{2}}$ & +0.5 & 3.64 & -2.1 \\
$\rho_{\mathrm{x}_{1} \mathrm{x}_{3}}$ & -0.5 & 3.71 & -0.1 \\
$\sigma_{\mathrm{V}}$ & 3.2 & 3.36 & -9.7 \\
$\sigma_{\mathrm{t}}$ & 0.215 & 3.57 & -4.1 \\
$\sigma_{\mathrm{a}}$ & 0.407 & 3.71 & -0.1 \\
\hline
\end{tabular}

${ }^{\text {a }}$ For the base data, $S S D_{\text {sup }}=84.6 \mathrm{~m}, \beta=3.72, \mathrm{CV}=10 \%$ 
Table 3.39 Sensitivity of the reliability index to the correlation coefficient of variables, $\mathrm{V}=40 \mathrm{Km} / \mathrm{h}^{\mathrm{a}}$

\begin{tabular}{cccc}
\hline$\rho_{X_{1} X_{2}}$ & $\rho_{X_{1} X_{3}}$ & $\begin{array}{c}\text { Reliability Index, } \\
\beta\end{array}$ & $\begin{array}{c}\text { Percent Change in } \\
\beta, \text { due to changes in } \\
\text { the correlation } \\
\text { coefficient }\end{array}$ \\
\hline 0.0 & -0.5 & 4.39 & 18.10 \\
1.0 & -0.5 & 3.28 & -11.71 \\
0.5 & -1.0 & 3.71 & -0.22 \\
0.5 & 0.0 & 3.73 & 0.23 \\
0.0 & 0.0 & 4.41 & 18.46 \\
\hline
\end{tabular}

${ }^{\text {a }}$ For the base data, $S S D_{\text {sup }}=48 \mathrm{~m}, \beta=3.72, \mathrm{CV}=10 \%, \rho_{X_{1} X_{2}}=+0.5, \rho_{X_{1} X_{2}}=-0.5$

Table 3.40 Sensitivity of the reliability index to the correlation coefficient of variables, $\mathrm{V}=60 \mathrm{Km} / \mathrm{h}^{\mathrm{a}}$

\begin{tabular}{cccc}
\hline$\rho_{X_{1} X_{2}}$ & $\rho_{X_{1} X_{3}}$ & $\begin{array}{c}\text { Reliability Index, } \\
\beta\end{array}$ & $\begin{array}{c}\text { Percent Change in } \\
\beta, \text { due to changes in } \\
\text { the correlation } \\
\text { coefficient }\end{array}$ \\
\hline 0.0 & -0.5 & 4.31 & 15.72 \\
1.0 & -0.5 & 3.32 & -10.67 \\
0.5 & -1.0 & 3.71 & -0.21 \\
0.5 & 0.0 & 3.73 & 0.21 \\
0.0 & 0.0 & 4.32 & 16.04 \\
\hline
\end{tabular}

${ }^{a}$ For bas data, $S S D_{\text {sup }}=84.6 m, \beta=3.72, \mathrm{CV}=10 \%, \rho_{X_{1} X_{2}}=+0.5, \rho_{X_{1} X_{2}}=-0.5$

Table 3.41 Sensitivity of $\beta$ to the coefficient of variation of variables, $V=40 \mathrm{Km} / \mathrm{h}^{\text {a }}$

\begin{tabular}{cccc}
\hline \multirow{2}{*}{ Variable } & \multicolumn{3}{c}{ Reliability Index $(\beta)$} \\
\cline { 2 - 4 } & $\mathrm{CV}=10 \%$ & $\mathrm{CV}=15 \%$ & Percent Change in $\beta$ \\
\hline $\mathrm{V}$ & 3.72 & 2.72 & -26.67 \\
$\mathrm{t}$ & 3.72 & 3.24 & -12.83 \\
$\mathrm{a}$ & 3.72 & 3.71 & -0.12 \\
\hline
\end{tabular}

${ }^{\text {a }}$ For base data, $S S D_{\text {sup }}=84.6 m, \rho_{X_{1} X_{2}}=+0.5, \rho_{X_{1} X_{2}}=-0.5$ 
Table 3.42 Sensitivity of $\beta$ to the coefficient of variation of variables, $V=60 \mathrm{Km} / \mathrm{h}^{\text {a }}$

\begin{tabular}{cccc}
\hline \multirow{2}{*}{ Variable } & \multicolumn{3}{c}{ Reliability Index $(\beta)$} \\
\cline { 2 - 4 } & $\mathrm{CV}=10 \%$ & $\mathrm{CV}=15 \%$ & Percent Change in $\beta$ \\
\hline $\mathrm{V}$ & 3.72 & 2.68 & -28.06 \\
$\mathrm{t}$ & 3.72 & 3.33 & -10.60 \\
$\mathrm{a}$ & 3.72 & 3.71 & -0.11 \\
\hline
\end{tabular}

${ }^{\text {a }}$ For base data, $S S D_{\text {sup }}=84.6 m, \rho_{X_{1} X_{2}}=+0.5, \rho_{X_{1} X_{2}}=-0.5$ 


\section{CHAPTER 4: APPLICATION}

This chapter shows the application of the reliability method for the calculation of the stopping and decision sight distances. The adequacy of the stopping and decision sight distance requirements is examined. The lateral clearance design values used to satisfy SSD were obtained at the approaches, exits, and circulatory lane of roundabouts. The lateral clearance design values used to satisfy DSD at the approaches of roundabouts were determined for urban and rural roundabouts.

\subsection{Geometry of the Roundabout}

The application involved the use of a symmetrical single-lane roundabout with two entry curves, curved in the same direction. The radius of the first entry curve was larger than the radius of the second entry curve. The roundabout considered for the application example has the following geometric elements dimensions:

$>$ Radius of the first entry curve $R_{1}=300 \mathrm{~m}$

$>$ Radius of the second entry curve (Exit curve radius) $R_{2}=40 \mathrm{~m}$

$>$ Radius of the inscribed circle, $R_{n}$, calculated using Equation (3.42)

$>$ Lane width for the approaches, circulatory lane, and exits $w_{1}=6 \mathrm{~m}$

$>$ Crosswalk width $w_{c}=3 \mathrm{~m}$

$>$ Distance from the driver's eye to the right curb $\mathrm{A}=1.77 \mathrm{~m}$

$>$ Distance from the driver's eye to the front of the vehicle, $d_{e}=2.4 \mathrm{~m}$

$>$ Distance from the near edge of the crosswalk to the inscribed circle $L_{\text {min }}=6 \mathrm{~m}$

$>$ Distance from the near edge of the crosswalk to the yield line, $\mathrm{D}=7 \mathrm{~m}$

\subsection{Probabilistic Sight Distance Calculation}

A coefficient of variation of $10 \%$ was assumed for all random variables. The mean values for the perception-reaction time, vehicle deceleration rate, pre-maneuver time, and design speed provided in Tables 3.4, 3.5, and 3.6, respectively, were used for the analysis. A correlation coefficient of +0.5 was assumed between the vehicle speed and perception-reaction time and -0.5 between the vehicle speed and vehicle deceleration rate. A design speed of $40 \mathrm{Km} / \mathrm{h}$ was used for the approaches and $20 \mathrm{Km} / \mathrm{h}$ for the circulatory lane and exits. Equation (2.12) was used to calculate 
the standard deviations of the variables. Table 4.1 shows the data used for the calculation of SSD and DSD using the FOSM and AFOSM methods.

Table 4.1 Data used for the probabilistic SSD and DSD design ${ }^{\text {a }}$

\begin{tabular}{ccccc}
\hline Variables & Extreme Value & Mean Value & $\begin{array}{c}\text { Coefficient of } \\
\text { Variation }(\%)\end{array}$ & $\begin{array}{c}\text { Standard } \\
\text { Deviation }\end{array}$ \\
\hline $\begin{array}{c}V_{1}(\mathrm{Km} / \mathrm{h}) \\
V_{2}(\mathrm{Km} / \mathrm{h})\end{array}$ & 40 & 32.0 & 10 & 3.200 \\
$\begin{array}{c}\text { Perception-reaction } \\
\text { time }(\mathrm{s})\end{array}$ & 20 & 16.0 & 10 & 1.6 \\
$\begin{array}{c}\text { Pre-maneuver time } \\
\text { at urban roundabouts }(\mathrm{s})\end{array}$ & 2.5 & 2.15 & 10 & 0.215 \\
$\begin{array}{c}\text { Pre-maneuver time } \\
\text { at rural roundabouts }(\mathrm{s})\end{array}$ & 3.0 & 7.81 & 10 & 0.781 \\
a $\left(\mathrm{m} / \mathrm{s}^{2}\right)$ & 3.4 & 2.57 & 10 & 0.257 \\
\hline$\rho_{\mathrm{x}_{1} \mathrm{x}_{3}}=-0.5$ & & 4.07 & 10 & 0.407
\end{tabular}

SSD and DSD were calculated for a probability of noncompliance of $0.01 \%$. A reliability index of 3.72 corresponding to a probability of noncompliance of $0.01 \%$ (found in Table 3.1) was used for the analysis.

\subsubsection{First-Order Second-Moment (FOSM) Method}

SSD was first calculated for the vehicle speed of $40 \mathrm{Km} / \mathrm{h}$ using the FOSM reliability method. $\mathrm{E}\left[S S D_{r e q}\right]$ and $\sigma_{\mathrm{H}}$ were 28.94 and 5.12 using Equations (3.3) and (3.7), respectively (note that $\sigma_{\mathrm{H}}=\sqrt{\operatorname{Var}[\mathrm{H}]}$ ). Using Equation (3.12), the required (supplied) SSD was 48.0 meters.

For the vehicle speed of $20 \mathrm{Km} / \mathrm{h}, \mathrm{E}\left[S S D_{\text {req }}\right]$ and $\sigma_{\mathrm{H}}$ were 12.02 and 2.10 , respectively. Using Equation (3.12), the required (supplied) SSD was 19.8 meters.

For DSD on the approaches of urban roundabouts, $\mathrm{E}\left[D S D_{\text {req }}\right]$ and $\sigma_{\mathrm{H}}$ were 79.3 and 13.8 using Equations (3.3) and (3.7), respectively (note that $\sigma_{\mathrm{H}}=\sqrt{\operatorname{Var}[\mathrm{H}]}$ ). Using Equation (3.12), the required (supplied) DSD was 130 meters. 
For DSD on the approaches of rural roundabouts, $\mathrm{E}\left[D S D_{r e q}\right]$ and $\sigma_{\mathrm{H}}$ were 32.7 and 5.7 using Equations (3.3) and (3.7), respectively (note that $\sigma_{\mathrm{H}}=\sqrt{\operatorname{Var}[\mathrm{H}]}$ ). Using Equation (3.12), the required (supplied) DSD was 54 meters.

\subsubsection{Advanced First-Order Second-Moment (AFOSM) Method}

In this section, SSD and DSD were calculated using the AFOSM reliability method for a system probability of failure of $0.01 \%$. Since the variables are correlated with each other, the procedure described in section 3.1.2 was used to transform the correlated variables into uncorrelated variables. The iterative algorithm was then applied.

First, SSD was calculated for a vehicle speed of $40 \mathrm{Km} / \mathrm{h}$. The required SSD, $S S D_{\text {req }}$, obtained by trial, was $50 \mathrm{~m}$. The iterations for SSD corresponding to a vehicle speed of $40 \mathrm{Km} / \mathrm{h}$ are presented in Table 4.2. Table 4.3 shows the calculated design parameters corresponding to the final iteration.

Table 4.2 Iterations for the reliability index, $\beta_{\mathrm{z}}$, of the SSD components for $S S D_{\text {req }}=50 \mathrm{~m}$

\begin{tabular}{cccc}
\hline Iteration No & $\beta_{\mathrm{z}}$ & $\mathrm{Z}$ & $\sigma_{\mathrm{H}}$ \\
\hline 1 & 0.00 & 21.07 & 5.55 \\
2 & 3.8 & -0.89 & 8.57 \\
3 & 3.7 & 0.08 & 8.75 \\
4 & 3.71 & 0.07 & 8.80 \\
5 & 3.72 & 0.00 & 8.83 \\
\hline
\end{tabular}

Table 4.3 Design parameters related to the final iteration of the approach $\mathrm{SSD}, S S D_{\text {req }}=50 \mathrm{~m}$

\begin{tabular}{ccc}
\hline Variables & $y_{i}^{*}$ & $X_{i}^{*}$ \\
\hline $\mathrm{V}$ & 0.97 & 43.23 \\
$\mathrm{t}$ & 0.71 & 2.18 \\
$\mathrm{a}$ & -3.52 & 3.06 \\
\hline
\end{tabular}

The SSD was then calculated for a vehicle speed of $20 \mathrm{Km} / \mathrm{h}$. The required SSD, $S S D_{\text {req }}$, obtained by trial, was $19.6 \mathrm{~m}$. The iterations for SSD corresponding to a vehicle speed of $20 \mathrm{Km} / \mathrm{h}$ are presented in Table 4.4. Table 4.5 shows the design elements corresponding to the final iteration. 
Table 4.4 Iterations for the reliability index, $\beta_{\mathrm{z}}$, of the SSD components for $S S D_{\text {req }}=19.6 \mathrm{~m}$

\begin{tabular}{cccc}
\hline Iteration No & $\beta_{\mathrm{z}}$ & $\mathrm{Z}$ & $\sigma_{\mathrm{H}}$ \\
\hline 1 & 0.00 & 7.60 & 2.19 \\
2 & 3.47 & 0.36 & 2.96 \\
3 & 3.59 & 0.22 & 3.01 \\
4 & 3.67 & 0.08 & 3.04 \\
5 & 3.72 & 0.00 & 3.05 \\
\hline
\end{tabular}

Table 4.5 Design parameters related to the final iteration for the circulatory and exit SSD,

\begin{tabular}{ccc}
\multicolumn{3}{c}{$S S D_{\text {req }}=19.6 \mathrm{~m}$} \\
\hline Variables & $y_{i}^{*}$ & $X_{i}^{*}$ \\
\hline $\mathrm{V}$ & 1.27 & 21.53 \\
$\mathrm{~T}$ & 0.033 & 2.35 \\
$\mathrm{a}$ & -3.48 & 3.27 \\
\hline
\end{tabular}

DSD was calculated for urban and rural roundabouts. The required DSD for urban roundabouts, $D S D_{\text {req }}$, obtained by trial, was $119 \mathrm{~m}$. The iterations for DSD corresponding to a vehicle speed of $40 \mathrm{Km} / \mathrm{h}$ are presented in Table 4.6. Table 4.7 shows the calculated design parameters corresponding to the final iteration.

Table 4.6 Iterations for the reliability index, $\beta_{z}$, of the DSD of urban roundabout components for $D S D_{\text {req }}=119 \mathrm{~m}$

\begin{tabular}{cccc}
\hline Iteration No & $\beta_{\mathrm{z}}$ & $\mathrm{Z}$ & $\sigma_{\mathrm{H}}$ \\
\hline 1 & 0.00 & 39.21 & 14.13 \\
2 & 2.77 & 10.98 & 16.89 \\
3 & 3.42 & 3.60 & 17.63 \\
4 & 3.63 & 1.15 & 17.90 \\
5 & 3.70 & 0.36 & 17.90 \\
6 & 3.72 & 0.00 & 18.0 \\
\hline
\end{tabular}


Table 4.7 Design parameters related to the final iteration for DSD at urban roundabouts, $D S D_{\text {req }}=119 \mathrm{~m}$

\begin{tabular}{ccc}
\hline Variables & $y_{i}^{*}$ & $X_{i}^{*}$ \\
\hline $\mathrm{V}$ & -0.56 & 42.8 \\
$\mathrm{t}$ & 1.38 & 8.20 \\
$\mathrm{a}$ & -3.41 & 3.42 \\
\hline
\end{tabular}

The required DSD for rural roundabouts, $D S D_{\text {req }}$, obtained by trial, was $55 \mathrm{~m}$. The iterations for DSD corresponding to a vehicle speed of $40 \mathrm{Km} / \mathrm{h}$ are presented in Table 4.8 . Table 4.9 shows the calculated design parameters corresponding to the final iteration.

Table 4.8 Iterations for the reliability index, $\beta_{z}$, of the DSD of rural roundabout components for $D S D_{\text {req }}=55 \mathrm{~m}$

\begin{tabular}{cccc}
\hline Iteration No & $\beta_{\mathrm{z}}$ & $\mathrm{Z}$ & $\sigma_{\mathrm{H}}$ \\
\hline 1 & 0.00 & 22.83 & 6.19 \\
2 & 3.69 & -0.30 & 9.14 \\
3 & 3.66 & 0.33 & 9.33 \\
4 & 3.70 & 0.16 & 9.41 \\
5 & 3.71 & 0.06 & 9.44 \\
6 & 3.72 & -0.00 & 9.45 \\
\hline
\end{tabular}

Table 4.9 Design parameters related to the final iteration for DSD at urban roundabouts $D S D_{\text {req }}=55 \mathrm{~m}$

\begin{tabular}{ccc}
\hline Variables & $y_{i}^{*}$ & $X_{i}^{*}$ \\
\hline $\mathrm{V}$ & 1.09 & 43.25 \\
$\mathrm{t}$ & 0.48 & 2.67 \\
$\mathrm{a}$ & -3.52 & 3.52 \\
\hline
\end{tabular}

Since the AFOSM method provides larger and more accurate SSD and DSD design values compared to the FOSM method, the SSD and DSD design values obtained using the AFOSM method were used for the calculation of the lateral clearances. 


\subsection{Lateral Clearance Requirements}

The lateral clearance requirements were calculated using the AFOSM SSD and the geometry of the roundabout. The lateral clearance used to satisfy the AFOSM DSD was calculated for urban and rural roundabouts.

The lateral clearance values for the roundabout approaches obtained to satisfy the probabilistic SSD, $50 m$, were $2.8 m$ to the crosswalk and $1.2 m$ to the yield line. Since the maximum lateral clearance to the crosswalk provides a higher value compared to the yield line, a lateral clearance value of $2.8 \mathrm{~m}$ should be implemented for the entire length of the $\operatorname{SSD}\left(S S D_{\text {req }}=50 \mathrm{~m}\right)$.

The maximum lateral clearance used to satisfy SSD for the circulatory lane of the roundabout was $1.6 \mathrm{~m}$ and the driver's peripheral angle was 0.56 radians (32 degrees). A lateral clearance of $1.6 \mathrm{~m}$ should therefore be provided for the entire length of the circulatory lane. The peripheral angle requirement was adequate for the existing geometry of the roundabout and the required SSD design value.

The maximum lateral clearance used to satisfy SSD for the exits was $2.5 \mathrm{~m}$. The difference between the typical location of the near edge of the pedestrian crosswalk $(6 \mathrm{~m}$ away from the inscribed circle) and the location of the near edge of the crosswalk required based on SSD was $5.21 \mathrm{~m}$. Based on the geometry of the roundabout and the required SSD, the typical location of the pedestrian crosswalk is adequate.

The lateral clearance required to satisfy DSD for the approaches of urban roundabouts to the pedestrian crosswalk and yield line were $7 \mathrm{~m}$ and $5.8 \mathrm{~m}$, respectively. The lateral clearance required to satisfy DSD for the approaches of rural roundabouts to the pedestrian crosswalk and yield line were 2.9 and $1.3 \mathrm{~m}$, respectively.

\subsection{Results and Discussion}

Table 4.10 presents the results for the design elements calculated using the deterministic and probabilistic (AFOSM) methods for roundabout approaches. For a vehicle speed of $40 \mathrm{Km} / \mathrm{h}$, the SSD design value of the deterministic design method was 7.5\% lower than the SSD design value of the probabilistic method. The lateral clearance design values for roundabout approaches 
calculated using the AFOSM reliability method were 3.6\% larger than the lateral clearance design values obtained using the deterministic method. Table 4.11 presents the results for the design elements calculated using the deterministic and reliability-based methods for the circulatory lane and exits of roundabouts. For a vehicle speed of $20 \mathrm{Km} / \mathrm{h}$, the SSD design value obtained using the reliability-based method was 5.6 percent higher than the SSD design value obtained using the deterministic method. The lateral clearance design values for the circulatory lane and exits of roundabouts calculated using the AFOSM reliability method were $8 \%$ larger than the lateral clearance values obtained using the deterministic method.

Tables 4.12 and 4.13 present the design elements of urban and rural roundabouts, respectively, for DSD calculated using the deterministic and probabilistic design methods. It can be concluded that the DSD values with a probability of failure of $0.01 \%$ provide slightly larger lateral clearance values compared to the deterministic DSD values. It can also be concluded that the difference between the DSD design values of the deterministic and probabilistic methods is lower for low vehicle speeds and vice versa.

Table 4.10 Comparison of the results of the design elements of approaches based on SSD

\begin{tabular}{cccc}
\hline $\begin{array}{c}\text { Design } \\
\text { Methods }\end{array}$ & $\begin{array}{c}\text { Stopping } \\
\text { Sight Distance } \\
(\mathrm{m})\end{array}$ & $\begin{array}{c}\text { Maximum Lateral } \\
\text { Clearance }(\mathrm{m}) \\
\text { (SSD to crosswalk) }\end{array}$ & $\begin{array}{c}\text { Maximum Lateral } \\
\text { Clearance (m) } \\
\text { (SSD to yield line) }\end{array}$ \\
\hline Deterministic & 46.2 & 2.7 & 0.9 \\
\hline Probabilistic (AFOSM) & 49.9 & 2.8 & 1.2 \\
\hline
\end{tabular}

Table 4.11 Comparison of the results of the design elements of the exits and circulatory lane based on SSD

\begin{tabular}{cccc}
\hline $\begin{array}{c}\text { Design } \\
\text { Methods }\end{array}$ & $\begin{array}{c}\text { Stopping } \\
\text { Sight Distance } \\
(\mathrm{m})\end{array}$ & $\begin{array}{c}\text { Maximum Lateral } \\
\text { Clearance }(\mathrm{m}) \\
\text { (SSD to crosswalk) }\end{array}$ & $\begin{array}{c}\text { Maximum Lateral } \\
\text { Clearance }(\mathrm{m}) \\
\text { (SSD to yield line) }\end{array}$ \\
\hline Deterministic & 18.5 & 2.3 & 1.4 \\
\hline Probabilistic (AFOSM) & 19.6 & 2.5 & 1.5 \\
\hline
\end{tabular}


Table 4.12 Comparison of the results of the design elements of urban roundabouts based on DSD

\begin{tabular}{cccc}
\hline $\begin{array}{c}\text { Design } \\
\text { Methods }\end{array}$ & $\begin{array}{c}\text { Decision } \\
\text { Sight Distance } \\
(\mathrm{m})\end{array}$ & $\begin{array}{c}\text { Maximum Lateral } \\
\text { Clearance }(\mathrm{m}) \\
\text { (DSD to crosswalk) }\end{array}$ & $\begin{array}{c}\text { Maximum Lateral } \\
\text { Clearance }(\mathrm{m}) \\
\text { (DSD to yield line) }\end{array}$ \\
\hline Deterministic & 119.0 & 7.0 & 5.8 \\
\hline Probabilistic (AFOSM) & 119.0 & 7.0 & 5.8 \\
\hline
\end{tabular}

Table 4.13 Comparison of the results of the design elements of rural roundabouts based on DSD

\begin{tabular}{cccc}
\hline $\begin{array}{c}\text { Design } \\
\text { Methods }\end{array}$ & $\begin{array}{c}\text { Decision } \\
\text { Sight Distance } \\
(\mathrm{m})\end{array}$ & $\begin{array}{c}\text { Maximum Lateral } \\
\text { Clearance }(\mathrm{m}) \\
\text { (DSD to crosswalk) }\end{array}$ & $\begin{array}{c}\text { Maximum Lateral } \\
\text { Clearance }(\mathrm{m}) \\
\text { (DSD to yield line) }\end{array}$ \\
\hline Deterministic & 51.7 & 2.8 & 1.2 \\
\hline Probabilistic (AFOSM) & 55.0 & 2.9 & 1.3 \\
\hline
\end{tabular}




\section{CHAPTER 5: CONCLUSIONS AND RECOMMENDATIONS}

\subsection{Conclusions}

The current method of calculating the stopping and decision sight distance design values for roundabouts is deterministic (all of the design variables are predetermined, fixed values). Since, in reality, all design variables are random variables and some are correlated with one another, there is a need to calculate stopping and decision sight distance values based on the randomness of the design variables. The safety of roundabouts is highly impacted by the adequacy of sight distances. The objective of this study was to develop a probabilistic method for the design of stopping and decision sight distance at roundabouts based on the desired probability of noncompliance. The SSD requirements of the approaches, circulatory lane, and exits of roundabouts were examined. DSD was only considered for the entries of roundabouts and design values were developed. Most researchers use the FOSM reliability method because of its simple mathematics. This study calculated SSD and DSD using both the FOSM and AFOSM reliability methods. The following conclusions were drawn from the results:

$>$ The results of this study revealed that the FOSM and AFOSM reliability methods produce nearly equal SSD and DSD values for lower vehicle speeds for the same probability of noncompliance. For higher vehicle speeds, the AFOSM reliability method yields larger SSD design values than the FOSM reliability method.

$>$ The model developed for the calculation of SSD and DSD using the FOSM reliability method can be easily applied since it uses simple mathematics. On the other hand, the AFOSM reliability method yields more precise results and removes errors associated with the FOSM reliability method, but it is an iterative process which is time-consuming.

$>$ A high level of reliability requires large SSD and DSD values and vice versa. The literature suggests that the probability of noncompliance for facilities is chosen based on the level of importance of the facility. One of the major benefits of the probabilistic design method is that it provides designers with insight into the reliability of their design. The existing SSD and DSD design values calculated using the deterministic (AASHTO) method seem to have a very low probability of failure. 
The stopping and decision sight distance design values were tabulated with respect to vehicle speed and different probabilities of noncompliance. These design values can be used to verify the adequacy of the roundabout sight distance requirements.

Design aids were developed for the lateral clearance requirements to satisfy SSD for the approaches, circulatory lane, and exits of roundabouts. For the approaches, the lateral clearance was calculated to satisfy SSD to the pedestrian crosswalk and the yield line. For the circulatory lane SSD, the peripheral angle was also checked for adequacy based on the recommended peripheral angle value provided in the design manuals. The results indicate that the peripheral angle is out of range for a small central island radius and higher vehicle speed. For the exit SSD, the location of the typical crosswalk, 6 meters away from the inscribed circle, was compared with the location of the crosswalk needed to satisfy the required stopping sight distance. The results indicate that a small entry radius and high vehicle entry speed affect the location of the pedestrian crosswalk. On the exits of roundabouts, the pedestrian crosswalk can be moved up to 20 meters away from the inscribed circle, as recommend in the design manuals. The other option would be to reduce the vehicle design speed at the exits in order to satisfy the SSD requirements.

Design aids were developed for the lateral clearance requirements of the approaches of urban and rural roundabouts in order to satisfy DSD. The largest of the lateral clearance design values obtained to satisfy DSD to the crosswalk and the yield line should be used for the entire length of the entry curves.

The lateral clearance values required to satisfy DSD for the approaches of urban roundabouts are significantly larger than the lateral clearance values required to satisfy SSD. On the other hand, the lateral clearance values required to satisfy DSD for the approaches of rural roundabouts are slightly larger than the lateral clearance values required to satisfy SSD. 


\subsection{Recommendations}

The following recommendations are offered based on the results of this study:

The probability methods developed in this study would enable designers to select SSD and DSD design values based on their desired probability of noncompliance. The SSD and DSD design values tabulated in this study can also be applied to the design of horizontal curves at other segments of the highway. These reliability models should be applied to the design of SSD and DSD for design speeds out of the range of the tabulated design values.

Design aids were developed for the lateral clearance requirements of the approaches, circulatory lane, and exits of roundabouts with different geometry and design speed combinations. In order to obtain the lateral clearance design values for roundabout geometry and vehicle speed combinations not included in the design aids, it is recommended that the AFOSM SSD and DSD design values and that the lateral clearances be calculated based on the analytical relationships.

One of the major limitations of this study is the unavailability of the variability of the design variables (design speed, perception-reaction time, vehicle deceleration rate, and premaneuver time, for urban and rural roundabouts). It is recommended that this information be gathered in future studies.

The design aids for the lateral clearance requirements of roundabouts are only applicable to the design of single-lane roundabouts. When an analytical model is developed for multilane roundabouts, the probabilistic SSD and DSD design values should be used to calculate lateral clearances.

$>$ Future research should involve the design of intersection sight distance at roundabouts using the reliability-based design method and the preparation of design aids for lateral clearance.

Future research should also involve the safety effects of speed bumps at the approaches of roundabouts. 


\section{APPENDIX A}

DESIGN AIDS FOR LATERAL CLEARANCE REQUIREMENTS, CV = 5\% 
Table A3.1 Design values of lateral clearance on the approaches (SSD to the crosswalk), $P_{f}=0.01 \%, \mathrm{CV}=5 \%$

\begin{tabular}{|c|c|c|c|c|c|}
\hline \multirow{5}{*}{$\begin{array}{c}\text { First Entry } \\
\text { Curve Radius } \\
R_{1}(\mathrm{~m})\end{array}$} & \multirow{5}{*}{$\begin{array}{c}\text { Second Entry } \\
\text { Curve Radius } \\
R_{2}(\mathrm{~m})\end{array}$} & \multicolumn{4}{|c|}{ Maximum Lateral Clearance (m) } \\
\hline & & \multicolumn{4}{|c|}{ Design Speed $(\mathrm{Km} / \mathrm{h})^{a}$} \\
\hline & & 40 & 50 & 60 & 70 \\
\hline & & \multicolumn{4}{|c|}{ Stopping Sight Distance (m) } \\
\hline & & 45 & 61 & 79 & 102 \\
\hline \multirow[t]{3}{*}{100} & 20 & 4.4 & 6.3 & & \\
\hline & 30 & 4.0 & 6.0 & & \\
\hline & 40 & 3.9 & 5.9 & & \\
\hline \multirow[t]{3}{*}{300} & 20 & 3.4 & 3.8 & 4.5 & 5.8 \\
\hline & 30 & 2.9 & 3.3 & 4.1 & 5.4 \\
\hline & 40 & 2.7 & 3.1 & 3.9 & 5.3 \\
\hline \multirow[t]{3}{*}{500} & 20 & 3.2 & 3.6 & 3.8 & 4.5 \\
\hline & 30 & 2.8 & 3.1 & 3.4 & 4.1 \\
\hline & 40 & 2.5 & 2.8 & 3.1 & 3.9 \\
\hline \multirow[t]{3}{*}{1000} & 20 & 3.1 & 3.4 & 3.6 & 3.8 \\
\hline & 30 & 2.7 & 2.9 & 3.1 & 3.3 \\
\hline & 40 & 2.4 & 2.6 & 2.8 & 3.0 \\
\hline
\end{tabular}

${ }^{\text {a }}$ For shaded cells, $R_{1}$ is less than $R_{\text {min }}$ for the respective vehicle speed on the Approaches and superelevation of up to 0.06 .

Table A3.2 Design values of lateral clearance on the approaches (SSD to the yield line),

$$
P_{f}=0.01 \%, \mathrm{CV}=5 \%
$$

\begin{tabular}{|c|c|c|c|c|c|}
\hline \multirow{5}{*}{$\begin{array}{c}\text { First Entry } \\
\text { Curve Radius } \\
R_{1}(\mathrm{~m})\end{array}$} & \multirow{5}{*}{$\begin{array}{c}\text { Second Entry } \\
\text { Curve Radius } \\
R_{2}(\mathrm{~m})\end{array}$} & \multicolumn{4}{|c|}{ Maximum Lateral Clearance (m) } \\
\hline & & \multicolumn{4}{|c|}{ Design Speed $(\mathrm{Km} / \mathrm{h})^{a}$} \\
\hline & & 40 & 50 & 60 & 70 \\
\hline & & \multicolumn{4}{|c|}{ Design Stopping Sight Distance (m) } \\
\hline & & 45 & 61 & 79 & 102 \\
\hline \multirow[t]{3}{*}{100} & 20 & 4.1 & 5.9 & & \\
\hline & 30 & 2.7 & 4.8 & & \\
\hline & 40 & 2.1 & 4.2 & & \\
\hline \multirow[t]{3}{*}{300} & 20 & 3.1 & 4.0 & 4.7 & 6.2 \\
\hline & 30 & 1.7 & 2.4 & 3.3 & 4.9 \\
\hline & 40 & 1.0 & 1.6 & 2.6 & 4.3 \\
\hline \multirow[t]{3}{*}{500} & 20 & 2.9 & 3.6 & 4.3 & 4.8 \\
\hline & 30 & 1.6 & 2.0 & 2.5 & 3.4 \\
\hline & 40 & 0.8 & 1.2 & 1.7 & 2.7 \\
\hline \multirow[t]{3}{*}{1000} & 20 & 2.8 & 3.3 & 3.8 & 4.2 \\
\hline & 30 & 1.4 & 1.7 & 2.1 & 2.4 \\
\hline & 40 & 0.6 & 1.0 & 1.2 & 1.6 \\
\hline
\end{tabular}

${ }^{\text {a }}$ For shaded cells, $R_{1}$ is less than $R_{\min }$ for the respective vehicle speed on the Approaches and superelevation of up to 0.06 . 
Table A3.3 Design values of lateral clearance on the approaches (SSD to the crosswalk), $P_{f}=0.1 \%, \mathrm{CV}=5 \%$

\begin{tabular}{|c|c|c|c|c|c|}
\hline \multirow{5}{*}{$\begin{array}{c}\text { First Entry } \\
\text { Curve Radius } \\
R_{1}(\mathrm{~m})\end{array}$} & \multirow{5}{*}{$\begin{array}{c}\text { Second Entry } \\
\text { Curve Radius } \\
R_{2}(\mathrm{~m})\end{array}$} & \multicolumn{4}{|c|}{ Maximum Lateral Clearance (m) } \\
\hline & & \multicolumn{4}{|c|}{ Design Speed $(\mathrm{Km} / \mathrm{h})^{a}$} \\
\hline & & 40 & 50 & 60 & 70 \\
\hline & & \multicolumn{4}{|c|}{ Stopping Sight Distance (m) } \\
\hline & & 36 & 50 & 67 & 89 \\
\hline \multirow[t]{3}{*}{100} & 20 & 3.7 & 4.9 & & \\
\hline & 30 & 3.3 & 4.5 & & \\
\hline & 40 & 3.1 & 4.4 & & \\
\hline \multirow[t]{3}{*}{300} & 20 & 3.1 & 3.5 & 4.0 & 5.1 \\
\hline & 30 & 2.7 & 3.0 & 3.5 & 4.7 \\
\hline & 40 & 2.5 & 2.8 & 3.3 & 4.6 \\
\hline \multirow[t]{3}{*}{500} & 20 & 3.0 & 3.3 & 3.7 & 4.0 \\
\hline & 30 & 2.6 & 2.9 & 3.2 & 3.6 \\
\hline & 40 & 2.4 & 2.6 & 3.0 & 3.4 \\
\hline \multirow[t]{3}{*}{1000} & 20 & 3.0 & 3.2 & 3.5 & 3.7 \\
\hline & 30 & 2.5 & 2.7 & 3.0 & 3.2 \\
\hline & 40 & 2.3 & 2.5 & 2.7 & 2.9 \\
\hline
\end{tabular}

${ }^{a}$ For shaded cells, $R_{1}$ is less than $R_{\text {min }}$ for the respective vehicle speed on the Approaches and superelevation of up to 0.06 .

Table A3.4 Design values of lateral clearance on the approaches (SSD to the yield Line),

$$
P_{f}=0.1 \%, \mathrm{CV}=5 \%
$$

\begin{tabular}{|c|c|c|c|c|c|}
\hline \multirow{5}{*}{$\begin{array}{c}\text { First Entry } \\
\text { Curve Radius } \\
R_{1}(\mathrm{~m})\end{array}$} & \multirow{5}{*}{$\begin{array}{c}\text { Second Entry } \\
\text { Curve Radius } \\
R_{2}(\mathrm{~m})\end{array}$} & \multicolumn{4}{|c|}{ Maximum Lateral Clearance (m) } \\
\hline & & \multicolumn{4}{|c|}{ Design Speed $(\mathrm{Km} / \mathrm{h})^{a}$} \\
\hline & & 40 & 50 & 60 & 70 \\
\hline & & \multicolumn{4}{|c|}{ Stopping Sight Distance (m) } \\
\hline & & 36 & 50 & 67 & 89 \\
\hline \multirow{3}{*}{100} & 20 & 3.1 & 4.6 & & \\
\hline & 30 & 1.8 & 3.3 & & \\
\hline & 40 & 1.2 & 2.7 & & \\
\hline \multirow[t]{3}{*}{300} & 20 & 2.5 & 3.4 & 4.2 & 5.3 \\
\hline & 30 & 1.2 & 1.9 & 2.6 & 3.9 \\
\hline & 40 & 0.6 & 1.2 & 1.9 & 3.3 \\
\hline \multirow[t]{3}{*}{500} & 20 & 2.4 & 3.2 & 3.8 & 4.5 \\
\hline & 30 & 1.1 & 1.7 & 2.2 & 2.8 \\
\hline & 40 & 0.5 & 0.9 & 1.4 & 2.1 \\
\hline \multirow[t]{3}{*}{1000} & 20 & 2.3 & 3.0 & 3.5 & 4.0 \\
\hline & 30 & 1.0 & 1.5 & 1.9 & 2.3 \\
\hline & 40 & 0.4 & 0.8 & 1.1 & 1.4 \\
\hline
\end{tabular}

${ }^{\text {a }}$ For shaded cells, $R_{1}$ is less than $R_{\min }$ for the respective vehicle speed on the Approaches and superelevation of up to 0.06 . 
Table A3.5 Design values of lateral clearance on the approaches (SSD to the crosswalk),

$$
P_{f}=1.00, \mathrm{CV}=5 \%
$$

\begin{tabular}{|c|c|c|c|c|c|}
\hline \multirow{5}{*}{$\begin{array}{c}\text { First Entry } \\
\text { Curve Radius } \\
R_{1}(\mathrm{~m})\end{array}$} & \multirow{5}{*}{$\begin{array}{c}\text { Second Entry } \\
\text { Curve Radius } \\
R_{2}(\mathrm{~m})\end{array}$} & \multicolumn{4}{|c|}{ Maximum Lateral Clearance (m) } \\
\hline & & \multicolumn{4}{|c|}{ Design Speed $(\mathrm{Km} / \mathrm{h})^{a}$} \\
\hline & & 40 & 50 & 60 & 70 \\
\hline & & \multicolumn{4}{|c|}{ Stopping Sight Distance (m) } \\
\hline & & 35 & 48 & 63 & 83 \\
\hline \multirow[t]{3}{*}{100} & 20 & 3.7 & 4.7 & & \\
\hline & 30 & 3.2 & 4.3 & & \\
\hline & 40 & 3.0 & 4.2 & & \\
\hline \multirow[t]{3}{*}{300} & 20 & 3.1 & 3.5 & 3.8 & 4.7 \\
\hline & 30 & 2.6 & 3.0 & 3.4 & 4.3 \\
\hline & 40 & 2.4 & 2.8 & 3.2 & 4.1 \\
\hline \multirow[t]{3}{*}{500} & 20 & 3.0 & 3.3 & 3.6 & 3.9 \\
\hline & 30 & 2.6 & 2.9 & 3.1 & 3.5 \\
\hline & 40 & 2.4 & 2.6 & 2.8 & 3.2 \\
\hline \multirow[t]{3}{*}{1000} & 20 & 2.9 & 3.2 & 3.4 & 3.6 \\
\hline & 30 & 2.5 & 2.8 & 2.9 & 3.1 \\
\hline & 40 & 2.3 & 2.5 & 2.7 & 2.8 \\
\hline
\end{tabular}

${ }^{\text {a }}$ For shaded cells, $R_{1}$ is less than $R_{\text {min }}$ for the respective vehicle speed on the Approaches and superelevation of up to 0.06 .

Table A3.6 Design values of lateral clearance on the approaches (SSD to yield line),

$$
P_{f}=1.00 \%, \mathrm{CV}=5 \%
$$

\begin{tabular}{|c|c|c|c|c|c|}
\hline \multirow{5}{*}{$\begin{array}{c}\text { First Entry } \\
\text { Curve Radius } \\
R_{1}(\mathrm{~m})\end{array}$} & \multirow{5}{*}{$\begin{array}{c}\text { Second Entry } \\
\text { Curve Radius } \\
R_{2}(\mathrm{~m})\end{array}$} & \multicolumn{4}{|c|}{ Maximum Lateral Clearance (m) } \\
\hline & & \multicolumn{4}{|c|}{ Design Speed $(\mathrm{Km} / \mathrm{h})^{a}$} \\
\hline & & 40 & 50 & 60 & 70 \\
\hline & & \multicolumn{4}{|c|}{ Stopping Sight Distance (m) } \\
\hline & & 35 & 48 & 63 & 83 \\
\hline \multirow[t]{3}{*}{100} & 20 & 3.0 & 4.3 & & \\
\hline & 30 & 1.7 & 3.0 & & \\
\hline & 40 & 1.1 & 2.4 & & \\
\hline \multirow[t]{3}{*}{300} & 20 & 2.5 & 3.3 & 4.0 & 4.9 \\
\hline & 30 & 1.2 & 1.8 & 2.5 & 3.5 \\
\hline & 40 & 0.5 & 1.1 & 1.7 & 2.9 \\
\hline \multirow[t]{3}{*}{500} & 20 & 2.4 & 3.1 & 3.4 & 4.2 \\
\hline & 30 & 1.1 & 1.6 & 2.1 & 2.5 \\
\hline & 40 & 0.4 & 0.8 & 1.3 & 1.8 \\
\hline \multirow[t]{3}{*}{1000} & 20 & 2.3 & 2.9 & 3.4 & 3.9 \\
\hline & 30 & 1.0 & 1.4 & 1.8 & 2.2 \\
\hline & 40 & 0.3 & 0.7 & 1.0 & 1.3 \\
\hline
\end{tabular}

${ }^{\text {a }}$ For shaded cells, $R_{1}$ is less than $R_{\text {min }}$ for the respective vehicle speed on the Approaches and superelevation of up to 0.06 . 
Table A3.7 Design values of lateral clearance on the approaches (SSD to the crosswalk), $P_{f}=5.00 \%, \mathrm{CV}=5 \%$

\begin{tabular}{|c|c|c|c|c|c|}
\hline \multirow{5}{*}{$\begin{array}{c}\text { First Entry } \\
\text { Curve Radius } \\
R_{1}(\mathrm{~m})\end{array}$} & \multirow{5}{*}{$\begin{array}{c}\text { Second Entry } \\
\text { Curve Radius } \\
R_{2}(\mathrm{~m})\end{array}$} & \multicolumn{4}{|c|}{ Maximum Lateral Clearance (m) } \\
\hline & & \multicolumn{4}{|c|}{ Design Speed $(\mathrm{Km} / \mathrm{h})^{a}$} \\
\hline & & 40 & 50 & 60 & 70 \\
\hline & & \multicolumn{4}{|c|}{ Stopping Sight Distance (m) } \\
\hline & & 33 & 45 & 60 & 77 \\
\hline \multirow[t]{3}{*}{100} & 20 & 3.5 & 4.4 & & \\
\hline & 30 & 3.0 & 4.0 & & \\
\hline & 40 & 2.9 & 3.9 & & \\
\hline \multirow[t]{3}{*}{300} & 20 & 3.1 & 3.4 & 3.8 & 4.4 \\
\hline & 30 & 2.6 & 2.9 & 3.3 & 4.0 \\
\hline & 40 & 2.4 & 2.7 & 3.1 & 3.8 \\
\hline \multirow[t]{3}{*}{500} & 20 & 3.0 & 3.2 & 3.5 & 3.8 \\
\hline & 30 & 2.5 & 2.8 & 3.1 & 3.3 \\
\hline & 40 & 2.3 & 2.5 & 2.8 & 3.1 \\
\hline \multirow[t]{3}{*}{1000} & 20 & 2.9 & 3.1 & 3.4 & 3.5 \\
\hline & 30 & 2.5 & 2.7 & 2.9 & 3.0 \\
\hline & 40 & 2.3 & 2.4 & 2.6 & 2.8 \\
\hline
\end{tabular}

${ }^{\text {a }}$ For shaded cells, $R_{1}$ is less than $R_{\text {min }}$ for the respective vehicle speed on the Approaches and superelevation of up to 0.06 .

Table A3.8 Design values of lateral clearance on the approaches (SSD to yield line),

$$
P_{f}=5.00 \%, \mathrm{CV}=5 \%
$$

\begin{tabular}{|c|c|c|c|c|c|}
\hline \multirow{5}{*}{$\begin{array}{c}\text { First Entry } \\
\text { Curve Radius } \\
R_{1}(\mathrm{~m})\end{array}$} & \multirow{5}{*}{$\begin{array}{c}\text { Second Entry } \\
\text { Curve Radius } \\
R_{2}(\mathrm{~m})\end{array}$} & \multicolumn{4}{|c|}{ Maximum Lateral Clearance (m) } \\
\hline & & \multicolumn{4}{|c|}{ Design Speed $(\mathrm{Km} / \mathrm{h})^{a}$} \\
\hline & & 40 & 50 & 60 & 70 \\
\hline & & \multicolumn{4}{|c|}{ Stopping Sight Distance (m) } \\
\hline & & 33 & 45 & 60 & 77 \\
\hline \multirow[t]{3}{*}{100} & 20 & 2.7 & 4.1 & & \\
\hline & 30 & 1.5 & 2.7 & & \\
\hline & 40 & 0.9 & 2.1 & & \\
\hline \multirow[t]{3}{*}{300} & 20 & 2.3 & 3.1 & 3.9 & 4.6 \\
\hline & 30 & 1.1 & 1.7 & 2.3 & 3.1 \\
\hline & 40 & 0.4 & 1.0 & 1.6 & 2.5 \\
\hline \multirow[t]{3}{*}{500} & 20 & 2.2 & 2.9 & 3.5 & 4.1 \\
\hline & 30 & 1.0 & 1.6 & 2.0 & 2.4 \\
\hline & 40 & 0.3 & 0.8 & 1.2 & 1.6 \\
\hline \multirow[t]{3}{*}{1000} & 20 & 2.1 & 2.8 & 3.3 & 3.7 \\
\hline & 30 & 0.9 & 1.4 & 1.7 & 2.0 \\
\hline & 40 & 0.3 & 0.6 & 0.9 & 1.2 \\
\hline
\end{tabular}

${ }^{\text {a }}$ For shaded cells, $R_{1}$ is less than $R_{\text {min }}$ for the respective vehicle speed on the Approaches and superelevation of up to 0.06 . 
Table A3.9 Design values of lateral clearance on the exits, $P_{f}=0.01 \%, \mathrm{CV}=5 \%$

\begin{tabular}{|c|c|c|c|c|c|c|}
\hline \multirow{5}{*}{$\begin{array}{c}\text { Entry-Exit } \\
\text { Curve Radius } \\
\text { R (m) }\end{array}$} & \multicolumn{6}{|c|}{${ }^{\mathrm{a}}$ Design Speed $(\mathrm{km} / \mathrm{h})$} \\
\hline & \multicolumn{2}{|c|}{20} & \multicolumn{2}{|c|}{30} & \multicolumn{2}{|c|}{40} \\
\hline & \multicolumn{6}{|c|}{ Stopping Sight Distance (m) } \\
\hline & \multicolumn{2}{|c|}{16} & \multicolumn{2}{|c|}{26} & \multicolumn{2}{|c|}{38} \\
\hline & ${ }^{\mathrm{b}} \mathrm{C}$ & ${ }^{\mathrm{c}} \mathrm{D}$ & ${ }^{\mathrm{b}} \mathrm{C}$ & ${ }^{\mathrm{c}} \mathrm{D}$ & ${ }^{\mathrm{b}} \mathrm{C}$ & ${ }^{\mathrm{c}} \mathrm{D}$ \\
\hline 20 & 2.9 & 3.65 & & & & \\
\hline 30 & 2.4 & 6.43 & 4.0 & -3.57 & & \\
\hline 40 & 2.2 & 9.35 & 3.3 & -0.65 & & \\
\hline 50 & 2.1 & 12.33 & 2.8 & 2.34 & 4.7 & -9.67 \\
\hline 60 & 2.0 & 15.34 & 2.5 & 5.34 & 4.1 & -6.66 \\
\hline
\end{tabular}

${ }^{a}$ For shaded areas, radius of exit curve is less than minimum radius for the entry speed and cross slopes.

${ }^{\mathrm{b}}$ Maximum Lateral Clearance on the exits

${ }^{\mathrm{c}}$ Difference between available sight distance (length of curve on vehicle path from vehicle entry on yield line to near edge of the typical crosswalk, $6 \mathrm{~m}$ away from yield line) and location of near edge of the crosswalk to satisfy SSD.

Table A3.10 Design values of lateral clearance on the exits, $P_{f}=0.1 \%, \mathrm{CV}=5 \%$

\begin{tabular}{|c|c|c|c|c|c|c|}
\hline \multirow{5}{*}{$\begin{array}{c}\text { Entry-Exit } \\
\text { Curve Radius } \\
\text { R (m) }\end{array}$} & \multicolumn{6}{|c|}{ a Design Speed (km/h) } \\
\hline & \multicolumn{2}{|c|}{20} & \multicolumn{2}{|c|}{30} & \multicolumn{2}{|c|}{20} \\
\hline & \multicolumn{6}{|c|}{ Stopping Sight Distance (m) } \\
\hline & \multicolumn{2}{|c|}{15} & \multicolumn{2}{|c|}{25} & \multicolumn{2}{|c|}{37} \\
\hline & ${ }^{\mathrm{b}} \mathrm{C}$ & ${ }^{\mathrm{c}} \mathrm{D}$ & ${ }^{\mathrm{b}} \mathrm{C}$ & ${ }^{\mathrm{c}} \mathrm{D}$ & ${ }^{\mathrm{b}} \mathrm{C}$ & ${ }^{\mathrm{c}} \mathrm{D}$ \\
\hline 20 & 2.7 & 4.65 & & & & \\
\hline 30 & 2.3 & 7.43 & 3.8 & -2.57 & & \\
\hline 40 & 2.2 & 10.35 & 3.1 & 0.35 & & \\
\hline 50 & 2.1 & 13.33 & 2.7 & 3.34 & 4.5 & -8.67 \\
\hline 60 & 2.0 & 16.34 & 2.5 & 6.34 & 3.9 & -5.66 \\
\hline
\end{tabular}

${ }^{a}$ For shaded areas, radius of exit curve is less than minimum radius for the entry speed and cross slopes.

${ }^{\mathrm{b}}$ Maximum Lateral Clearance on the exits

${ }^{\mathrm{c}}$ Difference between available sight distance (length of curve on vehicle path from vehicle entry on yield line to near edge of the typical crosswalk, $6 \mathrm{~m}$ away from yield line) and location of near edge of the crosswalk to satisfy SSD. 
Table A3.11 Design values of lateral clearance on the exits, $P_{f}=1.00 \%, \mathrm{CV}=5 \%$

\begin{tabular}{|c|c|c|c|c|c|c|}
\hline \multirow{5}{*}{$\begin{array}{c}\text { Entry-Exit } \\
\text { Curve Radius } \\
\text { R (m) }\end{array}$} & \multicolumn{6}{|c|}{${ }^{a}$ Design Speed $(\mathrm{km} / \mathrm{h})$} \\
\hline & \multicolumn{2}{|c|}{20} & \multicolumn{2}{|c|}{30} & \multicolumn{2}{|c|}{20} \\
\hline & \multicolumn{6}{|c|}{ Stopping Sight Distance (m) } \\
\hline & \multicolumn{2}{|c|}{15} & \multicolumn{2}{|c|}{24} & \multicolumn{2}{|c|}{35} \\
\hline & ${ }^{\mathrm{b}} \mathrm{C}$ & ${ }^{\mathrm{c}} \mathrm{D}$ & ${ }^{\mathrm{b}} \mathrm{C}$ & ${ }^{\mathrm{c}} \mathrm{D}$ & ${ }^{\mathrm{b}} \mathrm{C}$ & ${ }^{\mathrm{c}} \mathrm{D}$ \\
\hline 20 & 2.8 & 4.36 & & & & \\
\hline 30 & 2.3 & 7.2 & 3.6 & -1.80 & & \\
\hline 40 & 2.1 & 10.22 & 3.0 & 1.22 & & \\
\hline 50 & 2.0 & 13.27 & 2.6 & 4.27 & 4.2 & -6.74 \\
\hline 60 & 2.0 & 16.33 & 2.4 & 7.33 & 3.6 & -3.68 \\
\hline
\end{tabular}

${ }^{a}$ For shaded areas, radius of exit curve is less than minimum radius for the entry speed and cross slopes.

${ }^{\mathrm{b}}$ Maximum Lateral Clearance on the exits

${ }^{\mathrm{c}}$ Difference between available sight distance (length of curve on vehicle path from vehicle entry on yield line to near edge of the typical crosswalk, $6 \mathrm{~m}$ away from yield line) and location of near edge of the crosswalk to satisfy SSD.

Table A3.12 Design values of lateral clearance on the exits, $P_{f}=5.00 \%, \mathrm{CV}=5 \%$

\begin{tabular}{|c|c|c|c|c|c|c|}
\hline \multirow{5}{*}{$\begin{array}{c}\text { Entry-Exit } \\
\text { Curve Radius } \\
\text { R (m) }\end{array}$} & \multicolumn{6}{|c|}{${ }^{a}$ Design Speed $(\mathrm{km} / \mathrm{h})$} \\
\hline & \multicolumn{2}{|c|}{20} & \multicolumn{2}{|c|}{30} & \multicolumn{2}{|c|}{20} \\
\hline & \multicolumn{6}{|c|}{ Stopping Sight Distance (m) } \\
\hline & \multicolumn{2}{|c|}{14} & \multicolumn{2}{|c|}{23} & \multicolumn{2}{|c|}{33} \\
\hline & ${ }^{\mathrm{b}} \mathrm{C}$ & ${ }^{\mathrm{c}} \mathrm{D}$ & ${ }^{\mathrm{b}} \mathrm{C}$ & ${ }^{\mathrm{c}} \mathrm{D}$ & ${ }^{\mathrm{b}} \mathrm{C}$ & ${ }^{\mathrm{c}} \mathrm{D}$ \\
\hline 20 & 2.6 & 5.36 & & & & \\
\hline 30 & 2.2 & 8.20 & 3.4 & -0.80 & & \\
\hline 40 & 2.1 & 11.22 & 2.9 & 2.22 & & \\
\hline 50 & 2.0 & 14.27 & 2.5 & 5.27 & 3.8 & -4.74 \\
\hline 60 & 2.0 & 17.33 & 2.3 & 8.30 & 3.3 & -1.68 \\
\hline
\end{tabular}

${ }^{a}$ For shaded areas, radius of exit curve is less than minimum radius for the entry speed and cross slopes.

${ }^{\mathrm{b}}$ Maximum Lateral Clearance on the exits

${ }^{\mathrm{c}}$ Difference between available sight distance (length of curve on vehicle path from vehicle entry on yield line to near edge of the typical crosswalk, $6 \mathrm{~m}$ away from yield line) and location of near edge of the crosswalk to satisfy SSD. 
Table A3.13 Design values of lateral clearance on circulatory lane, $P_{f}=5.00 \% \%, \mathrm{CV}=5 \%$

\begin{tabular}{|c|c|c|c|c|c|c|}
\hline \multirow{5}{*}{$\begin{array}{c}\text { Central Island } \\
\text { Radius } \\
\text { R (m) }\end{array}$} & \multicolumn{6}{|c|}{ Design Speed (km/h) } \\
\hline & \multicolumn{2}{|c|}{20} & \multicolumn{2}{|c|}{30} & \multicolumn{2}{|c|}{40} \\
\hline & \multicolumn{6}{|c|}{ Stopping Sight Distance (m) } \\
\hline & \multicolumn{2}{|c|}{16} & \multicolumn{2}{|c|}{26} & \multicolumn{2}{|c|}{38} \\
\hline & ${ }^{\mathrm{a}} \mathrm{M}$ & ${ }^{\mathrm{b}} \psi$ & ${ }^{\mathrm{a}} \mathrm{M}$ & ${ }^{\mathrm{b}} \psi$ & ${ }^{\mathrm{a}} \mathrm{M}$ & ${ }^{\mathrm{b}} \psi$ \\
\hline 20 & 2.1 & 0.92 & 4.9 & 1.42 & 9.4 & 2.02 \\
\hline 30 & 1.4 & 0.62 & 3.3 & 0.95 & 6.6 & 1.35 \\
\hline 40 & 1.1 & 0.46 & 2.5 & 0.71 & 5.0 & 1.0 \\
\hline 50 & 2.1 & 0.92 & 4.9 & 1.42 & 9.4 & 2.02 \\
\hline
\end{tabular}

${ }^{a}$ Maximum Lateral Clearance on Circulatory Lane

${ }^{\mathrm{b}}$ Drivers Peripheral Vision (Central angle) in radians, central island radius with design speed which result to peripheral vision of over 2.44 is inadequate and should not be used in design.

Table A3.14 Design values of lateral clearance on circulatory lane, $P_{f}=0.1 \%, \mathrm{CV}=5 \%$

\begin{tabular}{|c|c|c|c|c|c|c|}
\hline \multirow{5}{*}{$\begin{array}{c}\text { Central Island } \\
\text { Radius } \\
\text { R (m) }\end{array}$} & \multicolumn{6}{|c|}{ Speed $(\mathrm{km} / \mathrm{h})$} \\
\hline & \multicolumn{2}{|c|}{20} & \multicolumn{2}{|c|}{30} & \multicolumn{2}{|c|}{40} \\
\hline & \multicolumn{6}{|c|}{ Stopping Sight Distance (m) } \\
\hline & \multicolumn{2}{|c|}{15} & \multicolumn{2}{|c|}{25} & \multicolumn{2}{|c|}{37} \\
\hline & ${ }^{\mathrm{a}} \mathrm{M}$ & ${ }^{\mathrm{b}} \psi$ & ${ }^{\mathrm{a}} \mathrm{M}$ & ${ }^{\mathrm{b}} \psi$ & ${ }^{\mathrm{a}} \mathrm{M}$ & ${ }^{\mathrm{b}} \psi$ \\
\hline 20 & 1.9 & 0.87 & 4.5 & 1.37 & 9.0 & 1.97 \\
\hline 30 & 1.3 & 0.58 & 3.1 & 0.9 & 6.3 & 1.31 \\
\hline 40 & 1.0 & 0.44 & 2.4 & 0.69 & 4.8 & 1.0 \\
\hline 50 & 1.9 & 0.87 & 4.5 & 1.37 & 9.0 & 1.97 \\
\hline
\end{tabular}

${ }^{a}$ Maximum Lateral Clearance on Circulatory Lane

${ }^{\mathrm{b}}$ Drivers Peripheral Vision (Central angle) in radians, central island radius with design speed which result to peripheral vision of over 2.44 is inadequate and should not be used in design. 
Table A3.15 Design values of lateral clearance on circulatory lane, $P_{f}=1.00 \%, C V=5 \%$

\begin{tabular}{|c|c|c|c|c|c|c|}
\hline \multirow{5}{*}{$\begin{array}{l}\text { Central Island } \\
\text { Radius } \\
\text { R (m) }\end{array}$} & \multicolumn{6}{|c|}{ Speed $(\mathrm{km} / \mathrm{h})$} \\
\hline & \multicolumn{2}{|c|}{20} & \multicolumn{2}{|c|}{30} & \multicolumn{2}{|c|}{40} \\
\hline & \multicolumn{6}{|c|}{ Stopping Sight Distance (m) } \\
\hline & \multicolumn{2}{|c|}{15} & \multicolumn{2}{|c|}{24} & \multicolumn{2}{|c|}{35} \\
\hline & ${ }^{\mathrm{a}} \mathrm{M}$ & ${ }^{\mathrm{b}} \psi$ & ${ }^{\mathrm{a}} \mathrm{M}$ & ${ }^{\mathrm{b}} \psi$ & ${ }^{\mathrm{a}} \mathrm{M}$ & ${ }^{\mathrm{b}} \psi$ \\
\hline 20 & 1.9 & 0.87 & 4.2 & 1.32 & 8.2 & 1.87 \\
\hline 30 & 1.3 & 0.58 & 2.9 & 0.88 & 5.7 & 1.25 \\
\hline 40 & 1.0 & 0.44 & 2.2 & 0.66 & 4.3 & 0.94 \\
\hline 50 & 1.9 & 0.87 & 1.8 & 0.53 & 3.5 & 0.75 \\
\hline
\end{tabular}

${ }^{a}$ Maximum Lateral Clearance on Circulatory Lane

${ }^{\mathrm{b}}$ Drivers Peripheral Vision (Central angle) in radians, central island radius with design speed which result to peripheral vision of over 2.44 is inadequate and should not be used in design.

Table A3.16 Design values of lateral clearance on circulatory lane, $P_{f}=5.00 \%, \mathrm{CV}=5 \%$

\begin{tabular}{|c|c|c|c|c|c|c|}
\hline \multirow{5}{*}{$\begin{array}{c}\text { Central Island } \\
\text { Radius } \\
\text { R (m) }\end{array}$} & \multicolumn{6}{|c|}{ Speed $(\mathrm{km} / \mathrm{h})$} \\
\hline & \multicolumn{2}{|c|}{20} & \multicolumn{2}{|c|}{30} & \multicolumn{2}{|c|}{40} \\
\hline & \multicolumn{6}{|c|}{ Stopping Sight Distance (m) } \\
\hline & \multicolumn{2}{|c|}{14} & \multicolumn{2}{|c|}{23} & \multicolumn{2}{|c|}{33} \\
\hline & ${ }^{\mathrm{a}} \mathrm{M}$ & ${ }^{\mathrm{b}} \psi$ & ${ }^{\mathrm{a}} \mathrm{M}$ & ${ }^{\mathrm{b}} \psi$ & ${ }^{\mathrm{a}} \mathrm{M}$ & ${ }^{\mathrm{b}} \psi$ \\
\hline 20 & 1.7 & 0.82 & 3.9 & 1.27 & 7.4 & 1.77 \\
\hline 30 & 1.2 & 0.55 & 2.7 & 0.9 & 5.1 & 1.18 \\
\hline 40 & 0.9 & 0.41 & 2.0 & 0.64 & 3.9 & 0.89 \\
\hline 50 & 0.67 & 0.33 & 1.6 & 0.51 & 7.4 & 1.77 \\
\hline
\end{tabular}

${ }^{a}$ Maximum Lateral Clearance on Circulatory Lane

${ }^{\mathrm{b}}$ Drivers Peripheral Vision (Central angle) in radians, central island radius with design speed which result to peripheral vision of over 2.44 is inadequate and should not be used in design. 


\section{APPENDIX B}

DESIGN AIDS FOR LATERAL CLEARANCE REQUIREMENTS, CV $=10 \%$ 
Table B3.1 Design values of lateral clearance on the approaches (SSD to the crosswalk), $P_{f}=0.1 \%, \mathrm{CV}=10 \%$

\begin{tabular}{|c|c|c|c|c|c|}
\hline \multirow{5}{*}{$\begin{array}{c}\text { First Entry } \\
\text { Curve Radius } \\
R_{1}(\mathrm{~m})\end{array}$} & \multirow{5}{*}{$\begin{array}{c}\text { Second Entry } \\
\text { Curve Radius } \\
R_{2}(\mathrm{~m})\end{array}$} & \multicolumn{4}{|c|}{ Maximum Lateral Clearance (m) } \\
\hline & & \multicolumn{4}{|c|}{ Design Speed $(\mathrm{Km} / \mathrm{h})^{a}$} \\
\hline & & 40 & 50 & 60 & 40 \\
\hline & & \multicolumn{4}{|c|}{ Stopping Sight Distance (m) } \\
\hline & & 45 & 64 & 85 & 115 \\
\hline \multirow[t]{3}{*}{100} & 20 & 4.4 & 6.7 & & \\
\hline & 30 & 4.0 & 6.5 & & \\
\hline & 40 & 3.9 & 6.3 & & \\
\hline \multirow[t]{3}{*}{300} & 20 & 3.4 & 3.9 & 4.8 & 7.1 \\
\hline & 30 & 2.9 & 3.4 & 4.5 & 6.8 \\
\hline & 40 & 2.7 & 3.2 & 4.3 & 6.5 \\
\hline \multirow[t]{3}{*}{500} & 20 & 3.2 & 3.6 & 3.9 & 5.1 \\
\hline & 30 & 2.8 & 3.1 & 3.5 & 4.7 \\
\hline & 40 & 2.5 & 2.9 & 3.2 & 4.5 \\
\hline \multirow[t]{3}{*}{1000} & 20 & 3.1 & 3.4 & 3.6 & 3.9 \\
\hline & 30 & 2.7 & 2.9 & 3.1 & 3.4 \\
\hline & 40 & 2.4 & 2.7 & 2.9 & 3.2 \\
\hline
\end{tabular}

${ }^{a}$ For shaded cells, $R_{1}$ is less than $R_{\text {min }}$ for the respective vehicle speed on the Approaches and superelevation of up to 0.06 .

Table B3.2 Design values of lateral clearance on the approaches (SSD to the yield Line),

$$
P_{f}=0.1, \mathrm{CV}=10 \%
$$

\begin{tabular}{|c|c|c|c|c|c|}
\hline \multirow{5}{*}{$\begin{array}{c}\text { First Entry } \\
\text { Curve Radius } \\
R_{1}(\mathrm{~m})\end{array}$} & \multirow{5}{*}{$\begin{array}{c}\text { Second Entry } \\
\text { Curve Radius } \\
R_{2}(\mathrm{~m})\end{array}$} & \multicolumn{4}{|c|}{ Maximum Lateral Clearance (m) } \\
\hline & & \multicolumn{4}{|c|}{ Design Speed $(\mathrm{Km} / \mathrm{h})^{a}$} \\
\hline & & 40 & 50 & 60 & 40 \\
\hline & & \multicolumn{4}{|c|}{ Stopping Sight Distance (m) } \\
\hline & & 45 & 64 & 85 & 115 \\
\hline \multirow[t]{3}{*}{100} & 20 & 4.1 & 6.4 & & \\
\hline & 30 & 2.7 & 5.2 & & \\
\hline & 40 & 2.1 & 4.7 & & \\
\hline \multirow[t]{3}{*}{300} & 20 & 3.1 & 4.1 & 5.0 & 7.2 \\
\hline & 30 & 1.7 & 2.5 & 3.6 & 6.0 \\
\hline & 40 & 1.0 & 1.8 & 3.0 & 5.4 \\
\hline \multirow[t]{3}{*}{500} & 20 & 2.9 & 3.7 & 4.3 & 5.4 \\
\hline & 30 & 1.6 & 2.1 & 2.6 & 4.0 \\
\hline & 40 & 0.8 & 1.3 & 1.9 & 3.3 \\
\hline \multirow[t]{3}{*}{1000} & 20 & 2.8 & 3.4 & 3.9 & 4.4 \\
\hline & 30 & 1.4 & 1.8 & 2.2 & 2.7 \\
\hline & 40 & 0.6 & 1.0 & 1.3 & 1.9 \\
\hline
\end{tabular}

${ }^{\text {a }}$ For shaded cells, $R_{1}$ is less than $R_{\text {min }}$ for the respective vehicle speed on the Approaches and superelevation of up to 0.06 . 
Table B3.3 Design values of lateral clearance on the approaches (SSD to the crosswalk), $P_{f}=1.00 \%, \mathrm{CV}=10 \%$

\begin{tabular}{|c|c|c|c|c|c|}
\hline \multirow{4}{*}{$\begin{array}{c}\text { First Entry } \\
\text { Curve Radius } \\
R_{1}(\mathrm{~m})\end{array}$} & \multirow{5}{*}{$\begin{array}{c}\text { Second Entry } \\
\text { Curve Radius } \\
R_{2}(\mathrm{~m})\end{array}$} & \multicolumn{4}{|c|}{ Maximum Lateral Clearance (m) } \\
\hline & & \multicolumn{4}{|c|}{ Design Speed $(\mathrm{Km} / \mathrm{h})^{a}$} \\
\hline & & 40 & 50 & 60 & 40 \\
\hline & & \multicolumn{4}{|c|}{ Stopping Sight Distance (m) } \\
\hline & & 41 & 56 & 76 & 99 \\
\hline \multirow[t]{3}{*}{100} & 20 & 4.0 & 5.6 & & \\
\hline & 30 & 3.6 & 5.3 & & \\
\hline & 40 & 3.5 & 5.2 & & \\
\hline \multirow[t]{3}{*}{300} & 20 & 3.3 & 3.7 & 4.3 & 5.8 \\
\hline & 30 & 2.8 & 3.2 & 3.9 & 5.4 \\
\hline & 40 & 2.6 & 3.0 & 3.7 & 5.3 \\
\hline \multirow[t]{3}{*}{500} & 20 & 3.1 & 3.5 & 3.8 & 4.3 \\
\hline & 30 & 2.7 & 3.0 & 3.3 & 4.0 \\
\hline & 40 & 2.5 & 2.7 & 3.0 & 3.8 \\
\hline \multirow[t]{3}{*}{1000} & 20 & 3.1 & 3.3 & 3.5 & 3.7 \\
\hline & 30 & 2.6 & 2.8 & 3.0 & 3.2 \\
\hline & 40 & 2.4 & 2.6 & 2.8 & 3.0 \\
\hline
\end{tabular}

${ }^{\text {a }}$ For shaded cells, $R_{1}$ is less than $R_{\text {min }}$ for the respective vehicle speed on the Approaches and superelevation of up to 0.06 .

Table B3.4 Design values of lateral clearance on the approaches (SSD to yield line),

$$
P_{f}=1.00 \%, \mathrm{CV}=10 \%
$$

\begin{tabular}{|c|c|c|c|c|c|}
\hline \multirow{5}{*}{$\begin{array}{c}\text { First Entry } \\
\text { Curve Radius } \\
R_{1}(\mathrm{~m})\end{array}$} & \multirow{5}{*}{$\begin{array}{c}\text { Second Entry } \\
\text { Curve Radius } \\
R_{2}(\mathrm{~m})\end{array}$} & \multicolumn{4}{|c|}{ Maximum Lateral Clearance (m) } \\
\hline & & \multicolumn{4}{|c|}{ Design Speed $(\mathrm{Km} / \mathrm{h})^{a}$} \\
\hline & & 40 & 50 & 60 & 40 \\
\hline & & \multicolumn{4}{|c|}{ Stopping Sight Distance (m) } \\
\hline & & 41 & 56 & 76 & 99 \\
\hline \multirow{3}{*}{100} & 20 & 3.6 & 5.3 & & \\
\hline & 30 & 2.3 & 4.0 & & \\
\hline & 40 & 1.7 & 3.5 & & \\
\hline \multirow[t]{3}{*}{300} & 20 & 2.8 & 3.7 & 4.6 & 5.9 \\
\hline & 30 & 1.5 & 2.2 & 3.1 & 4.6 \\
\hline & 40 & 0.8 & 1.4 & 2.4 & 4.0 \\
\hline \multirow[t]{3}{*}{500} & 20 & 2.7 & 3.4 & 4.1 & 4.7 \\
\hline & 30 & 1.3 & 1.9 & 2.4 & 3.2 \\
\hline & 40 & 0.6 & 1.1 & 1.6 & 2.5 \\
\hline \multirow[t]{3}{*}{1000} & 20 & 2.6 & 3.2 & 3.7 & 4.1 \\
\hline & 30 & 1.2 & 1.6 & 2.0 & 2.4 \\
\hline & 40 & 0.5 & 0.8 & 1.2 & 1.5 \\
\hline
\end{tabular}

${ }^{\text {a }}$ For shaded cells, $R_{1}$ is less than $R_{\min }$ for the respective vehicle speed on the Approaches and superelevation of up to 0.06 . 
Table B3.5 Design values of lateral clearance on the approaches (SSD to the crosswalk), $P_{f}=5.00 \%, \mathrm{CV}=10 \%$

\begin{tabular}{|c|c|c|c|c|c|}
\hline \multirow{5}{*}{$\begin{array}{c}\text { First Entry } \\
\text { Curve Radius } \\
R_{1}(\mathrm{~m})\end{array}$} & \multirow{5}{*}{$\begin{array}{c}\text { Second Entry } \\
\text { Curve Radius } \\
R_{2}(\mathrm{~m})\end{array}$} & \multicolumn{4}{|c|}{ Maximum Lateral Clearance (m) } \\
\hline & & \multicolumn{4}{|c|}{ Design Speed $(\mathrm{Km} / \mathrm{h})^{a}$} \\
\hline & & 40 & 50 & 60 & 40 \\
\hline & & \multicolumn{4}{|c|}{ Stopping Sight Distance (m) } \\
\hline & & 37 & 51 & 68 & 88 \\
\hline \multirow[t]{3}{*}{100} & 20 & 3.8 & 5.0 & & \\
\hline & 30 & 3.3 & 4.7 & & \\
\hline & 40 & 3.1 & 4.5 & & \\
\hline \multirow[t]{3}{*}{300} & 20 & 3.2 & 3.5 & 4.0 & 5.0 \\
\hline & 30 & 2.7 & 3.0 & 3.6 & 4.7 \\
\hline & 40 & 2.5 & 2.8 & 3.4 & 4.5 \\
\hline \multirow[t]{3}{*}{500} & 20 & 3.0 & 3.4 & 3.7 & 4.0 \\
\hline & 30 & 2.6 & 2.9 & 3.2 & 3.6 \\
\hline & 40 & 2.4 & 2.6 & 3.0 & 3.4 \\
\hline \multirow[t]{3}{*}{1000} & 20 & 3.0 & 3.2 & 3.5 & 3.7 \\
\hline & 30 & 2.5 & 2.7 & 3.0 & 3.2 \\
\hline & 40 & 2.3 & 2.5 & 2.7 & 2.9 \\
\hline
\end{tabular}

${ }^{\text {a }}$ For shaded cells, $R_{1}$ is less than $R_{\text {min }}$ for the respective vehicle speed on the Approaches and superelevation of up to 0.06 .

Table B3.6 Design values of lateral clearance on the approaches (SSD to Yield line),

$$
P_{f}=5.00 \%, \mathrm{CV}=10 \%
$$

\begin{tabular}{|c|c|c|c|c|c|}
\hline \multirow{5}{*}{$\begin{array}{c}\text { First Entry } \\
\text { Curve Radius } \\
R_{1}(\mathrm{~m})\end{array}$} & \multirow{5}{*}{$\begin{array}{c}\text { Second Entry } \\
\text { Curve Radius } \\
R_{2}(\mathrm{~m})\end{array}$} & \multicolumn{4}{|c|}{ Maximum Lateral Clearance (m) } \\
\hline & & \multicolumn{4}{|c|}{ Design Speed $(\mathrm{Km} / \mathrm{h})^{a}$} \\
\hline & & 40 & 50 & 60 & 40 \\
\hline & & \multicolumn{4}{|c|}{ Stopping Sight Distance $(\mathrm{m}),{ }^{\mathrm{b}} \mathrm{P}_{\mathrm{f}}=5.00(\%)$} \\
\hline & & 37 & 51 & 68 & 88 \\
\hline \multirow{3}{*}{100} & 20 & 3.2 & 4.7 & & \\
\hline & 30 & 1.9 & 3.4 & & \\
\hline & 40 & 1.3 & 2.8 & & \\
\hline \multirow[t]{3}{*}{300} & 20 & 2.6 & 3.5 & 4.3 & 5.2 \\
\hline & 30 & 1.3 & 1.9 & 2.7 & 3.8 \\
\hline & 40 & 0.6 & 1.2 & 2.0 & 3.2 \\
\hline \multirow[t]{3}{*}{500} & 20 & 2.5 & 3.2 & 3.8 & 4.4 \\
\hline & 30 & 1.2 & 1.7 & 2.2 & 2.7 \\
\hline & 40 & 0.5 & 0.9 & 1.4 & 2.0 \\
\hline \multirow[t]{3}{*}{1000} & 20 & 2.4 & 3.0 & 3.5 & 4.0 \\
\hline & 30 & 1.1 & 1.5 & 1.9 & 2.3 \\
\hline & 40 & 0.4 & 0.8 & 1.1 & 1.4 \\
\hline
\end{tabular}

${ }^{\text {a }}$ For shaded cells, $R_{1}$ is less than $R_{\min }$ for the respective vehicle speed on the Approaches and superelevation of up to 0.06 . 
Table B3.7 Design values of lateral clearance on the exits, $P_{f}=0.10 \%, \mathrm{CV}=10 \%$

\begin{tabular}{|c|c|c|c|c|c|c|}
\hline \multirow{5}{*}{$\begin{array}{c}\text { Entry-Exit } \\
\text { Curve Radius } \\
\text { R (m) }\end{array}$} & \multicolumn{6}{|c|}{${ }^{\mathrm{a}}$ Design Speed $(\mathrm{km} / \mathrm{h})$} \\
\hline & \multicolumn{2}{|c|}{20} & \multicolumn{2}{|c|}{30} & \multicolumn{2}{|c|}{40} \\
\hline & \multicolumn{6}{|c|}{ Stopping Sight Distance (m) } \\
\hline & \multicolumn{2}{|c|}{18} & \multicolumn{2}{|c|}{31} & \multicolumn{2}{|c|}{45} \\
\hline & ${ }^{\mathrm{b}} \mathrm{C}$ & ${ }^{\mathrm{c}} \mathrm{D}$ & ${ }^{\mathrm{b}} \mathrm{C}$ & ${ }^{\mathrm{c}} \mathrm{D}$ & ${ }^{\mathrm{b}} \mathrm{C}$ & ${ }^{\mathrm{c}} \mathrm{D}$ \\
\hline 20 & 3.3 & 1.36 & & & & \\
\hline 30 & 2.6 & 4.20 & 5.1 & -8.80 & & \\
\hline 40 & 2.3 & 7.22 & 4.1 & -5.79 & & \\
\hline 50 & 2.1 & 10.27 & 3.5 & -2.74 & 6.1 & -16.74 \\
\hline 60 & 2.1 & 13.33 & 3.1 & 0.33 & 5.3 & -13.68 \\
\hline
\end{tabular}

${ }^{a}$ For shaded areas, radius of exit curve is less than minimum radius for the entry speed and cross slopes.

${ }^{\mathrm{b}}$ Maximum Lateral Clearance on the exits

${ }^{\mathrm{c}}$ Difference between available sight distance (length of curve on vehicle path from vehicle entry on yield line to near edge of the typical crosswalk, $6 \mathrm{~m}$ away from yield line) and location of near edge of the crosswalk to satisfy SSD.

Table B3.8 Design values of lateral clearance on the exits, $P_{f}=1.00 \%, \mathrm{CV}=10 \%$

\begin{tabular}{|c|c|c|c|c|c|c|}
\hline \multirow{5}{*}{$\begin{array}{c}\text { Entry-Exit } \\
\text { Curve Radius } \\
\text { R (m) }\end{array}$} & \multicolumn{6}{|c|}{${ }^{a}$ Design Speed $(\mathrm{km} / \mathrm{h})$} \\
\hline & \multicolumn{2}{|c|}{20} & \multicolumn{2}{|c|}{30} & \multicolumn{2}{|c|}{40} \\
\hline & \multicolumn{6}{|c|}{ Stopping Sight Distance (m) } \\
\hline & \multicolumn{2}{|c|}{17} & \multicolumn{2}{|c|}{28} & \multicolumn{2}{|c|}{41} \\
\hline & ${ }^{\mathrm{b}} \mathrm{C}$ & ${ }^{\mathrm{c}} \mathrm{D}$ & ${ }^{\mathrm{b}} \mathrm{C}$ & ${ }^{\mathrm{c}} \mathrm{D}$ & ${ }^{\mathrm{b}} \mathrm{C}$ & ${ }^{\mathrm{c}} \mathrm{D}$ \\
\hline 20 & 3.1 & 2.36 & & & & \\
\hline 30 & 2.5 & 5.20 & 4.4 & -5.79 & & \\
\hline 40 & 2.2 & 8.22 & 3.57 & -2.79 & & \\
\hline 50 & 2.1 & 11.27 & 3.1 & 0.27 & 5.3 & -12.74 \\
\hline 60 & 2.0 & 14.33 & 2.7 & 3.33 & 4.5 & -9.68 \\
\hline
\end{tabular}

${ }^{a}$ For shaded areas, radius of exit curve is less than minimum radius for the entry speed and cross slopes.

${ }^{\mathrm{b}}$ Maximum Lateral Clearance on the exits

${ }^{c}$ Difference between available sight distance (length of curve on vehicle path from vehicle entry on yield line to near edge of the typical crosswalk, $6 \mathrm{~m}$ away from yield line) and location of near edge of the crosswalk to satisfy SSD. 
Table B3.9 Design values of lateral clearance on the exits, $P_{f}=5.00 \%, \mathrm{CV}=10 \%$

\begin{tabular}{|c|c|c|c|c|c|c|}
\hline \multirow{5}{*}{$\begin{array}{c}\text { Entry-Exit } \\
\text { Curve Radius } \\
\text { R (m) }\end{array}$} & \multicolumn{6}{|c|}{${ }^{a}$ Design Speed $(\mathrm{km} / \mathrm{h})$} \\
\hline & \multicolumn{2}{|c|}{20} & \multicolumn{2}{|c|}{30} & \multicolumn{2}{|c|}{40} \\
\hline & \multicolumn{6}{|c|}{ Stopping Sight Distance (m) } \\
\hline & \multicolumn{2}{|c|}{15} & \multicolumn{2}{|c|}{25} & \multicolumn{2}{|c|}{37} \\
\hline & ${ }^{\mathrm{b}} \mathrm{C}$ & ${ }^{\mathrm{c}} \mathrm{D}$ & ${ }^{\mathrm{b}} \mathrm{C}$ & ${ }^{\mathrm{c}} \mathrm{D}$ & ${ }^{\mathrm{b}} \mathrm{C}$ & ${ }^{\mathrm{c}} \mathrm{D}$ \\
\hline 20 & 2.7 & 4.36 & & & & \\
\hline 30 & 2.3 & 7.21 & 3.8 & -2.80 & & \\
\hline 40 & 2.2 & 10.22 & 3.1 & 0.22 & & \\
\hline 50 & 2.1 & 13.27 & 2.7 & 3.27 & 4.5 & -8.74 \\
\hline 60 & 2.0 & 16.33 & 2.5 & 6.33 & 3.9 & -5.68 \\
\hline
\end{tabular}

${ }^{a}$ For shaded areas, radius of exit curve is less than minimum radius for the entry speed and cross slopes.

${ }^{\mathrm{b}}$ Maximum Lateral Clearance on the exits

${ }^{\mathrm{c}}$ Difference between available sight distance (length of curve on vehicle path from vehicle entry on yield line to near edge of the typical crosswalk, $6 \mathrm{~m}$ away from yield line) and location of near edge of the crosswalk to satisfy SSD.

Table B3.10 Design values of lateral clearance on circulatory lane, $\mathrm{P}_{\mathrm{f}}=0.1 \%, \mathrm{CV}=10 \%$

\begin{tabular}{|c|c|c|c|c|c|c|}
\hline \multirow{5}{*}{$\begin{array}{c}\text { Entry-Exit } \\
\text { Curve Radius } \\
\text { R (m) }\end{array}$} & \multicolumn{6}{|c|}{${ }^{a}$ Design Speed $(\mathrm{km} / \mathrm{h})$} \\
\hline & \multicolumn{2}{|c|}{20} & \multicolumn{2}{|c|}{30} & \multicolumn{2}{|c|}{20} \\
\hline & \multicolumn{6}{|c|}{ Stopping Sight Distance (m) } \\
\hline & \multicolumn{2}{|c|}{18} & \multicolumn{2}{|c|}{31} & \multicolumn{2}{|c|}{45} \\
\hline & ${ }^{\mathrm{a}} \mathrm{M}$ & ${ }^{\mathrm{b}} \psi$ & ${ }^{\mathrm{a}} \mathrm{M}$ & ${ }^{\mathrm{b}} \psi$ & ${ }^{\mathrm{a}} \mathrm{M}$ & ${ }^{\mathrm{b}} \psi$ \\
\hline 20 & 2.6 & 1.02 & 6.6 & 1.67 & 12.5 & 2.37 \\
\hline 30 & 1.7 & 0.68 & 4.6 & 1.12 & 8.9 & 1.58 \\
\hline 40 & 1.3 & 0.51 & 3.5 & 0.84 & 6.8 & 1.19 \\
\hline 50 & 1.1 & 0.41 & 2.8 & 0.67 & 5.5 & 0.95 \\
\hline
\end{tabular}

${ }^{a}$ Maximum Lateral Clearance on Circulatory Lane

${ }^{\mathrm{b}}$ Drivers Peripheral Vision (Central angle) in radians, central island radius with design speed which result to peripheral vision of over 2.44 is inadequate and should not be used in design. 
Table B3.11 Design values of lateral clearance on circulatory lane, $P_{f}=1.00 \%, \mathrm{CV}=10 \%$

\begin{tabular}{|c|c|c|c|c|c|c|}
\hline \multirow{5}{*}{$\begin{array}{c}\text { Entry-Exit } \\
\text { Curve Radius } \\
\text { R (m) }\end{array}$} & \multicolumn{6}{|c|}{${ }^{a}$ Design Speed $(\mathrm{km} / \mathrm{h})$} \\
\hline & \multicolumn{2}{|c|}{20} & \multicolumn{2}{|c|}{30} & \multicolumn{2}{|c|}{20} \\
\hline & \multicolumn{6}{|c|}{ Stopping Sight Distance (m) } \\
\hline & \multicolumn{2}{|c|}{17} & \multicolumn{2}{|c|}{28} & \multicolumn{2}{|c|}{41} \\
\hline & ${ }^{\mathrm{a}} \mathrm{M}$ & ${ }^{\mathrm{b}} \psi$ & ${ }^{\mathrm{a}} \mathrm{M}$ & ${ }^{\mathrm{b}} \psi$ & ${ }^{\mathrm{a}} \mathrm{M}$ & ${ }^{\mathrm{b}} \psi$ \\
\hline 20 & 2.3 & 0.97 & 5.5 & 1.52 & 10.7 & 2.17 \\
\hline 30 & 1.6 & 0.65 & 3.8 & 1.02 & 7.5 & 1.45 \\
\hline 40 & 1.2 & 0.49 & 2.9 & 0.76 & 5.8 & 1.10 \\
\hline 50 & 1.0 & 0.39 & 2.3 & 0.61 & 4.7 & 0.87 \\
\hline
\end{tabular}

${ }^{a}$ Maximum Lateral Clearance on Circulatory Lane

${ }^{\mathrm{b}}$ Drivers Peripheral Vision (Central angle) in radians, central island radius with design speed which result to peripheral vision of over 2.44 is inadequate and should not be used in design.

Table B3.12 Design values of lateral clearance on circulatory lane, $\mathrm{P}_{\mathrm{f}}=5.00 \%, \mathrm{CV}=10 \%$

\begin{tabular}{|c|c|c|c|c|c|c|}
\hline \multirow{5}{*}{$\begin{array}{c}\text { Entry-Exit } \\
\text { Curve Radius } \\
\text { R (m) }\end{array}$} & \multicolumn{6}{|c|}{${ }^{a}$ Design Speed $(\mathrm{km} / \mathrm{h})$} \\
\hline & \multicolumn{2}{|c|}{20} & \multicolumn{2}{|c|}{30} & \multicolumn{2}{|c|}{20} \\
\hline & \multicolumn{6}{|c|}{ Stopping Sight Distance (m) } \\
\hline & \multicolumn{2}{|c|}{15} & \multicolumn{2}{|c|}{25} & \multicolumn{2}{|c|}{37} \\
\hline & ${ }^{\mathrm{a}} \mathrm{M}$ & ${ }^{\mathrm{b}} \psi$ & ${ }^{\mathrm{a}} \mathrm{M}$ & ${ }^{\mathrm{b}} \psi$ & ${ }^{\mathrm{a}} \mathrm{M}$ & ${ }^{\mathrm{b}} \psi$ \\
\hline 20 & 1.9 & 0.87 & 4.5 & 1.37 & 9.0 & 1.97 \\
\hline 30 & 1.3 & 0.58 & 3.1 & 0.9 & 6.3 & 1.31 \\
\hline 40 & 1.0 & 0.44 & 2.4 & 0.69 & 4.8 & 1.0 \\
\hline 50 & 0.8 & 0.35 & 1.9 & 0.55 & 3.9 & 0.79 \\
\hline
\end{tabular}

${ }^{a}$ Maximum Lateral Clearance on Circulatory Lane

${ }^{\mathrm{b}}$ Drivers Peripheral Vision (Central angle) in radians, central island radius with design speed which result to peripheral vision of over 2.44 is inadequate and should not be used in design. 
APPENDIX C

DESIGN AIDS FOR LATERAL CLEARANCE REQUIREMENTS, CV $=15 \%$ 
Table C3.1 Design values of lateral clearance on the approaches (SSD to the crosswalk), $P_{f}=0.01 \%, \mathrm{CV}=15 \%$

\begin{tabular}{|c|c|c|c|c|c|}
\hline \multirow{5}{*}{$\begin{array}{c}\text { First Entry } \\
\text { Curve Radius } \\
R_{1}(\mathrm{~m})\end{array}$} & \multirow{5}{*}{$\begin{array}{c}\text { Second Entry } \\
\text { Curve Radius } \\
\qquad R_{2}(\mathrm{~m})\end{array}$} & \multicolumn{4}{|c|}{ Maximum Lateral Clearance (m) } \\
\hline & & \multicolumn{4}{|c|}{ Design Speed $(\mathrm{Km} / \mathrm{h})^{a}$} \\
\hline & & 40 & 50 & 60 & 70 \\
\hline & & \multicolumn{4}{|c|}{ Stopping Sight Distance (m) } \\
\hline & & 67 & 95 & 133 & 172 \\
\hline \multirow[t]{3}{*}{100} & 20 & 7.2 & 12.6 & & \\
\hline & 30 & 7.0 & 12.4 & & \\
\hline & 40 & 6.8 & 12.3 & & \\
\hline \multirow[t]{3}{*}{300} & 20 & 4.0 & 5.5 & 8.9 & 13.7 \\
\hline & 30 & 3.5 & 5.1 & 8.7 & 13.5 \\
\hline & 40 & 3.3 & 5.0 & 8.5 & 13.4 \\
\hline \multirow[t]{3}{*}{500} & 20 & 3.7 & 4.2 & 6.1 & 8.9 \\
\hline & 30 & 3.2 & 3.8 & 5.8 & 8.6 \\
\hline & 40 & 3.0 & 3.6 & 5.5 & 8.5 \\
\hline \multirow[t]{3}{*}{1000} & 20 & 3.5 & 3.7 & 4.2 & 5.4 \\
\hline & 30 & 3.0 & 3.2 & 3.8 & 5.0 \\
\hline & 40 & 2.7 & 3.0 & 3.6 & 4.8 \\
\hline
\end{tabular}

${ }^{\text {a }}$ For shaded cells, $R_{1}$ is less than $R_{\text {min }}$ for the respective vehicle speed on the Approaches and superelevation of up to 0.06 .

Table C3.2 Design values of lateral clearance on the approaches (SSD to the yield Line),

$$
P_{f}=0.01 \%, \mathrm{CV}=15 \%
$$

\begin{tabular}{|c|c|c|c|c|c|}
\hline \multirow{5}{*}{$\begin{array}{c}\text { First Entry } \\
\text { Curve Radius } \\
R_{1}(\mathrm{~m})\end{array}$} & \multirow{5}{*}{$\begin{array}{c}\text { Second Entry } \\
\text { Curve Radius } \\
R_{2}(\mathrm{~m})\end{array}$} & \multicolumn{4}{|c|}{ Maximum Lateral Clearance (m) } \\
\hline & & \multicolumn{4}{|c|}{ Design Speed $(\mathrm{Km} / \mathrm{h})^{a}$} \\
\hline & & 40 & 50 & 60 & 40 \\
\hline & & \multicolumn{4}{|c|}{ Stopping Sight Distance (m) } \\
\hline & & 67 & 95 & 133 & 172 \\
\hline \multirow{3}{*}{100} & 20 & 6.8 & 12.1 & & \\
\hline & 30 & 5.7 & 11.2 & & \\
\hline & 40 & 5.2 & 10.7 & & \\
\hline \multirow[t]{3}{*}{300} & 20 & 4.2 & 5.6 & 9.0 & 13.7 \\
\hline & 30 & 2.6 & 4.3 & 7.8 & 12.7 \\
\hline & 40 & 1.9 & 3.7 & 7.3 & 12.2 \\
\hline \multirow[t]{3}{*}{500} & 20 & 3.8 & 4.6 & 6.3 & 9.1 \\
\hline & 30 & 2.2 & 3.0 & 5.0 & 7.9 \\
\hline & 40 & 1.4 & 2.3 & 4.4 & 7.4 \\
\hline \multirow[t]{3}{*}{1000} & 20 & 3.5 & 4.0 & 4.7 & 5.8 \\
\hline & 30 & 1.9 & 2.3 & 3.1 & 4.4 \\
\hline & 40 & 1.1 & 1.4 & 2.4 & 3.8 \\
\hline
\end{tabular}

${ }^{\text {a }}$ For shaded cells, $R_{1}$ is less than $R_{\text {min }}$ for the respective vehicle speed on the Approaches and superelevation of up to 0.06 . 
Table C3.3 Design values of lateral clearance on the approaches (SSD to the crosswalk), $P_{f}=0.1 \%, \mathrm{CV}=15 \%$

\begin{tabular}{|c|c|c|c|c|c|}
\hline \multirow{5}{*}{$\begin{array}{c}\text { First Entry } \\
\text { Curve Radius } \\
R_{1}(\mathrm{~m})\end{array}$} & \multirow{5}{*}{$\begin{array}{c}\text { Second Entry } \\
\text { Curve Radius } \\
R_{2}(\mathrm{~m})\end{array}$} & \multicolumn{4}{|c|}{ Maximum Lateral Clearance (m) } \\
\hline & & \multicolumn{4}{|c|}{ Design Speed $(\mathrm{Km} / \mathrm{h})^{a}$} \\
\hline & & 40 & 50 & 60 & 40 \\
\hline & & \multicolumn{4}{|c|}{ Stopping Sight Distance (m) } \\
\hline & & 57 & 81 & 111 & 144 \\
\hline \multirow[t]{3}{*}{100} & 20 & 5.7 & 4.6 & & \\
\hline & 30 & 5.4 & 4.5 & & \\
\hline & 40 & 5.3 & 4.4 & & \\
\hline \multirow[t]{3}{*}{300} & 20 & 3.7 & 4.5 & 6.7 & 10.1 \\
\hline & 30 & 3.2 & 4.2 & 6.5 & 9.9 \\
\hline & 40 & 3.0 & 4.0 & 6.3 & 9.8 \\
\hline \multirow[t]{3}{*}{500} & 20 & 3.5 & 3.9 & 4.9 & 6.8 \\
\hline & 30 & 3.0 & 3.4 & 4.5 & 6.5 \\
\hline & 40 & 2.7 & 3.2 & 4.3 & 6.3 \\
\hline \multirow[t]{3}{*}{1000} & 20 & 3.3 & 3.6 & 3.8 & 4.4 \\
\hline & 30 & 2.8 & 3.1 & 3.3 & 4.1 \\
\hline & 40 & 2.6 & 2.8 & 3.1 & 3.9 \\
\hline
\end{tabular}

${ }^{\text {a }}$ For shaded cells, $R_{1}$ is less than $R_{\text {min }}$ for the respective vehicle speed on the Approaches and superelevation of up to 0.06 .

Table C3.4 Design values of lateral clearance on the approaches (SSD to the yield Line), $P_{f}=0.1 \%, \mathrm{CV}=15 \%$

\begin{tabular}{|c|c|c|c|c|c|}
\hline \multirow{5}{*}{$\begin{array}{c}\text { First Entry } \\
\text { Curve Radius } \\
R_{1}(\mathrm{~m})\end{array}$} & \multirow{5}{*}{$\begin{array}{c}\text { Second Entry } \\
\text { Curve Radius } \\
R_{2}(\mathrm{~m})\end{array}$} & \multicolumn{4}{|c|}{ Maximum Lateral Clearance (m) } \\
\hline & & \multicolumn{4}{|c|}{ Design Speed $(\mathrm{Km} / \mathrm{h})^{a}$} \\
\hline & & 40 & 50 & 60 & 40 \\
\hline & & \multicolumn{4}{|c|}{ Stopping Sight Distance (m) } \\
\hline & & 57 & 81 & 111 & 144 \\
\hline \multirow[t]{3}{*}{100} & 20 & 5.4 & 9.2 & & \\
\hline & 30 & 4.1 & 8.2 & & \\
\hline & 40 & 3.6 & 7.7 & & \\
\hline \multirow[t]{3}{*}{300} & 20 & 3.7 & 4.8 & 6.9 & 10.2 \\
\hline & 30 & 2.2 & 3.4 & 5.7 & 9.1 \\
\hline & 40 & 1.4 & 2.7 & 5.1 & 8.6 \\
\hline \multirow[t]{3}{*}{500} & 20 & 3.4 & 4.2 & 5.2 & 7.0 \\
\hline & 30 & 1.9 & 2.5 & 3.8 & 5.8 \\
\hline & 40 & 1.1 & 1.7 & 3.1 & 5.2 \\
\hline \multirow[t]{3}{*}{1000} & 20 & 3.2 & 3.8 & 4.3 & 4.9 \\
\hline & 30 & 1.7 & 2.1 & 2.6 & 3.4 \\
\hline & 40 & 0.9 & 1.3 & 1.7 & 2.7 \\
\hline
\end{tabular}

${ }^{\text {a }}$ For shaded cells, $R_{1}$ is less than $R_{\text {min }}$ for the respective vehicle speed on the Approaches and superelevation of up to 0.06 . 
Table C3.5 Design values of lateral clearance on the approaches (SSD to the crosswalk), $P_{f}=1.00 \%, \mathrm{CV}=15 \%$

\begin{tabular}{|c|c|c|c|c|c|}
\hline \multirow{5}{*}{$\begin{array}{c}\text { First Entry } \\
\text { Curve Radius } \\
R_{1}(\mathrm{~m})\end{array}$} & \multirow{5}{*}{$\begin{array}{c}\text { Second Entry } \\
\text { Curve Radius } \\
R_{2}(\mathrm{~m})\end{array}$} & \multicolumn{4}{|c|}{ Maximum Lateral Clearance (m) } \\
\hline & & \multicolumn{4}{|c|}{ Design Speed $(\mathrm{Km} / \mathrm{h})^{a}$} \\
\hline & & 40 & 50 & 60 & 40 \\
\hline & & \multicolumn{4}{|c|}{ Stopping Sight Distance (m) } \\
\hline & & 48 & 67 & 91 & 117 \\
\hline \multirow[t]{3}{*}{100} & 20 & 4.7 & 7.2 & & \\
\hline & 30 & 4.3 & 7.0 & & \\
\hline & 40 & 4.2 & 6.8 & & \\
\hline \multirow[t]{3}{*}{300} & 20 & 3.5 & 4.0 & 5.2 & 7.3 \\
\hline & 30 & 3.0 & 3.5 & 4.9 & 7.0 \\
\hline & 40 & 2.8 & 3.3 & 4.7 & 6.9 \\
\hline \multirow[t]{3}{*}{500} & 20 & 3.3 & 3.7 & 4.1 & 5.2 \\
\hline & 30 & 2.9 & 3.2 & 3.7 & 4.8 \\
\hline & 40 & 2.6 & 3.0 & 3.5 & 4.6 \\
\hline \multirow[t]{3}{*}{1000} & 20 & 3.2 & 3.5 & 3.7 & 3.9 \\
\hline & 30 & 2.8 & 3.0 & 3.2 & 3.4 \\
\hline & 40 & 2.5 & 2.7 & 2.9 & 3.2 \\
\hline
\end{tabular}

${ }^{\text {a }}$ For shaded cells, $R_{1}$ is less than $R_{\text {min }}$ for the respective vehicle speed on the Approaches and superelevation of up to 0.06 .

Table C3.6 Design values of lateral clearance on the approaches (SSD to yield line),

$$
P_{f}=1.00 \%, \mathrm{CV}=15 \%
$$

\begin{tabular}{|c|c|c|c|c|c|}
\hline \multirow{5}{*}{$\begin{array}{c}\text { First Entry } \\
\text { Curve Radius } \\
R_{1}(\mathrm{~m})\end{array}$} & \multirow{5}{*}{$\begin{array}{c}\text { Second Entry } \\
\text { Curve Radius } \\
R_{2}(\mathrm{~m})\end{array}$} & \multicolumn{4}{|c|}{ Maximum Lateral Clearance (m) } \\
\hline & & \multicolumn{4}{|c|}{ Design Speed $(\mathrm{Km} / \mathrm{h})^{a}$} \\
\hline & & 40 & 50 & 60 & 40 \\
\hline & & \multicolumn{4}{|c|}{ Stopping Sight Distance (m) } \\
\hline & & 48 & 67 & 91 & 117 \\
\hline \multirow[t]{3}{*}{100} & 20 & 4.3 & 6.8 & & \\
\hline & 30 & 3.0 & 5.7 & & \\
\hline & 40 & 2.4 & 5.2 & & \\
\hline \multirow[t]{3}{*}{300} & 20 & 3.3 & 4.2 & 5.4 & 7.4 \\
\hline & 30 & 1.8 & 2.6 & 4.0 & 6.2 \\
\hline & 40 & 1.1 & 1.9 & 3.4 & 5.6 \\
\hline \multirow[t]{3}{*}{500} & 20 & 3.1 & 3.8 & 4.5 & 5.5 \\
\hline & 30 & 1.6 & 2.2 & 2.9 & 4.1 \\
\hline & 40 & 0.8 & 1.4 & 2.2 & 3.5 \\
\hline \multirow[t]{3}{*}{1000} & 20 & 2.9 & 3.5 & 4.0 & 4.4 \\
\hline & 30 & 1.4 & 1.9 & 2.3 & 2.6 \\
\hline & 40 & 0.7 & 1.1 & 1.4 & 1.7 \\
\hline
\end{tabular}

${ }^{\text {a }}$ For shaded cells, $R_{1}$ is less than $R_{\text {min }}$ for the respective vehicle speed on the Approaches and superelevation of up to 0.06 . 
Table C3.7 Design values of lateral clearance on the approaches (SSD to the crosswalk), $P_{f}=5.00 \%, \mathrm{CV}=15 \%$

\begin{tabular}{|c|c|c|c|c|c|}
\hline \multirow{5}{*}{$\begin{array}{c}\text { First Entry } \\
\text { Curve Radius } \\
R_{1}(\mathrm{~m})\end{array}$} & \multirow{5}{*}{$\begin{array}{l}\text { Second Entry } \\
\text { Curve Radius } \\
\qquad R_{2}(\mathrm{~m})\end{array}$} & \multicolumn{4}{|c|}{ Maximum Lateral Clearance (m) } \\
\hline & & \multicolumn{4}{|c|}{ Design Speed $(\mathrm{Km} / \mathrm{h})^{a}$} \\
\hline & & 40 & 50 & 60 & 40 \\
\hline & & \multicolumn{4}{|c|}{ Stopping Sight Distance (m) } \\
\hline & & 42 & 57 & 77 & 98 \\
\hline \multirow[t]{3}{*}{100} & 20 & 4.1 & 5.7 & & \\
\hline & 30 & 3.7 & 5.4 & & \\
\hline & 40 & 3.5 & 5.3 & & \\
\hline \multirow[t]{3}{*}{300} & 20 & 3.3 & 3.7 & 4.4 & 5.7 \\
\hline & 30 & 2.8 & 3.2 & 4.0 & 5.3 \\
\hline & 40 & 2.6 & 3.0 & 3.8 & 5.2 \\
\hline \multirow[t]{3}{*}{500} & 20 & 3.2 & 3.5 & 3.8 & 4.3 \\
\hline & 30 & 2.7 & 3.0 & 3.3 & 3.9 \\
\hline & 40 & 2.5 & 2.7 & 3.1 & 3.7 \\
\hline \multirow[t]{3}{*}{1000} & 20 & 3.1 & 3.3 & 3.5 & 3.7 \\
\hline & 30 & 2.6 & 2.8 & 3.0 & 3.2 \\
\hline & 40 & 2.4 & 2.6 & 2.8 & 3.0 \\
\hline
\end{tabular}

${ }^{\text {a }}$ For shaded cells, $R_{1}$ is less than $R_{\text {min }}$ for the respective vehicle speed on the Approaches and superelevation of up to 0.06 .

Table C3.8 Design values of lateral clearance on the approaches (SSD to yield line),

$$
P_{f}=5.00 \%, \mathrm{CV}=15 \%
$$

\begin{tabular}{|c|c|c|c|c|c|}
\hline \multirow{5}{*}{$\begin{array}{c}\text { First Entry } \\
\text { Curve Radius } \\
R_{1}(\mathrm{~m})\end{array}$} & \multirow{5}{*}{$\begin{array}{c}\text { Second Entry } \\
\text { Curve Radius } \\
R_{2}(\mathrm{~m})\end{array}$} & \multicolumn{4}{|c|}{ Maximum Lateral Clearance (m) } \\
\hline & & \multicolumn{4}{|c|}{ Design Speed $(\mathrm{Km} / \mathrm{h})^{a}$} \\
\hline & & 40 & 50 & 60 & 70 \\
\hline & & \multicolumn{4}{|c|}{ Stopping Sight Distance (m) } \\
\hline & & 42 & 57 & 77 & 98 \\
\hline \multirow[t]{3}{*}{100} & 20 & 3.7 & 5.4 & & \\
\hline & 30 & 2.4 & 4.2 & & \\
\hline & 40 & 1.8 & 3.6 & & \\
\hline \multirow[t]{3}{*}{300} & 20 & 2.9 & 3.8 & 4.6 & 5.9 \\
\hline & 30 & 1.5 & 2.2 & 3.1 & 4.6 \\
\hline & 40 & 0.8 & 1.4 & 2.5 & 4.0 \\
\hline \multirow[t]{3}{*}{500} & 20 & 2.8 & 3.5 & 4.1 & 4.7 \\
\hline & 30 & 1.4 & 1.9 & 2.4 & 3.2 \\
\hline & 40 & 0.7 & 1.1 & 1.6 & 2.5 \\
\hline \multirow[t]{3}{*}{1000} & 20 & 2.7 & 3.2 & 3.7 & 4.1 \\
\hline & 30 & 1.3 & 1.7 & 2.0 & 2.4 \\
\hline & 40 & 0.6 & 0.9 & 1.2 & 1.5 \\
\hline
\end{tabular}

${ }^{\text {a }}$ For shaded cells, $R_{1}$ is less than $R_{\text {min }}$ for the respective vehicle speed on the Approaches and superelevation of up to 0.06 . 
Table C3.9 Design values of lateral clearance on the exits, $P_{f}=0.01 \%, \mathrm{CV}=15 \%$

\begin{tabular}{|c|c|c|c|c|c|c|}
\hline \multirow{5}{*}{$\begin{array}{c}\text { Entry-Exit } \\
\text { Curve Radius } \\
\text { R (m) }\end{array}$} & \multicolumn{6}{|c|}{${ }^{\mathrm{a}}$ Design Speed $(\mathrm{km} / \mathrm{h})$} \\
\hline & \multicolumn{2}{|c|}{20} & \multicolumn{2}{|c|}{30} & \multicolumn{2}{|c|}{40} \\
\hline & \multicolumn{6}{|c|}{ Stopping Sight Distance (m) } \\
\hline & \multicolumn{2}{|c|}{25} & \multicolumn{2}{|c|}{43} & \multicolumn{2}{|c|}{67} \\
\hline & ${ }^{\mathrm{b}} \mathrm{C}$ & ${ }^{\mathrm{c}} \mathrm{D}$ & ${ }^{\mathrm{b}} \mathrm{C}$ & ${ }^{\mathrm{c}} \mathrm{D}$ & ${ }^{\mathrm{b}} \mathrm{C}$ & ${ }^{\mathrm{c}} \mathrm{D}$ \\
\hline 20 & 5.0 & -5.64 & & & & \\
\hline 30 & 3.8 & -2.57 & 7.8 & -20.80 & & \\
\hline 40 & 3.1 & 0.35 & 6.8 & -17.79 & & \\
\hline 50 & 2.7 & 3.34 & 5.7 & -14.8 & 11.9 & -38.73 \\
\hline 60 & 2.5 & 6.34 & 4.9 & -11.68 & 10.2 & -35.68 \\
\hline
\end{tabular}

${ }^{a}$ For shaded areas, radius of exit curve is less than minimum radius for the entry speed and cross slopes.

${ }^{\mathrm{b}}$ Maximum Lateral Clearance on the exits

${ }^{\mathrm{c}}$ Difference between available sight distance (length of curve on vehicle path from vehicle entry on yield line to near edge of the typical crosswalk, $6 \mathrm{~m}$ away from yield line) and location of near edge of the crosswalk to satisfy SSD.

Table C3.10 Design values of lateral clearance on the exits, $P_{f}=0.1 \%, \mathrm{CV}=15 \%$

\begin{tabular}{|c|c|c|c|c|c|c|}
\hline \multirow{5}{*}{$\begin{array}{c}\text { Entry-Exit } \\
\text { Curve Radius } \\
\text { R (m) }\end{array}$} & \multicolumn{6}{|c|}{${ }^{a}$ Design Speed $(\mathrm{km} / \mathrm{h})$} \\
\hline & \multicolumn{2}{|c|}{20} & \multicolumn{2}{|c|}{20} & \multicolumn{2}{|c|}{20} \\
\hline & \multicolumn{6}{|c|}{ Stopping Sight Distance (m) } \\
\hline & \multicolumn{2}{|c|}{22} & \multicolumn{2}{|c|}{37} & \multicolumn{2}{|c|}{57} \\
\hline & ${ }^{\mathrm{b}} \mathrm{C}$ & ${ }^{\mathrm{c}} \mathrm{D}$ & ${ }^{\mathrm{b}} \mathrm{C}$ & ${ }^{\mathrm{c}} \mathrm{D}$ & ${ }^{\mathrm{b}} \mathrm{C}$ & ${ }^{\mathrm{c}} \mathrm{D}$ \\
\hline 20 & 4.2 & -2.64 & & & & \\
\hline 30 & 3.2 & 0.21 & 6.7 & -14.80 & & \\
\hline 40 & 2.7 & 3.22 & 5.4 & -11.79 & & \\
\hline 50 & 2.4 & 6.27 & 4.5 & -8.74 & 9.03 & -28.74 \\
\hline 60 & 2.2 & 9.33 & 3.9 & -5.68 & 7.8 & -25.68 \\
\hline
\end{tabular}

${ }^{a}$ For shaded areas, radius of exit curve is less than minimum radius for the entry speed and cross slopes.

${ }^{\mathrm{b}}$ Maximum Lateral Clearance on the exits

${ }^{c}$ Difference between available sight distance (length of curve on vehicle path from vehicle entry on yield line to near edge of the typical crosswalk, $6 \mathrm{~m}$ away from yield line) and location of near edge of the crosswalk to satisfy SSD. 
Table C3.11 Design values of lateral clearance on the exits, $P_{f}=1.00 \%, \mathrm{CV}=15 \%$

\begin{tabular}{|c|c|c|c|c|c|c|}
\hline \multirow{5}{*}{$\begin{array}{c}\text { Entry-Exit } \\
\text { Curve Radius } \\
\text { R (m) }\end{array}$} & \multicolumn{6}{|c|}{${ }^{a}$ Design Speed $(\mathrm{km} / \mathrm{h})$} \\
\hline & \multicolumn{2}{|c|}{20} & \multicolumn{2}{|c|}{30} & \multicolumn{2}{|c|}{40} \\
\hline & \multicolumn{6}{|c|}{ Stopping Sight Distance (m) } \\
\hline & \multicolumn{2}{|c|}{19} & \multicolumn{2}{|c|}{32} & \multicolumn{2}{|c|}{48} \\
\hline & ${ }^{\mathrm{b}} \mathrm{C}$ & ${ }^{\mathrm{c}} \mathrm{D}$ & ${ }^{\mathrm{b}} \mathrm{C}$ & ${ }^{\mathrm{c}} \mathrm{D}$ & ${ }^{\mathrm{b}} \mathrm{C}$ & ${ }^{\mathrm{c}} \mathrm{D}$ \\
\hline 20 & 3.5 & 0.36 & & & & \\
\hline 30 & 2.8 & 3.20 & 5.4 & -9.80 & & \\
\hline 40 & 2.4 & 6.22 & 4.3 & -6.79 & & \\
\hline 50 & 2.2 & 9.27 & 3.7 & -3.74 & 6.8 & -19.74 \\
\hline 60 & 2.1 & 12.33 & 3.2 & -0.68 & 5.8 & -16.68 \\
\hline
\end{tabular}

${ }^{a}$ For shaded areas, radius of exit curve is less than minimum radius for the entry speed and cross slopes.

${ }^{\mathrm{b}}$ Maximum Lateral Clearance on the exits

${ }^{c}$ Difference between available sight distance (length of curve on vehicle path from vehicle entry on yield line to near edge of the typical crosswalk, $6 \mathrm{~m}$ away from yield line) and location of near edge of the crosswalk to satisfy SSD.

Table C3.12 Design values of lateral clearance on the exits, $\mathrm{P}_{\mathrm{f}}=5.00 \%, \mathrm{CV}=15 \%$

\begin{tabular}{|c|c|c|c|c|c|c|}
\hline \multirow{5}{*}{$\begin{array}{c}\text { Entry-Exit } \\
\text { Curve Radius } \\
\text { R (m) }\end{array}$} & \multicolumn{6}{|c|}{${ }^{\mathrm{a}}$ Design Speed $(\mathrm{km} / \mathrm{h})$} \\
\hline & \multicolumn{2}{|c|}{20} & \multicolumn{2}{|c|}{30} & \multicolumn{2}{|c|}{40} \\
\hline & \multicolumn{6}{|c|}{ Stopping Sight Distance (m) } \\
\hline & \multicolumn{2}{|c|}{17} & \multicolumn{2}{|c|}{28} & \multicolumn{2}{|c|}{42} \\
\hline & ${ }^{\mathrm{b}} \mathrm{C}$ & ${ }^{\mathrm{c}} \mathrm{D}$ & ${ }^{\mathrm{b}} \mathrm{C}$ & ${ }^{\mathrm{c}} \mathrm{D}$ & ${ }^{\mathrm{b}} \mathrm{C}$ & ${ }^{\mathrm{c}} \mathrm{D}$ \\
\hline 20 & 3.1 & 2.65 & & & & \\
\hline 30 & 2.5 & 5.43 & 4.4 & -5.57 & & \\
\hline 40 & 2.2 & 8.35 & 3.57 & -2.65 & & \\
\hline 50 & 2.1 & 11.33 & 3.1 & 0.34 & 5.4 & -13.74 \\
\hline 60 & 2.0 & 14.34 & 2.7 & 3.34 & 4.7 & -10.68 \\
\hline
\end{tabular}

${ }^{a}$ For shaded areas, radius of exit curve is less than minimum radius for the entry speed and cross slopes.

${ }^{\mathrm{b}}$ Maximum Lateral Clearance on the exits

${ }^{\mathrm{c}}$ Difference between available sight distance (length of curve on vehicle path from vehicle entry on yield line to near edge of the typical crosswalk, $6 \mathrm{~m}$ away from yield line) and location of near edge of the crosswalk to satisfy SSD. 
Table C3.13 Design values of lateral clearance on circulatory lane, $P_{f}=0.01 \%, \mathrm{CV}=15 \%$

\begin{tabular}{|c|c|c|c|c|c|c|}
\hline \multirow{5}{*}{$\begin{array}{c}\text { Central Island } \\
\text { Radius } \\
\text { R (m) }\end{array}$} & \multicolumn{6}{|c|}{ Design Speed $(\mathrm{Km} / \mathrm{h})$} \\
\hline & \multicolumn{2}{|c|}{20} & \multicolumn{2}{|c|}{30} & \multicolumn{2}{|c|}{40} \\
\hline & \multicolumn{6}{|c|}{ Stopping Sight Distance (m) } \\
\hline & \multicolumn{2}{|c|}{25} & \multicolumn{2}{|c|}{43} & \multicolumn{2}{|c|}{67} \\
\hline & ${ }^{\mathrm{a}} \mathrm{M}$ & ${ }^{\mathrm{b}} \psi$ & ${ }^{\mathrm{a}} \mathrm{M}$ & ${ }^{\mathrm{b}} \psi$ & ${ }^{\mathrm{a}} \mathrm{M}$ & ${ }^{\mathrm{b}} \psi$ \\
\hline 20 & 4.5 & 1.37 & 11.6 & 2.27 & 23.3 & 3.44 \\
\hline 30 & 3.1 & 0.92 & 8.2 & 1.52 & 18.0 & 2.32 \\
\hline 40 & 2.4 & 0.69 & 6.3 & 1.14 & 14.2 & 1.74 \\
\hline 50 & 1.9 & 0.55 & 5.1 & 0.91 & 11.6 & 1.39 \\
\hline
\end{tabular}

${ }^{a}$ Maximum Lateral Clearance on Circulatory Lane

${ }^{\mathrm{b}}$ Drivers Peripheral Vision (Central angle) in radians, central island radius with design speed which result to peripheral vision of over 2.44 is inadequate and should not be used in design.

Table C3.14Design values of lateral clearance on circulatory lane, $P_{f}=0.1 \%, \mathrm{CV}=15 \%$

\begin{tabular}{|c|c|c|c|c|c|c|}
\hline \multirow{5}{*}{$\begin{array}{c}\text { Central Island } \\
\text { Radius } \\
\text { R (m) }\end{array}$} & \multicolumn{6}{|c|}{ Design Speed $(\mathrm{Km} / \mathrm{h})$} \\
\hline & \multicolumn{2}{|c|}{20} & \multicolumn{2}{|c|}{30} & \multicolumn{2}{|c|}{20} \\
\hline & \multicolumn{6}{|c|}{ Stopping Sight Distance (m) } \\
\hline & \multicolumn{2}{|c|}{22} & \multicolumn{2}{|c|}{37} & \multicolumn{2}{|c|}{57} \\
\hline & ${ }^{\mathrm{a}} \mathrm{M}$ & ${ }^{\mathrm{b}} \psi$ & ${ }^{\mathrm{a}} \mathrm{M}$ & ${ }^{\mathrm{b}} \psi$ & ${ }^{\mathrm{a}} \mathrm{M}$ & ${ }^{\mathrm{b}} \psi$ \\
\hline 20 & 3.6 & 1.22 & 9.0 & 1.97 & 18.3 & 2.97 \\
\hline 30 & 2.5 & 0.82 & 6.3 & 1.31 & 13.6 & 1.98 \\
\hline 40 & 1.9 & 0.61 & 4.8 & 1.0 & 10.6 & 1.49 \\
\hline 50 & 1.48 & 0.49 & 9.0 & 1.97 & 8.6 & 1.19 \\
\hline
\end{tabular}

${ }^{a}$ Maximum Lateral Clearance on Circulatory Lane

${ }^{\mathrm{b}}$ Drivers Peripheral Vision (Central angle) in radians, central island radius with design speed which result to peripheral vision of over 2.44 is inadequate and should not be used in design. 
Table C3.15 Design values of lateral clearance on circulatory lane, $P_{f}=1.00 \%, \mathrm{CV}=15 \%$

\begin{tabular}{|c|c|c|c|c|c|c|}
\hline \multirow{5}{*}{$\begin{array}{l}\text { Central Island } \\
\text { Radius } \\
\text { R (m) }\end{array}$} & \multicolumn{6}{|c|}{ Design Speed $(\mathrm{Km} / \mathrm{h})$} \\
\hline & \multicolumn{2}{|c|}{20} & \multicolumn{2}{|c|}{30} & \multicolumn{2}{|c|}{20} \\
\hline & \multicolumn{6}{|c|}{ Stopping Sight Distance (m) } \\
\hline & \multicolumn{2}{|c|}{19} & \multicolumn{2}{|c|}{32} & \multicolumn{2}{|c|}{48} \\
\hline & ${ }^{\mathrm{a}} \mathrm{M}$ & ${ }^{\mathrm{b}} \psi$ & ${ }^{\mathrm{a}} \mathrm{M}$ & ${ }^{\mathrm{b}} \psi$ & ${ }^{\mathrm{a}} \mathrm{M}$ & ${ }^{\mathrm{b}} \psi$ \\
\hline 20 & 2.9 & 1.07 & 7.0 & 1.72 & 13.9 & 2.52 \\
\hline 30 & 1.9 & 0.72 & 4.8 & 1.15 & 10.0 & 1.68 \\
\hline 40 & 1.5 & 0.54 & 3.7 & 0.86 & 7.7 & 1.26 \\
\hline 50 & 1.2 & 0.43 & 2.9 & 0.69 & 6.3 & 1.01 \\
\hline
\end{tabular}

${ }^{a}$ Maximum Lateral Clearance on Circulatory Lane

${ }^{\mathrm{b}}$ Drivers Peripheral Vision (Central angle) in radians, central island radius with design speed which result to peripheral vision of over 2.44 is inadequate and should not be used in design.

Table C3.16 Design values of lateral clearance on circulatory lane, $P_{f}=5.00 \%, \mathrm{CV}=15 \%$

\begin{tabular}{|c|c|c|c|c|c|c|}
\hline \multirow{5}{*}{$\begin{array}{c}\text { Central Island } \\
\text { Radius } \\
\text { R (m) }\end{array}$} & \multicolumn{6}{|c|}{ Design Speed $(\mathrm{Km} / \mathrm{h})$} \\
\hline & \multicolumn{2}{|c|}{20} & \multicolumn{2}{|c|}{30} & \multicolumn{2}{|c|}{20} \\
\hline & \multicolumn{6}{|c|}{ Stopping Sight Distance (m) } \\
\hline & \multicolumn{2}{|c|}{17} & \multicolumn{2}{|c|}{28} & \multicolumn{2}{|c|}{42} \\
\hline & ${ }^{\mathrm{a}} \mathrm{M}$ & ${ }^{\mathrm{b}} \psi$ & ${ }^{\mathrm{a}} \mathrm{M}$ & ${ }^{\mathrm{b}} \psi$ & ${ }^{\mathrm{a}} \mathrm{M}$ & ${ }^{\mathrm{b}} \psi$ \\
\hline 20 & 2.3 & 0.97 & 5.5 & 1.52 & 11.1 & 2.22 \\
\hline 30 & 1.6 & 0.65 & 3.8 & 1.02 & 7.85 & 1.48 \\
\hline 40 & 1.2 & 0.49 & 2.9 & 0.76 & 6.0 & 1.11 \\
\hline 50 & 1.0 & 0.39 & 2.3 & 0.61 & 4.9 & 0.88 \\
\hline
\end{tabular}

${ }^{a}$ Maximum Lateral Clearance on Circulatory Lane

${ }^{\mathrm{b}}$ Drivers Peripheral Vision (Central angle) in radians, central island radius with design speed which result to peripheral vision of over 2.44 is inadequate and should not be used in design. 
APPENDIX D

DESIGN AIDS FOR DECISION SIGHT DISTANCE OF URBAN ROUNDABOUTS 
Table D3. 1 Lateral clearance design values for urban roundabouts (DSD to the crosswalk), $P_{f}=0.1 \%, \mathrm{CV}=10 \%$

\begin{tabular}{|c|c|c|c|c|c|}
\hline \multirow{5}{*}{$\begin{array}{l}\text { First Entry Curve } \\
\qquad \begin{array}{c}\text { Radius } \\
R_{1}(\mathrm{~m})\end{array}\end{array}$} & \multirow{5}{*}{$\begin{array}{c}\text { Second Entry } \\
\text { Curve Radius } \\
R_{2}(\mathrm{~m})\end{array}$} & \multicolumn{4}{|c|}{ Maximum Lateral Clearance (m) } \\
\hline & & \multicolumn{4}{|c|}{ Design Speed $(\mathrm{Km} / \mathrm{h})^{a}$} \\
\hline & & 40 & 50 & 60 & 70 \\
\hline & & \multicolumn{4}{|c|}{ Decision Sight Distance (m) } \\
\hline & & 111 & 146 & 185 & 227 \\
\hline \multirow[t]{3}{*}{100} & 20 & 16.4 & 26.8 & & \\
\hline & 30 & 16.3 & 26.7 & & \\
\hline & 40 & 16.2 & 26.6 & & \\
\hline \multirow[t]{3}{*}{300} & 20 & 6.7 & 10.4 & 15.6 & 22.7 \\
\hline & 30 & 6.4 & 10.1 & 15.4 & 22.5 \\
\hline & 40 & 6.3 & 10.0 & 15.3 & 22.4 \\
\hline \multirow[t]{3}{*}{500} & 20 & 4.8 & 6.9 & 10.0 & 14.3 \\
\hline & 30 & 4.5 & 6.6 & 9.8 & 14.1 \\
\hline & 40 & 4.3 & 6.5 & 9.6 & 13.9 \\
\hline \multirow[t]{3}{*}{1000} & 20 & 3.8 & 4.5 & 5.9 & 7.9 \\
\hline & 30 & 3.3 & 4.1 & 5.6 & 7.6 \\
\hline & 40 & 3.1 & 3.9 & 5.4 & 7.5 \\
\hline
\end{tabular}

${ }^{\text {a }}$ For shaded cells, $R_{1}$ is less than $R_{\min }$ for the respective vehicle speed on the Approaches and superelevation of up to 0.06 .

Table D3. 2 Lateral clearance design values for urban roundabouts (DSD to the crosswalk)

$$
P_{f}=1.0 \%, \mathrm{CV}=10 \%
$$

\begin{tabular}{|c|c|c|c|c|c|}
\hline \multirow{5}{*}{$\begin{array}{c}\text { First Entry Curve } \\
\qquad \begin{array}{c}\text { Radius } \\
R_{1}(\mathrm{~m})\end{array}\end{array}$} & \multirow{5}{*}{$\begin{array}{c}\text { Second Entry } \\
\text { Curve Radius } \\
R_{2}(\mathrm{~m})\end{array}$} & \multicolumn{4}{|c|}{ Maximum Lateral Clearance (m) } \\
\hline & & \multicolumn{4}{|c|}{ Design Speed $(\mathrm{Km} / \mathrm{h})^{a}$} \\
\hline & & 40 & 50 & 60 & 70 \\
\hline & & \multicolumn{4}{|c|}{ Decision Sight Distance (m) } \\
\hline & & 103 & 134 & 170 & 208 \\
\hline \multirow[t]{3}{*}{100} & 20 & 14.4 & 23.0 & & \\
\hline & 30 & 14.3 & 22.9 & & \\
\hline & 40 & 14.2 & 22.8 & & \\
\hline \multirow[t]{3}{*}{300} & 20 & 6.1 & 9.0 & 13.5 & 19.3 \\
\hline & 30 & 5.8 & 8.7 & 13.3 & 19.1 \\
\hline & 40 & 5.6 & 8.6 & 13.1 & 19.0 \\
\hline \multirow[t]{3}{*}{500} & 20 & 4.5 & 6.1 & 8.7 & 12.2 \\
\hline & 30 & 4.1 & 5.8 & 8.5 & 12.0 \\
\hline & 40 & 3.9 & 5.6 & 8.3 & 11.9 \\
\hline \multirow[t]{3}{*}{1000} & 20 & 3.8 & 4.2 & 5.3 & 6.9 \\
\hline & 30 & 3.3 & 3.8 & 4.9 & 6.6 \\
\hline & 40 & 3.0 & 3.6 & 4.8 & 6.5 \\
\hline
\end{tabular}

${ }^{\text {a }}$ For shaded cells, $R_{1}$ is less than $R_{\min }$ for the respective vehicle speed on the Approaches and superelevation of up to 0.06 . 
Table D3. 3 Lateral clearance design values for urban roundabouts (DSD to the crosswalk), $P_{f}=5 \%, \mathrm{CV}=10 \%$

\begin{tabular}{|c|c|c|c|c|c|}
\hline \multirow{5}{*}{$\begin{array}{c}\text { First Entry Curve } \\
\qquad \begin{array}{c}\text { Radius } \\
R_{1}(\mathrm{~m})\end{array}\end{array}$} & \multirow{5}{*}{$\begin{array}{c}\text { Second Entry } \\
\text { Curve Radius } \\
R_{2}(\mathrm{~m})\end{array}$} & \multicolumn{4}{|c|}{ Maximum Lateral Clearance (m) } \\
\hline & & \multicolumn{4}{|c|}{ Design Speed $(\mathrm{Km} / \mathrm{h})^{a}$} \\
\hline & & 40 & 50 & 60 & 40 \\
\hline & & \multicolumn{4}{|c|}{ Decision Sight Distance (m) } \\
\hline & & 96 & 124 & 157 & 191 \\
\hline \multirow[t]{3}{*}{100} & 20 & 12.8 & 20.0 & & \\
\hline & 30 & 12.6 & 19.9 & & \\
\hline & 40 & 12.6 & 19.8 & & \\
\hline \multirow[t]{3}{*}{300} & 20 & 5.5 & 8.0 & 11.7 & 16.6 \\
\hline & 30 & 5.2 & 7.7 & 11.5 & 16.4 \\
\hline & 40 & 5.0 & 7.5 & 11.4 & 16.2 \\
\hline \multirow[t]{3}{*}{500} & 20 & 4.2 & 5.5 & 7.7 & 10.6 \\
\hline & 30 & 3.8 & 5.2 & 7.4 & 10.3 \\
\hline & 40 & 3.6 & 5.0 & 7.3 & 10.2 \\
\hline \multirow[t]{3}{*}{1000} & 20 & 3.7 & 4.0 & 4.8 & 6.1 \\
\hline & 30 & 3.2 & 3.6 & 4.5 & 5.8 \\
\hline & 40 & 2.9 & 3.3 & 4.3 & 5.6 \\
\hline
\end{tabular}

${ }^{\text {a }}$ For shaded cells, $R_{1}$ is less than $R_{\min }$ for the respective vehicle speed on the Approaches and superelevation of up to 0.06 .

Table D3. 4 Lateral clearance design values for urban roundabouts (DSD to the yield line),

$$
P_{f}=0.01 \%, \mathrm{CV}=10 \%
$$

\begin{tabular}{|c|c|c|c|c|c|}
\hline \multirow{5}{*}{$\begin{array}{c}\text { First Entry Curve } \\
\qquad \begin{array}{c}\text { Radius } \\
R_{1}(\mathrm{~m})\end{array}\end{array}$} & \multirow{5}{*}{$\begin{array}{c}\text { Second Entry } \\
\text { Curve Radius } \\
R_{2}(\mathrm{~m})\end{array}$} & \multicolumn{4}{|c|}{ Maximum Lateral Clearance (m) } \\
\hline & & \multicolumn{4}{|c|}{ Design Speed $(\mathrm{Km} / \mathrm{h})^{a}$} \\
\hline & & 40 & 50 & 60 & 70 \\
\hline & & \multicolumn{4}{|c|}{ Decision Sight Distance (m) } \\
\hline & & 119 & 155 & 198 & 245 \\
\hline \multirow[t]{3}{*}{100} & 20 & 18.0 & 29.0 & & \\
\hline & 30 & 17.2 & 28.4 & & \\
\hline & 40 & 16.8 & 28.0 & & \\
\hline \multirow[t]{3}{*}{300} & 20 & 7.5 & 11.5 & 17.6 & 26.0 \\
\hline & 30 & 6.4 & 10.4 & 16.6 & 25.0 \\
\hline & 40 & 5.8 & 9.9 & 16.1 & 24.6 \\
\hline \multirow[t]{3}{*}{500} & 20 & 5.5 & 7.7 & 11.3 & 16.4 \\
\hline & 30 & 4.2 & 6.6 & 10.3 & 15.4 \\
\hline & 40 & 3.6 & 6.0 & 9.8 & 14.9 \\
\hline \multirow[t]{3}{*}{1000} & 20 & 4.4 & 5.2 & 6.8 & 9.2 \\
\hline & 30 & 2.7 & 3.8 & 5.5 & 8.1 \\
\hline & 40 & 1.9 & 3.1 & 4.9 & 7.5 \\
\hline
\end{tabular}

${ }^{\text {a }}$ For shaded cells, $R_{1}$ is less than $R_{\min }$ for the respective vehicle speed on the Approaches and superelevation of up to 0.06 . 
Table D3. 5 Lateral clearance design values for urban roundabouts (DSD to the yield line), $P_{f}=0.1 \%, \mathrm{CV}=10 \%$

\begin{tabular}{|c|c|c|c|c|c|}
\hline \multirow{5}{*}{$\begin{array}{c}\text { First Entry Curve } \\
\qquad \begin{array}{c}\text { Radius } \\
R_{1}(\mathrm{~m})\end{array}\end{array}$} & \multirow{5}{*}{$\begin{array}{c}\text { Second Entry } \\
\text { Curve Radius } \\
R_{2}(\mathrm{~m})\end{array}$} & \multicolumn{4}{|c|}{ Maximum Lateral Clearance (m) } \\
\hline & & \multicolumn{4}{|c|}{ Design Speed $(\mathrm{Km} / \mathrm{h})^{a}$} \\
\hline & & 40 & 50 & 60 & 70 \\
\hline & & \multicolumn{4}{|c|}{ Decision Sight Distance (m) } \\
\hline & & 111 & 146 & 185 & 227 \\
\hline \multirow[t]{3}{*}{100} & 20 & 15.9 & 26.0 & & \\
\hline & 30 & 15.0 & 25.4 & & \\
\hline & 40 & 14.6 & 25.0 & & \\
\hline \multirow[t]{3}{*}{300} & 20 & 6.8 & 10.4 & 15.6 & 22.5 \\
\hline & 30 & 5.6 & 9.3 & 14.6 & 21.6 \\
\hline & 40 & 5.1 & 8.8 & 14.1 & 21.0 \\
\hline \multirow[t]{3}{*}{500} & 20 & 5.1 & 7.1 & 10.2 & 14.3 \\
\hline & 30 & 3.7 & 5.9 & 9.1 & 13.3 \\
\hline & 40 & 3.1 & 5.3 & 8.5 & 12.8 \\
\hline \multirow[t]{3}{*}{1000} & 20 & 4.3 & 4.9 & 6.2 & 8.2 \\
\hline & 30 & 2.5 & 3.4 & 4.9 & 7.0 \\
\hline & 40 & 1.8 & 2.7 & 4.3 & 6.5 \\
\hline
\end{tabular}

${ }^{\text {a }}$ For shaded cells, $R_{1}$ is less than $R_{\min }$ for the respective vehicle speed on the Approaches and superelevation of up to 0.06 .

Table D3. 6 Lateral clearance design values for urban roundabouts (DSD to the yield line),

$$
P_{f}=1.0 \%, \mathrm{CV}=10 \%
$$

\begin{tabular}{|c|c|c|c|c|c|}
\hline \multirow{4}{*}{$\begin{array}{l}\text { First Entry Curve } \\
\qquad \begin{array}{c}\text { Radius } \\
R_{1}(\mathrm{~m})\end{array}\end{array}$} & \multirow{4}{*}{$\begin{array}{c}\text { Second Entry } \\
\text { Curve Radius } \\
R_{2}(\mathrm{~m})\end{array}$} & \multicolumn{4}{|c|}{ Maximum Lateral Clearance (m) } \\
\hline & & \multicolumn{4}{|c|}{ Design Speed $(\mathrm{Km} / \mathrm{h})^{a}$} \\
\hline & & 40 & 50 & 60 & 70 \\
\hline & & \multicolumn{4}{|c|}{ Decision Sight Distance (m) } \\
\hline & & 103 & 134 & 170 & 208 \\
\hline \multirow[t]{3}{*}{100} & 20 & 13.9 & 22.3 & & \\
\hline & 30 & 13.0 & 21.5 & & \\
\hline & 40 & 12.5 & 21.1 & & \\
\hline \multirow[t]{3}{*}{300} & 20 & 6.1 & 9.0 & 13.4 & 19.2 \\
\hline & 30 & 5.0 & 7.9 & 12.4 & 18.2 \\
\hline & 40 & 4.3 & 7.4 & 11.9 & 17.7 \\
\hline \multirow[t]{3}{*}{500} & 20 & 4.8 & 6.3 & 8.9 & 12.3 \\
\hline & 30 & 3.4 & 5.1 & 7.7 & 11.3 \\
\hline & 40 & 2.7 & 4.4 & 7.2 & 10.7 \\
\hline \multirow[t]{3}{*}{1000} & 20 & 4.3 & 4.6 & 5.6 & 7.2 \\
\hline & 30 & 2.4 & 3.1 & 4.3 & 6.0 \\
\hline & 40 & 1.6 & 2.4 & 3.7 & 5.4 \\
\hline
\end{tabular}

${ }^{\text {a }}$ For shaded cells, $R_{1}$ is less than $R_{\min }$ for the respective vehicle speed on the Approaches and superelevation of up to 0.06 . 
APPENDIX E

DESIGN AIDS FOR DECISION SIGHT DISTANCE OF RURAL ROUNDABOUTS 
Table E3.1 Lateral clearance design values for rural roundabouts (DSD to the crosswalk), $P_{f}=0.1 \%, \mathrm{CV}=10 \%$

\begin{tabular}{|c|c|c|c|c|c|}
\hline \multirow{5}{*}{$\begin{array}{l}\text { First Entry Curve } \\
\qquad \begin{array}{c}\text { Radius } \\
R_{1}(\mathrm{~m})\end{array}\end{array}$} & \multirow{5}{*}{$\begin{array}{c}\text { Second Entry } \\
\text { Curve Radius } \\
R_{2}(\mathrm{~m})\end{array}$} & \multicolumn{4}{|c|}{ Maximum Lateral Clearance (m) } \\
\hline & & \multicolumn{4}{|c|}{ Design Speed $(\mathrm{Km} / \mathrm{h})^{a}$} \\
\hline & & 40 & 50 & 60 & 70 \\
\hline & & \multicolumn{4}{|c|}{ Decision Sight Distance (m) } \\
\hline & & 51 & 70 & 91 & 118 \\
\hline \multirow[t]{3}{*}{100} & 20 & 5.0 & 7.6 & & \\
\hline & 30 & 4.7 & 7.4 & & \\
\hline & 40 & 4.5 & 7.3 & & \\
\hline \multirow[t]{3}{*}{300} & 20 & 3.5 & 4.1 & 5.2 & 7.3 \\
\hline & 30 & 3.0 & 3.6 & 4.9 & 7.1 \\
\hline & 40 & 2.8 & 3.4 & 4.7 & 6.9 \\
\hline \multirow[t]{3}{*}{500} & 20 & 3.4 & 3.6 & 4.1 & 5.1 \\
\hline & 30 & 2.9 & 3.2 & 3.7 & 4.8 \\
\hline & 40 & 2.6 & 2.9 & 3.5 & 4.6 \\
\hline \multirow[t]{3}{*}{1000} & 20 & 3.2 & 3.5 & 3.7 & 3.9 \\
\hline & 30 & 2.7 & 3.0 & 3.2 & 3.4 \\
\hline & 40 & 2.5 & 2.7 & 2.9 & 3.2 \\
\hline
\end{tabular}

${ }^{\text {a }}$ For shaded cells, $R_{1}$ is less than $R_{\min }$ for the respective vehicle speed on the Approaches and superelevation of up to 0.06 .

Table E3.2 Lateral clearance design values for rural roundabouts (DSD to the crosswalk), $P_{f}=1.0 \%, \mathrm{CV}=10 \%$

\begin{tabular}{|c|c|c|c|c|c|}
\hline \multirow{5}{*}{$\begin{array}{l}\text { First Entry Curve } \\
\qquad \begin{array}{c}\text { Radius } \\
R_{1}(\mathrm{~m})\end{array}\end{array}$} & \multirow{5}{*}{$\begin{array}{c}\text { Second Entry } \\
\text { Curve Radius } \\
R_{2}(\mathrm{~m})\end{array}$} & \multicolumn{4}{|c|}{ Maximum Lateral Clearance (m) } \\
\hline & & \multicolumn{4}{|c|}{ Design Speed $(\mathrm{Km} / \mathrm{h})^{a}$} \\
\hline & & 40 & 50 & 60 & 70 \\
\hline & & \multicolumn{4}{|c|}{ Decision Sight Distance (m) } \\
\hline & & 46 & 62 & 81 & 105 \\
\hline \multirow[t]{3}{*}{100} & 20 & 4.4 & 6.4 & & \\
\hline & 30 & 4.0 & 6.1 & & \\
\hline & 40 & 3.9 & 6.0 & & \\
\hline \multirow[t]{3}{*}{300} & 20 & 3.4 & 3.8 & 4.5 & 6.2 \\
\hline & 30 & 2.9 & 3.3 & 4.2 & 5.9 \\
\hline & 40 & 2.7 & 3.1 & 4.0 & 5.7 \\
\hline \multirow[t]{3}{*}{500} & 20 & 3.2 & 3.6 & 3.9 & 4.6 \\
\hline & 30 & 2.8 & 3.1 & 3.4 & 4.2 \\
\hline & 40 & 2.5 & 2.8 & 3.2 & 4.0 \\
\hline \multirow[t]{3}{*}{1000} & 20 & 3.1 & 3.4 & 3.6 & 3.8 \\
\hline & 30 & 2.7 & 2.9 & 3.1 & 3.3 \\
\hline & 40 & 2.4 & 2.6 & 2.8 & 3.0 \\
\hline
\end{tabular}

${ }^{\text {a }}$ For shaded cells, $R_{1}$ is less than $R_{\text {min }}$ for the respective vehicle speed on the Approaches and superelevation of up to 0.06 . 
Table E3.3 Lateral clearance design values for rural roundabouts (DSD to the crosswalk), $P_{f}=5 \%, C V=10 \%$

\begin{tabular}{|c|c|c|c|c|c|}
\hline \multirow{5}{*}{$\begin{array}{l}\text { First Entry Curve } \\
\qquad \begin{array}{c}\text { Radius } \\
R_{1}(\mathrm{~m})\end{array}\end{array}$} & \multirow{5}{*}{$\begin{array}{l}\text { Second Entry } \\
\text { Curve Radius } \\
\qquad R_{2}(\mathrm{~m})\end{array}$} & \multicolumn{4}{|c|}{ Maximum Lateral Clearance (m) } \\
\hline & & \multicolumn{4}{|c|}{ Design Speed $(\mathrm{Km} / \mathrm{h})^{a}$} \\
\hline & & 40 & 50 & 60 & 70 \\
\hline & & \multicolumn{4}{|c|}{ Decision Sight Distance (m) } \\
\hline & & 42 & 57 & 73 & 94 \\
\hline \multirow[t]{3}{*}{100} & 20 & 4.1 & 5.7 & & \\
\hline & 30 & 3.7 & 5.4 & & \\
\hline & 40 & 3.6 & 5.2 & & \\
\hline \multirow[t]{3}{*}{300} & 20 & 3.3 & 3.7 & 4.2 & 5.4 \\
\hline & 30 & 2.8 & 3.2 & 3.8 & 5.0 \\
\hline & 40 & 2.6 & 3.0 & 3.5 & 4.9 \\
\hline \multirow[t]{3}{*}{500} & 20 & 3.1 & 3.5 & 3.7 & 4.2 \\
\hline & 30 & 2.7 & 3.0 & 3.3 & 3.8 \\
\hline & 40 & 2.5 & 2.7 & 3.0 & 3.6 \\
\hline \multirow[t]{3}{*}{1000} & 20 & 3.1 & 3.3 & 3.5 & 3.7 \\
\hline & 30 & 2.6 & 2.8 & 3.0 & 3.2 \\
\hline & 40 & 2.4 & 2.6 & 2.7 & 3.0 \\
\hline
\end{tabular}

${ }^{\text {a }}$ For shaded cells, $R_{1}$ is less than $R_{\min }$ for the respective vehicle speed on the Approaches and superelevation of up to 0.06 .

Table E3.4 Lateral clearance design values for rural roundabouts (DSD to the yield line), $P_{f}=0.01 \%, \mathrm{CV}=10 \%$

\begin{tabular}{|c|c|c|c|c|c|}
\hline \multirow{5}{*}{$\begin{array}{c}\text { First Entry Curve } \\
\qquad \begin{array}{c}\text { Radius } \\
R_{1}(\mathrm{~m})\end{array}\end{array}$} & \multirow{5}{*}{$\begin{array}{c}\text { Second Entry } \\
\text { Curve Radius } \\
R_{2}(\mathrm{~m})\end{array}$} & \multicolumn{4}{|c|}{ Maximum Lateral Clearance (m) } \\
\hline & & \multicolumn{4}{|c|}{ Design Speed $(\mathrm{Km} / \mathrm{h})^{a}$} \\
\hline & & 40 & 50 & 60 & 40 \\
\hline & & \multicolumn{4}{|c|}{ Decision Sight Distance (m) } \\
\hline & & 55 & 77 & 101 & 131 \\
\hline \multirow[t]{3}{*}{100} & 20 & 5.1 & 8.4 & & \\
\hline & 30 & 3.9 & 7.4 & & \\
\hline & 40 & 3.3 & 6.9 & & \\
\hline \multirow[t]{3}{*}{300} & 20 & 3.6 & 4.6 & 6.0 & 8.8 \\
\hline & 30 & 2.1 & 3.1 & 4.8 & 7.6 \\
\hline & 40 & 1.3 & 2.5 & 4.2 & 7.0 \\
\hline \multirow[t]{3}{*}{500} & 20 & 3.3 & 4.1 & 4.8 & 6.1 \\
\hline & 30 & 1.8 & 2.4 & 3.4 & 4.9 \\
\hline & 40 & 1.0 & 1.6 & 2.7 & 4.3 \\
\hline \multirow[t]{3}{*}{1000} & 20 & 3.2 & 3.7 & 4.2 & 4.6 \\
\hline & 30 & 1.6 & 2.0 & 2.4 & 3.0 \\
\hline & 40 & 0.8 & 1.2 & 1.6 & 2.3 \\
\hline
\end{tabular}

${ }^{\text {a }}$ For shaded cells, $R_{1}$ is less than $R_{\text {min }}$ for the respective vehicle speed on the Approaches and superelevation of up to 0.06 . 
Table E3.5 Lateral clearance design values for rural roundabouts (DSD to the yield line), $P_{f}=0.1 \%, \mathrm{CV}=10 \%$

\begin{tabular}{|c|c|c|c|c|c|}
\hline \multirow{5}{*}{$\begin{array}{l}\text { First Entry Curve } \\
\qquad \begin{array}{c}\text { Radius } \\
R_{1}(\mathrm{~m})\end{array}\end{array}$} & \multirow{5}{*}{$\begin{array}{c}\text { Second Entry } \\
\text { Curve Radius } \\
R_{2}(\mathrm{~m})\end{array}$} & \multicolumn{4}{|c|}{ Maximum Lateral Clearance (m) } \\
\hline & & \multicolumn{4}{|c|}{ Design Speed $(\mathrm{Km} / \mathrm{h})^{a}$} \\
\hline & & 40 & 50 & 60 & 40 \\
\hline & & \multicolumn{4}{|c|}{ Decision Sight Distance (m) } \\
\hline & & 51 & 70 & 91 & 118 \\
\hline \multirow[t]{3}{*}{100} & 20 & 4.7 & 7.2 & & \\
\hline & 30 & 3.4 & 6.2 & & \\
\hline & 40 & 2.8 & 5.6 & & \\
\hline \multirow[t]{3}{*}{300} & 20 & 3.5 & 5.2 & 5.3 & 7.4 \\
\hline & 30 & 1.9 & 3.8 & 4.0 & 6.3 \\
\hline & 40 & 1.2 & 3.2 & 3.4 & 5.7 \\
\hline \multirow[t]{3}{*}{500} & 20 & 3.2 & 4.4 & 4.5 & 5.5 \\
\hline & 30 & 1.7 & 2.7 & 2.9 & 4.2 \\
\hline & 40 & 0.9 & 2.0 & 2.1 & 3.5 \\
\hline \multirow[t]{3}{*}{1000} & 20 & 3.0 & 4.0 & 4.0 & 4.4 \\
\hline & 30 & 1.5 & 2.3 & 2.2 & 2.7 \\
\hline & 40 & 0.8 & 1.4 & 1.4 & 1.9 \\
\hline
\end{tabular}

${ }^{\text {a }}$ For shaded cells, $R_{1}$ is less than $R_{\min }$ for the respective vehicle speed on the Approaches and superelevation of up to 0.06 .

Table E3.6 Lateral clearance design values for rural roundabouts (DSD to the yield line),

$$
P_{f}=1.0 \%, \mathrm{CV}=10 \%
$$

\begin{tabular}{|c|c|c|c|c|c|}
\hline \multirow{5}{*}{$\begin{array}{c}\text { First Entry Curve } \\
\qquad \begin{array}{c}\text { Radius } \\
R_{1}(\mathrm{~m})\end{array}\end{array}$} & \multirow{5}{*}{$\begin{array}{c}\text { Second Entry } \\
\text { Curve Radius } \\
R_{2}(\mathrm{~m})\end{array}$} & \multicolumn{4}{|c|}{ Maximum Lateral Clearance (m) } \\
\hline & & \multicolumn{4}{|c|}{ Design Speed $(\mathrm{Km} / \mathrm{h})^{a}$} \\
\hline & & 40 & 50 & 60 & 40 \\
\hline & & \multicolumn{4}{|c|}{ Decision Sight Distance (m) } \\
\hline & & 46 & 62 & 81 & 105 \\
\hline \multirow[t]{3}{*}{100} & 20 & 4.2 & 6.3 & & \\
\hline & 30 & 2.8 & 5.1 & & \\
\hline & 40 & 2.2 & 4.6 & & \\
\hline \multirow[t]{3}{*}{300} & 20 & 3.1 & 4.0 & 4.8 & 6.4 \\
\hline & 30 & 1.7 & 2.4 & 3.4 & 5.1 \\
\hline & 40 & 1.0 & 1.7 & 2.7 & 4.5 \\
\hline \multirow[t]{3}{*}{500} & 20 & 2.9 & 3.6 & 4.2 & 4.9 \\
\hline & 30 & 1.6 & 2.0 & 2.5 & 3.5 \\
\hline & 40 & 0.8 & 1.2 & 1.7 & 2.8 \\
\hline \multirow[t]{3}{*}{1000} & 20 & 2.8 & 3.4 & 3.8 & 4.3 \\
\hline & 30 & 1.4 & 1.8 & 2.1 & 2.5 \\
\hline & 40 & 0.6 & 1.0 & 1.3 & 1.7 \\
\hline
\end{tabular}

${ }^{\text {a }}$ For shaded cells, $R_{1}$ is less than $R_{\min }$ for the respective vehicle speed on the Approaches and superelevation of up to 0.06 . 


\section{REFERENCES}

American Association of State Highway and Transportation Officials. (2011). A Policy on Geometric Design of Highways and Streets, $6^{\text {th }}$ Edition, Washington, D.C.

Brilon, W., \& Vandehey, M. (2008). Roundabouts--the state of the art in Germany. Institute of Transportation Engineers. ITE Journal, 68(11), 48. https://doi.org/10.1098/rspb.2010.1895

Candappa, N., Stephan, K., Fotheringham, N., Lenné, M. G., \& Corben, B. (2014). Raised Crosswalks on Entrance to the Roundabout-A Case Study on Effectiveness of Treatment on Pedestrian Safety and Convenience. Traffic Injury Prevention, 15(6), 631-639. https://doi.org/10.1080/15389588.2013.854885

de Santos-Berbel, C., Essa, M., Sayed, T., \& Castro, M. (2017). Reliability-Based Analysis of Sight Distance Modelling for Traffic Safety. Journal of Advanced Transportation, 2017, 112. https://doi.org/10.1155/2017/5612849

Easa, S. (1993). Reliability-based Design of Intergreen Interval at Traffic Signals. Journal of Transportation Engineering, 119(2), 255-271.

Easa, S. (1994). Reliability-based Design of Sight Distance at Railroad Grade Crossings. Transportation Research Part A: Policy and Practice, 28(1), 1-15.

Easa, S. (2000). Reliability Approach to Intersection Sight Distance Design. Transportation Research Record: Journal of the Transportation Research Board, 1701, 42-52. https://doi.org/10.3141/1701-06

Easa, S. (2017). Lateral Clearance Needs for Stopping Sight Distance at Single-Lane

Symmetrical Roundabouts (pp. 1-18). Retrieved from https://www.researchgate.net/publication/312374187

Easa, S. (2018). Modeling of Unsymmetrical Single-Lane Roundabouts Based on Stopping Sight Distance. KSCE J. of Civil Engineering. Retrieved from https://www.researchgate.net/publication/323654701\%0AModeling

Easa, S., \& Cheng, J. (2013). Reliability Analysis of Minimum Pedestrian Green Interval for Traffic Signals. Journal of Transportation Engineering, ASCE, 139(7), 651-660. 
https://doi.org/10.1061/(ASCE)TE.1943-5436.0000549.

Easa, S., \& Hussain, A. (2016). Reliability of sight distance at stop-control intersections. ICE Proceedings Transport, 169(3), 138-147. https://doi.org/10.1680/jtran.14.00090

Easa, S., \& Mehmood, A. (2004). Optimizing geometric design of single-lane roundabouts: consistency analysis. Canadian Journal of Civil Engineering, 31(6), 1024-1038. https://doi.org/10.1139/104-066

Fambro, D. B., Fitzpatrick, K., \& Koppa, R. (2000). New Stopping Sight Distance Model for Use in Highway Geometric Design. In Transportation Research Record (pp. 1-8). https://doi.org/10.3141/1701-01

Fambro, D. B., Koppa, R. J., Picha, D. L., \& Fitzpatrick, K. (n.d.). Driver Perception-Brake Response in Stopping Sight Distance Situations. Transportation Research Record, 1628(98), $1-7$.

Fambro et al, D. B. (1997). Determination of Stopping Sight Distances. National cooperative highway research program. Retrieved from http://onlinepubs.trb.org/onlinepubs/nchrp/nchrp_rpt_400.pdf

Flannery, A., \& Datta, T. (n.d.). Operational Performance Measures of. Transportation Research Record, 1572(971335), 68-75.

Godavarthy, R. P. (2012). NETWORK AND DESIGN CONCEPTS FOR ACCOMODATING LARGE TRUCKS AT ROUNDABOUTS. Kansas State University.

Godavarthy, R. P., Russell, E., \& Landman, D. (2016). Using vehicle simulations to understand strategies for accommodating oversize, overweight vehicles at roundabouts. Transportation Research Part A: Policy and Practice, 87(2016), 41-50.

https://doi.org/10.1016/j.tra.2016.03.002

Hasofer, A. M, \& Lind, N. C. (1974). Exact and invariant second-moment code format. J. Eng. Mechs. Div., ASCE., 100.

Himes, S., \& Donnell, E. (2014). Reliability Approach to Horizontal Curve Design. Transportation Research Record: Journal of the Transportation Research Board, 2436(2436), 51-59. 
https://doi.org/10.3141/2436-06

Hussain, A., \& Easa, S. M. (2016). Reliability Analysis of Left-Turn Sight Distance at Signalized Intersections, 142(1990), 1-12. https://doi.org/10.1061/(ASCE)TE.1943-5436.0000824.

Jensen, S. U. (2017). Safe roundabouts for cyclists. Accident Analysis and Prevention, 105(2017), 30-37. https://doi.org/10.1016/j.aap.2016.09.005

Johansson, G., \& Rumar, K. (1971). Drivers’ Brake Reaction Times. Human Factors: The Journal of Human Factors and Ergonomics Society, 13(1), 23-27. https://doi.org/10.1177/001872087101300104

Lochrane, T., Zhang, W., \& Bared, J. (2012). Mini-roundabouts for the united states and traffic capacity models. ITE Journal (Institute of Transportation Engineers), 82(11), 20-24.

Mahdalova, I., Krivda, V., \& Skvain, V. (2013). Influence of Roundabout Inscribed Circle Diameter to the Traffic Safety. Applied Mechanics and Materials, 409-410(2013), 11221125. https://doi.org/10.4028/www.scientific.net/AMM.409-410.1122

Manoj, N. R. (2016). First-order Reliability Method: Concepts and Application. Delft University of Technology.

Maurya, A. K., \& Bokare, P. S. (2012). STUDY OF DECELERATION BEHAVIOUR OF DIFFERENT VEHICLE, 2(3), 253-270.

Montella, A., Turner, S., Chiaradonna, S., \& Aldridge, D. (2013). International overview of roundabout design practices and insights for improvement of the Italian standard. Canadian Journal of Civil Engineering, 40:1215-12(2013).

Mujahid, R. S. (2012). Dual-Lane Roundabouts Geometric Design for Optimum Design Consistency and Operation. Ryerson University.

Myers, E. J. (1994). “Modern roundabouts for Maryland.’' ITE J., Oct., 18-22.

Nikou, D., Vardaki, S., Mavromatis, S., Engineering, G., \& Kanellaidis, G. (2015). Design considerations of modern roundabouts. International Symposium on Highway Geometric Design.

Persaud, B., Retting, R., Garder, P., \& Lord, D. (2001). Safety Effect of Roundabout Conversions 
in the United States: Empirical Bayes Observational Before-After Study. Transportation Research Record, 1751(1), 1-8. https://doi.org/10.3141/1751-01

Queensland Department of Transportation and Main Roads. (2013). Road Planning and Design Manual, $2^{\text {nd }}$ Edition. Queensland.

Richl, L., \& Sayed, T. (2006). Evaluating the Safety Risk of Narrow Medians. Journal of Transportation Engineering, 132(5), 366-375.

Robinson, B., Lee, R., Troutbeck, R., Brilon, W., Bondzio, L., Courage, K., .. Bunker, Jonathan Jacquemart, G. (2000). Roundabouts: An Informational Guide. https://doi.org/10.17226/22914

Rodegerdts, L. (2005). State-of-the-Art in U.S. Roundabout Practice. In Institute of Transportation Engineers 2005 Annual Meeting. Portland, Oregon,.

Rodegerdts, L., Blogg, M., Wemple, E., Myers, E., Kyte, M., Dixon, M., ... Carter, D. (2007).

Roundabouts in the United States. Retrieved from onlinepubs.trb.org/onlinepubs/nchrp/nchrp_rpt_572.pdf

Rubio-Martín, J. L., Jurado-Piña, R., \& Pardillo-Mayora, J. M. (2015). Heuristic procedure for the optimization of speed consistency in the geometric design of single-lane roundabouts. Canadian Journal of Civil Engineering, 42(1), 13-21. https://doi.org/10.1139/cjce-20140283

Sakshaug, L., Laureshyn, A., Svensson, Å., \& Hydén, C. (2010). Cyclists in roundabouts Different design solutions. Accident Analysis and Prevention, 42(4), 1338-1351. https://doi.org/10.1016/j.aap.2010.02.015

Sarhan, M., \& Hassan, Y. (2011). Reliability-based three-dimensional design of horizontal lateral clearance. Canadian Journal of Civil Engineering, 38: 900-90(2011), 900-908. https://doi.org/10.1139/L11-060

Schroeder, B. J., Rouphail, N. M., \& Hughes, R. G. (2008). Toward Roundabout AccessibilityExploring the Operational Impact of Pedestrian Signalization Options at Modern Roundabouts. Journal of Transportation Engineering, 134(6), 262-271. https://doi.org/10.1061/(ASCE)0733-947X(2008)134:6(262) 
Sisiopiku, V. P., \& Oh, H.-U. (2001). EVALUATION OF ROUNDABOUT PERFORMACNE USING SIDRA. Journal of Transportation Engineering, 127(2), 143-150.

Smith, G.N. (1986). Probability and statistics in civil engineering. Nichols Publishing Company, New York., N.Y.

The City of Calgary. (2010). CONE-OF-VISION IMPACTS IN ROUNDABOUTS Prepared for: Centre of Transportation Engineering \& Planning. Calgary, Alberta.

Transportation Association of Canada. (2007). Geometric Design Guide for Canadian Roads. TAC, Ottawa, Ontario

Van, M.-J. T., \& Balmefrezol, P. (2007). Design of Roundabouts in France: Historical Context and State of the Art. Transportation Research Record: Journal of the Transportation Research Board, 1737(1), 92-97. https://doi.org/10.3141/1737-12 